A psychological perspective of drivers' speed preferences in work zones and its implications for policy and practice

Renata Torquato Steinbakk

Submitted for the degree of $\mathrm{PhD}$

Department of Psychology, Faculty of Social Sciences, University of Oslo 
(C) Renata Torquato Steinbakk, 2020

Series of dissertations submitted to the

Faculty of Social Sciences, University of Oslo

No. 793

ISSN 1564-3991

All rights reserved. No part of this publication may be

reproduced or transmitted, in any form or by any means, without permission.

Cover: Hanne Baadsgaard Utigard.

Print production: Reprosentralen, University of Oslo. 


\section{LIST OF CONTENTS}

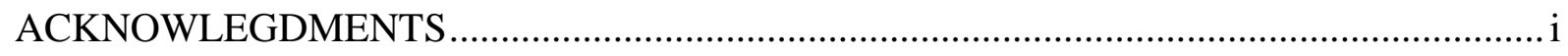

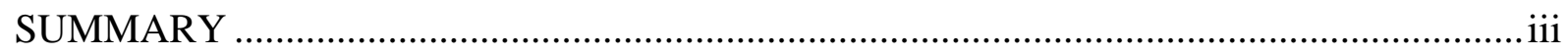

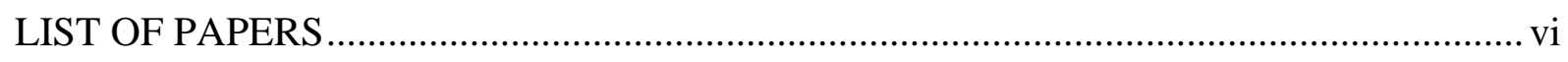

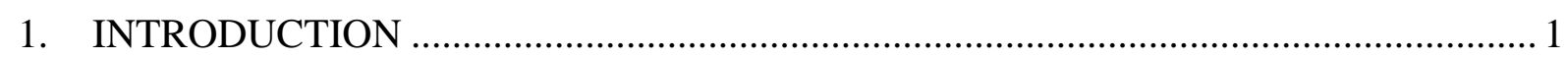

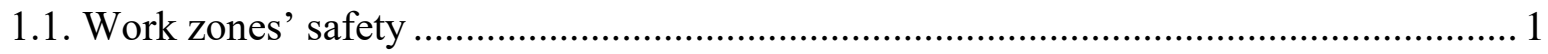

1.1.1. Safety issues and risk factors in work zones ...................................................... 2

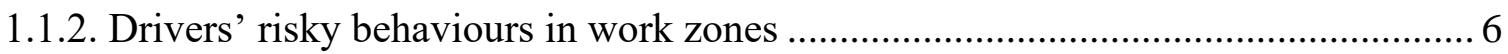

1.1.3. Effects of traffic management measures in work zones ...................................... 11

1.2. Theories and models of driving behaviour and their application to understanding

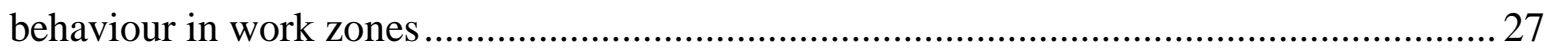

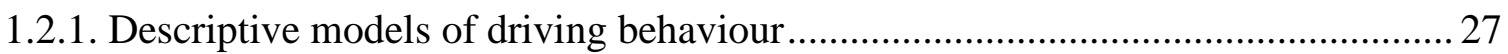

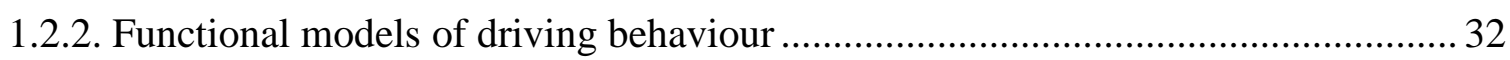

1.2.3. Theories in psychology used to understand and predict drivers' behaviours ......... 37

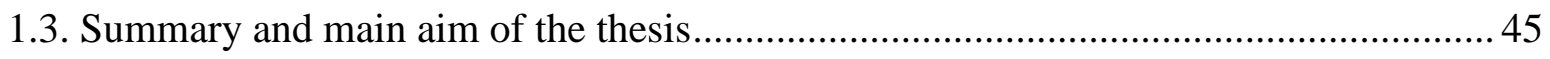

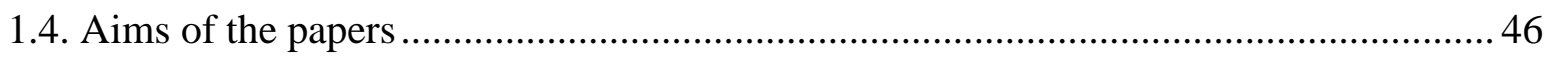

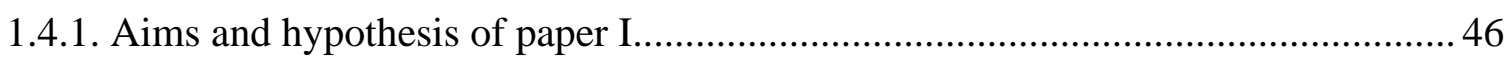

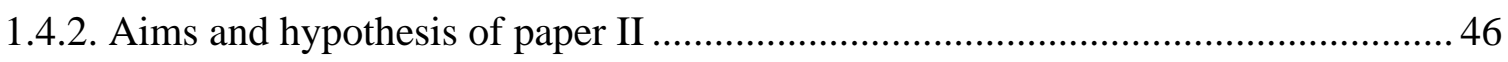

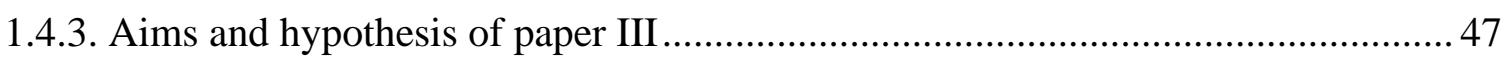

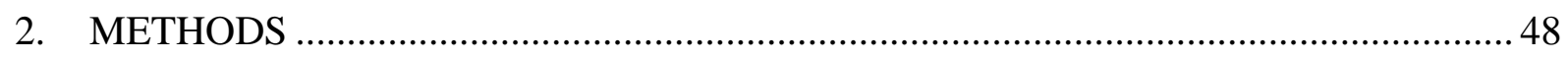

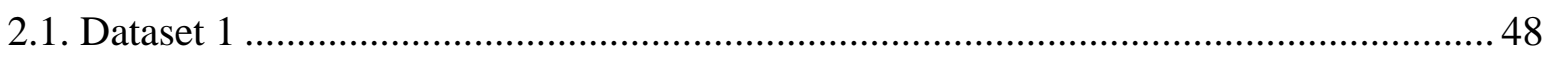

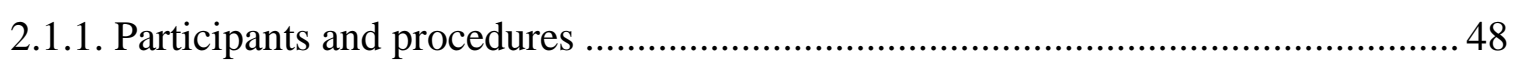

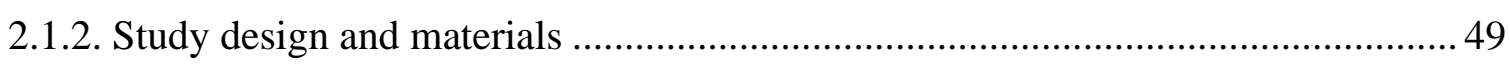

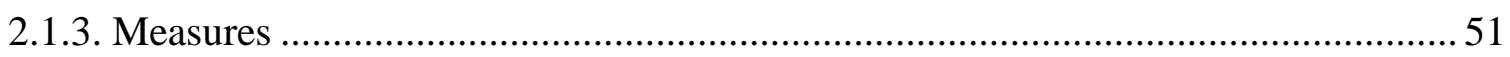

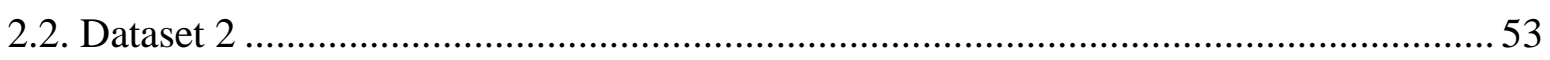

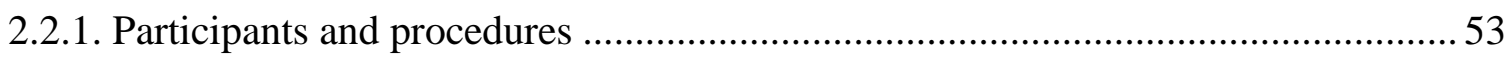

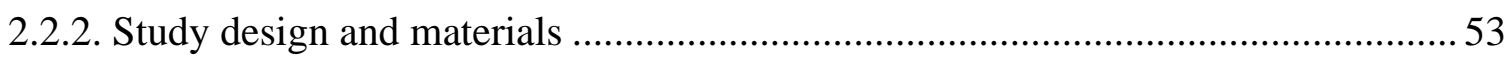

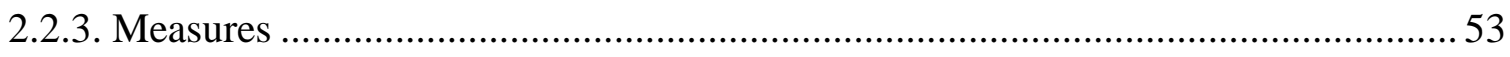

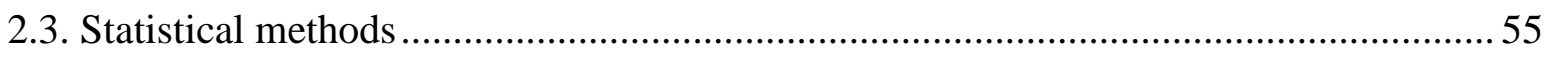

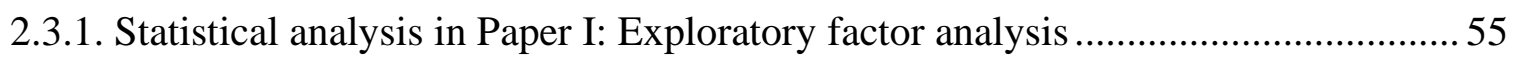

2.3.2. Statistical analysis in Paper II: Structural Equation Modelling (SEM) .................. 55

2.3.3. Statistical analysis in Paper III: Multilevel modelling ........................................56

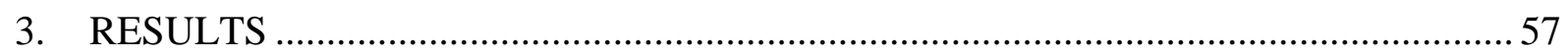




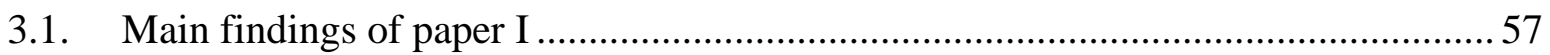

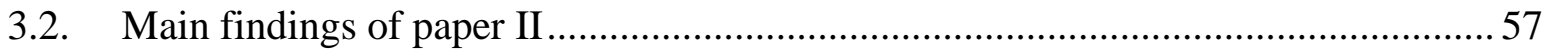

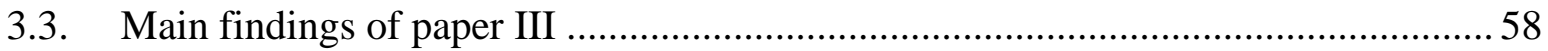

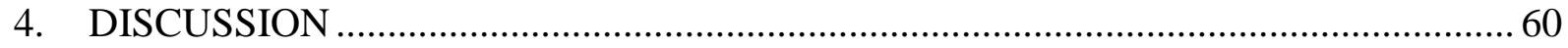

4.1. Speed preferences and motivation to prefer higher speeds in work zones ....................60

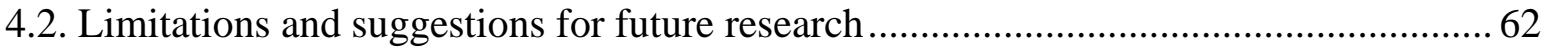

4.2.1. The use of videos and photographs to study drivers' speed preferences ................ 62

4.2.2. Socially desirable response of self-reported driving behaviours ...........................66

4.2.3. Reliability of the scales and the explained variance for speed preferences ............ 67

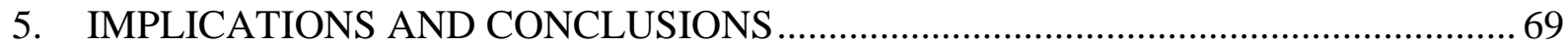

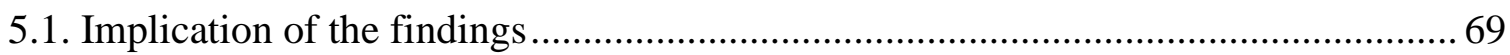

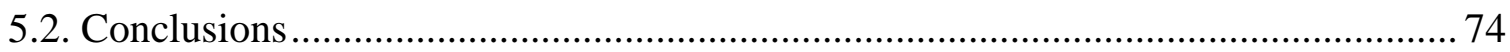

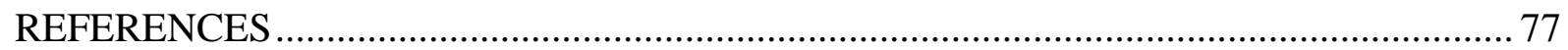

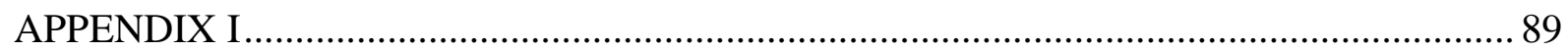

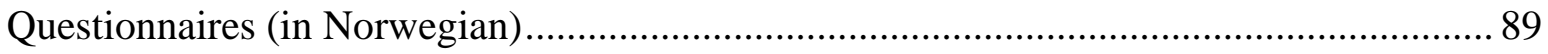

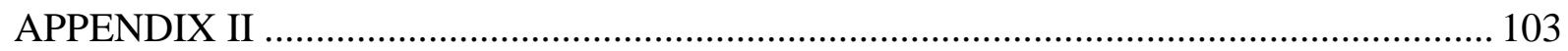

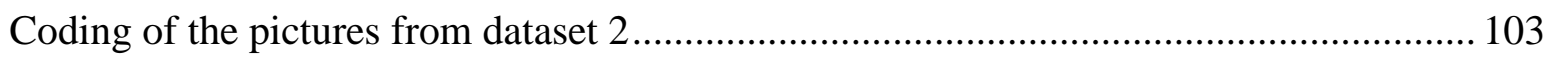

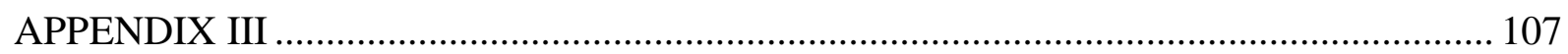

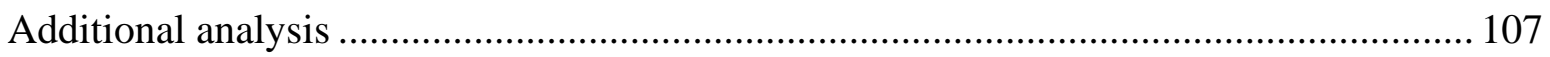

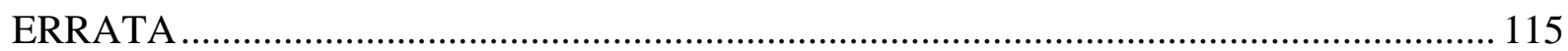

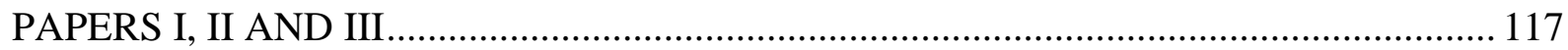




\section{ACKNOWLEGDMENTS}

Many drivers have experienced the frustration of driving in a work zone. I have heard about how the speed limits are too low, that road workers never work, and how road authorities should stop bothering drivers and delaying their journeys. I realised that new and better roads are something every driver wants, but few are willing to "pay the price" for it. When I started to wonder more about work zone issues, I became curious about addressing the complaints regarding low posted speed limits and what road authorities should do to increase their credibility. I tried to find studies on work zone safety from a drivers' perspective, and I was surprised when I discovered how little attention this issue had received in the scientific literature. Many studies only answered what drivers do at work zones, without answering why. This is how my journey with this thesis began, and I would like to thank everyone that made it possible.

First, I would like to express my gratitude to the Norwegian Public Roads Administration for giving me the opportunity to conduct this research and by funding this study. I am also deeply grateful to my three supervisors, Pål Ulleberg, Knut Inge Fostervold, and Fridulv Sagberg for their guidance, thoughts, and help in the work with this thesis. I could not think of better guidance throughout these years! Thank you Pål for agreeing to supervise me in the first place, and Knut Inge for joining us later. I always appreciated our discussions and felt a little bit wiser after them. It was also very interesting to have your perspectives in the understanding of traffic signs' effects and driver's behaviours in work zones. Thanks also to Fridulv for always being eager to discuss traffic psychology with me. I am really honoured that you agreed to supervise me!

I would also like to thank many good colleagues in the NPRA for their encouragement, curiosity, and support throughout this process. Everyone has contributed in a different manner to my completion of this thesis. Thanks to my former superiors, Ivar Christiansen and Jacob Trondsen, for giving me the opportunity to start this study. Thanks to my current superior, Guro Ranes, for facilitating the final days of my writing. Thanks to all members of the NPRA's roadwork group for seeing the value of this study and encouraging me to share my results. Thanks to Morten Hafting for allowing me to use his videos of work zones. Thanks also to the English experts in the NPRA who revised the English in the papers.

Thanks also to my family for their encouragement. Special thanks to the most important person in my life, my dear husband Adrian. You were on the sideline this entire time, cheering me on 
and loving me even when I felt like I was failing. I would never have found the strength to finish this thesis if it hadn't been for you!

Finally, I really hope that my results can contribute to making the efforts concerning safety at roadworks more scientific and provide valuable ideas for roadworks professionals. I hope that with this study we can get a little bit closer to the goal that no one is killed or seriously injured in traffic - including in work zones. 


\section{SUMMARY}

All traffic safety work conducted in Norway is based on the goal that nobody should be killed or severely injured in a traffic crash. According to this philosophy, called "Vision Zero", road authorities will work proactively to improve traffic safety. This viewpoint should also be applicable to work zones. In Norway, in the period 2005-2009, 23 traffic deaths related to work zones were registered. The causes pointed to by the traffic accident analysis performed by the Norwegian Public Roads Administration (NPRA) (2011) demonstrated that several of those traffic crashes involved local conditions and organisational factors, such as lack of warning/safety measures and inadequate interactions between contractors and road authorities. Even though these factors were recognised as being partially accountable for the crashes, the underlying human factors did not receive an in-depth investigation.

In recent years, several field studies have been performed to assess the effects of a varied number of traffic control devices (e.g. traffic signs, road markings, etc.) on driving behaviour in work zones. Nevertheless, only a few studies have addressed the effects of those countermeasures from a behavioural and psychological perspective. For this reason, the main aim of this thesis was to increase our understandings of the role of human factors in roadworks safety, more specifically, the effects of drivers' personal variables and their interactions with the traffic environment on speed preferences in work zones.

In the first paper, a video-based experiment was developed to examine the effects of roadwork activity on preferred speeds. The results corroborated other studies that indicated that drivers prefer lower speeds if they see a reason for it (i.e. visible work activity). Analysis of the drivers' self-assessments of the elements that influenced their speed choice in work zones showed that speed regulations and transient motives were the factors that gave significant contributions to predicting speed preferences. The results from the first paper allowed us to establish the importance of the road characteristics and surroundings when drivers choose which speed they would prefer in work zones.

In the second paper, we analysed drivers' personal characteristics in terms of personality traits, attitudes, risk perceptions, and driving styles and their impacts on drivers' preferred speeds at work zones. An important contribution of this paper is in recognising the interaction and indirect effects of personality traits on speed preferences in work zones. The indirect effects of personality traits were found to be through attitudes, risk perceptions, and driving styles. 
Furthermore, it was found that the situational cues (i.e. visible work activity) influenced the expression of personality traits. This perspective has not been widely investigated before. Roadwork activity was found to act as a moderator in the relationship between personality and preferred speeds, where visible work activity influenced the strength and direction of this influence. The results give recommendations for future studies and highlight the importance of taking into consideration specific traffic situations that can be of great importance when studying personality traits and their effects on driving behaviour.

The third paper utilised another approach to investigate the effects of drivers' personal characteristics on speed preferences in work zones. It strengthened the assumption that the situational cues are important variables to consider when explaining driving behaviour. For instance, situational cues (such as roadside delineators) that indicate that a road section is not in typical condition gave greater reduction in preferred speeds. We could also conclude that for some drivers scoring higher on specific personality traits the situational cues should be stronger in order to indicate what kind of behaviour is expected for the situation. For the study in this paper, we utilised a series of screenshots of one work zone at the point after passing the reduced speed limit sign. The scenes with stronger situational cues yielded preferred speeds closer to the posted speed limit. In contrast, for the scenes that appeared to have weak situational cues (e.g. the road seems in good condition), drivers preferred higher speeds. We also found that preferred speeds increased with age, higher scores on the normlessness scale, and higher selfassessment of one's driving skills. Recommendations to road authorities were given based on the findings.

Overall, the present thesis makes significant contributions in understanding speed preferences in work zones. First, it provides evidence that situational factors are of great importance for drivers when choosing at which speed they prefer to drive in a situation. The results provide support for road authorities when it comes to the importance of using countermeasures that emphasise to drivers that the road section is a work zone. Second, the results point to the fact that even though drivers' personal characteristics are important factors that influence driving behaviour, the environment will facilitate certain personality expressions that manifest in the form of risky behaviours. It is important to keep in mind that situational cues indicating a situation (in this case work zones) that give guidance for the expected behaviour have the possibility to inhibit the expression of certain personality traits in the form of risky behaviour (e.g. higher speeds). Moreover, this thesis also contributes by gathering the 
existing knowledge from reports and articles about drivers' behaviours in work zones and discussing it from a psychological perspective. The knowledge produced by this thesis is expected to provide a stronger basis for policy and traffic management practices in work zones and to enhance traffic safety for both drivers and road workers. 


\section{LIST OF PAPERS}

\section{Paper I}

Steinbakk, R. T., Ulleberg, P., Sagberg, F., \& Fostervold, K. I. (2017). Analysing the influence of visible roadwork activity on drivers' speed choice at work zones using a video-based experiment. Transportation Research Part F: Traffic Psychology and Behaviour, 44, 53-62.

\section{Paper II}

Steinbakk, R. T., Ulleberg, P., Sagberg, F., \& Fostervold, K. I. (2019). Speed preferences in work zones: Does the presence of roadwork activity moderate the influence of personality traits? Transportation Research Part F: Traffic Psychology and Behaviour, 62, 390-405.

\section{Paper III}

Steinbakk, R. T., Ulleberg, P., Sagberg, F., \& Fostervold, K. I. (2019). Effects of roadwork characteristics and drivers' individual differences on speed preferences in a rural work zone. Accident Analysis \& Prevention, 132, 105263. 


\section{INTRODUCTION}

Although efficient countermeasures have increased traffic safety in recent years, public managers are still facing challenges when it comes to optimising the outcomes of these measures, especially in places such as work zones. Improving the understanding of drivers' behaviour in work zones from a psychological perspective can contribute to better planning and implementation of these countermeasures. Hence, the main aim of this thesis was to investigate personal and environmental characteristics and their influence on preferred speeds in work zones.

The present thesis has the following structure. The first chapter will present findings about the most common safety issues of roadworks, the effects of the most common countermeasures, and studies on drivers' behaviour in work zones. The second chapter will present the most important theories about driver behaviour. Common behaviours in work zones and the effects of countermeasures will be discussed in the light of those theories. Finally, the aims, hypotheses, methods, and main findings of each paper will be presented. At the end, a discussion of the main findings about drivers' speed preferences in work zones will be given, as well as methodological considerations and suggestions for future research. The main implications of the results for policy and practice will be discussed last.

\subsection{Work zones' safety}

According to the NPRA, all type of work that takes place on the road or its surroundings that requires warning and/or safety measures towards road users is considered a work zone (NPRA, 2012). The purpose of roadworks is ultimately to enhance traffic safety and/or improve traffic flow of a road section. Paradoxically, the work zone itself can generate safety issues as well as congestions. At such places, drivers often have uncommon elements to deal with in a relatively short time such as closed lanes, new traffic regulations, etc. A possible consequence of increasing the complexity of the road environment is an increase in crash rates.

Many studies have pointed to the fact that work zones have higher crash rates compared to non-work areas (e.g. Silverstein, Schorr \& Hamdar, 2014; Høye, Phillips \& Hesjevoll, 2015; Wang et al., 1996). The severity of those crashes was also found to be higher compared to other road sections (Høye et al., 2015; Qi et al., 2013; Wang et al., 1996). Nevertheless, it is worth pointing out that there is some uncertainty whether work zones are indeed more dangerous than 
other road sections, mainly due to the variety of data collection quality (see Yang et al., 2015). Furthermore, not all crashes are categorised as a work zone crash because this information is not always obvious when authorities inspect the crash site. Still, many studies have provided a great amount of data about common crash types and contributing risk factors for crash occurrence at work zones. These will be presented in the next subsection.

\subsubsection{Safety issues and risk factors in work zones}

The most common crash types in work zones were categorised as being rear-end crashes, followed by head-on and sideswipe collisions (Akepati \& Dissanayake, 2011; Høye et al., 2012; Silverstein et al., 2014; Wang et al., 1996; Weng, Meng \& Yan, 2014; Qi et al., 2013). Passenger vehicles were found to be more frequently involved in crashes, often as a multiple vehicle rather than a single vehicle crash (Akepati \& Dissanayake, 2011). The suddenness of a work zone and the possible different reactions drivers have to the existing traffic regulations may explain why those types of crashes are more common. For heavy vehicles, rear-end crash risks were also found to be high (Meng \& Weng, 2011), particularly the combination car-truck crash (Weng et al., 2014). An explanation for heavy vehicles' high risks is that they have longer braking distances, which increases the probability of a rear-end crash in case of an abrupt stop. Furthermore, crashes involving trucks were found to be more severe compared to crashes without trucks (Qi et al., 2013) because their larger size can aggravate the consequences of a crash.

The literature has identified many risk factors for crash occurrence and severity in work zones. For example, Akepati and Dissanayake (2011) analysed several crashes in the United States and found that most crashes occurred in daylight, in clear weather, and on a dry surface. Other studies also found that daylight conditions were associated with higher crash rates, especially for head-on and rear-end crashes, and high probability of severe injuries (Osman, Paleti \& Mishra, 2018; Silverstein et al., 2014). Speeds are usually higher under good weather conditions, and this is a well-known factor that increases crash probability and severity (e.g. Elander, West \& French, 1993). For nighttime, there was a higher frequency of single-vehicle crashes (Silverstein et al., 2014) and an increased severity of rear-end crashes (Qi et al., 2013). Poor visibility conditions can contribute to driving off the road, often involving only one vehicle. The lack of adaptation of driving speeds in poor visibility conditions can explain why crash severity is higher at nighttime. For weekends, there was an increased likelihood of higher 
injury severity compared to weekdays, probably because some drivers, once finding out that the work zone is not operational, are most likely to increase their speed (Osman et al., 2018).

Traffic conditions and road and work zone characteristics were also factors found to be related to crash risks. Traffic volume was found to positively correlate with frequency of rearend crashes (Qi et al., 2013), especially for lanes with high traffic volume and a large number of heavy vehicles (Meng \& Weng, 2011; Weng et al., 2014). One explanation may be that drivers tend to decrease headway when there is a large number of vehicles, which in turn shortens stopping distances and increases the risks of rear-end crashes in case of sudden braking. As for the presence of a curve, it was only found to increase single-vehicle crashes and increase injury severity (Osman et al., 2018; Silverstein et al., 2014). Lack of speed adaptation increased the chances of driving off the road, which often involved only one vehicle. Interestingly, the presence of intersections was not found to increase crash rates and severity in work zones (Qi et al., 2013). At those places, there was a lower rate of rear-end crashes (Qi et al., 2013; Silverstein et al., 2014). One explanation is that drivers may be more cautious and attentive in those areas.

As for the road characteristic, work zones on highways were found to have high crash risks (Meng \& Weng, 2011; Wang et al., 1996), especially on straight highways with high speed limits (Akepati \& Dissanayake, 2011; Silverstein et al., 2014). Crashes on rural roads were found to have higher injury severity outcome than urban roads (Osman et al., 2018). Highways and rural roads often have higher speed limits compared to urban roads, which has an impact on crash risk and severity. Other risk factors for highways were a combination of exposure and traffic disruptions because construction and maintenance work are more common and longer on those roads (Qi et al., 2013; Wang et al., 1996). The number of lanes was also found to be a risk factor for work zones, where the number of lanes was positively associated with rear-end crash probability (Silverstein et al., 2014). Additionally, Weng and Meng (2012) found that the number of lanes contributed to risky driving behaviour in work zones depending on the traffic condition: under daylight conditions, risky behaviours occurred more often on multi-lane compared to single-lane roads. Overall, straight roads with high speed limits and multiple lanes were the main risk factors related to crashes in work zones.

Each work zone has specific warning and safety measures that vary from place to place being specific to the type of roadwork that is being performed and the length and duration of the work. Bryden, Andrew, and Fortuniewicz (1998) analysed accidents involving traffic 
control devices (e.g. traffic signs, barriers, etc.) and concluded that serious injuries were mainly related to high speeds or avoidance impact and were not directly attributable to the design of the devices. The authors concluded that many of the crashes would have resulted in more severe injuries if the control and safety devices had not been present. Akepati and Dissanayake (2011) corroborated this conclusion, pointing out that the fatal crashes occurred more often in work zones without traffic control compared to places with the presence of traffic signs.

The work zone characteristics found to influence crash risks were pavement surface features, with excavations and construction materials being involved in a great number of crashes especially because of secondary or avoidance collisions, not direct impacts (Bryden et al., 1998). Moreover, Akepati and Dissanayake (2011) found that most crashes occurred at a lane-closure type of work zone. Likewise, Qi et al. (2013) found that work zones with alternating one-way traffic (contra lane-shift zones) and lane blockage situations (contra shoulder-blocked work areas) were associated with higher rates of rear-end crashes. The same trend was identified for short-term work zones by Yang et al. (2015), who found a $66 \%$ higher crash risk when one lane was closed. Capacity, bridge, and pavement were the types of roadworks found to increase crash risks and crash severity because they are often long-term types of work, which increases exposure (Qi et al., 2013). However, in a recent meta-analysis performed by Theofilatos et al. (2017), the duration of work zones was not found to be significant in crash rates, while work zone length was. Their results suggested that for every unit increase in work zone length the crash rates increased more than two-fold. This can be explained by the fact that the length of a work zone increases exposure, while the duration of the work activity does not necessarily do so. More evidence to support this assumption comes from the study by Qi et al. (2013), who found that moving and short-term work zones had fewer crash rates compared to long-term work zones. Moreover, Yang et al. (2015) showed that an increase in work zone length also increased the crash rates for short-term work zones. The reasons for lower crash risks in short-term work zones pointed to by both studies were the limited exposure to the roadwork area and probably lower traffic volumes because those types of work are more flexible in terms of the time of day they are performed (e.g. rush hour vs. offpeak hours).

As for location of crash occurrence, the risks were found to be higher for the lane closer to the work activity area compared to the other lanes (Meng \& Weng, 2011; Weng et al., 2014; Weng et al. 2015). The frequency of crashes increased towards the point of activity in the work 
area, whereas there were fewer crashes at the advanced warning area and termination area (Akepati \& Dissanayake, 2011). As for crash severity, Osman et al. (2018) found that the advanced warning, activity, and termination areas were associated with higher injury severity crashes, also when road workers were present. Similarly, Qi et al. (2013) found that the rearend crashes before the narrowing lanes (transition area) were significantly more severe compared to other work zone locations. The reason for this might be due to higher variability in speeds, especially at advanced warning, transition, and activity areas, where some drivers might brake very abruptly in the view of the work activity or might start performing a lane shift. However, it is worth mentioning the concern of Yang et al. (2015) regarding a careful interpretation of studies that account for crash distribution in different sections of work zones because of the great variability in lengths of work zones as well the changes of elements in accordance with the project's progress. Thus, further studies are needed to provide a more accurate location where there the most crashes occur.

This subsection has given an account of studies regarding risk factors in work zones. A summary of the research findings can be seen at Table 1. Although there are many risk factors related to the road and work zones' characteristics and traffic conditions, the major factors contributing to crashes are mostly related to driver behaviour (Bryden et al., 1998; Silverstein et al., 2014). Consequently, the next subsection will account for studies that examine the most common risky behaviours in roadworks areas.

\section{Table 1}

Summary of work zone risk factors

\begin{tabular}{ll}
\hline \multicolumn{1}{c}{ Risk factor } & \multicolumn{1}{c}{ Characteristic } \\
\hline Traffic conditions & - High traffic volume \\
& - Number of heavy vehicles \\
\hline Road & - Curve (only for single-vehicle crash) \\
& - High posted speed limits \\
& - Highways \\
& - Rural roads \\
& - Number of lanes (multiple lanes) \\
& - Without traffic control and safety devices (e.g. traffic signs, \\
& \\
& - barriers, etc.) \\
& - Construction materials \\
& - Lane blockage
\end{tabular}


- Work zone length

- Closer to the work activity area

- Advanced-warning, activity, and termination areas (only for crash severity)

\begin{tabular}{lll}
\hline Weather and time & - & Daylight \\
& - & Nighttime (only for single-vehicle crash) \\
- & Dry surface \\
- & Clear weather \\
- & Weekends \\
\hline
\end{tabular}

\subsubsection{Drivers' risky behaviours in work zones}

Data from 23 fatal crashes in work zones in Norway showed that males were most often involved (80\%) (NPRA, 2011). Similarly, a crash database from Michigan showed that drivers who were more prone to risk-taking behaviour in work zones were male drivers and with a medium vehicle age of 5-10 years (Weng \& Meng, 2012). These findings are in line with traffic safety studies that showed that males had a higher risk of fatal crash involvement per mile driven compared to females (Massie, Green \& Campbell, 1997).

Alcohol use was identified by some American studies as one factor related to crashes in work zones (e.g. Akepati \& Dissanyake, 2011; Qi et al., 2013; Weng \& Meng 2012). However, this was not the case in fatal crashes analysed in Norway (NPRA, 2011). These differences can be due to differences in the traffic culture between those countries. The prevalence of driving under the influence of alcohol is supposed to be in general very low among Norwegian drivers (about $0.2 \%$ ) (Gjerde et al., 2013). However, it is worth mentioning that the Norwegian data may be too small to draw strong conclusion on the prevalence of drink driving and crashes in work zones.

It is well established that speed is the most important risk factor for traffic fatalities, given that crash probability, rates, and severity are shown to rise along with increasing driving speeds (Aarts \& van Schagen, 2006; Elvik, 2013). Speed violations were one of the main factors in fatal crashes in work zones (NPRA, 2011) and caused more severe crashes in rural and highspeed work zones (from 80 to $110 \mathrm{~km} / \mathrm{h}$ ) (Li \& Bai, 2009). The high number of speed violations and speed variance are often pointed to as the main safety concerns for work zones (Advanced Research on Road Work Zone Safety Standards in Europe Consortium [ARROWS], 1998, Akepati \& Dissanayake, 2011; Conference of European Directors of Roads [CEDR], 2013; Silverstein et al., 2014). Road workers also felt that excessive vehicle speed was the most 
common hazard for them (Debnath, Blackman \& Haworth, 2015). In a study about the speed of drivers in work zones, Benekohal et al. (1992) divided drivers into different speed profile categories. Sixty-tree per cent of drivers reduced their speeds near the first speed limit signs. Among those, about $26 \%$ increased their speeds between the first speed limit signs and before the work activity area. Only $11 \%$ of drivers travelled faster than the posted speed limits when passing the first signs but slowed down when arriving at the work activity area. The main finding in this study was that most drivers decreased their speed near the work activity area; however, their speeds were still higher than the posted speed limits (about 70\% of car and 55\% of truck drivers). Similar results were found by Paolo and Sar (2012) in a study of various twolane rural work zones in Italy, where the speeds at the beginning of the work zone were higher than the posted speed limits, and nearly $80 \%$ of all drivers drove above this limit. Further analysis of the data from the study of Benekohal et al. (1992) showed that the speed of a vehicle in the work zone was related to its initial speed, where drivers with higher initial speeds tended to keep higher speeds throughout the work zone (Benekohal \& Wang, 1994). Based on these results, one recommendation is that different measures should be used throughout the work zone to reach drivers in different speed categories and that speed reduction countermeasures should be located before the transition area as well as before the work activity area to encourage most drivers to slow down.

The high variety in speeds throughout the work zone and the reactions of some drivers to work activity have an impact on speed homogeneity in those places, which in turn has an impact on crash risks. Akepati and Dissanayake (2011) found an increase in frequency of crashes towards the beginning of the work activity area compared to the advanced warning and termination areas. Wang et al. (1996) also found high rates of rear-end collisions in those areas. These findings indicate that some drivers will only react when they see roadwork activity and decelerate, whereas this reaction is not the same for all drivers. The divergence in drivers' reactions shows that it is necessary to understand how roadwork activity influences the speed of some drivers, while others seemed to be unaffected. One possible explanation is linked to risk perception and attitudes towards the posted speed limits. Benekohal et al. (1993) found that drivers who knew they were speeding in a work zone reported that they felt their speeds were safe enough for the road conditions. Correspondingly, drivers who reported often complying with the overall speed limits also reported perceiving a greater risk in exceeding the speed limit and perceived the traffic rules as adequate for real safety needs (Havârneanu \& Havârneanu, 2012). We can thus assume that drivers who choose not to comply with posted speed limits may 
underestimate the risks in work zones and perceive the posted speed limit as inadequate. Studies about risk perceptions and attitudes towards reduced posted speed limits in work zones were not found, indicating that further studies are needed on this topic.

Another factor found to affect speeding behaviour in work zones was the speeding characteristics of the surrounding traffic. In a simulator study, Morgan, Duley, and Hancock (2010) found that in the presence of a lead vehicle that was visually obstructive participants drove slower compared to when the lead vehicle was absent. Greater peak braking (in terms of pedal actuation) was also observed when the lead vehicle was present. Debnath, Blackman, and Haworth (2014) found that drivers were more likely to speed when the leader vehicle was speeding, when a larger proportion of drivers were speeding, and when there were larger gaps between vehicles. The authors hypothesised that drivers may feel pressured by vehicles behind them to increase speed to catch the lead vehicle. The driving culture and its effects on speed choice for work zones was addressed by Walker and Calvert (2015) who pointed out that this choice is based on drivers' expectations and beliefs about how other drivers see their behaviours. For that reason, the driving culture, composed by norms and expected behavioural standards, would influence drivers to feel pressured not to slow down if the surrounding traffic is driving over the posted speed limit. This pressure would be especially existent in work zones without visible work activity and places with no apparent reason to slow down. The authors concluded that social aspects and traffic culture might explain why engineering and enforcement interventions often have very little effect on drivers' behaviour in work zones. Although interesting hypotheses can be drawn using a cultural and psychological perspective on what influences drivers' speed behaviour in work zones, there are still few studies on the topic.

Closed lanes are quite common in work zones, thus merging behaviour is a common manoeuvre. There is evidence to support that techniques to merge lanes have an effect on drivers' behaviour and risks. In a simulator experiment, Shakouri et al. (2014) compared drivers' behaviours in a conventional lane merge (one closed lane and one merging lane) with a joint lane merge (both lanes merge into one lane). In the joint lane merge scenario, drivers applied less braking force, remained longer in the closed lane, and expressed lower temporal demands, frustration, and total workload. Nevertheless, the authors pointed out that more studies are needed to find which forms for lane merging are more suitable in terms of drivers' performance and crash risks. As for crash risk in merging situations, higher merging vehicle 
speeds were found to be associated with higher rear-end crash risks (Meng \& Weng, 2011). Later, Weng et al. (2015) examined rear-end crash risk in work zone merging areas and the effects of different factors on drivers' merging behaviours. Their results showed that closeness to the work activity area was associated with a high degree of crash risk, especially if the merging vehicle had higher speeds during the merging manoeuvre. They also found that the merging vehicle preferred to merge more quickly if it had high speeds, if there was enough space in the merging lane, and if they were closer to the work activity area. Higher crash risks for merging vehicles closer to the work activity area were also found by Meng and Weng (2011). Based on those finding, early merge control measures were recommended in order to decrease the risks of rear-end crashes closer to the work activity area (Meng \& Weng, 2011; Weng et al., 2014). However, early merge control measures may influence capacity, reducing traffic volume on the closing lane and the traffic flow on the merging lane. The so-called "early merge" phenomenon is another issue that further undermines capacity. This means that some drivers tend to merge as soon as possible and not at the end of the closing lane. According to Walker and Calvert (2015) the drivers who merge early do so in fear of being seen as "sneaky" or "arrogant" due to social norms in traffic and low levels of social resistance. Therefore, to sustain an acceptable traffic flow and reduce the queues derived from work zones, other researchers would rather recommend late merging control measures (e.g. Shakouri et al., 2014). An evaluation of the traffic condition and particularities of a work zone would probably point to which form of merging control measure should be used.

Another risk behaviour found to account for a high percentage of crash-related injuries at work zones was following too closely (Li \& Bai, 2009). Results from Yousif, Alterawi, and Henson (2014) revealed that a larger percentage of drivers who violated the "two-second rule" was found after the working area (38\%) compared with those who were tailgating before approaching the work activity area (24\%). They also observed a high proportion of drivers who followed too closely who did not comply with temporary traffic lights. These results corroborate the findings of Li and Bai (2009) who showed that the presence of a stop sign/signal control in a work zone increased the odds of a severe crash caused by tailgating behaviour. This may be due to some drivers experiencing delays, do not allow a safe headway in order to "gain" the time they feel they "lost". Red light violations in urban work zones were proposed to be associated with drivers' frustration, especially at long red phases with good visibility and no vehicles approaching in the opposite stream (Yousif et al., 2014). Road workers believed that the frustration due to delays also influenced drivers' speeding behaviour (Debnath et al., 2015). 
They also reported to perceive drivers' frustration and aggression as a hazard to them during their work. Driver aggression in general traffic (e.g. cursing, obscene gestures, threats, etc.) was found to be associated with increasing odds of a crash, even after adjusting for other confounding variables such as substance use (Wickens et al., 2012). Road workers reported that verbal abuse, throwing objects, spitting, and threats were some of aggressions they were typically exposed to (Debnath et al., 2015). Driver aggression and frustration in work zones has not gained much attention in the literature but is particularly relevant for the working conditions of road workers and because of the increased crash risks.

Driving distraction, especially regarding mobile phone use, was reported by road workers as one common hazard for their work (Debnath et al., 2015). Inattentive driving is a risky behaviour that caused proportionally more multi-vehicle and severe crashes in work zones with speed limits lower than $64 \mathrm{~km} / \mathrm{h}$ (Qi et al., 2013). It is well established in the literature that mobile phone use impairs driving performance in terms of drivers' reaction times and vehicle position in the lane (for a deeper review of the impacts of mobile phone use, see Lipovac et al., 2017). One type of distraction caused by mobile phone use is the visual distraction, which involves looking away from the road and loss of visual attentiveness (Lipovac et al., 2017). Drivers that are distracted by mobile phones can miss important information when driving towards a work zone. Traffic signs at the advanced area such as lane merging, traffic controllers, or other obstacles can pass unnoticed if the driver is distracted. Another potential problem is queued drivers who use their phones because they are bored and want to "spend time" while they wait for the traffic to move. The result could be a reduction in capacity because they do not follow the traffic flow, leaving larger gaps between vehicles. Another probable consequence is the risk of a rear-end crash in case of a sudden stop. Furthermore, Osman et al. (2018) hypothesised that drivers can be distracted by work zone equipment and thus pay more attention to road workers in order to avoid collisions, giving less attention to surrounding traffic and control devices, which in turn would explain the higher risk of severe crash injuries found when road workers were present. Inattentive driving and distraction in work zone are issues that have not received much attention in the literature, and future studies are needed to elucidate the sources of distraction in those areas (Høye et al., 2015).

Many authors have pointed out the scarcity of studies on the topic of driver behaviour and work zone safety as an obstacle to understanding and mitigating safety problems in those areas (Yang et al., 2015; Theofilatos, et al., 2017; Wang et al., 1996). In particular, a large gap 
exists on studies that analyse safety issues and countermeasures from a drivers' behaviour perspective (Blackman, Debnath \& Haworth, 2014a). As an attempt to contribute to this understanding, the next subsection will present the most common traffic management measures used in work zones along with studies about their effects on driver behaviour.

\subsubsection{Effects of traffic management measures in work zones}

\subsubsection{Warning and informational signs}

One of the most common countermeasures used in traffic is warning signs. Generally, the purpose of a warning is to provide information to reduce the chances that a human error will result in a serious accident (Letho, 1991). In the words of Wolgater (1999), the purpose of a warning is "to communicate information about potential hazards effectively and to reduce unsafe behaviour that might otherwise occur without their presence" (p. 93). Other warning functions are to prevent personal injuries and property damage, as well as being a reminder to persons who already know about a hazard (Wolgater, 2006). Warning signs are a countermeasure to warn and inform drivers about upcoming hazards in the road and aim to create correct expectations on the road ahead thus stimulating drivers' active observation (Allen Lunenfeld \& Alexander, 1971). It is expected that drivers will perceive the signs and adjust their behaviours to cope with the upcoming hazards. However, many studies have shown that the effects of warnings are highly variable and depend on a large number of factors (Letho \& Papastravrou, 1993).

As for the roadworks' warning signs, they have been found to be ineffective in improving safety in form of reduced speeds in work zones (e.g. Gupta, Singh \& Tiwari, 2014; Finley, Jenkins \& McAvoy, 2015; Haworth, Symmins \& Mulvihill, 2002; Hildebrand, Wilson \& Copeland, 2003). One hypothesis to explain their lack of effect is that drivers do not notice the signs. As demonstrated by Costa et al. (2014), drivers do not look at all traffic signs when driving. Increasing traffic signs' conspicuity and visibility is one way to increase the probability of their detection, thus having a positive effect on safety. In some countries the traffic signs regarding work zones usually have a different colour than the rest of the traffic signs in order to increase their conspicuity in traffic and to indicate that it is a temporary signage. Fluorescent orange sheeting on warning signs was found to reduce traffic conflicts compared to standard signs in work zones (Hummer \& Scheffler, 1999). However, the effects of fluorescent orange signs on speeds were not found to be statistically significant. Wang, Dixon, and Jared (2003) 
did find a slight speed reduction at the advanced warning and work activity area when utilising fluorescent orange warning signs, but this effect on speeds was found to diminish over time. Moreover, their results showed that variance of speeds increased immediately after the installation of the fluorescent orange sheeting but decreased several weeks after. Their conclusion was that drivers slowed down when they first saw the signs in the advanced warning area, but that the signs had a reduced effect on the speeds of fast drivers at the start of a work zone. The same trend was found by Hildebrand et al. (2003), where the average speeds were not found to be significantly reduced and the variation in speeds increased after the fluorescent sign was installed. Furthermore, their results showed that the signs had a stronger effect on speeds at nighttime but no effects on speed variability. The conclusion that can be drawn from these studies is that fluorescent orange sheeting on warning signs does not necessarily increase work zone safety in terms of lower speeds. Another method to improve the conspicuity of important traffic signs is flashing lights on the top of the sign. Some studies showed that flashing lights could increase the chances that drivers look at the traffic sign and reduce their speeds (Charlton, 2006; Summala \& Hietamäki, 1984). Still, it is unclear if flashing lights alone would affect driving speeds in work zones. It has been hypothesised that some drivers may perceive flashing lights as indicating worker activity (Blackman et al., 2014a) but not as a general hazard alert. If the reasons of the flashing light are not evident, especially when there is no visible work activity present, its effects can be reduced. An additional effect of misunderstanding the reasons for the flashing light can be an increase in speed variations, which in turn would decrease safety. Also proposed to increase the sign conspicuity is to display LED symbols and/or messages using a variable message sign (VMS). However, Charlton (2006) found that a flashing VMS format was only a little more conspicuous compared to a large dimensioned roadwork sign. Furthermore, the author found that the VMS was equal in comprehensibility and slightly worse in memorability and ability to prime drivers' reaction to hazards. Taking all those studies into account, we can assume that warning signs in work zones are for the most part conspicuous enough, but for other reasons are not effective in promoting safe driving speeds. This statement can be corroborated by the study of Haworth et al. (2002), who reported that only a few drivers stated that they did not notice warning signs when approaching work zones. In addition, Charlton (2006) found that roadworks warning signs were associated with higher average detection percentages during an attentional conspicuity task and were more often remembered and understood. In the field study by Costa et al. (2014), roadworks warning signs were also one of the most frequent signs looked at by drivers when driving on an unfamiliar road ( $36 \%$ of 8 signs). Thus, we can conclude that it is improbable that 
increasing conspicuity of warning signs alone using flashing lights, VMS, or high reflective sheeting on the signs would lead to a significant increase in safety in work zones.

There are several objective aspects of a traffic sign that increase its perception (e.g. size and visibility), but other aspects such as its surroundings and placement are also important to facilitate its perception. In an experiment to investigate the detectability of traffic signs in a road test, Akagi, Seo, and Motoda (1996) recorded the distribution of drivers' eye fixation points using an eye tracker. The results showed that visual noise, defined as the number of objects that hinder a driver's field of view such as billboards and buildings along roadsides, influenced the visibility of a traffic sign. They found a negative correlation between the distance at which a driver first recognised a traffic sign and the visual noise ratio. They concluded that the increase in visual noise can be dangerous because it reduces a sign's detection distance. Thus, we conclude that it is important to maintain the visual noise at low levels in work zones in order to increase the chances of traffic sign detection. Advertisements and information that is not relevant for driving thus should be restricted or removed. Placement of a traffic sign was also found to be important for the promptness of its perception. In the study of Borowsky, Shinar, and Parmet (2008), experienced drivers were exposed to photos of real street scenes in which some photos showed "no right-turn" signs in an expected location (on the right-hand curb), while other photos showed the same sign in an unexpected location (on the left-hand curb). The results demonstrated that when the sign was in an unexpected location, drivers were less likely to identify the sign and needed much more time to find it. The authors concluded that placing traffic signs in expected locations could reduce reaction times and increase sign compliance. Those results support the hypothesis by Alexander and Lunenfeld (1986) that the information must be available when needed, where required, and in a suitable form to fulfil the drivers' expectations and information needs.

Another factor in a traffic sign's effectiveness is its comprehensibility. When perceiving a sign, the driver needs to interpret its true meaning, and correct interpretation of traffic signs is a precondition for correct adjustment of driving behaviour and therefore important when it comes to traffic safety. Several studies have shown that many of the pictorial signs are poorly understood by drivers (e.g. Al-Madani \& Al-Janahi, 2002; Ben-Bassat \& Shinar, 2006; Lajunen, Hakkarainen \& Summala, 1996; Ng \& Chan, 2007; Shinar \& Vogelzang, 2013; Shinar et al., 2003). Nevertheless, the ineffectiveness of warning signs for work zones does not appear to be a problem related to understanding of the sign: the symbol "men at work" was one of the 
most correctly understood sign by drivers in different countries (e.g. Ben-Bassat \& Shinar, 2006; Kirmizioglu \& Tuydes-Yaman, 2012; Shinar et al., 2003). Yet, one can wonder in which way drivers interpret this warning sign. Do they consider that it indicates road workers in the area or do they interpret it as if there are hazards related to a work zone? As Bazire and Tijus (2009) suggested, the driver will search in the road environment for the corresponding information intended by the meaning of the symbol displayed on a traffic sign and will only adapt their behaviour if the expected element is seen. Consequently, it is possible to assume that if some drivers interpret this sign as a warning of active work activity in the road (i.e. men working in or by the road), they probably will find no reason to drive slower when they do not see any road workers (e.g. Blackman, Debnath \& Haworth, 2014b). No study was found that investigated the difference between interpretations of the legal meaning (i.e. "what does the sign mean?") and normal meaning (i.e. "what do you have to do?") for this particular warning sign, only about the interpretation of embedded speed limit signs in urban areas (see Lajunen et al., 1996). Even so, one can still wonder if a more accurate understanding of warning signs would lead to safer speeds in work zones. Results from the study by Al-Madani and Al-Janahi (2002) did not show any differences in the number of speeding citations or traffic crashes between drivers who better understood the traffic signs compared to those who had a poorer understanding. Thus, it can be concluded that there is no reason to assume that a more accurate knowledge of warning signs would improve traffic safety in work zones.

Although traffic warning signs may not affect speed in work zones, they may have other effects on drivers' behaviours. For instance, warning signs have been shown to decrease reaction times to a hazard (e.g. Bhagavathula \& Gibbon, 2013; Chalton, 2006; Koyuncu \& Amado, 2008). This kind of effect is known as priming. The priming effects of traffic signs were demonstrated in the study of Chalton (2006), who used scenes containing hazards primed with roadwork hazard warning signs. The results showed that reaction times to hazards for the primed scenes were shorter than the reaction times for non-primed scenes. This suggests that warning signs can "set the stage" for an appropriate response at an implicit level where drivers react to hazards faster at places with warning traffic signs. Drivers may become more alert when driving in a work zone and more prompt to react to a potential hazard even without decreasing their speeds. Even though warning signs may create correct hazard expectations, static warning signs present a limitation: the information about a particular road hazard will not always be up to date. For instance, on weekends or after work hours there is often no roadwork activity or road workers present after passing a roadworks warning sign. The traffic signs are also expected 
to act as a discriminative stimulus for a behaviour-consequence contingency, where it will miss its effect when failing to address this contingency (Fuller, 2004). Because the sign's behaviourconsequence contingency is not always obvious for the roadwork warning sign, it may be unclear which behaviour is expected from drivers. Moreover, Summala and Hietamäki (1984) argued that the symbol of a sign is frequently redundant in a road environment, and drivers will often rely on their own experience and expectation rather than on information from a sign. Accordingly, the drivers will choose their speeds based on what they see and perceive as a hazard. A way to overcome such issues is to make the information on the sign current for a specific road situation or describe what kind of behaviour is expected. A portable VMS can be used in work zones to generate a more credible message to drivers, thus strengthening the relationship between the sign's message and behaviour-consequence contingency. Bai, Finger, and Li (2010) found that a portable VMS with the messages "Slow Down" and "Drive Safely" was more effective in reducing truck speeds in a work zone. However, those messages did not have the same effect for passenger vehicles and semitrailers, where the message "Road Work Ahead" was more effective in reducing their speeds. Results from Domenichini et al. (2017) showed that a VMS with the message "Reduce speed" located in the advanced warning area was effective at reducing speeds in a work zone; however, it lost effect in the following areas. The overall usefulness of VMS in terms of safety may be questionable. In the study of Bai et al. (2010), none of the signs used (portable VMS vs. temporary signs) influenced drivers' compliance with the speed limits because the mean speeds were still higher than the posted speed limit. Similar results were obtained by Rahman et al. (2017) who did not find any evidence of the effects of VMS content (worker mentioned vs. worker not mentioned) on initial speeds, speed reduction, or drivers' compliance with posted speed limits. Also, no significant differences in compliance rates between sign type (static vs. dynamic) were found. The only effect found was an interaction effect of sign type and time of day, where the dynamic message signs were more effective in reducing speeds at nighttime. This interaction effect points to the fact that increasing traffic sign conspicuity using a VMS may have a small but positive effect on drivers' behaviours in work zones, especially at nighttime. An important aspect to have in mind is that the VMS might lose effectiveness when operated for long periods with the same message (Richards \& Dudek, 1986). Correspondingly, displaying the message only to specific drivers would have the potential to increase the effects of the VMS because the message will only be available for those who have use for the information. Such a VMS is known as a vehicle activated sign (VAS) and works in a way that the sign/message will only be activated if the driver's speed exceeds a specific threshold. Fountaine and Carlson (2001) investigated a speed 
display that showed the speeds for all passing vehicles in a work zone. When a driver passed at speeds higher than a pre-set speed threshold, a strobe lamp began to flash. The results showed that the display gave speed reductions up to $16 \mathrm{~km} / \mathrm{h}$ and that average speeds were lower than speeds when the display was not active. The display had an effect on both passenger vehicles' and trucks' speeds but had greater effects on trucks' speeds. Unfortunately, the effects on speed variations were not assessed. In the study of Wang et al. (2003), another type of VAS was tested. For vehicles that had a speed $8 \mathrm{~km} / \mathrm{h}$ above the speed limit, the sign displayed the message "You are speeding, slow down now". Otherwise, the sign displayed the message "Active work zone, reduce speed". The results showed a speed reduction up to $13 \mathrm{~km} / \mathrm{h}$, but its effects did not extend into the work activity area. After a three-week period, the effects were still present indicating no novelty effects. A speed reduction was also found adjacent to the work activity area, which indicated some generalisation effects. Even though speed variance decreased after the installation of this VAS, it increased after several weeks. Similar results were also found in the study of Hildebrand et al. (2003), with the exception of effects in the reduction in speed variance. Mattox III et al. (2007) evaluated a simpler variant of VAS in a short-term work zone. The sign had a fixed message - "You are speeding if flashing" - with orange plastic flags and a flashing beacon on the top. When a driver's speed reached the threshold measured by radar, the beacon on the top of the sign started to flash. The results showed that this type of sign reduced mean speeds up to $10 \mathrm{~km} / \mathrm{h}$. No effects on speed variance or long-term effects were assessed. Even though different types of VMS have shown positive results, some drawbacks linked to this measure should be acknowledge. For instance, PCSs have been shown to decrease driving performance in the form of vehicle control, to increase mental workload, and to demand more visual attention (Craig et al., 2017). Thus, it is important to assess what kind of information would be more relevant for the drivers in a work zone and the possible negative effects of its use.

In summary, warning and informational signs have the potential to assist road users when driving in work zones. They are important countermeasures to eliminate surprise elements, reduce uncertainty on what to expect, and decrease hazard detection times. However, their low effect on safer behaviours, especially in terms of reduced driving speeds, indicate that warning signs are not an effective measure to strengthen the behaviour-consequence contingency and thus should be combined with other countermeasures. A way to strengthen this contingency is using mandatory signs (Fuller, 2004). Indeed, the reduced speed limit mandatory signs appear to be slightly more effective in lowering speeds than roadwork warning sign (e.g. 
Gupta et al. 2014; Finley et al., 2015; Hildebrand et al., 2003). The next subsection will present the effects of regulatory signs, more specifically speed limits signs.

\subsubsection{Regulatory signs (Reduced speed limits)}

Drivers' speed choice is not always an objective rational decision. As pointed out by Elvik (2010) drivers tended to ignore environmental impacts of speed, to incorrectly perceive the relationship between speed and travel time, and to underestimate the increase in risks with increased speeds. It is also reasonable to assume that if posted speed limits were not present, the mean speeds would have been higher due to the wide spectrum of drivers' speed preferences (Elvik, 2010). Additionally, drivers have different motivations to speed (Ahie, Charlton \& Starkey, 2015), which in turn influence their speed preferences contributing to a widespread speed heterogeneity in traffic. The lack of objective rationality of drivers' speed choice and their different motivations thus gives a strong argument for the use of posted speed limits to guide and regulate this choice (Elvik, 2010). According to this standpoint, posted speed limits are an important traffic safety measure because they stipulate the fastest safe speed for a road section for all drivers independently of their speed preferences. Nevertheless, the presence of speed limit signs can also produce great speed variance among vehicles (Finley et al., 2015). This is because posted speed limits are a type of passive speed control, meaning that they do not check which drivers are not complying with the limits imposed.

Several studies on speed choice in work zones have shown that the majority of drivers had speeds over the posted speed limits (Bai et al., 2010; Debnath et al., 2014; Debnath et al., 2015; Domenichini et al., 2017; Finley et al., 2015; Ullman \& Brewer, 2014; Rahman et al., 2017). Disregarding traffic signs, especially speed limits signs, was a risk behaviour found to be associated with severe crashes in work zones ( $\mathrm{Li} \&$ Bai, 2009). Interestingly, the reduced speed limits in short-term work zones seemed to be more efficient than in long-term work zones. As Hou, Edara, and Sun (2013) showed, there was an increase in the percentage of drivers complying with the posted speed limit when lowering the speed limits in short-term work zones. The authors suggested that because short-term work zones have shorter durations, drivers are more likely to expect road workers to be present in the work zone and are therefore more cautious.

There is much evidence to support the hypothesis that drivers adapt their speeds when they see a reason for it. Several studies revealed that drivers were more compliant with speed 
limits near the work activity area where it is more likely to see on-going work activity (Benekohal, Wang, Orloski and Kastel, 1992; Benekohal \& Wang, 1994; Debnath et al., 2014; Paolo \& Sar, 2012). Drivers tend to comply with speed limits they evaluate as credible and are unlikely to select appropriate speeds if the speed limits differ drastically from the speeds they see as reasonable (Goldenbeld \& van Schagen, 2007; Lee et al., 2017; van Nes, Brandenburg \& Twisk, 2010; van Nes, Houtenbous \& van Schagen, 2008). Additionally, drivers themselves reported being more willing to comply with speed limits in work zones if they perceived the posted speed limits to be justified (Blackman, et al., 2014a). Using a simulator study, van Nes et al. (2008) found that high speed limit credibility led to lower driving speeds and less time spent exceeding the posted speed limit. In the same way, Lee et al. (2017) found that when the value of the posted speed limit was similar to what drivers believed to be appropriate speeds (established when no speed limit information was given), the judgements about appropriate speeds were consistent with the posted speed limits. Sagberg (2005) found that two-thirds of drivers exceeded the speed limits in a road section and about $74 \%$ evaluated the posted speed limits as too low. Those who evaluated the speed limit as too low had higher mean speeds compared to those who evaluated the speed limits as appropriate or as too high. The relation found between evaluation about the speed limit and actual speed indicates that most of the drivers judged the acceptable speed for the road and sped deliberately.

Different studies have pointed out that some road characteristics influence speed judgments, including road width, presence of curves, sight distance, presence of intersections, and number of lanes (Goldenbeld \& van Schagen, 2007; Lee et al., 2017). As for work zones, no study was found that directly addressed the relation between speed limit credibility and the influence of road characteristics on speed preferences. Nevertheless, the study of Finley et al. (2015) indicates that such relations might also exist. Their results revealed that at work zones where a lane shift or closure was within view of the first posted speed limits signs, there was a greater decrease in mean speeds. However, a small increase in speed variance was found indicating that drivers reacted differently in this situation. Ullman and Brewer (2014) argued that if the reduced speed limit in a work zone is perceived to be unreasonable, drivers would probably lose respect for it and choose a speed they find appropriate for the situation. It is therefore realistic to assume that the lack of credibility of speed limits is one reason for low compliance in work zones. This leads to an important issue associated with the planning of work zones, especially related to the selection of speed limits and types of measures to support this choice. Lowering the speed limits will not always produce a safer work zone because the 
speed variance may increase (Finley et al., 2015). Migletz, Graham, and Harwood (1993) found that a speed limit reduction of more than $16 \mathrm{~km} / \mathrm{h}$ actually increased speed variance as well as the percentage of vehicles exceeding the speed limit from the advanced warning area to the work activity area. Similarly, large speed reductions increased the percentage of fatal injuries in work zones. Reductions of speed limits also affect capacity thus creating congestion that in turn can increase the potential for rear-end crashes. This points to the fact that it is necessary to provide the speed limits in sufficient time so that the drivers have enough time to react without needing to brake abruptly. The placement of speed limit signs should be the usual standard distances described in national traffic manuals. As argued by Alexander and Lunenfeld (1986), driving errors are likely to occur if the traffic system violates driver expectations. This statement was corroborated by Shakouri et al. (2014) who found that varying the distance between work zones' warning signs from the standard distances increased mental demand, total perceived workload, and frustration among drivers. The authors concluded that reducing the distance between traffic signs might impose upon drivers more information processing in less timespace, while increasing the distance would require drivers to look for the signs in unexpected places. Repeating the speed limit signs throughout a long work zone would be necessary to remind drivers of the limits and to reach drivers who did not see the first signs. It is also recommended that at least one speed limit sign should be positioned in the field of view of the work zone condition or work activity area (Finley et al., 2015).

A well-known problem pointed out by many drivers is the abuse and misuse of reduced speed limits in work zones (Richards \& Dudek, 1986). Thus, the reduced speed limits should be a result of an engineering evaluation of the maximum speed that can be considered safe for the work activity and road situation (Richards \& Dudek, 1986). Reducing speed limits without such evaluation might undermine its credibility, thus reducing its effect. Lower speeds than the usual were found to be associated to a high frequency of crashes (Akepati \& Dissanayake, 2011). This is probably because some drivers would rather drive at speeds they evaluate as reasonable while others will choose to follow the speed limits. Leaving reduced posted speed limits after work activity hours is a practice that can damage the credibility of the speed limits and frustrate drivers. Many drivers agreed that the speed limits should be higher at empty work zones without visible activity (Craig et al., 2017). Nonetheless, as pointed by Haworth et al. (2002), the consequences of leaving the signage while no road worker is present must be balanced against the ever-present risks in work zones and the risks involved in taking down and repositioning the signs. Variable speed limits, where the limit is set according to the current 
roadwork situation, is a countermeasure that might increase the credibility of posted speed limit signs when no work is being performed. In theory, the value of the limit would change if the reasons of the reduced speed limit were temporarily absent (like road workers near the road). In a simulator study, van Nes et al. (2010) found that variable speed limits were perceived as more credible compared with static speed limits for some situations. Still, a question that arises is if a single speed limit value would be seen as credible by all drivers. While it may be impossible to have a speed limit that is equally credible for all drivers, it is reasonable to assume that a speed limit that is credible for most drivers would increase speed compliance, decrease mean vehicle speeds, and decrease speed variance in work zones. Even though there are many positive aspects of changing the value of the speed limits according to real-time changes in road conditions, it is also a point of concern whether drivers will be aware of the changes. Several studies found that changes in traffic signs were often not perceived, especially if drivers were not looking for a change, if they were familiar with the route, or if the changes were small (Harms \& Brookhuis, 2016; Martens \& Fox, 2007; Martens; 2011). Evidence for change blindness was also found in the study of Beanland, Filtness, and Jeans (2017), who showed that detections of changes in traffic signs and signals were inaccurate and required longer reaction times for detection. Furthermore, Martens and Fox (2007) found that drivers paid less attention to changes in a familiar road environment and tended to increase speed as they became more familiar with the road. There is also evidence that changes in rural areas were perceived more accurately and faster than changes in urban areas, probably due to the greater complexity of the urban areas and thus more elements to scan (Beanland et al., 2017). Change blindness should be a source of concern when evaluating whether to use a variable speed limit in work zones. While the consequences of missing a change in increase of a speed limit from 50 to $70 \mathrm{~km} / \mathrm{h}$ may be small, missing a change from 70 to $50 \mathrm{~km} / \mathrm{h}$ will turn drivers into serious speed offenders, even if not deliberately (Harms \& Brookhuis, 2016). At places where the relation between safety and speed is not evident and the consequences of speed violations are crucial for safety of road users and workers, traffic calming measures should be used in addition to posted speed limit signs. These will be presented in the next subsection.

\subsubsection{Perceptual treatments of traffic calming measures}

Richards and Dudek (1986) proposed that speed limit signs alone should be sufficient in places where the hazards are obvious, not needing special encouragement to select safer speeds. At places where this is not possible, it will be necessary to increase drivers' speed 
perception in other ways. This is the idea behind perceptual treatments, i.e. manipulating the visual environment to produce a behavioural adaptation in form of a slower speed. Examples of perceptual treatments of traffic calming measures are narrowed lane widths and road markings such as optical speed bars and rumble strips. The behavioural adaptation derived from perceptual treatments is supposed to be of an implicit nature, i.e. the drivers are not necessarily aware of it (Lewis-Evans \& Charlton, 2006).

Narrowed lanes aim to induce lower vehicle speeds, decrease the distance between the vehicle and the centre of the road, and reduce lateral position variability. A variety of channelising devices can be used to reduce lane widths in work zones such as delineators, traffic cones, drums, and temporary barriers (CEDR, 2013). Several studies showed that narrowed lane widths influenced driving behaviour. For example, using a simulator Lewis-Evans and Charlton (2006) found that narrow lanes were associated with lower driving speeds. Moreover, they also found that narrower lanes influenced lane positions farther away from the road shoulder. Results from Mecheri, Rosey, and Lobjois (2017) also revealed an influence of narrowed lanes on lane position and, additionally, an effect of traffic situation on in-lane position variability. In their study, participants drove closer to the centre lane when there was a lane width reduction, but variations in in-lane position were only affected by lane width in the absence of oncoming traffic. When there was no oncoming traffic, significant shifts in the vehicles' distance from the centre lane towards the shoulder line were observed. Nevertheless, there are some problems tied to this countermeasure that road planners must be aware of. Narrowing lanes has the potential to affect capacity in work zones for some situations. Yousif, Nassrullah, and Norgate (2017) recommended a minimum of a 3.25-meter wide lane when the work zone expected a high percentage of large vehicles. Their results showed that under low percentage of heavy goods vehicles, narrow lanes in work zones achieved better capacity and reduced delays compared to other methods like lane closures. However, when heavy goods vehicles were more common, a significant number of drivers avoided overtaking them. When they finally decided to overtake large vehicles, drivers tended to reposition their vehicles far away, which could have implications for safety. The authors concluded that this observed behaviour might have an impact on capacity reduction in work zones and recommended lowering speed limits to $65 \mathrm{~km} / \mathrm{h}$ when there is a high percentage of heavy goods vehicles. On the other hand, Mecheri et al. (2017) recommended a 3-meter wide lane because they found that this distance did not generate higher driving speeds and vehicles positioned farther away from the edge of the road showed less swerving behaviour. The size of lane width may also 
have an effect on drivers' subjective perception of driving demand. Results yielded by some studies point to the fact that the drivers perceived narrow roads as more difficult, riskier, and more likely to produce crashes (Lewis-Evans \& Charlton, 2006). Another interesting finding is that speed percentiles seem to be less homogeneous on narrowed roads (Aarts, Branderburg \& van Nes, 2011), suggesting that the perceived task demand and feeling of risk are not equal for all drivers. Narrowed work zone lanes were also associated with ratings of stress and difficulty and were pointed out by drivers as one of the factors that make it difficult to drive through work zones (Petzoldt et al., 2016). Narrowed lanes can also increase workload, which in turn could influence driving performance and make drivers more prone to errors. For this reason, the best way to use this countermeasure would be in the transition area, before the work activity area, giving drivers enough time to adjust their speeds and focus their attention on potential hazards in work zones.

Optical speed bars are a type of road marking that follows the same principle of narrowed lanes, i.e. to induce a perception of higher driving speeds using a series of transverse stripes in or alongside the road. Two different simulator studies found that optical bars had an effect on drivers' speed choice (Ding et al., 2013; Montella et al., 2011). Different speedreducing treatments were tested in Montella et al. (2011), and the most effective treatments were the "dragon teeth markings", which were based on the principle of visually narrowing the road width. In the study of Ding et al. (2013), they found that transverse markings had a significant effect on reducing speed, deceleration willingness, and manoeuvring (releasing the accelerator and braking). Drivers also reported that their driving was affected by the marking. However, the effect of the transversal bars on speed was very low, with an average speed difference of only $-0.02 \mathrm{~km} / \mathrm{h}$ for this type of treatment. Meyer (2004) also tested a transverse bar marking with different patterns towards a work zone and found reductions in standard deviations, meaning greater homogeneity in speed in the location. The mean speeds were also reduced at the site, but although statistically significant, the changes were quite small. The positive aspect is that those effects did not seem to decline after three months, and the markings were still perceptible after this period. The variance in effects of optical bars also depends on traffic conditions. For example, Hildebrand et al. (2003) found that transverse speed bars were more effective during nighttime due to their retroreflective characteristic. The optical bars also showed a visual warning effect that alerted the driver. It is hypothesised that perceptual cues assist drivers to more rapidly detect hazards even though their driving speeds are unchanged; however, further studies are needed to establish the effects of optical speed bars on hazard 
perception. Summarising the results, it is recommended to combine optical speed bars with other types of measures because this measure only gave a minimal speed reduction.

Rumble strips are a type of optical speed bar having an additional effect of alerting drivers by physical vibration and thus reducing inattentive driving in the advanced warning area (Li \& Bai, 2007). There are two types of rumble strips that can be used to warn of an upcoming roadwork area: portable or fixed. Fountaine and Carlson (2001) investigated the effects of portable rumble strips and did not find a significant effect on speed of passenger cars, but did find one for trucks. The speed reductions were $3.2 \mathrm{~km} / \mathrm{h}$ for cars and $11.3 \mathrm{~km} / \mathrm{h}$ for trucks. In another study, portable rubber rumble strips were later found to reduce mean speeds by $7 \mathrm{~km} / \mathrm{h}$, to reduce the $85^{\text {th }}$ percentile by $9.5 \mathrm{~km} / \mathrm{h}$, and to produce significant reductions in speed variance (Hildebrand et al., 2003). Similar results were found by Meyer (2011), who showed significant speed reductions with removable rumble strips of up to $3.7 \mathrm{~km} / \mathrm{h}$ for cars and trucks. Nevertheless, it was observed that the thickness of the strips appeared to be insufficient to create an audible and tactile warning for some drivers, but because a speed reduction was found the author assumed that the colour of the strips was enough to have a warning effect. One unexpected effect observed of rumble strips was that some vehicles drove into the opposing lane apparently to avoid driving on the rumble strips (Fountaine \& Carlson, 2001). The authors thus do not recommend the use rumble strips in rural work zones. Furthermore, the rumble strips should be avoided in work zones within residential areas due to the noise generated by the vehicles when driving on them.

Not all work zones have clear road markings. In the analysis of Li and Bai (2009), centre/edge lines in work zone pavement was effective in reducing by $29 \%$ the odds of severe crashes caused by drivers who drove "too fast for condition/exceeded speed limit" and a reduction of $19 \%$ in crashes by drivers who tailgated. Road markings were also found to influence lane position. In the study conducted by de Waard, Steyvers, and Brookhuis (2004) participants drove at a more central position in non-delineated roads, while with a centre-line marking they drove more towards the road's shoulder. Another interesting finding was that elderly drivers appeared to need the visual aid of the centre-line more than young drivers. In work zones without clear road markings, other channelling devices can be used to assist road users in lane positioning and keeping them away from the work activity area. Vertical delineators could also serve as perceptual measures and contribute to a greater homogenisation of speeds (Domenichini et al., 2017). Allpress and Leland Jr. (2010) tested the effects of both 
uneven and even cone arrangements through a work zone. They found that the speeds decreased in both conditions, with a greater reduction when the cones were placed unevenly by the road. This effect was also maintained in the work activity area (without any cones) demonstrating that the cone arrangements had generalising effects on speeds. Because cones are easily implemented and removed, they can be used at the entry of work areas, and they have better effects when they are arranged in an uneven manner (Allpress \& Leland Jr, 2010).

Perceptual countermeasures used to increase drivers' perceptions of speed or to guide them through the work zone area are measures that have the potential to diminish unsafe driving behaviours such as speeding and swerving. Nevertheless, the studies presented here highlight the necessity of evaluating each work zone in order to find more suitable measures or combinations of measures to achieve the expected results.

\subsubsection{Other solutions}

The literature on work zone safety also mentions other solutions that are not directly related to traffic management measures but have been shown to have the potential to reduce speeds in work zones. Flaggers (i.e. persons who direct traffic through a work zones using gestures, signs, and/or flags) are often used in work zones and are supposed to have a repressive effect on driving speeds. Indeed, speeds near flaggers were found to be generally lower than the posted speed limits (Benekohal \& Kastel, 1991). According to Li and Bai (2009), flaggers could reduce by $54 \%$ the odds of a severe crash caused by "disregarded traffic control" and by $40 \%$ the odds of a severe crash caused by "inattentive driving" and by driving "too fast for condition/exceeded speed limits". However, Qi et al. (2013) found that work zones with flaggers were associated with more rear-end crashes, although those were less severe. A possible reason for an increased risk of rear-end crashes is that drivers make a more immediate response to flaggers compared to traffic signs, often braking more abruptly instead of gradually reducing their speeds. There is also a possibility that the driver does not see the flagger, reacting only after seeing the leading vehicle slow down or stop. For those reasons, as suggested by Richard and Dudek (1986), flaggers should not be used on roads where the speeds are too high, roads with limited sight distance, and in places where they need to compete for drivers' attention (i.e. places with roadside advertisements). Furthermore, some studies showed that increased visibility of workers wearing high visibility clothing (e.g. Turner, Simmons \& Graham, 1997) and training programmes for flaggers (e.g. Benekohal \& Kastel, 1991) could increase the effects of flaggers in work zones. 
Visible police presence in work zones and speed photo-radar were also found to be effective, indicating the importance of enforcement (e.g. Benekohal, Resende \& Orloski, 1992). As indicated by Richard and Dudek (1986), speed control in work zones will often be needed to enforce compliance with passive control measures (e.g. speed limit signs). However, some studies pointed out that the effectiveness of enforcement depends on several factors other than its presence, such as the swiftness, severity, and certainty of the punishment given for the violation. Ullman et al. (2013) found that increased fines for traffic violations in work zones have not resulted in changes in driving behaviour, probably due to the low risks of being caught. Another important issue is that police control has the potential to decrease the effects of traffic calming measures when enforcement is not present (Ullman et al., 2013). Later, Ullman and Brewer (2014) presented studies that showed that participants believed that they reacted similarly to reduced posted speed limits regardless of active enforcement in work zones. Those studies revealed that enforcement and speed control might not always be the ultimate solution to increase safety in work zones. This is not to say that they are not important, but that other factors must also be considered to make the most of their effects. To increase the potential of speed control in work zones, Richard and Dudek (1986) suggested that active control and enforcement should only be used on the opening days of the work zone and when major changes in traffic and road conditions take place.

Traffic safety and public awareness campaigns addressing work zone safety are not very common, and evaluations of their effects are even less common. Only one article was found analysing the effects of a campaign in a work zone in Finland. The study of Summala and Philman (1993) evaluated the effects of a music tape with information focusing on the experience of road workers when truck drivers passed them too fast and close. Measurements of truck behaviour were collected before and three times after the tape was released. Truck speeds in the work zones were not changed after the campaign started, but there was an increase in lateral safety margins when a road worker was standing at the beginning of the work activity area. Nevertheless, this effect was only found when no oncoming vehicles were present. The authors concluded that the presence of the road worker seemed to activate the safety message from the tape in truck drivers' memories, but that the drivers relied more on their experience and traffic characteristics rather than signage or safety information. In general, traffic safety campaigns have been shown to have some effects on traffic crashes, although the effects are usually small (Phillips, Ulleberg \& Vaa, 2011). In line with the authors' analysis, a traffic safety campaign focusing on driving behaviours in work zones would be most likely to have positive 
results if combined with personal communication, roadside media delivery, and enforcement. A less systematised type of public awareness campaign in work zones is with traffic signs with innovative messages. Wang et al. (2003) tested a warning traffic sign with the message "My $\mathrm{dad} / \mathrm{mom}$ works here, drive slowly" written in a child-like font. The signs resulted in a speed reduction up to $2.9 \mathrm{~km} / \mathrm{h}$ for one site but had no effect at a second site or during nighttime conditions. The speed variance in the advanced warning area increased for one site, but then decreased adjacent to the work activity area. Speeds decreased a little after several weeks following the implementation of the site, indicating no novelty effects. Although innovative messages in some work zones have the potential to give small speed reductions, they might increase speed variability because the type of message used will only influence those drivers who find the content persuasive enough to change their speeds.

In this section, several studies that accounted for drivers' behaviours in work zones are presented to understand more about crash risks. Numerous studies indicated that it is unlikely that only one countermeasure will be enough to increase safety in a work zone. Each work zone needs to be evaluated separately, and potential safety issues linked to correct countermeasures should be planned in terms of speed, speed variance, and workload. Because the effects of road environment and countermeasures are highly variable, it is important to take a deeper look into drivers' behaviours from a psychological perspective. The most common theories in traffic psychology will therefore be presented in the next section. 


\subsection{Theories and models of driving behaviour and their application to understanding behaviour in work zones}

It is well established in the scientific literature that drivers' risky behaviours are the main factors that contribute to crashes and deaths in traffic (Elander et al., 1993). To comprehend such behaviours and predict drivers' reactions to the traffic environment and countermeasures, many models and theories have been developed during the past decades in the field of traffic psychology. To systematise the existent driver behaviour models, Oppenheim and Shinar (2011) proposed a classification into descriptive and functional models. The descriptive models sought to define and describe what the driver does in traffic. Those models divide driving behaviour into different driving tasks or levels. Some examples of descriptive models are the hierarchical model of performance by Rasmussen (1983) and the hierarchical risk model by van der Molen and Bötticher (1988). As for the functional models, they attempt to describe the situational and motivational factors of driving in order to understand why drivers do what they do. The main functional models are the risk homeostasis theory by Wilde (1982), the zero-risk model by Näätänen and Summala (1974), and the task-capability interface model by Fuller (2005).

While theories have been developed specifically to analyse driving behaviour, other theories and models in psychology have also been applied to explain and predict drivers' behaviours in different traffic contexts. Some examples are human error (Reason et al., 1990), the theory of planned behaviour (Ajzen, 1991), personality traits (Costa \& McCrae, 1995; Zuckerman, 2007), and risk perception (Slovic, 1987). In the next subsections, the most prominent models and theories in traffic psychology will be presented, and their implications for understanding drivers' behaviours and the effectiveness of work zone countermeasures will be discussed.

\subsubsection{Descriptive models of driving behaviour}

Driving is a complex behaviour with numerous interrelated subtasks that need to be handled simultaneously. Defining the subtasks of driving behaviour and ordering them into a hierarchy according to the level of cognitive activity relevant for their performance would allow an examination of distinct forms of information needs and types of control actions for each type of subtask (Allen et al., 1971). The existent models suggest different terms for each level, but 
they all divide the behaviour into at least three different levels in relation to information processes and behavioural performance.

According to the hierarchical models, the lowest level of behavioural performance involves skilled sensory-motor behaviours such as steering, speed control, and emergency reactions to avoid sudden threads (Allen et al., 1971; van der Molen \& Bötticher, 1988). These types of behaviours are procedural, highly automated, and involve very little or no conscious control (Rasmussen, 1983). The information processing approach at the skill-based level is bottom-up. This means that there is no active search for information and only objects that attract drivers' attention are perceived. As described by Rasmussen (1983), the sensory input (e.g. vision) is only directed towards the environmental characteristics needed to orient the internal map to aid in task performance at the skill-based level. The basic information comes primarily from the vehicle's response to the driver's control actions (e.g. sounds from the motor, steering wheel vibrations, etc.), vehicle location on the road according to the lane width, road markings, and further visual perceptions of the environment (Allen et al., 1971). Common errors that can occur at the skill-based level are generally of a psychomotor nature, such as failing to brake in a given situation or attempting to drive off in third gear (Reason et al., 1990).

Because behaviours at the skill-based level are highly automated, responses due to countermeasures will not necessarily be perceived at a conscious level. One example of work zone countermeasures aiming at behaviours at the skilled-based level are narrowed lane widths. This countermeasure aims to mostly influence speed behaviour, but it also influences lane positioning. As demonstrated by Lewis-Evans and Charlton (2006), narrower lanes influenced lane positioning farther away from the road shoulder, but the difference in lane width was not always perceived. This result suggests that when expectations about lane widths are not fulfilled, control errors, such as driving too close to the road centre, are more prone to occur. To prevent errors at the skill-based level, Letho (1991) suggested that additional information should be provided to trigger information processing and decision-making to shift to a higher level of performance. Using the example of narrowed lanes, because they can be contrary to drivers' expectations on how wide a lane should be, a warning sign should inform drivers thus triggering the information to be processed at a higher level in the hierarchy. In this way, chances of control errors can be diminished. While the warning signs generally have the intention to influence behaviours at a skill-based level (e.g. decreasing speeds), this information is necessary to be processed at a higher level in the behavioural hierarchy. 
At the next level of performance (rule-based), behaviours are a function of drivers' perceptions of a situation and their ability to respond in an appropriate manner (Allen et al., 1971). There is a conscious problem solving effort directed towards attaining a goal (Letho \& Papastravrou, 1993), and, although behaviours can be routine in nature, the goals are present in consciousness (Rasmussen, 1983). There are numerous types of situational performances, including different responses to road situations, obstacle avoidance, gap acceptance, turning, and overtaking. Safety performance at the rule-based level will mostly depend on drivers' prior knowledge in order to understand the situational demands and on their skills in order to enable them to choose appropriate control actions for the situation. One example of a behaviour occurring at the rule-based level is when a driver approaches a signalised intersection and hits the brakes when the traffic light turns red. In this example, the driver has a rule (i.e. one should stop at a red light), and its application (i.e. hitting the brakes) reflects the brief transition from the skill-based level upward in the hierarchy. The source of information at the rule-based level comes from the physical, traffic, and road situation. The information from the environment should elicit a response, otherwise the behaviour will continue to occur at a skill-based level. Common types of errors are often due to the failure of a situation to trigger a transition up the hierarchy when the behaviour is skill-based or to trigger an appropriate rule for the situation (Letho, 1991; Letho \& Papastavrou, 1993).

Examples of countermeasures that are processed at the rule-based level are warning signs. A warning sign gives information about a road characteristic in order to elicit a rule and trigger a sequence of events (e.g. slowing down). As for the roadworks warning signs, they have been found to be ineffective to improve traffic safety in form of reduced speeds in work zones (e.g. Gupta et al., 2014). It is possible that those warning signs are insufficient to trigger a behavioural transition to a higher level, resulting in the driver continuing the driving task at a skill-based level. As pointed out by Letho and Papastavrou (1993), tasks performed at a skillbased level showed the lowest levels of noticing signs or warning labels. A way to succeed in triggering a behavioural transition between levels and increase the chances of noticing warnings is to increase the conspicuity of signs (Letho \& Papastavrou, 1993). Different countermeasures to increase traffic signs' conspicuity were discussed in the previous section. Another way to trigger a transition from a skill-based level is interrupting the performance or using non-verbal signals (e.g. sounds or vibrations). An example of a work zone countermeasure is rumble strips that cause a vibration in the vehicle when driving on them. Hildebrand et al. (2003) found that rumble strips reduced mean speeds by $7 \mathrm{~km} / \mathrm{h}$ and produced significant reductions in speed 
variance. The authors concluded that the strips had both auditory and visual effects because they also influenced speeds even when their thickness did not create any audible effects. These results indicate that rumble strips are a countermeasure likely to assist in a transition of information processing from skill-based to higher levels of performance. Furthermore, a different explanation for why failure in information processing occurs at the rule-based level is that the situational performance triggers the wrong rule. For work zones, a possibility is that the signs are not able to evoke correct behaviours, and the inconsistency of many of temporary traffic signs in work zones might be one reason for this. The presence of traffic signs such as "men at work" or reduced posted speed limits are often associated with low expectancy of encountering road workers or salient risks, and this in turn undermines the induction of the right rule (i.e. an association between signs and the act of slowing down). However, modifying already established rules might be challenging. As pointed out by Rasmussen (1986, cited by Letho \& Papastavrou, 1993), one of the difficulties in inducing upwards transitions from the rule-based level to higher levels is peoples' overconfidence in the adequacy of their routine behaviour. Drivers might select usual speeds through a work zone because they are confident that they have the skills to manage unforeseen elements. Because there is usually no consequence for incorrect behaviours (e.g. getting a fine or crashing one's vehicle), there is no opportunity for the rule to be revised. Thus, for the purpose of modifying incorrect rules or learning new ones the behavioural performance must be shifted to higher levels in the hierarchy (Letho \& Papastavrou, 1993).

The third level of performance is knowledge-based and consists of behaviours that are not directly involved in actual driving but influence behaviours at the lower levels. According to Letho (1991), behaviour at the knowledge-based level requires cognitive decisions from the driver. Typical behaviours are direction finding, trip and route planning, and mode choice (Allen et al., 1971; van der Molen \& Bötticher, 1988). This involves conscious problem solving towards attaining a goal and actively seeking information to help with this task (i.e. top-down information processing) (Lehto \& Papastavrou, 1993). An example of a behaviour at the knowledge-based level is driving to a particular destination. While driving, the driver searches for information from guide signs, landmarks, etc., and compares this information with the planned trip in order to decide which control action is required (e.g. changing lane position in order to take an exit ramp). The information provided by guide and service signs is supposed to fulfil the information needs at the knowledge-based level (Allen et al., 1971). To assist in safety performance at the knowledge-based level, instructions/information to allow a shift to 
other lower levels (e.g. a lane change) must be given in time to permit the driver to perform a safe manoeuvre. Errors at the knowledge-based level involve the initiation of inappropriate actions and the inability to adequately consider the consequences of actions (Letho, 1991). Events on the road that will influence drivers' route planning, direction finding, and sometimes mode choice (e.g. traffic congestion, closed roads) should be given in advance so that drivers have time to adapt their plans in order to achieve their goals. One countermeasure is VMSs that inform and give advice to drivers. Erke, Sagberg, and Hagman (2007) investigated the effects of VMSs with information about a closed road and recommendations for alternative routes. They found that about every fifth vehicle followed the recommended route. These results indicate that some drivers considered the information from the VMS and adapted their behaviours accordantly. For work zones, Bai et al. (2010) found that a VMS with the message "Road Work Ahead" was more effective in reducing speeds compared to the messages "Slow Down" and "Drive Safely". One explanation for this is that drivers might prefer information about a specific traffic situation, so they can reconsider their goals rather than advice on how to perform a behaviour at a lower level. The results from the study of Petzoldt et al. (2016) corroborate this conclusion, and they found that drivers rather preferred to receive information about a work zone's length and time of completion. Drivers also reported that a long work zone was a factor that elicited stress and annoyance. Accordingly, informing about work zones' characteristics and current traffic situations using, for instance, a VMS might have the potential to make drivers less annoyed by the delays caused by work zones and less prone to commit errors at the lower levels of performance.

In an attempt to incorporate other cognitive variables in the hierarchical model, Letho (1991) proposed a fourth level of performance called the judgment-based level. The judgmentbased level encompasses affective reactions triggered by a stimulus that is processed at the value level such as fear, pleasure, comfort, etc. (Lehto \& Papastavrou, 1993). Such reactions alter goal priorities, triggering either knowledge-based behaviours (e.g. a re-examination of opinions and beliefs) or behaviours at a rule-based level (e.g. a conscious decision to act in a certain way). According to the author, information at the judgment-based level should persuade drivers to change their beliefs and attitudes towards safety and thus produce behavioural changes at the lowest levels of performance. Traffic safety campaigns are an attempt to influence behaviour at the lowest levels (e.g. speed) by targeting attitudes and beliefs at the highest level of behavioural performance. Changes at the judgment-based level are expected to have more long-lasting effects at the lowest levels of performance by influencing behaviours at 
the rule-based and knowledge-based levels that in turn would have an effect on skill-based levels. However, effects of traffic safety campaigns on the lowest levels of performance are not guaranteed. As emphasised by Letho (1991), information alone is unlikely to ensure compliance, and for this reason the message should be mandated and enforced in order to correct errors at lower levels of performance.

Generally, the hierarchical models can provide valuable knowledge about tasks the driver has to perform in different traffic situations and the type of information the drivers need according to each level of performance. The models' applicability includes assistance in the planning and execution of countermeasures targeting specific behaviours at a particular level. Nevertheless, these models have some limitations. The first is that the driver is perceived as a passive agent performing multiple tasks with limited influence on their own performance. The second limitation is that hierarchical models do not take into account the influence of motivational factors and transient motives on performing the driving task. For instance, there is evidence that motivation influences drivers' perception of traffic signs (Summala \& Näätanen, 1974) and their speed choice (Ahie et al., 2015). Furthermore, hierarchical models do not explain the interactions between driving skills and individual differences nor are they able to explain why drivers sometimes respond differently in similar traffic situations. For this reason, functional models focus on motivation and transient factors as determinants of behaviour. These models perceive drivers as active agents of their performance, where they can choose the amount of effort and risk they are willing to accept. The most well-known functional models are described in the next subsection.

\subsubsection{Functional models of driving behaviour}

Näätänen and Summala (1974) assumed that driving is a complex behaviour, but it can be considered a self-paced task. This means that drivers are active creators of traffic situations because they can determine the degree of difficulty of the tasks and the level of performance they are willing to accept. The model proposed by Näätänen and Summala is known as the zerorisk theory. This model focuses on motivational tendencies and inhibitory processes that influence drivers' decision-making and behaviour. According to the model, drivers' decisions and actions are affected by the strength of the desired action (influenced by motivation) and the subjective risk. Mobility is supposed to be the primary motive for using the traffic system, and for this reason the utilities associated with higher speeds (e.g. shorter travel times) would push drivers towards faster driving and, consequently, to higher objective risks. In this model, 
motivation is the excitatory component and is supposed to be influenced by a driver's personality, state of mind, and transient motives. On the contrary, the subjective risk has an inhibitory role on drivers' decision-making, and once activated "generates different degrees of subjective risk or fear depending on the risk experienced in the traffic situation". The risk or fear is thought to be a direct result of a perception of losing control of the vehicle or of heading on a collision course and slowing down would be the immediate inhibitory response. According to the theory, drivers adapt to risks on the road in order to experience no risk at all and will only adjust their performance when the perceived risk exceeds a certain threshold. Consequently, when countermeasures attenuate the subjective risk, making the traffic environment appear safer (e.g. improved sight distance), the excitatory components in drivers' decision-making could result in faster speeds and/or decreased vigilance. Summala (1988) also argued that even though the driver is motivated to escape or avoid experience of risk, they often use the road to satisfy their motives of mobility. Thus, the psychological mechanism behind drivers' responses should not be seen as a risk compensation, but as a tendency for motivational satisfaction in the sense that an adjustment only begins when perceived risks exceed a threshold. According to him, the adaptation to risk is largely a function of increasing self-confidence because drivers' feelings of uncertainty (which would have inhibitory effects) diminish as the confidence in their control skills increases, which tends to eliminate conscious attention to safe driving practices.

The main contribution of the zero-risk theory is the focus on motivational aspects of risk-taking in traffic, and it provides an explanation for why some safety countermeasures do not have the expected effects on objective risks. According to the model, for a countermeasure to be effective it should prevent drivers from satisfying their motives, limit manifestations of motivational tendencies, and increase the subject risk without increasing the objective risk (Näätänen \& Summala, 1974). One example of a countermeasure that would increase safety at work zones, according to this theory, is barriers separating two-lane roads. Such barriers would increase the immediate subjective risk by increasing the subjective speeds while at the same time providing a physical safety function by preventing head-on collisions. Thus, countermeasures will be effective if they decrease objective risks, increase the subjective risk, and do not encourage drivers to satisfy their motives for higher speeds. As demonstrated by Allpress and Leland Jr. (2010), traffic cones used at the beginning of a work zone were found to decrease speeds, which they explained by an increase in drivers' perception of risk due to an illusion of increased speeds. They did not assess the effects of cones on crash rates, but because 
they influenced speeds, it is reasonable to assume that they also had some effect on the objective risk in the work zone.

While the zero-risk theory suggests that drivers' subjective risk is most of the time zero, the theory of risk homeostasis proposed by Wilde (1982) postulates that the driver seeks some level of risk (i.e. target risk). According to his theory, the target level of risk is based on the perceived advantages and disadvantages of behaviours (a cost-benefit evaluation), which in turn determines the choice between risky or safe behaviours (Wilde, 2013). This comparison process is thought to be largely automated and not a part of the drivers' awareness (Wilde, 1982). This theory suggests that the actual risk experience is constantly compared with the target risk. When there is a discrepancy, behavioural changes will occur to re-establish the equilibrium between the target and experienced level of risk (Wilde, 1982). As a result, if the perceived level of risk is lower than the target level of risk, then the action will be a riskier behaviour (i.e. higher speeds). Whenever the perceived level of risk is higher than the target level of risk, the choice will be safer behaviour (i.e. lower speeds).

The target level of risk is argued to be determined by four factors: the perceived benefits and costs of risky behaviours and the perceived benefits and costs of cautious behaviours. Wilde (1982) proposed further that the target level of risk can be increased if there is an increase in perceived benefits of risky behaviours and in perceived costs of cautious behaviours. On the other hand, the target level of risk can be reduced if there is an increase in the perceived benefits of cautious behaviours and in perceived costs of risky behaviours. Wilde (1982) also argued that to be successful in inducing behavioural changes and decreasing crash rates, motivational countermeasures oriented towards crash avoidance should be used. For instance, countermeasures should either discourage driving, discourage specific unsafe driving behaviours, increase the costs of a crash, or increase the benefits of not crashing. The theory postulates that the level of accepted risk is stable and that drivers will unavoidably compensate for improvements in the traffic environment, vehicle, or driving skills through faster and less caution driving in order to establish their level of risk. Drivers will not try to minimise the risks, but instead will make an effort to maximise the benefits of their motivations to maintain a constant level of risk. An example Wilde used is the introduction of anti-lock brakes (ABS) that resulted in delayed braking, increased speed, and closer following. Thus, countermeasures will not have their intended effects if they fail to lower the risks that drivers are willing to accept (i.e. reduce the level of target risk). As a result, Wilde's theory would yield contrary 
recommendations than the zero-risk theory because it considers education and safety campaigns to have larger potential effects on target risks compared to better vehicles or better roads. Another difference between the zero-risk theory and risk homeostasis theory is that, according to Wilde, drivers are always adjusting their performance, while Summala (1988) assumes that the compensation only begins when the perceived risk exceeds a certain threshold.

The main contribution of Wilde's theory is providing one explanation for why some countermeasures have contrary effects on drivers' behaviours. However, his theory has been the target of much criticism. One critique is that the homeostatic process proposed to explain risk compensation would only have meaning at an aggregate and not an individual level (Michon, 1985). Moreover, it will not show why some drivers behave differently in similar traffic situation, presuming that the target of risk is somewhat stable, nor does it explain how emotions influence behaviour. The theory also has a pessimistic undertone because it postulates that countermeasures will inevitably produce behavioural adaptation in order to restore the balance between the experience of risk and the target level of risk. Many studies have confirmed substantial reductions in crash rates achieved by diverse safety countermeasures, thus not supporting the assumption of the theory that they will fail if they do not target the level of risk.

Attempting to integrate concepts from the zero-risk and risk homeostasis theories, Fuller (2005) proposed the task-capability interface model. This model suggests that drivers select a range of task difficulties they are prepared to accept and then modify their speeds to maintain that level. Contrary to the idea that risk plays a relevant role in drivers' behaviours, this model proposes that an important aspect in drivers' decision-making is the perceived task difficulty. According to Fuller, drivers adjust their speed to deal more easily with hazards or potential difficulties, while risk perception is not a constant determinant of drivers' decision-making. The assumption is that the drivers are motivated to maintain a preferred level of task difficulty to reach a destination while avoiding collisions. Thus, the perception of the difficulty in meeting those demands (mobility vs. collision) is the determinant for driver decision-making. Speed adaptation is understood as a compensatory behaviour to deal with an increase in task demands, where task difficulty is thought to be sustained in a homeostatic way. Important concepts in this theory are capability and task-demand. The driver possesses a certain level of capability, which is constrained by constitutional features (i.e. biological characteristics such as information processing capacity and reaction times) as well as knowledge and skills that are acquired through training and experience. The combination of biological components and education, 
training, and experience is referred to as a driver's competence, and these are proposed to be relatively stable. Less stable and more dependent on the situation are the human factors such as attitude, motivation, effort, emotion, etc. These components are proposed to constitute capability, reflecting the current ability of the driver to respond to the task demands, which are determined by a combination of many factors such as environmental factors, other road users, weather conditions, etc. Task difficulty is defined as the interaction of task demands and drivers' capability, and according to the theory the closer the capability is to the task demand the more difficult the task will be, and less capability will be available to deal with an increase in task demand, which in turn could lead to loss of control and a collision (Fuller, 2005). One of the assumptions of this theory is that task difficulty is closely related to speed. Fuller et al. (2008) found that ratings of task difficulty increased with speeds; however, risk ratings (of crash risk) only increased once a certain speed threshold was exceeded. Their results also showed that ratings of perceived risk increased with ratings of task difficulty and speeds. Their conclusion was that experience of risk is not the same as subjective estimates of the probability of collision, which is contrary to what Wilde argued but closer to Summala's (1988) idea about the experience of risk as a fear resulting from the perception of loss of control.

Applying this theory to explain risky behaviours in work zones, one may say that drivers do not adapt their speed because they assume it is compatible with the current task demands. To support this assumption, we refer to the results of Benekohal et al. (1993) who found that drivers who knew they were speeding in a work zone reported that they felt their speeds were safe enough for the road conditions. Consequently, to increase safety in work zones, the task demands should not surpass drivers' capabilities as constrained by biological characteristics. Although some drivers have high capabilities, there is still a limit to the amount of information that can be processed. For instance, only a limited number of words can be read during a fixed time. For this reason, demands from the environment that are not necessary to a safety-related behavioural performance should be kept at a minimum so as not to compete with critical information. Furthermore, the perceived task demand is not equal for all drivers. Aarts et al. (2011) found that speed percentiles were less homogeneous on narrowed roads, and narrower work zone lanes were also associated with increased ratings of stress and difficulty and were pointed out by drivers as one of the factors that make for difficult driving in work zones (Petzoldt et al., 2016). According to Fuller (2005), when a task demand exceeds the driver's perceived capability, the driver will probably be unable to avoid an obstacle or stop in time. Thus, narrower lanes could also increase workload, which in turn might influence driving 
performance and make drivers more prone to errors. Therefore, the best way to use this countermeasure would be before the work zone activity area thus giving enough time to drivers to adjust their speeds and to focus their attention on potential hazards when driving in the work zone (Richards \& Dudek, 1986).

Even though different driver behavioural models can be used to describe drivers' behaviours and the reasons they take place, other theories in psychology are also used to understand and predict this complex behaviour. The most common psychological theories used in the study of driving behaviours will be presented next.

\subsubsection{Theories in psychology used to understand and predict drivers' behaviours}

A prominent approach to studying risky driving behaviours is based on the error taxonomy proposed by Reason et al. (1990). The hypothesis behind this taxonomy is that aberrant driving behaviours have different underlying psychological mechanisms. The authors classified different types of driving behaviours into errors and violations. Errors were defined as "failure of planned actions to achieve their intended consequences" and were considered to result from deficiencies in judgmental and/or inferential processes. Reason et al. further divided errors into slips, lapses, and mistakes. Slips were classified as "potentially observable as externalised actions-not-as-planned" (e.g. intending to switch on the windscreen wipers but switching on the lights instead). Lapses were defined as "covert memory failures" (e.g. forgetting where the car is parked). Both were assumed to result from attention and memory deficits. Mistakes were "departure of planned actions from some satisfactory path towards a desired goal" (e.g. underestimating speed when overtaking); in other words, they are errors of intention. Violations were defined as intentional "deviations from those practices believed necessary to maintain the safe operation of a potentially hazardous system" (e.g. crossing an intersection after the lights turned red). The main distinction between errors and violations regards intentionality - if there was a prior intention to commit it, then it is a violation; if no intention exists, it is an error. Later, an additional distinction between types of driving violations was suggested by Lawton et al. (1997a). They argued that violations could be either ordinary deviations of the traffic code (e.g. disregarding the speed limit on a residential road) or aggressive violations involving "acting aggressively toward other road users" (e.g. sounding your horn to indicate your annoyance with another road user). 
A questionnaire was created to encompass the different types of aberrant driving behaviours and was named the Driver Behaviour Questionnaire (DBQ; Reason et al., 1990). The assumption that aberrant driving behaviours are different types of behaviour was supported by factor analysis. The DBQ has gained popularity in recent decades, and several studies connecting aberrant behaviours with other measures relevant for traffic safety have been conducted. For instance, violations and errors were found to be correlated with self-reported crash involvement (Winter \& Dodou, 2010). As for drivers' characteristics, male and younger drivers were found to more often report violations and aggressive violations, such as drinking and driving and speed violations, than female and older drivers (Constantinou et al., 2011; Lawton et al., 1997a; Reason et al., 1990). On the other hand, female and older drivers reported more lapses and errors (Reason et al., 1990; Winter \& Dodou, 2010). Regarding age, younger drivers tended to report more risky driving behaviours, where age had a negative correlation with ordinary violations (Constantinou et al., 2011). Likewise, younger drivers were more likely to report intention to speed in different traffic contexts (Lawnton et al., 1997b). A meta-analysis conducted by Winter and Dodou (2010) confirmed that being male, younger age, and increased mileage were related to increased violations scores. Drivers who reported more violations also tended to rate themselves as skilful drivers, suggesting that they believe that a good driver can break the rules (Reason et al., 1990). Furthermore, personality traits, such as sensation seeking and impulsivity, were found to be positively correlated with violations (Constantinou et al., 2011). Hostility was found to predict aggressive and ordinary violations scores and separation insecurity predicted errors, while perseverance predicted lapses (Beanland, Sellbom \& Johnson, 2014). The relationship between personality traits and risk behaviours strengthens the hypothesis that dimensions of individual differences are a basis of driving behaviour.

This taxonomy has implications from both a theoretical and practical perspective. Theoretically, it endorses the need to combine both cognitive (information processing) and social (motivational) processes when studying aberrant behaviours. Practically, it provides a framework to design more targeted interventions. Aberrant behaviours that are committed systematically in the form of errors and violations can be qualified as a driving style. As underlined by Sagberg et al. (2015), driving style is "a habitual way of driving (...) that tends to occur in a consistent way across driving occasions for a given driver and that may include both automatised skills and more consciously controlled behaviour" (p. 1251). Thus, successful interventions should be able to alter the drivers' usual way of driving. Because errors are related to individual cognitive processes, they might be minimised, for instance, by memory aids and/or 
better environment-human interfaces (Oppenheim \& Shinar, 2011). To mitigate violations, efforts to change drivers' attitudes and safety culture would be more appropriate.

Even though personality traits were found to be weak predictors of accidents (Wåhlberg, Barraclough \& Freeman, 2017), it is assumed that the willingness to commit driving violations might be explicable in terms of personality (Elander, et al., 1993). Näätänen and Summala (1974) also argued that the driver comes into the traffic situations with different types of motivations that are influenced, among other things, by the driver's personality and transient motivations (i.e. state of mind). As pointed out by Ulleberg and Rundmo (2003), personality traits can help to predict risky driver behaviour from a more global perspective, making possible inferences about the motivation underlying this behaviour and thus increasing the generalisability of the results. The construct of personality traits was earlier described as a basic disposition that explains the consistency of patterns of thoughts, feelings, and actions (Costa \& McCrae, 1995). Traits also contribute to the development of habits, attitudes, and skills and are supposed to be more stable and general compared to attitudes. Personality traits moreover have an influence on how drivers perceive different traffic situations. For instance, extroverted subjects have been shown to have longer reaction times to embedded traffic signs in actual road scenes (Loo, 1978 cited in Loo, 1979). Similarly, drivers scoring high on sensation seeking were found to be less influenced by road features and had higher preferred speeds in rural roads compared to other drivers (Goldenbeld \& van Schagen, 2007).

To manifest as behaviour, personality depends on the strength of the situation (i.e. if the situation allows the trait to express itself) and on something that triggers the expression of the trait (Judge \& Zapata, 2014). It is reasonable to assume that work zones represent a type of situation that might trigger the expression of certain personality traits resulting in large individual differences on speed preferences. Personality traits of impulsivity, normlessness, and altruism are of relevance in the work zone setting. Work zones and their possible adverse effects (e.g. delays, congestion, and lowered speeds) might trigger risky behaviours for some drivers due to their greater disposition to behave impulsively. Drivers that score high on normlessness might be more prone to ignore the implicit and explicit rules at work zones and prefer higher speeds, while drivers scoring high on altruism are expected to show more active concern for others, in this case road workers, and thus prefer lower speeds. The trait of sensation seeking is maybe one of the most studied traits in the traffic context. This trait is associated with the seeking of varied, novel, complex, and intense sensations and experiences (Zuckerman, 1994 
cited by Zuckerman, 2007). Still, it is important to point out that sensation seekers do not always seek risks for the risk's sake, but for the rewards of novel and intense stimulation (Zuckerman, 2007). For the same reason, Whiteside and Lynam (2001) incorporated other aspects in the conceptualisation of sensation seeking to encompass the "tendency to enjoy and pursue activities that are exciting and openness to trying new experiences that may or may not be dangerous" (p. 686). It is assumed that individuals scoring high on sensation seeking seek excitement and stimulation, reflected by several risky driving behaviours. Common types of risky behaviours among drivers scoring high on sensation seeking are speeding, violations, drunk driving, non-seat belt use, cell phone driving (e.g. Bachoo, Bhagwanjee \& Govender, 2013; Delhomme, Chaurand \& Paran, 2012; Loo, 1979; Lucidi et al., 2014; Goldenbeld \& van Schagen, 2007; Pearson, Murphy \& Doane, 2013; Ulleberg, Rundmo, 2003). Sensation seeking is considered one facet of a construct called impulsivity. Other facets proposed by Whiteside and Lynam (2001) included distinct aspects of impulsivity, namely (lack) of perseverance, (negative) urgency, and (lack) of premeditation. Perseverance refers to the "individual's ability to remain focused on a task that may be boring or difficult", and premeditation refers to the "tendency to think and reflect on the consequences of an act before engaging in that act" (Whiteside \& Lynam, 2001, p. 685). Individuals who score low on perseverance are assumed to have difficulties completing projects and working under conditions that require resistance to distracting stimuli, while those with low scores on premeditation are assumed to act impulsively without regard to the consequences. The trait of (negative) urgency refers to the "tendency to experience strong impulses, frequently under conditions of negative affect" where individuals scoring high on this trait are assumed to "engage in impulsive behaviours in order to alleviate negative emotions despite the long-term harmful consequences of these actions" (Whiteside \& Lynam, 2001, p. 685).

Impulsivity traits and risky driving behaviours have not been widely investigated, but some studies have been conducted. Pearson et al. (2013) examined the relations between impulsivity traits and driving outcomes (errors, lapses, violations, and cell-phone driving). Their results showed that perseverance and premeditation were significantly negatively correlated with most of the driving outcomes. Sensation seeking was only correlated with violations and cell-phone driving. When controlling for covariates and other impulsivity traits, negative urgency was the only trait related to driving violations and cell-phone use. Because sensation seeking became non-significant when controlling for the other traits, their conclusion was that the role of sensation seeking should be revised considering other related impulsivity traits. In the same way, Bachoo et al. (2013) found that safer drivers reported higher levels of 
premeditation and perseverance along with lower levels of sensation seeking and urgency. Sensation seeking and perseverance were not found to be significant predictors of self-reported risky driving behaviour. These studies show that distinct personality traits have unlikely relationships with driving outcomes, highlighting the importance of investigating different personality traits in the study of driving behaviour.

Other personality traits that have been investigated in the context of traffic are altruism and normlessness. Altruism refers to the "active concern for others' welfare as shown in generosity, consideration of others, and willingness to assist others in need of help" (McCrae \& Costa, 1997, p. 18) and was found to be negatively correlated with speeding and risk taking in traffic (Machin \& Sankey, 2008; Ulleberg \& Rundmo, 2003). Individuals scoring high on this trait are expected to have more concern for others in traffic as reflected in less risky driving behaviour. The trait normlessness refers to "individual's belief that it is acceptable to do whatever [one] can get away with" (Kohn \& Schooler, 1983, p. 87) and was found to be positively correlated with speeding, risk taking in traffic, accidents, and near-accidents (Iversen \& Rundmo, 2002; Machin \& Sankey, 2008; Ulleberg \& Rundmo, 2003). Individuals scoring high on this trait are assumed to not care much about violating the rules as long as such violations help to achieve a certain goal. They are also expected to show lower barriers towards rule violations in traffic.

Although personality traits can give us important insights into driving behaviour, there are still some challenges related to their practical applications. For this reason, it would be valuable to investigate other behavioural determinants that are less stable and easier to change. Because personality traits not only have direct effects on behaviour, but also indirect effects, other determinants should be explored (e.g. Ulleberg \& Rundmo, 2003). An example is the attitude construct that was shown to mediate the effects of personality traits on violations, lapses, and errors (Lucidi et al., 2014). Moreover, attitude towards traffic safety was also found to have a significant effect on risk-taking behaviour, where more positive attitudes were associated with safer driving behaviour (Ulleberg \& Rundmo, 2003). A basic definition of attitude was provided by Ajzen (1991), describing it as a summary evaluation of psychological objects that reflects a deeper underlying motivation. It also concerns the degree to which performance of the behaviour is positively or negatively evaluated (Ajzen, 2010). The central idea is that a positive attitude towards a behaviour will facilitate its performance. One theory that has been very popular for assessing the influence of attitudes on behaviours is the theory 
of planned behaviour (TPB) (Ajzen, 1991; 2010). The TPB proposes that the influences of attitude on behaviour are mediated by intention, which is itself influenced by the two other factors of social norms and perceived behavioural control. According to this theory, behavioural intention is a direct determinant of behaviour and concerns a decision to perform a behaviour. The subjective norm refers to the perceived social pressure to perform or not perform the behaviour, while perceived behavioural control refers to a person's perception of the ease or difficulty of performing a behaviour. Thus, according to the TPB, the intention to perform a behaviour will be higher if there is a more positive attitude towards the behaviour, greater perceived behavioural control, and greater perceived subjective norm. Warner and Forward (2016) found that interventions combining factual messages had the largest effect on attitudes and suggested that, of all TPB constructs, attitudes are easier to change because they only comprise an internal dimension, contrary to subjective norms and perceived behavioural control that are also dependant on a social context. Attitudes and behaviours were found to be relatively stable when measured on different occasions, thus making them a reliable indicator of future driving behaviour (Iversen, 2004). Another important aspect of attitudes is that they have different dimensions. For instance, Iversen (2004) and Ulleberg and Rundmo (2003) found that the attitude dimension towards rule violations and speeding was most successful in predicting risky driving behaviour. Similarity, Lucidi, et al. (2014) found that attitudes towards traffic rules were more successful in predicting traffic violations, errors, and lapses. Thus, specific attitudes such as attitudes towards speeding are more likely to explain preferred speeds compared to general safety attitudes.

Furthermore, several studies found that attitudes had a positive relationship with risk perception, where drivers who had a more positive attitude towards safety perceived higher risks in traffic (e.g. Ulleberg \& Rundmo, 2003; Ram \& Chand, 2016). It has also been proposed that risk perception is an important factor that affects traffic safety attitudes. For instance, the path diagram presented by Ulleberg and Rundmo (2003) showed that risk perception had a significant effect on attitudes towards traffic safety $(\beta=0.21)$, while Ram and Chand (2016) found that risk perception directly affected road safety attitudes $(\beta=0.20)$. Risk perception is a concept used to explain decision-making, and it concerns an intellectual judgment about the probability of an event, while worry is assumed to refer to the emotional reaction to risks. The feelings of worry and risk perception were found to be independent, suggesting that emotional reactions are independent of the cognitive system (Sjöberg, 1998). According to the zero-risk model (Näätänen \& Summala, 1974), personality is one of the factors that influences risk 
perception. Some support can be found in studies that showed that measures of risk perception were positively correlated with anxiety and altruism while negatively correlated with normlessness and sensation seeking (Machin \& Sankey 2008; Ulleberg \& Rundmo, 2003).

However, risks are often misjudged and are prone to several biases. Charlton et al. (2014) found that the level of risk that experienced drivers rated for several roads generally corresponded with the objective risks for the road, but there were some exceptions. For roads with curves and narrow lanes, the risk estimates were overrated, while risks due to intersections and narrow road shoulders, power poles, and ditches were significantly underrated. The same trend was described by Elvik (2015), with several examples of traffic behaviours with an overestimation of small risks and an underestimation of large risks. An important case is evaluation of speeds, where drivers tend to overestimate how much their speed must be increased to save travel time and how they underestimate the increase in accident risk associated with a large increase in speed. As underlined by Slovic (1987), it is important to investigate people's risk perception and to understand how they respond to risks in order to aid risk analysis and policy-making. Most models on drivers' behaviour propose that drivers modify their behaviours depending on the risks they perceive. For instance, Fuller et al. (2008) argued that feelings of risk, as a direct expression of task difficulty, might provide the motivational dimension to avoid taking on a task difficulty that is too high due to higher speeds. Several other studies showed a relationship between risk perception and risky behaviours. Ulleberg and Rundmo (2003) found that risk perception was negativity correlated with risk-taking behaviour, where those with a higher perception of risk reported fewer risky behaviours. Lawton et al. (1997b) also found that drivers with less regard for the negative consequences of speeding reported stronger intentions to speed. It is reasonable to assume that drivers do not perceive all risks that work zones can impose, and this can partially explain why speeds are often high in such places.

The driver behaviour models presented here may provide different explanations and give different recommendations regarding the issue of high speeds and speed heterogeneity in work zones. We can assume that drivers have a misconception of risk in work zones, which in turn is reflected in their insufficient speed adaptation for the traffic demands in such places. According to the zero-risk theory, this might be explained by the fact that the risks drivers experience in work zones do not exceed the threshold needed in order to have an inhibitory effect in their speeds. The theory would recommend preventing drivers from satisfying their 
motives towards faster mobility through speed regulations. Speed regulations would provide a vicarious risk (i.e. getting a speed ticket) equal for all drivers, which in turn would have better effects on decreasing speed heterogeneity in work zones. Because police enforcement is relatively rare in work zones, as are crashes, by the assumptions of the risk homeostasis theory drivers' levels of risk are lower than their target level of risk. This in turn would motivate them towards riskier behaviour (i.e. speeding) in order to be closer their target level of risk. For work zones, some drivers might perceive the costs of safe behaviours (e.g. slower mobility due to low speeds) as greater than their benefits (e.g. avoiding a crash) and thus perceive the benefits of riskier behaviours (e.g. saving time due to higher speeds) as higher than the costs (e.g. getting a speed ticket). Safety campaigns, for instance, would have the potential to adjust the costbenefit analysis of drivers' behaviour in work zones and diminish their target level of risk.

In sum, theoretical models and constructs from diverse areas of psychology can be used to explain driving behaviour in different contexts, including in work zones. The studies presented here suggest that it might be valuable to use several constructs to gain a more comprehensive understanding of multifaceted driver behaviour. 


\subsection{Summary and main aim of the thesis}

Previous analysis of work zones showed that drivers react differently to road characteristics and countermeasures as reflected in the pronounced speed heterogeneity in such places. Therefore, it is necessary to gain knowledge on how drivers' individual differences affect their preferred speed in work zones and how road characteristics influence this. Studies about risk perceptions and attitudes towards speed limits in work zones are still lacking, indicating the importance of investigating this topic.

For this reason, this thesis aimed to empirically study the influences of road characteristics and drivers' individual differences on preferred speeds in work zones. More specifically, it aimed to examine personal aspects of drivers (i.e. attitudes, risk perceptions, personality traits, and driving style) and road characteristics (i.e. visible work activity, several roadwork countermeasures) and their effects on speed preference in work zones, as well as to analyse their interactions. The aims of the individual papers will be presented in the next section. 


\subsection{Aims of the papers}

\subsubsection{Aims and hypothesis of paper I}

The aim of the first paper was to investigate the effects of visible roadwork activity and drivers' expectation to encounter such activity on their preferred and comfortable speeds utilising a video-based experiment. The second aim was to explore drivers' assessments of elements that influence their speed choice in work zones and their effects on speed preferences.

The hypothesis for this paper was that lower preferred and comfortable speeds would be stated for the scenarios with visible roadwork activity compared to scenarios with no visible activity. The same hypothesis was applied for expectancy. For the context with high expectancy for roadworks activity (i.e. instructions describing the action on a weekday), we would expect lower preferred and comfortable speeds. We did not make any predictions for the drivers' assessment of roadwork factors because this was an exploratory analysis.

\subsubsection{Aims and hypothesis of paper II}

The general aim of the second paper was to examine the effects of personality traits, attitudes towards speeding, risk perceptions, and driving style on preferred speeds for two work zones. The specific aims were to investigate the moderator effects of visible activity and to analyse the direct and indirect effects of the variables on speed preferences.

We hypothesised that visible roadwork activity would moderate the effects of personality traits on speed preferences. Furthermore, we hypothesised that individuals who score high on impulsivity traits (i.e. lack of perseverance, lack of premeditation, negative urgency, and sensation seeking) and normlessness would prefer higher speeds in work zones, while altruistic drivers would prefer lower speeds on roads with visible roadwork activity.

Regarding the indirect effects, it was expected that personality traits would have effects on speed preferences through socio-cognitive variables (i.e. attitudes towards speeding and risk perception), thus acting as mediators between the traits and behaviour. Regarding the direct effects, it was expected that socio-cognitive variables and driving style would have effects on preferred speeds, i.e. drivers scoring higher for attitudes towards speeding and lower risk perception would prefer higher speeds. 


\subsubsection{Aims and hypothesis of paper III}

The aim of the third paper was to investigate the effects of drivers' individual differences (in terms of personality traits and assessment of driving skills) and roadwork characteristics on speed preferences for a rural work zone with a $50 \mathrm{~km} / \mathrm{h}$ speed limit (not known by the participants).

We assumed that the personality traits and self-assessment of driving skills would explain differences in preferred speeds. Furthermore, we hypothesised that drivers with higher confidence in their driving skills, drivers with lower barriers towards socially unapproved behaviour (i.e. high scores for normlessness), drivers who experience strong impulses under conditions of negative affect (i.e. high scores on negative urgency), and drivers who lack the ability to remain focused on a task (i.e. low scores on perseverance) would prefer higher speeds for the scenarios.

Based on the assumption that personality traits will only manifest as behaviour when the situation facilitates their expression and that strong cues give guidance on what constitutes appropriate behaviour, we predicted that environmental cues that clearly indicated the presence of a work zone (i.e. presence of road delineators) would weaken the effects of personality traits on speed preferences. 


\section{METHODS}

Two different datasets were used for the different papers. All participants who answered the questionnaire had a valid driving licence and took part in the study on a voluntary basis. The particularities of the two datasets are described below.

\subsection{Dataset 1}

\subsubsection{Participants and procedures}

A questionnaire survey was carried out among 822 Norwegian drivers. Only those who had a valid driving licence participated. Seven participants were excluded from further analysis because they stated that they had stopped driving. The total number of respondents was therefore 815 . Papers I and II were based on this dataset.

Participants were randomly drawn from an existing panel at the independent survey bureau Respons Analyse and were invited to participate by e-mail. As a reward for their participation, the subjects who answered the questionnaire took part in a lottery to win a gift voucher. First, informed consent was presented, which contained the objective of the study and contact information. The participants were also informed that their participation in no way would have any consequence for their driving licence. It was emphasised that the data collected would be anonymised and impossible to retrace to the individual. After reading the informed consent and agreeing to participate, the participants watched two videos and answered the questionnaire.

The respondents were $52 \%$ male $(\mathrm{N}=421)$ and $48 \%$ female $(\mathrm{N}=394)$. The majority had completed university/college (62\%) followed by those who had completed high school (34\%). Their ages ranged from 18 to 70 years $(M=45.7$ years; $S D=13.0$ years), and they had held a driving licence for 26 years on average ( $S D=13.0$ years). The majority drove almost every day (66\%) and had an annual mileage of over $16000 \mathrm{~km}(25 \%)$, followed by those who reported driving $4000 \mathrm{~km}$ to $8000 \mathrm{~km}$ annually (22.6\%). The majority also reported that they drive through work zones weekly (54.5\%). The minority reported that they had been involved in a car crash as a driver in the past 5 years (13.4\%). The characteristics of the sample by gender can be seen in Table 1. 
Table 1. Personal characteristics of the participants by gender

\begin{tabular}{|c|c|c|c|c|c|}
\hline \multirow{2}{*}{ Variable } & \multicolumn{2}{|c|}{ Male drivers } & \multirow{2}{*}{$\frac{\text { Female drivers }}{\mathrm{N}}$} & \multicolumn{2}{|c|}{ Total } \\
\hline & $\mathrm{N}$ & $\%$ & & $\%$ & $\%$ \\
\hline \multicolumn{6}{|l|}{ Age } \\
\hline $18-25$ & 17 & 4.1 & 33 & 8.4 & 6.1 \\
\hline $26-39$ & 115 & 27.3 & 111 & 28.2 & 27.7 \\
\hline $40-55$ & 182 & 43.2 & 151 & 38.3 & 40.9 \\
\hline $56+$ & 107 & 25.4 & 99 & 25.1 & 25.3 \\
\hline \multicolumn{6}{|l|}{ Education level } \\
\hline Primary school & 15 & 3.6 & 24 & 6.1 & 4.8 \\
\hline High school & 157 & 37.3 & 117 & 29.7 & 33.6 \\
\hline University/College & 249 & 59.1 & 253 & 64.2 & 61.6 \\
\hline \multicolumn{6}{|l|}{ Region } \\
\hline South & 26 & 6.2 & 16 & 4 & 5.3 \\
\hline East & 223 & 53 & 237 & 60.2 & 56.4 \\
\hline West & 101 & 24 & 81 & 20.6 & 22.3 \\
\hline Middle & 33 & 7.8 & 21 & 5.3 & 6.6 \\
\hline North & 38 & 9 & 39 & 9.9 & 9.4 \\
\hline \multicolumn{6}{|c|}{$\begin{array}{l}\text { Number of crashes (past } 5 \\
\text { years) }\end{array}$} \\
\hline None & 360 & 85.5 & 346 & 87.8 & 86.7 \\
\hline One & 58 & 13.8 & 46 & 11.7 & 12.8 \\
\hline Multiple & 3 & 0.7 & 2 & 0.5 & 0.6 \\
\hline \multicolumn{6}{|l|}{$\begin{array}{l}\text { Kilometres driven last } \\
\text { year }\end{array}$} \\
\hline Less than $4000 \mathrm{~km}$ & 27 & 6.4 & 49 & 12.4 & 9.3 \\
\hline $4000-6000 \mathrm{~km}$ & 19 & 4.5 & 39 & 9.9 & 7.1 \\
\hline $6000-8000 \mathrm{~km}$ & 33 & 7.8 & 64 & 16.2 & 11.9 \\
\hline $8000-10000 \mathrm{~km}$ & 37 & 8.8 & 50 & 12.7 & 10.7 \\
\hline $10000-12000 \mathrm{~km}$ & 56 & 13.3 & 31 & 7.9 & 10.7 \\
\hline $12000-14000 \mathrm{~km}$ & 45 & 10.7 & 41 & 10.4 & 10.6 \\
\hline $14000-16000 \mathrm{~km}$ & 40 & 9.5 & 23 & 5.8 & 7.7 \\
\hline $16000 \mathrm{~km}$ or more & 158 & 37.5 & 46 & 11.7 & 25 \\
\hline Don’t know & 6 & 1.4 & 51 & 12.9 & 7 \\
\hline \multicolumn{6}{|l|}{ Driving frequency } \\
\hline $7-5$ days per week & 309 & 73.4 & 227 & 57.6 & 65.8 \\
\hline 4-1 days per week & 83 & 19.7 & 117 & 29.7 & 24.5 \\
\hline $1-3$ days per month & 17 & 4 & 23 & 5.8 & 4.9 \\
\hline Seldom & 12 & 2.9 & 27 & 6.9 & 4.8 \\
\hline \multicolumn{6}{|l|}{$\begin{array}{l}\text { Driving through work } \\
\text { zones (last month) }\end{array}$} \\
\hline $\begin{array}{l}\text { zones (last month) } \\
7-5 \text { days per week }\end{array}$ & 91 & 21.6 & 60 & 15.2 & 18.5 \\
\hline 4-1 days per week & 156 & 37 & 137 & 34.8 & 36 \\
\hline $1-3$ days per month & 151 & 35.9 & 136 & 34.5 & 35.2 \\
\hline None & 23 & 5.5 & 61 & 15.5 & 10.3 \\
\hline
\end{tabular}

\subsubsection{Study design and materials}

This study comprised an online video-based experiment with a repeated-measure design. The manipulated conditions were the expectancy and presence of roadwork activity. The expectancy variable was manipulated through the information given to the participants 
before they watched the videos (e.g. "imagine that it is you driving alone on this road on a typical Wednesday at 6 p.m." or "imagine that it is you driving alone on this road on a typical Sunday at 6 p.m."). For this variable, expectations to encounter on-going roadworks were anticipated to be higher when driving on a weekday during ordinary working hours (Wednesday at 6 p.m.) than on weekends outside ordinary working hours (Sunday at 6 p.m.). Participants received the same instructions for both videos. The variable "presence of roadwork activity" was manipulated in the videos, which depicted either the presence of workers/work machinery or no visible activity. Roadworks warning signs were depicted in the beginning of each video, so there was no doubt that the video depicted a work zone area.

Four videos of real two-lane work zones located in Norway were used (approx. 30 seconds each). One work zone was located in an urban area and another in a rural area. Screenshots and road characteristics of the videos can be seen in Table 2. In paper I (Steinbakk et al., 2017) there is a link where it is possible to watch the videos. The videos did not show sections with sharp curves and/or sight obstructions because these road characteristics have been shown to influence self-reported speed choices (Goldenbeld \& van Schagen, 2007). The videos were taken in late summer, without rain or snow, when higher speeds and crashes in work zones are more frequent (Akepati \& Dissanayake, 2011; Silverstein et al., 2014). The videos were taken from the perspective of the driver. Existing posted speed limit signs along the route were censored, and participants did not receive any information about the speed limits.

\section{Table 2. Screenshots of the work zone videos for each video}

Location With activity

To rule out order effects, participants watched the two videos, one of each area, in a randomised order. About 50 participants were randomly assigned to each group of the $2 \times 2 \times$ 
$2 \times 2$ experimental design. The design of the study can be seen in Table 3. After watching each video, the participants were asked about their speed preferences, and they completed a questionnaire online with the measures presented in the next section. The questionnaire utilised in the first data collection can be seen in Appendix I.

Table 3. Number of participants for each condition (Total $=815$ )

\begin{tabular}{cccc}
\hline Instruction & First video & Second video & $N$ \\
\hline \multirow{5}{*}{ Weekday } & $1 \mathrm{~A}$ & $2 \mathrm{~A}$ & 52 \\
& $1 \mathrm{~A}$ & $2 \mathrm{~B}$ & 53 \\
& $1 \mathrm{~B}$ & $2 \mathrm{~A}$ & 51 \\
& $1 \mathrm{~B}$ & $2 \mathrm{~B}$ & 51 \\
& $2 \mathrm{~A}$ & $1 \mathrm{~A}$ & 53 \\
& $2 \mathrm{~A}$ & $1 \mathrm{~B}$ & 50 \\
& $\mathrm{~B}$ & $1 \mathrm{~A}$ & 50 \\
& $2 \mathrm{~B}$ & $1 \mathrm{~B}$ & 52 \\
\hline & $1 \mathrm{~A}$ & $2 \mathrm{~A}$ & 51 \\
& $1 \mathrm{~A}$ & $2 \mathrm{~B}$ & 50 \\
\multirow{5}{*}{ Weekend } & $1 \mathrm{~B}$ & $2 \mathrm{~A}$ & 49 \\
& $1 \mathrm{~B}$ & $2 \mathrm{~B}$ & 52 \\
& $2 \mathrm{~A}$ & $1 \mathrm{~A}$ & 49 \\
& $2 \mathrm{~A}$ & $1 \mathrm{~B}$ & 50 \\
& $2 \mathrm{~B}$ & $1 \mathrm{~B}$ & 51 \\
& $2 \mathrm{~B}$ & & 51 \\
\hline
\end{tabular}

\subsubsection{Measures}

The measures for papers I and II originated from the same sample. For a more detailed description and format of the items used, see papers I and II.

\subsubsection{Demographic variables}

The demographic variables collected were gender, age, level of education, region of residence, accidents as a driver in the past 5 years, driving frequency, kilometres driven in the last year, and frequency of driving through work zones.

\subsubsection{Speed choice}

Assessed by most comfortable speed $(\mathrm{km} / \mathrm{h})$ and preferred speed $(\mathrm{km} / \mathrm{h})$.

\subsubsection{Assessment of elements on speed choice in work zones (Paper I)}

There were seventeen items comprising work zone situations/elements. Seven items concerned drivers' evaluations of the likelihood of different work zone features to affect speed. Six items were related to motivation to speed, three items concerned the behaviour of other 
drivers, and one item concerned the presence of roadworks vehicles. For a more detailed description and format of the items used, see paper I.

\subsubsection{Personality traits (Paper II)}

The personality traits collected were impulsivity traits (perseverance, premeditation, negative urgency, sensation seeking), altruism, and normlessness. For a more detailed description and format of the items used, see paper II.

\subsubsection{Attitude towards speeding (Paper II)}

Two attitude scales were used: attitudes towards speeding and attitudes towards traffic flow vs. rule obedience. For a more detailed description and format of the items used, see paper II.

\subsubsection{Risk perception (Paper II)}

Risk perception was measured by five items asking the participant about the probability of a person of their age being involved in a traffic crash, the probability for them to be involved in a traffic crash, the probability for them to be involved in a traffic crash in a work zone and worry and concern of being hurt or hurting others in a traffic crash in a work zone. For a more detailed description and format of the items used, see paper II.

\subsubsection{Driving style (Paper II)}

To assess driving style, the ordinary violations scale from the DBQ by Reason et al. (1990) and the aggressive violations scale from Lawton et al. (1997a) were used. Two items about speeding and rule violations by Ulleberg and Rundmo (2003) were also used.

\subsubsection{Socially desirable response}

The Driver Social Desirability Scale by Lajunen, et al. (1997) was used to assess socially desirable response tendencies. 


\subsection{Dataset 2}

\subsubsection{Participants and procedures}

Participants were randomly drawn for an existing panel of the independent survey bureau Respons Analyse and invited to participate by e-mail. In total, 845 Norwegian drivers responded to the online questionnaire. First, the informed consent was presented, and participants were informed that participation was anonymous and that the data could not be traceable to the individual. After agreeing to participate, participants answered the questionnaire. Of the respondents, $57 \%$ were male $(\mathrm{N}=482)$ and $43 \%$ were female $(\mathrm{N}=363)$. Their mean age was 51.47 ( $\mathrm{SD}=15.79$, range 18 to 91 years), and they had held a driving licence for an average of 32 years $(S D=15.30)$. Most participants drove one to three times through a work zone in the last month (29\%), followed by one to two days weekly (23\%) and five to seven days weekly (20\%). The largest proportion had an annual mileage of $16000 \mathrm{~km}$ or more $(23 \%)$.

\subsubsection{Study design and materials}

Ten pictures of a real work zone were extracted from one video of a rural work zone in Norway. The video was taken from the perspective of the driver of a moving car. The screenshots were taken right after a sign of a reduced speed limit of $50 \mathrm{~km} / \mathrm{h}$ was passed by; however, the participants did not receive any information about the speed limits. The questionnaire and the road scenes used can be seen in Appendix I.

A within-subjects design was used where all pictures were presented to all participants. Participants received the instruction to state which speed they would prefer to drive on the road depicted. The pictures were presented in a randomised order to rule out order effects.

\subsubsection{Measures}

\subsubsection{Road and roadwork characteristics}

The characteristics analysed covered the characteristics of the road, the roadside environment, and the elements present in the work zone. The roadwork characteristics depicted in the pictures that were analysed were as follows: (1) Curve: yes/no; (2) Barriers (guardrail or jersey barriers) on same side: yes/no; (3) Centre marking: yes/no; and (4) Road 
delineators (vertical panel barricades or chevron signs): yes/no. The coding used for each picture can be seen in Appendix III. The four road characteristics were the independent variables.

Initially 19 pictures were analysed, and two persons independently coded the road characteristics. The inter-rater correspondence had to reach a minimum of $50 \%$ for the picture to be selected. This procedure was to ensure that most of the characteristics depicted would be perceived by participants. Only 10 pictures were selected for the final questionnaire.

\subsubsection{Preferred speeds}

Participants were instructed to state which speed, in km per hour, they would prefer for the road section displayed in each picture. The mean scores were the dependent variables.

\subsubsection{Self-assessment of driving ability}

The self-assessment of driving ability was measured using the questionnaire developed by Tronsmoen (2008). For a more detailed description and the format of the items used, see paper III.

\subsubsection{Drivers' characteristics}

Based on the results from previous the sample, three personality traits were selected: perseverance, negative urgency, and normlessness. For a more detailed description and format of the items used, see paper III.

\subsubsection{Demographic variables}

The demographic variables collected were gender, age, years with a driving licence, kilometres driven in the last year, and the frequency of driving in work zones (exposure). 


\subsection{Statistical methods}

A range of different statistical methods was applied in the three papers. Basic methods such as $t$-tests, analysis of variance (ANOVA), Pearson's product-moment correlation, and multiple regression analysis were used in all three papers. The distinct statistical analyses for the three papers are only briefly described below, and more detailed information can be found in the papers.

\subsubsection{Statistical analysis in Paper I: Exploratory factor analysis}

Exploratory factor analysis was used in paper I. A principal axis factoring analysis with Oblimin rotation was performed with the items of work zone elements that participants assessed as being important for their speed choice in work zones. The Kaiser-Meyer-Olkin value was 0.82, exceeding the recommended value, and Bartlett's test of sphericity was $p<0.001$, supporting the factorability of the correlation matrix. The results revealed the presence of four factors with eigenvalues greater than Kaiser's criterion of 1 , and in combination the four factors explained $45 \%$ of the variance. An inspection of the scree plot revealed an inflexion after the fourth factor. Parallel analysis was also performed using the Monte Carlo PCA for Parallel Analysis, which resulted in four factors with eigenvalues exceeding the corresponding criterion values for a randomly generated data matrix of the same size (17 variables $\times 815$ respondents). Three items loaded below the value of 0.40 and therefore were excluded from further analysis. Each factor was also evaluated based on the content of the items clustering on the factor in order to find common themes among the items. To improve the scale, items that did not fit well within the factor (the meaning of the factor) were excluded from further analysis. After scale improvement (with the elimination of four items), a principal axis factoring analysis with Oblimin rotation and with a fixed number of four factors was performed again.

\subsubsection{Statistical analysis in Paper II: Structural Equation Modelling (SEM)}

The structural model concerns the relationship between latent variables and observable variables that are not indicators of latent variables. It also estimates indirect and direct effects between the variables. Structural equation modelling (SEM) was used in paper II to estimate a serial mediation model describing the hypothesised relationships between personality traits, attitudes, risk perceptions, driving styles, and preferred speeds in work zones for urban and rural areas. The fit of the model was evaluated using several $\chi 2$ goodness-of-fit statistics, 
including the comparative fit index (CFI), the root mean square error of approximation (RMSEA), and the standardised root mean squared residual (SRMR). If all indices indicate a satisfactory fit, this is evidence for a good correspondence between the observed covariance matrix and the hypothesised model.

\subsubsection{Statistical analysis in Paper III: Multilevel modelling}

To test whether variation in preferred speed could be explained by the proposed predictors, multilevel modelling (MLM) was employed. The predictors investigated were gender, age, normlessness, perseverance, negative urgency, and self-assessment of driving skills as well as the presence of curves, roadside barriers, centre road markings, and road delineators. MLM is advantageous for the kind of data used in the present study because each participant rated their preferred speed based on 10 pictures. The repeated measurements were nested within participants. MLM takes this kind of dependency into account by specifying that each of the repeated measurements (level 1) are nested within individuals (level 2). Data were analysed using IBM SPSS version 25.0. Preferred speed was the outcome variable, and random intercepts for each participant were included in the multilevel model. 


\section{RESULTS}

\subsection{Main findings of paper I}

The major aim of paper I was to examine the effects of visible work activity for the different road areas. The results showed that visible work activity had a significant effect on preferred speeds. For the videos where there was road activity present, participants preferred lower speeds compared to the videos where there was no visible activity. The effect sizes were large $\left(\eta^{2}=0.17\right.$ for the urban area and $\eta^{2}=0.08$ for the rural area). Preferred speeds for the rural area where higher compared to the urban area. However, the preferred speeds were lower than the posted speed limit for the rural area $(70 \mathrm{~km} / \mathrm{h})$ and higher for the urban area $(50 \mathrm{~km} / \mathrm{h})$, which was hypothesised to be due to the proximity of the work zone.

Regarding drivers' self-evaluations of the influence of roadworks elements on their speed choice, a factor analysis showed that the items could be grouped into four categories: speed regulation (e.g. traffic signs), transient motives (e.g. police control and time pressure), flow pressure (e.g. speed of other vehicles), and situational conditions (e.g. characteristics of the road). Drivers who evaluated speed regulations as having a greater importance for their speed choice in work zones also rated situational conditions high. Furthermore, those who considered speed regulations to be more important were less likely to prefer higher speeds, while those who considered transient motives as more important preferred higher speeds. Nevertheless, the presence of roadwork activity gave the largest contribution to explaining speed preferences for both work zones.

\subsection{Main findings of paper II}

Paper II aimed at investigating the influence of personality traits, attitudes toward speeding, risk perceptions, and driving styles on preferred speeds for work zones with and without visible work activity. The presence of roadwork activity to some extent influenced the relation between some personality traits (i.e. normlessness and perseverance) and speed preference. Drivers scoring high on normlessness preferred higher speeds in work zones, but when there was visible roadwork activity for the urban area the preferred speeds were lower. For perseverance, drivers scoring high on this trait preferred lower speeds in the rural area with visible roadwork activity, but no effect was found in the absence of visible roadwork. Drivers scoring high on negative urgency preferred lower speeds in the rural work zone area, but no interaction effects between visible work activity and the trait were found. 
The results showed that personality traits (i.e. sensation seeking, normlessness, and altruism) had indirect effects on preferred speeds through attitudes towards speeding for both roads. Indirect effects on speed preference through risk perception were found for the trait of negative urgency, but only for the rural area. Sensation seeking was also found to have indirect effects through driving style for the urban area. On this basis, it was concluded that personality traits primarily influenced speed preferences indirectly by affecting the attitudinal determinants of behaviour. This indicates that deeper motivation represented as personality traits is reflected in attitudes towards speeding, which in turn influences speed preferences.

The results also strengthen the assumption that personality traits would only manifest as a behaviour when the situation triggers and allows its expression. The fact that roadwork activity acted as moderator for personality traits suggested that the context is an important variable when investigating the influence of personality traits on behaviour. The different paths of these effects, as well as for different roads (i.e. urban and rural), strengthen this hypothesis. It was concluded that contextual factors are important when exploring the influence of sociocognitive variables for explaining driving behaviour. Furthermore, it was established that the presence of work activity could represent a credible stimulus for speed reduction, especially for drivers who scored high on normlessness and perseverance. Implications of the findings for traffic safety work were also discussed.

\subsection{Main findings of paper III}

The main aim of paper III was to investigate the credibility of speed limits and the influence of road characteristics and drivers' characteristics on speed preferences for a work zone. The results showed that the preferred speeds for the road sections were evaluated in different ways even though they all had the same speed limit. This indicates that a road situation will not always provide the necessary cues to drivers as to what is the expected behaviour. Road delineators were found to diminish preferred speeds by $9 \mathrm{~km} / \mathrm{h}$ and roadside barriers by $5 \mathrm{~km} / \mathrm{h}$. These roadworks characteristics provide a situational cue to drivers, indicating that lower speed is necessary. On the other hand, when a centre road marking was present the preferred speed increased by almost $11 \mathrm{~km} / \mathrm{h}$. The quality of road markings was quite good in the pictures and could have suggested to the drivers that the road was in a good condition and that higher speeds might be plausible. 
Moreover, drivers scoring high on normlessness and high assessment of their driving skills preferred higher speeds. The results indicated that to influence those drivers' speeds countermeasures are needed that will force them to drive slower. Other implications for practice were also discussed. 


\section{DISCUSSION}

The major aim of the present thesis was to explore drivers' speed preferences in work zones. Furthermore, it investigated the influence of socio-cognitive variables and their interactions with environmental characteristics on speed preference. In this section, the results from the three papers will be briefly discussed followed by discussion on some methodological issues and suggestions for future studies.

\subsection{Speed preferences and motivation to prefer higher speeds in work zones}

Speed is one of the most important risk factors for work zones, thus efforts to understand more about what influences drivers' speed preferences will contribute to increasing safety in work zones. The present results showed that drivers preferred lower speeds for the urban area than for the rural area, but the mean preferred speeds were still higher than the posted speed limits. The participants did not know the speed limits for the roads studied, but as defined by Goldenbeld and van Schagen (2007) if the difference between the preferred speed and the actual speed limit is large, then the speed limit has low credibility, which in turn can contribute to speed limit violations. Other studies have shown that drivers usually ignore speed limits in work zones and choose the speeds they consider adequate for the situation (e.g. Ullman \& Brewer, 2014). The present results indicate that the speed limits would not be credible for most of the work zones studied. One factor that influenced the credibility of speed limits was visible work activity. Work activity was shown to have an influence on speed preferences, and speeds were lower when work activity was visible. We can assume that drivers will prefer lower speeds when they perceive a reason to do so, thus the road environment is an important source of information when drivers choose the speed they prefer to drive. Speed regulations might still be necessary at work zones, but the results of this thesis indicate that it is important to consider a work zone's characteristics when choosing the speed limits. An interesting result from paper I was that drivers who evaluated transient motives (such as time pressure and police control) as more important for their speed choice in work zones also preferred higher speeds for the roads. This indicates that personal factors also play a role in preferred speeds. The high variability in preferred speeds found in this thesis confirms findings from speed data in work zones (e.g. Akepati \& Dissanayake, 2011), indicating that personal factors such as personality traits might explain speed heterogeneity in real life. 
The influence of personality traits on behaviours has been widely studied in the context of traffic, and such traits are assumed to explain a deeper motivation for drivers' behaviours. Specifically, traits linked to impulsive behaviours such as lack of perseverance, lack of premeditation, negative urgency, and sensation seeking, as well as normlessness and lack of altruism, were earlier linked to risky behaviour and were therefore explored further in the present study. The hypothesis that personality traits influence driving behaviour in work zones was supported. The trait of normlessness stood out because it predicted speed preferences for different roads. Individuals scoring higher on normlessness are assumed to be inclined to have a disdain for implicit and explicit rules if their personal goals are more important than following those rules. They are also assumed to have lower barriers to breaking existing rules, which might explain why they may prefer higher speeds in different work zones. Another possible explanation for why they prefer higher speeds is that drivers scoring higher on normlessness assess their driving skills as higher (those variables were found to be positively correlated in paper III) and might think they are entitled to choose whatever speed they find acceptable because they think they are "exceptional drivers". Interestingly, when there was visible activity in a work zone, normless drivers preferred lower speeds (paper II), which indicates that the visible work activity acted as a moderator in the relationship between personality traits and speed preferences. As the present results showed, the effects of different personality traits varied as a function of visible work activity and for different roads. Even though personality traits are supposed to be quite stable (McCrae \& Costa, 1995), recent research has provided evidence that the degree to which they influence behaviour might vary due to the context (e.g. Judge \& Zapata, 2014). The interactionism model claims that the strength of the situation would constrain or allow a personality trait to be expressed as a behaviour. In this sense, personality will only be "activated" and be expressed in terms of behaviour if a given situation does not provide guidance as to what constitutes appropriate behaviour (Judge \& Zapata, 2014). In strong situations, the situation provides clear guidance on appropriate behaviours, constraining the expression of a personality trait. In the present study, visible work activity (paper II), barriers, and road delineators (paper III) were types of environmental cues that made the work zone a strong situation, thus limiting personality traits (e.g. normlessness) from being expressed in terms of higher speed preferences. In contrast, in weak situations there are few cues for what constitutes expected behaviour, which in turn will result in "behavioural expressions that are in line with one's basic personal tendencies" (p. 6). This was the case when there was no visible work activity or when the roads appeared to be in normal condition (e.g. visible centre road markings). This corroborates our assumption that certain characteristics of work zones represent 
a strong situation that triggers (or limits) the expression of certain personality traits. Although personality traits can give us important insights about driving behaviour, there are still some challenges related applying the results. For this reason, attitudes towards speeding and risk perceptions, which are supposed to be less stable and easier to change compared to personality traits, should be the focus of traffic safety interventions. Our results confirmed that personality traits had direct effects on attitudes, risk perception, and driving style as well as indirect effects on preferred speeds in work zones. As demonstrated, these variables made a significant contribution to explaining speed preferences in work zones (paper II). Based on results from this thesis, we conclude that the most important aspect influencing drivers' speed preferences is environmental cues that make a work zone a strong situation such as roadside barriers, delineators, and visible roadwork activity. These work zones' characteristics could also increase the drivers' subjective risks without increasing the objective risk and thus limiting their motivational tendencies to choose higher speeds (Näätänen \& Summala, 1974). Such characteristics also have the potential to inhibit the expression of some personality traits (such as normlessness) and provide guidance as to what is the expected behaviour (e.g. slower speeds).

Standard traffic systems have limited room for exercising speed choices and posted speed limits should compel speed choice because drivers are obliged to obey the traffic laws. Even though the motivation to comply with traffic laws will vary among drivers and in different situations, we can assume that "behaviour selection is strongly determined by current driving situations, which creates opportunities or constraints for action" (Sagberg et al., 2015, p. 1253). In this sense, the role of the road planners and contractors should be to create opportunities for drivers to choose the right speeds (e.g. using credible speed limits based on road characteristics) or to constrain the opportunity to choose high speeds (e.g. using traffic calming measures). Even if road authorities would like to be able to predict the behaviour of drivers in all situations, this thesis emphasises the necessity of recognising the role of individual differences and of specific contexts in drivers' speed preferences in work zones.

\subsection{Limitations and suggestions for future research}

\subsubsection{The use of videos and photographs to study drivers' speed preferences}

Even though the use of videos and photographs presents several advantages to understanding factors that influence driving speeds, there are some limitations that should be 
acknowledged. One of the biggest issues is the way the variables were collected - stating which speed one would have preferred/chosen based on a video or a picture is not the same as when driving a vehicle. Videos and pictures do not provide road and driving conditions. Photographs only present a snapshot of the driving environment and do not have the changing of road scenes that are present in real driving. Videos lack kinaesthetic cues (e.g. vibration of the steering wheel) and auditory feedback that are factors that influence speed choice (see Horswill \& McKenna, 1999). Speed is an observable variable, thus observational techniques with high ecological validity would include in-vehicle speed monitoring or field studies using speed lasers. However, those methods still have some limitations when it comes to studying the influence of personal characteristics because it will not always be possible to assess such variables and link them to a single vehicle's speed. In those cases, it can be possible to stop some vehicles after their speeds were measured and interview the drivers (e.g. Sagberg, 2005), but this method can be difficult and costly. In addition, the manipulation of the road environment might increase information processing and thus reduce drivers' reaction times and, in the worst case, increase the crash risk.

To avoid exposing drivers to potentially dangerous situations and to be able to collect data that would not otherwise be accessible, alternative methods to study drivers' behaviours are therefore necessary. Driving simulators are a method to study drivers' behaviours while performing driving tasks and give the possibility of controlling aspects of the traffic and road environment without putting drivers at risk. Even though driving simulators provide the opportunity to have greater experimental control, the images of the road environment generated by a computer program might lack realism. Consequently, participants might choose a riskier behaviour when driving using a simulator because no consequences are attached to this behaviour such as a crash or a ticket. For instance, Zöller, Abendroth, and Bruder (2017) found that braking behaviour near intersections differed between real and simulated environments, where participants showed higher speeds in the simulator. Another issue is that access to a driving simulator and creating a data-generated traffic environment that is compatible with the study's aims might be quite costly.

An alternative method to provide a more convincing road environment and still be able to provide experimental control is a video-based simulation or the use of photographs. Horswill and McKenna (1999) developed a video speed test and proposed several advantages to utilising videos to study drivers' speed choice, such as the presentation of the same stimuli to participants 
that would otherwise not possible in naturalistic studies and lower costs compared to simulators. The video depicted a road from the driver's perspective, and participants needed to decide whether they would choose a speed faster or slower than the speed of the vehicle in the video. The speed choice from the videos was highly correlated with self-reported habitual speeding and past involvement in speed-related accidents. The authors concluded that video-based simulation could be a valid method for assessing speed choice. In papers I and II, the data collection used videos of work zones to assess drivers' speed preferences. The use of videos allowed us to get valuable information about their personality traits, attitudes, risk perceptions, and other variables in order to understand more about their speed preferences. The most important advantage with the videos was the possibility to manipulate the experimental condition (i.e. visible roadwork activity vs. non-visible roadwork activity) and to collect personal variables to investigate their relation to speed preferences in work zones. The use of photographs was used previously by Goldenbeld and van Schagen (2007) to study speed preferences. Their results showed a positive correlation between preferred speeds and the number of speeding tickets in the past 3 years, which indicated that speed preferences based on photographs could be related to speed choices in real life. In paper III, several photographs of a work zone with reduced speed limits were used to assess the interaction between work zone characteristics and personal variables and their effects on speed preferences. The reason for using photographs and not videos was that in this way we could have a better control over the situational condition (i.e. roadwork characteristic), which is otherwise difficult in a video with a continuum of road scenes.

An interesting discussion is whether the present results can be generalised to encompass speed preferences in all work zones. In this regard, we can use the same argument made by Mook (1983) that "even where findings cannot possibly generalise and are not supposed to, they can contribute to an understanding of the processes going on" (p. 382). The present results showed a strong effect of environment characteristics (e.g. visible roadwork activity) on speed preferences as well interaction effects with personal variables leading to the conclusion that those factors influence drivers' speed preferences. Work zones are quite different from one another, and for this reason it is more important to show what kinds of processes can take place in similar situations rather than to try to generalise the empirical findings to most real-life situations. 
The relationship between actual speeds and self-assessment of speeds has not been widely investigated, but some studies have provided some insights. In a roadside study, Sagberg (2005) stopped and interviewed 125 drivers after measuring their mean speed over a $3 \mathrm{~km}$ section and found a significant correlation between estimated comfortable speeds and actual mean speeds $(r=0.31)$. Those who estimated higher comfortable speeds also had higher mean speeds. In a study conducted by Ahie et al. (2015), they measured speeds at a road section (observed speeds) and interviewed some drivers who had stopped nearby. They asked them about their speeds on the road they just drove (self-reported speeds) and their usual speed for that road. The authors were able to match speed data with the interviews for only ten vehicles and found that self-reported speeds were on average $4 \mathrm{~km} / \mathrm{h}$ faster than their observed speeds, but the correlation between them was not significant. On the other hand, they found that selfreported speed was highly correlated with reported usual speed for the same road $(r=0.88)$ and that usual speeds accounted for the greatest proportion of the variance of self-reported speeds (33\%). In the study of Debnath et al. (2015), the participants stated which speed they would choose for the different photographs of work zones, and speed data for the same location as the pictures were also collected. The results showed that self-reported speeds were lower than the observed speeds, however these were not collected from the same drivers. The compliance rates were also higher for the self-reported speeds compared to the observed speeds, leading the authors to conclude that self-reported speeds are not a valid indication of actual speeds in work zones. It is worth noticing that different ways in which the variable of self-reported speed is operationalised might affect the conclusions of the different studies. As demonstrated by Ahie et al. (2015), different speed aspects receive different ratings by drivers. For example, "fun speeds" were rated higher than "safe speeds" and "fuel-efficient speeds". Correspondingly, Goldenbeld and van Schagen (2007) found that drivers rated "preferred speed" higher than the "safe speed". In paper I, both "comfortable speed" and "preferred speed" were analysed. The results showed that preferred speeds were rated a little bit higher than comfortable speeds, but that they were highly correlated (up to $r=0.88$ ). Further studies are needed to establish the relationship between reported and actual speeds to assess if self-reported speed is a good indicator of drivers' actual speeds. Moreover, different ways in which the variable self-reported speed is operationalised should be further studied to establish which aspect is more suitable in relation to actual speed choice.

One of the challenges regarding guidelines for signage and countermeasures is the aspects of the road that vary among different work zones and the period of the work. Different 
kind of work zones on urban roads, with a high volume of pedestrians and cyclists, for instance, were not explored in the present thesis and would probably influence speed preference in a different manner. Other studies could attempt to replicate our results utilising different work zone types and in different contexts.

\subsubsection{Socially desirable response of self-reported driving behaviours}

Self-reports are a popular research method and provide a way to obtain data about a person that are otherwise not accessible. Nevertheless, this method has been the target of criticism due to its proneness to bias. An important question that arises when self-reports are used is whether the participants were honest when responding to the questionnaire. Paulhus (1984) distinguished two types of response bias as "impression management" or "selfdeception". Impression management is when the participant gives a favourable self-description about themself. It is a "conscious bias that may shift with the situation" (Paulhus, 1984, p. 608), and it is expected to especially distort self-reporting of violation behaviours (Lajunen \& Summala, 2003). Self-deception is when a person gives a positively biased self-description that is "a socially desirable self-representation but do not involve conscious dissimulation" (Paulhus, 1984, p. 608), and this might result in under-reporting of lapses and errors (Lajunen $\&$ Summala, 2003). Social desirability might affect the way drivers report their own driving behaviour. Some studies have investigated the extent of social bias in drivers' self-reports (e.g. Lajunen \& Summala, 2003; Sullman \& Taylor, 2010), but the general conclusion is that risky driving behaviours are usually not viewed as unwanted behaviours and thus not prone to be highly influenced by socially desirable responses.

In the present study, to consider the possible effects of socially desirable responses on self-reported driving behaviours, the Driver Social Desirability Scale (Lajunen, Corry, Summala \& Hartley, 1997) was used. A preliminary analysis revealed that the variable Driver Impression Management (DIM) was significantly related to preferred speeds (urban: $r=-0.20$; rural: $r=-0.22)$, attitudes towards speeding $(r=-0.44)$, and driving style $(r=-0.62)$. Even though the correlations were significant, they were not especially high (except for driving style). Still, it was decided to exclude participants who scored over two standard deviations above the DIM mean, as proposed by Lajunen, et al. (1997). Thirty-five participants were therefore discarded from some further analysis, reducing the total sample from 815 participants to 780 participants. 
It is reasonable to assume that asking about preferable speeds would not yield highly biased responses for two reasons. First, the speed limits were not known by the participants, and thus they were less bound to choose a speed closer to the speed limit (i.e. more legal). In Norway, there are two general speed limits (i.e. $50 \mathrm{~km} / \mathrm{h}$ for urban areas and $80 \mathrm{~km} / \mathrm{h}$ for rural areas), which could have guided drivers on which speed would be most "legal". However, the stated mean preferable speeds were still higher than the general speed limit. If participants felt compelled to answer closer to the legal speeds, much lower speeds would be given. Furthermore, asking participants how often they drive over the speed limit is a direct way of asking how many times they violate a rule. Asking about the speed they would prefer for a road section only indirectly reflects a rule violation, and thus preferred speeds are not likely to be influenced by socially desirable responses.

\subsubsection{Reliability of the scales and the explained variance for speed preferences}

Most scales used in this thesis demonstrated moderate reliability, but some of the personality scales had a rather low alpha value, especially the normlessness scale and the perseverance scale (paper II). A high alpha coefficient on short scales usually means that the items have very similar wording and will thus not capture the heterogeneity of the construct intended to be measured. The low reliability suggests an underestimation of the strength of the relationship between the scales used in this study, thus for some of the personality measures the relationships estimated in the model were underestimated. More reliable measurement would probably have increased the strength of the interaction effects between perseverance, normlessness, and visible roadwork activity detected in the present study, as well as increasing the strength of the effects detected in the multiple mediation model.

The rather low percentage of explained variance in speed preference for both videos in the present study (15\%-23\%) suggests that a large amount of speed preference for work zones is still unexplained. This low amount of explained variance was not unexpected because general measures such as personality traits, attitudes, risk perception, and driving style are not supposed to predict much of the variance in very specific measures such a preferred speed in a work zone. In this study, we were only able to address a limited number of variables compared to all possible variables that influence driving behaviour in a real driving situation. Nonetheless, we can conclude that our results strengthen the hypothesis that some personality traits will depend on contextual factors for them to be manifested as behaviour. 
Finally, we can point out that it is not uncommon that studies in the field of traffic psychology that have analysed personality traits have also reported low alpha coefficients and/or low amounts of explained variance. Driving is a very complex behaviour, thus further studies that consider other variables not explored in this present study would be valuable to increase our understanding of driving in different scenarios. 


\section{IMPLICATIONS AND CONCLUSIONS}

\subsection{Implication of the findings}

This thesis contributed to gathering existent knowledge about countermeasures commonly used in work zones. These were presented and discussed in chapter 1, and a summary of those findings is presented at Table 4. Later, recommendations for road authorities and contractors, based on the literature and the results from the three papers, are also given.

Table 4.

Summary of work zones countermeasures and their effects on driver behaviour

\begin{tabular}{|c|c|c|}
\hline Type & Effect & Recommendation \\
\hline Lane merging & $\begin{array}{l}\text { - Drivers applied less braking force, } \\
\text { and expressed lower frustration and } \\
\text { workload at joint lane merges (versus } \\
\text { conventional merges) (Shakouri et al., 2014) } \\
-\quad \text { High crash risks if the merging } \\
\text { vehicle had high speeds and if it was closer } \\
\text { to the work activity area (Meng \& Weng, } \\
\text { 2011; Weng et al., 2015) }\end{array}$ & $\begin{array}{l}\text { Joint lane merge and } \\
\text { early merge control } \\
\text { (before the work activity } \\
\text { area), but evaluations on } \\
\text { capacity should be made }\end{array}$ \\
\hline Traffic lights & $\begin{array}{l}-\quad \text { Increased the odds of crashes caused } \\
\text { by tailgaiting behaviour (Li \& Bai, 2009) } \\
-\quad \text { Associated with frustration at long } \\
\text { red phases, good visibility, and no vehicles } \\
\text { in the opposite stream (Yousif et al., 2014) }\end{array}$ & $\begin{array}{l}\text { Long red phases should } \\
\text { be avoided. Possible } \\
\text { good effects of a } \\
\text { countdown display }\end{array}$ \\
\hline $\begin{array}{l}\text { Roadwork } \\
\text { warning sign }\end{array}$ & $\begin{array}{l}\text { - No effects on reduced speeds (e.g. } \\
\text { Finley et al, 2015) } \\
-\quad \text { Decreased reaction times to a hazard } \\
\text { (priming effects) (Charlton, 2006) } \\
-\quad \text { Placement of signs: traffic signs } \\
\text { placed at expected location reduced reaction } \\
\text { times and increased sign compliance } \\
\text { (Borowsky et al., 2008); visual noise ratio } \\
\text { was negatively correlated with the } \\
\text { recognition distance of a traffic sign (Akagi } \\
\text { et al. 1996) } \\
-\quad \text { Fluorescent orange sheeting: speed } \\
\text { reduction only in the beginning (novelty } \\
\text { effects) (Wang et al., 2003); stronger effects } \\
\text { on speeds at night time, but not on speed } \\
\text { variability (e.g. Hildebrand et al., 2003) } \\
-\quad \text { Flashing lights: increases the chance } \\
\text { that drivers look at the sign and reduce }\end{array}$ & $\begin{array}{l}\text { Important to eliminate } \\
\text { surprise elements, reduce } \\
\text { uncertainty on what to } \\
\text { expect and decrease } \\
\text { hazard detection times } \\
\text { Place traffic signs at } \\
\text { locations recommended } \\
\text { by road authorities to } \\
\text { ensure general practice } \\
\text { Maintain low levels of } \\
\text { visual noise in work } \\
\text { zones (e.g. advertisement } \\
\text { and irrelevant } \\
\text { information) }\end{array}$ \\
\hline
\end{tabular}


speed (e.g. Charlton, 2006), but can be misunderstood as indicating road worker activity (Blackman et al., 2014a)

\section{- LED symbols and/or messages}

(VMS): only a little more conspicuous than a large dimensioned sign (Charlton, 2006); more effective at night time (Rahman et al., 2017); may lose effect when operated for long periods (Richards \& Dudek, 1986); portable VMS: limited effect on speeds (e.g. Bai et al., 2010)

- $\quad$ Vehicle Activated Sign (VAS): speed reduction, but no data on speed variation (Fountaine and Carlson, 2001); no novelty effects (Wang et al, 2003); decreased driving performance, increased mental workload, and greater demand on visual attention (Craig et al., 2017)
Should be combined with other countermeasures in work zones

\begin{tabular}{ll}
\hline $\begin{array}{l}\text { Regulatory signs } \\
\text { (reduced speed }\end{array}$ & $-\quad$ Great speed variability (Finley et al., \\
limits) & associated with severe crashes in work zones \\
& (Li \& Bai, 2009) \\
& $-\quad$ More efficient in short-term work \\
& zones; drivers are more compliant with \\
& speed limits in close proximity to the work \\
& activity area (e.g. Benekohal et al., 1992) \\
& $-\quad$ Change blindness effects on familiar \\
& roads (Martens \& Fox, 2007), variable speed \\
& limits (Harms \& Brookhuis, 2016)
\end{tabular}

Regulatory signs - $\quad$ Great speed variability (Finley et al., (reduced speed associated with severe crashes in work zones (Li \& Bai, 2009)

- $\quad$ More efficient in short-term work zones; drivers are more compliant with speed limits in close proximity to the work activity area (e.g. Benekohal et al., 1992) roads (Martens \& Fox, 2007), variable speed limits (Harms \& Brookhuis, 2016)
Reduced speed limits should only be used in special situations and close to activity area where workers are not protected by barriers

Great speed reductions $(>16 \mathrm{~km} / \mathrm{h}$ ) should be avoided

Place speed limit signs at locations recommended by road authorities to ensure general practice

Variable speed limits should be used with care, and other countermeasures should be used to prevent change blindness effects (e.g. flashing lights)

Reduced speed limit signs should be used together with other traffic calming measures to become more credible 


\begin{tabular}{ll}
\hline Perceptual & $-\quad$ Narrowed lanes: lower driving \\
treatments & speeds, effects on lane position towards \\
& centre (e.g. Evans \& Charlton, 2006). Effect \\
& on capacity and delays (Yousif et al., 2017); \\
& increase in workload and stress ratings \\
& (Petzoldt et al., 2016) \\
& $-\quad$ Optical speed bars: small speed \\
& reductions, more homogeneity in speeds \\
& (e.g. Meyer, 2004); more effective at night \\
& (Hildebrand et al., 2003) \\
& $-\quad$ Rumble strips: higher effects for \\
& truck speeds (e.g. Fountaine and Carlson, \\
& 2001); more homogeneity in speeds \\
& (Hildebrand et al., 2003). Some vehicles \\
& drove in opposite lane to avoid the strips \\
& (Fountaine \& Carlson, 2001) \\
& $-\quad$ Road markings: Effect on lane \\
& position towards the centre on non- \\
& delineated roads (Waard et al., 2004) \\
& $-\quad$ Channelling devices: vertical \\
& delineators gave more homogeneity in \\
& speeds (Domenichini et al., 2017) \\
&
\end{tabular}

Other solutions $\quad-\quad$ Flaggers: lower speeds near flaggers

(Benekohal \& Kastel, 1991), but an increase in rear-end crashes (Qi et al., 2013).

Increased effects of flaggers when

increasing their conspicuity and

participation in training programmes (Turner et al., 1997)

- Enforcement: Visible police and speed photo-radar had effects on speeds (Benekohal et al., 1992); low effects of increased fines for violations in work zones (Ullman et al., 2013)

- $\quad$ Traffic safety campaigns: little information about their effects. Signs with message "My dad works here" had low or no effect (Wang et al. 2003)
Reduce speeds, but percentage of heavy goods vehicles should be considered to establish lane width

Combined with other types of measures have the potential to give better effects on speeds

Rumble strips should not be used in rural work zones, work zones with high posted speed limits and work zones close to residential areas

At work zones without road markings, channelling devices should be used. Uneven placement is preferred

Flaggers should not be used at roads with high posted speed limits and poor sight sections. Flaggers should be trained and use standard visibility clothing

Enforcement should be rather used on the first days of work zone and during major changes in traffic and road conditions during the period

Traffic safety campaigns should be used in combination with other measures and enforcement

Until now, only few published articles have addressed driver behaviour and motivation regarding speed preferences in work zones. Most studies have merely observed drivers' behaviours in work zones and have taken a retroactive approach towards safety. Considering 
the high number of traffic crashes in work zones and the scarce number of studies that analyse this safety problem from different perspectives, it was important to not only investigate what drivers do, but also to investigate the motives for their behaviours. Therefore, considering the psychological variables for comprehending and predicting driving behaviour in work zones, the results from this thesis help us understand more about why drivers do what they do. This knowledge makes it possible to plan work zone countermeasures in a more proactive way.

The need for traffic signs is based on society's demand for traffic regulation in order to ensure good traffic flow and adequate safety. Because the effects of warning and informational signs were found to be small, those measures should not be considered the best form of injury prevention. For hazard control and prevention, a hierarchy of approaches is instead recommended. In this way of thinking, the first approach should be removing the hazard or designing it out in order to eliminate exposure to the danger. For example, roads should be closed when there are road workers present. However, hazards are not always possible to be removed or eliminated, and thus a second approach is placing physical barriers to limit the contact between people and the hazard. Guardrails and roadside barriers separate the drivers from the road workers and/or hazards. The last advised form for hazard control is warnings intended to induce safe behaviour. If properly designed, traffic signs should help induce higher levels of expectancy thus increasing drivers' detection distance, shortening their reaction times, stimulating an active perception of the road, and generating a behavioural adaptation. The sign must be visible, conspicuous, comprehensible, accurate, and credible. However, a warning is not recommended to be a replacement or substitute for good road design or guarding, but as a supplement.

The results from this thesis suggest that if the environment provides cues behind the motive of reduced speed limits, drivers will be prone to prefer lower speeds. One practical implication is the importance of providing drivers with the reason for the reduced speed limits when they are not obvious. Traffic information could provide a reason for reduced speed limits, driving instructions, or facts about the work zone. Such measures will probably strengthen the credibility of reduced posted speed limits. The literature presented here also gives support to the assumption that if drivers perceive the motives of reduced speed limits they will choose lower speeds, though this effect will likely vary among different types of drivers. In our study, the warning sign displayed at the beginning of the work zone may have provided a clue that lower preferred speeds would be necessary. Because the results showed higher speeds than the 
proposed speed limit, this might indicate that speed limit signs in work zones are also necessary if the intention is to reduce mean speeds. Because traffic signs do not always have significant effects on speeds, and because roadwork activity is not always visible, other countermeasures that strengthen the cues signalling that a road section is not in a normal condition and that speed adaptation is necessary should be used. At places where the speeds are higher than the posted speed limits or the reasons for reduced speed limits are not evident, it might be necessary to use traffic calming measures to force drivers to drive at safe speeds. Based on our results, we recommend in those situations the use of perceptual countermeasures such as road delineators and roadside barriers.

Providing credible speed limits has the potential to reduce speed heterogeneity in work zones. An evaluation based on the road and work zone's characteristics should be made to establish the speed limit that will be posted. In most cases, the work zone conditions will justify a speed limit reduction, such as roads that appear to have lower standards (e.g. without centre markings). Furthermore, it should be evaluated if it will be necessary to reduce the speed limit if workers are not present or if they are protected by a barrier. Taking down reduced posted speed limits signs when the risks are not present (e.g. road workers are not working), might increase the speed limit credibility when workers are present.

Another way to use the present results in practical interventions is in designing safety campaigns aiming especially at attitudes and risk perceptions, which can be seen as "points of attack" for interventions. Targeting attitudes towards speeding might have the potential to affect speed preferences in work zones. Even if there is some evidence that safety campaigns may be less effective in reducing speeds in work zones, they may influence other behaviours such as increased awareness (Summala \& Pihlman, 1993). Informing about the risks linked to work zones also has the potential to influence speed preferences in work zones. The nature of the message used should be adjusted to reach different types of drivers. According to our results, interventions should especially focus on attitudes toward driving speeds among drivers who are sensation seekers and normless.

It is important to mention some significant issues related to the study of work zone safety such as lack of information and inaccurate data (Wang et al., 1996). Crashes that are not reported as a work zone crash, underreporting of minor crashes, and differences in the coding process are issues that might have affected the reliability of some investigations (Akepati \& Dissanayake, 2011; Bryden et al., 1998; Wang et al., 1996). Therefore, it is crucial that the data 
concerning crashes in work zones are better collected/recorded in order to better comprehend the risks that work zones can impose on road users.

Finally, we would recommend that road authorities consider some factors when making regulations concerning traffic signs and countermeasures for work zones:

- Post work zone signs according to drivers' information needs throughout the work zone and repeat the traffic signs if necessary. In some places, warning drivers about specific risks would be more important, while in other places speed regulations should be the focus.

- Adapt the traffic signs consistently with the work activity that is taking place.

- The length of the work zone and type of work being performed is necessary to consider because different countermeasures might be necessary at different points in the same work zone. Long work zones can induce boredom, and it is important to remind drivers that they are still driving in a work zone.

- Revoking traffic regulations at the end of the work zones can also reinforce the importance of following the regulations in the work zone and not relying on drivers' subjective evaluation on when such regulations apply.

- Evaluate the potential side effects of countermeasures and, if possible, use other countermeasures to diminish those effects.

- Choose reasonable speed limits for the road situation or change the road situation to make the speed limits credible.

- Use strong environmental cues such as perceptual countermeasures to signal that the road section is not in a normal situation and that speed adaptation may be necessary.

- Use countermeasures to induce speed reduction at places where it is crucial for traffic safety.

- Ensure that the rules regarding warning and security measures for work zones are based on empirical evidence and that the contractors follow them.

- Improve data collection in work zones especially regarding speeds, speed profiles, and crashes.

\subsection{Conclusions}

The results of the present thesis highlight the importance of environmental factors when planning interventions for work zones. Even though personal variables helped to understand 
speed preferences at a more global level, environmental cues gave the largest contribution to predicting speed preferences. Visible activity was shown to have the most important role in predicting lower speed preferences in work zones than other individual variables. Moreover, visible activity interacted with some personality traits having diverse effects on preferred speeds. Efforts to increase traffic safety in work zones can take into account the motivations drivers have to prefer higher speeds but will probably only succeed if they concentrate on physical and perceptual measures in the traffic environment in order to motivate and induce safer driving speeds. Perceptual countermeasures, beyond increasing speed perception, are objects that can be run over and potentially damage one's vehicle and will thus provide a motivation to drivers to slow down and be more careful when driving in such places.

We can conclude that there is no single ultimate approach as a solution for safety issues in work zones. Drivers will react differently based on road characteristics, and they have different preferences on which speeds they would prefer to drive in work zones. This highlights the importance of keeping in mind drivers' personal factors in planning countermeasures in work zones because such measures will not necessarily affect all drivers. This thesis has presented several studies conducted on work zones and has provided valuable knowledge that can assist in planning countermeasures and interventions.

Achieving speed compliance in work zones is not an easy task, thus efforts should be made to use countermeasures that induce most of the drivers to drive slower in such places. Speed compliance will also increase safety for those who work to improve road conditions, and this should be a motivation for all who drive through a work zone. 


\section{REFERENCES}

Aarts, L., Brandenburg, S., \& van Nes, N. (2011, June). The influence of environmental factors on speed choice. In Integrated and Sustainable Transportation System (FISTS), 2011 IEEE Forum on (pp. 91-96). IEEE.

Aarts, L., \& Van Schagen, I. (2006). Driving speed and the risk of road crashes: A review. Accident Analysis \& Prevention, 38(2), 215-224.

Advanced Research on Road Work Zone Safety Standards in Europe Consortium [ARROWS]. (1998). Road Work Zone Safety Practical Handbook. Final Report for Publication, 1-87 National Technical University Athens.

Ahie, L. M., Charlton, S. G., \& Starkey, N. J. (2015). The role of preference in speed choice. Transportation Research Part F: Traffic Psychology and Behaviour, 30, 66-73.

Ajzen, I. (1991). The theory of planned behavior. Organizational Behavior and Human Decision Processes, 50(2), 179-211.

Ajzen, I. (2010). Predicting and changing behavior. Psychology Press.

Akagi, Y., Seo, T., \& Motoda, Y. (1996). Influence of visual environments on visibility of traffic signs. Transportation Research Record: Journal of the Transportation Research Board, (1553), 53-58.

Akepati, S., \& Dissanayake, S. (2011). Characteristics and Contributory Factors of Work Zone Crashes. In 90th Transportation Research Board Annual Meeting, 11-3769, Washington DC: Transportation Research Board.

Alexander, G. J., \& Lunenfeld, H. (1986). Driver expectancy in highway design and traffic operations. Report nr. FHWA-TO-86-1. U.S. Department of Transportation. Washington, D.C.

Allen, T. M., Lunenfeld, H., \& Alexander, G. J. (1971). Driver information needs. Highway Research Record, 366, 102-115.

Allpress, J. A., \& Leland Jr., L. S. (2010). Reducing traffic speed within roadwork sites using obtrusive perceptual countermeasures. Accident Analysis \& Prevention, 42(2), 377-383.

Al-Madani, H., \& Al-Janahi, A. R. (2002). Role of drivers' personal characteristics in understanding traffic sign symbols. Accident analysis \& prevention, 34(2), 185-196.

Bachoo, S., Bhagwanjee, A., \& Govender, K. (2013). The influence of anger, impulsivity, sensation seeking and driver attitudes on risky driving behaviour among post-graduate university students in Durban, South Africa. Accident Analysis \& Prevention, 55, 67-76.

Bai, Y., Finger, K., \& Li, Y. (2010). Analyzing motorists' responses to temporary signage in highway work zones. Safety science, 48(2), 215-221.

Bazire, M., \& Tijus, C. (2009). Understanding road signs. Safety science, 47(9), 1232-1240. 
Beanland, V., Filtness, A. J., \& Jeans, R. (2017). Change detection in urban and rural driving scenes: Effects of target type and safety relevance on change blindness. Accident Analysis \& Prevention, 100, 111-122.

Beanland, V., Sellbom, M., \& Johnson, A. K. (2014). Personality domains and traits that predict self-reported aberrant driving behaviours in a southeastern US university sample. Accident Analysis \& Prevention, 72, 184-192.

Ben-Bassat, T., \& Shinar, D. (2006). Ergonomic guidelines for traffic sign design increase sign comprehension. Human factors, 48(1), 182-195.

Benekohal, R. F., Orloski, R. L., \& Hashmi, A. M. (1993). Drivers' opinions on work zone traffic control. Transportation quarterly, 47(1) 19-38.

Benekohal; R. F. \& Kastel, L. M. (1991). Evaluation of flagger training session on speed control in rural interstate construction zones. Transportation Research Record, (1304).

Benekohal, R. F., Resende, P. T. V., \& Orloski, R. L. (1992). Effects of police presence on speed in a highway work zone: circulating marked police car experiment. Project report (No. FHWA/IL/UI-240).

Benekohal, R. F., \& Wang, L. (1994). Relationship between initial speed and speed inside a highway work zone. Transportation Research Record, (1442).

Benekohal, R. F., Wang, L., Orloski, R., \& Kastel, L. M. (1992). Speed-reduction patterns of vehicles in a highway construction zone. Transportation Research Record, (1352).

Bhagavathula, R., \& Gibbons, R. B. (2013). Role of expectancy, motion and overhead lighting on nighttime visibility. In Proceedings of the Human Factors and Ergonomics Society annual meeting 57 (1) 1963-1967. Sage CA: Los Angeles, CA: SAGE Publications.

Blackman, R. A., Debnath, A. K., Haworth, N. (2014a). Work zone items influencing driver speeds at roadworks: worker, driver and expert perspectives. In ARSRPE Conference Paper Database. Accessed from http://arsrpe.acrs.org.au/index.cfm?action=main.paper\&id=2932

Blackman, R. A., Debnath, A. K., \& Haworth, N. L. (2014b). Influence of visible work activity on drivers' speed choice at roadworks. In Proceedings of the $2^{\text {nd }}$ Occupational Safety in Transport Conference, CARRS-Q, Queensland University of Technology, 1-10. Accessed from: http://eprints.qut.edu.au/76277/.

Borowsky, A.; Shinar, D.; \& Parmet, Y. (2008). Sign location, sign recognition, and driver expectancies. Transportation Research Part F, 11, 459-465.

Bryden, J. E., Andrew, L. B. \& Fortuniewicz, J. S. (1998). Work zone traffic accidents involving traffic control devices, safety features, and construction operations. Transportation Research Record, (1650), 71-81.

Charlton, S. G. (2006). Conspicuity, memorability, comprehension, and priming in road hazard warning signs. Accident Analysis \& Prevention, 38(3), 496-506. 
Charlton, S. G., Stargkey, N. J., Perrone, J. A., \& Isler, R. B. (2014). What's the risk? A comparison of actual and perceived driving risk. Transportation Research Part F: Traffic Psychology and Behaviour, 25, 50-64.

Conference of European Directors of Roads [CEDR] (2013). State of the Art on Speed Management Methods, Deliverable D2.1.ASAP - Appropriate Speed saves All People. In the Transnational Road Research Programme Call 2012: Safety, pp. 1-82.

Constantinou, E., Panayiotou, G., Konstantinou, N., Loutsiou-Ladd, A., \& Kapardis, A. (2011). Risky and aggressive driving in young adults: Personality matters. Accident Analysis \& Prevention, 43(4), 1323-1331.

Costa Jr., P. T., \& McCrae, R. R. (1995). Domains and facets: Hierarchical personality assessment using the Revised NEO Personality Inventory. Journal of Personality Assessment, 64(1), 21-50.

Costa, M., Simone, A., Vignali, V., Lantieri, C., Bucchi, A., \& Dondi, G. (2014). Looking behavior for vertical road signs. Transportation Research Part F: Traffic Psychology and Behaviour, 23, 147-155.

Craig, C. M., Achtemeier, J., Morris, N. L., Tian, D., \& Patzer, B. (2017). In-vehicle work zone messages. Accessed from: https://conservancy.umn.edu/handle/11299/189538

de Waard, D., Steyvers, F. J., \& Brookhuis, K. A. (2004). How much visual road information is needed to drive safely and comfortably? Safety Science, 42(7), 639-655.

Debnath, A. K., Backman, R., \& Haworth, N. (2014). A Tobit model for analysing speed limit compliance in work zones. Safety Science, 70, 367-377.

Debnath, A. K., Blackman, R., \& Haworth, N. (2015). Common hazards and their mitigating measures in work zones: A qualitative study of worker perceptions. Safety Science, 72. 293301.

Delhomme, P., Chaurand, N., \& Paran, F. (2012). Personality predictors of speeding in young drivers: Anger vs. sensation seeking. Transportation Research Part F: Traffic Psychology and Behaviour, 15(6), 654-666.

Ding, H., Zhao, X., Rong, J., \& Ma, J. (2013). Experimental research on the effectiveness of speed reduction markings based on driving simulation: A case study. Accident Analysis \& Prevention, 60, 211-218.

Domenichini, L., La Torre, F., Branzi, V., \& Nocentini, A. (2017). Speed behaviour in work zone crossovers. A driving simulator study. Accident Analysis \& Prevention, 98, 10-24.

Elander, J., West, R., \& French, D. (1993). Behavioral correlates of individual differences in road-traffic crash risk: An examination of methods and findings. Psychological bulletin, 113(2), 279-294.

Elvik, R. (2010). A restatement of the case for speed limits. Transport Policy 17, 196-204. 
Elvik, R. (2013). A re-parameterisation of the Power Model of the relationship between the speed of traffic and the number of accident victims. Accident Analysis \& Prevention, 50, 854860.

Elvik, R. (2015). A statistical law in the perception of risks and physical quantities in traffic. Accident Analysis \& Prevention, 82, 36-44.

Erke, A., Sagberg, F., \& Hagman, R. (2007). Effects of route guidance variable message signs (VMS) on driver behaviour. Transportation Research Part F: Traffic Psychology and Behaviour, 10(6), 447-457.

Finley, M. D., Jenkins, J., \& McAvoy, D. S. (2015). Motorists' Speed Response to NonVariable and Variable Work Zone Speed Limits and Other Work Zone Conditions. In Transportation Research Board 94th Annual Meeting (No. 15-3214).

Fontaine, M., \& Carlson, P. (2001). Evaluation of speed displays and rumble strips at ruralmaintenance work zones. Transportation Research Record: Journal of the Transportation Research Board, (1745), 27-38.

Fuller, R. (2004). Motivational aspects of traffic signs. The human factors of transport signs, 135-154.

Fuller, R. (2005). Towards a general theory of driver behaviour. Accident Analysis \& Prevention, 37(3), 461-472.

Fuller, R., McHugh, C., \& Pender, S. (2008). Task difficulty and risk in the determination of driver behaviour. Revue Européenne de Psychologie Appliquée/European Review of Applied Psychology, 58(1), 13-21.

Gjerde, H., Christophersen, A. S., Normann, P. T., Assum, T., Øiestad, E. L., \& Mørland, J. (2013). Norwegian roadside survey of alcohol and drug use by drivers (2008-2009). Traffic injury prevention, 14(5), 443-452.

Goldenbeld, C., \& van Schagen, I. (2007). The credibility of speed limits on $80 \mathrm{~km} / \mathrm{h}$ rural roads: The effects of road and person(ality) characteristics. Accident Analysis and Prevention, 39, 1121-1130.

Gupta, S., Singh, Y., Tiwari, G. (2014), Driver behaviour and warning signs in highway work zones. In Transportation Research Board annual meeting 2014, Washington DC: Transportation Research Board.

Harms, I. M., \& Brookhuis, K. A. (2016). Dynamic traffic management on a familiar road: Failing to detect changes in variable speed limits. Transportation research part F: traffic psychology and behaviour, 38, 37-46.

Havârneanu, G. M., \& Havârneanu, C. E. (2012). When norms turn perverse: Contextual irrationality vs. rational traffic violations. Transportation research part $F$ : traffic psychology and behaviour, 15(2), 144-151. 
Haworth, N., Symmons, M., \& Mulvihill, C. (2002). Safety of small workgroups on roadways. Report 195. Monash University Accident Research Centre, Victoria, Australia.

Hildebrand, E. D., Wilson, F. R., \& Copeland, J. J. (2003). Speed management strategies for rural temporary work zones. In Proceedings of the Canadian Multidisciplinary Road Safety Conference XIII.

Hou, Y., Edara, P., \& Sun, C. (2013). Speed limit effectiveness in short-term rural interstate work zones. Transportation Letters: The International Journal of Transportation Research, 5.

Høye, A., Elvik, E., Sørensen, M. W. J., \& Vaa, T. (2012). Trafikksikkerhetshåndboken. [The Handbook of Traffic Safety]. Institute of Transport Economics, Oslo. Retrieved from http://tsh.toi.no/doc647.htm\#anchor_22006-50

Høye, A., Phillips, R., \& Hesjevoll, I. S. (2015). Evaluering av E18 Gulli-Langåker: Trafikantenes sikkerhet $i$ anleggsperioden [Evaluation of E18 Gulli-Langåker: Road safety during the construction period]. TØI report 1445. Oslo, Norway: Institute of Transport Economics.

Horswill, M. S., \& McKenna, F. P. (1999). The development, validation, and application of a video-based technique for measuring an everyday risk-taking behavior: Drivers' speed choice. Journal of Applied psychology, 84(6), 977.

Hummer, J., \& Scheffler, C. (1999). Driver performance comparison of fluorescent orange to standard orange work zone traffic signs. Transportation Research Record: Journal of the Transportation Research Board, (1657), 55-62.

Iversen, H. (2004). Risk-taking attitudes and risky driving behaviour. Transportation Research Part F: Traffic Psychology and Behaviour, 7(3), 135-150.

Iversen, H., \& Rundmo, T. (2002). Personality, risky driving and accident involvement among Norwegian drivers. Personality and Individual Differences, 33(8), 1251-1263.

Judge, T., \& Zapata, C. (2014). The person-situation debate revisited: Effect of situation strength and trait activation on the validity of the big five personality traits in predicting job performance. Academy of Management Journal, 58(4), 1149-1179.

Kirmizioglu, E. \& Tuydes-Yaman, H. (2012). Comprehensibility of traffic signs among urban drivers in Turkey. Accident Analysis \& Prevention, 45, 131-142.

Kohn, M. L., \& Schooler, C. (1983). Work and personality: An inquiry into the impact of social stratification. New Jersey: Ablex Publishing Corporation.

Koyuncu, M., \& Amado, S. (2008). Effects of stimulus type, duration and location on priming of road signs: Implications for driving. Transportation Research Part F: Traffic Psychology and Behaviour, 11(2), 108-125.

Lajunen, T., Corry, A., Summala, H., \& Hartley, L. (1997). Impression management and selfdeception in traffic behaviour inventories. Personality and Individual Differences, 22(3), 341353. 
Lajunen, T., Hakkarainen, P., \& Summala, H. (1996). The ergonomics of road signs: Explicit and embedded speed limits. Ergonomics, 39(8), 1069-1083.

Lajunen, T., \& Summala, H. (2003). Can we trust self-reports of driving? Effects of impression management on driver behaviour questionnaire responses. Transportation Research Part F, 6, 97-107.

Lawton, R., Parker, D., Manstead, A. S., \& Stradling, S. G. (1997a). The role of affect in predicting social behaviors: The case of road traffic violations. Journal of Applied Social Psychology, 27(14), 1258-1276.

Lawton, R.; Parker, D.; Stradling, S. G., \& Manstead, A. S. R. (1997b). Self-reported attitude towards speeding and its possible consequences in five different road contexts. Journal of Community \& Applied Social Psychology, 7, 153-165.

Lee, Y. M., Chong, S. Y., Goonting, K., \& Sheppard, E. (2017). The effect of speed limit credibility on drivers' speed choice. Transportation research part F: traffic psychology and behaviour, 45, 43-53.

Lehto, M. R. (1991). A proposed conceptual model of human behavior and its implications for design of warnings. Perceptual and Motor Skills, 73(2), 595-611.

Lehto, M. R., \& Papastavrou, J. D. (1993). Models of the warning process: Important implications towards effectiveness. Safety Science, 16(5-6), 569-595.

Lewis-Evans, B., \& Charlton, S. G. (2006). Explicit and implicit processes in behavioural adaptation to road width. Accident Analysis \& Prevention, 38(3), 610-617.

Li, Y., \& Bai, Y. (2007). Investigating the human factors involved in severe crashes in highway work zones. In Proceedings of the 2007 Mid-Continent Transportation Research Symposium (pp. 16-17).

Li, Y., \& Bai, Y. (2009). Highway work zone risk factors and their impact on crash severity. Journal of Transportation engineering, 135(10), 694-701.

Lipovac, K., Đerić, M., Tešić, M., Andrić, Z., \& Marić, B. (2017). Mobile phone use while driving-literary review. Transportation research part F: traffic psychology and behaviour, 47, $132-142$.

Loo, R. (1979). Role of primary personality factors in the perception of traffic signs and driver violations and accidents. Accident Analysis \& Prevention, 11(2), 125-127.

Lucidi, F., Mallia, L., Lazuras, L., \& Violani, C. (2014). Personality and attitudes as predictors of risky driving among older drivers. Accident Analysis \& Prevention, 72, 318-324.

Machin, M. A., \& Sankey, K. S. (2008). Relationships between young drivers' personality characteristics, risk perceptions, and driving behaviour. Accident analysis \& prevention, 40(2), 541-547. 
Martens, M. H. (2011). Change detection in traffic: where do we look and what do we perceive? Transportation Research, 14, 240-250.

Martens, M. H., \& Fox, M. R. J. (2007). Do familiarity and expectations change perception? Drivers' glances and response to changes. Transportation Research Part F, 10, 476-492.

Massie, D. L., Green, P. E., \& Campbell, K. L. (1997). Crash involvement rates by driver gender and the role of average annual mileage. Accident Analysis \& Prevention, 29(5), 675-685.

Mattox III, J. H., Sarasua, W. A., Ogle, J. H., Eckenrode, R. T., \& Dunning, A. (2007). Development and evaluation of speed-activated sign to reduce speeds in work zones. Transportation Research Record, 2015(1), 3-11.

McCrae, R. R., \& Costa Jr, P. T. (1997). Personality trait structure as a human universal. American psychologist, 52(5), 509-516.

Mecheri, S., Rosey, F., \& Lobjois, R. (2017). The effects of lane width, shoulder width, and road cross-sectional reallocation on drivers' behavioral adaptations. Accident Analysis \& Prevention, 104, 65-73.

Meng, Q., \& Weng, J. (2011). Evaluation of rear-end crash risk at work zone using work zone traffic data. Accident Analysis \& Prevention, 43(4), 1291-1300.

Meyer, E. (2004). Evaluation of data from test application of optical speed bars to highway work zones (KTRAN: KU-00-4). Kansas Department of Transportation.

Meyer, E. (2011). Evaluation of orange removable rumble strips for highway work zones. Transportation Research Record: Journal of the Transportation Research Board, (1715), 3642.

Michon, J. A. (1985). A critical view of driver behavior models: what do we know, what should we do? In Human behavior and traffic safety (pp. 485-524). Springer, Boston, MA.

Migletz, J., Graham, J. L., \& Harwood, D. W. (1993). Procedure for Determining Work Zone Speed Limits. In Compendium of Technical Papers, ITE, 63rd Annual MeetingInstitute of Transportation Engineers.

Montella, A.; Aria, M.; D’Ambrosio, A.; Galante, F.; Mauriello, F. \& Pernetti, M. (2011). Simulator evaluation of drivers' speed, deceleration and lateral position at rural intersections in relation to different perceptual cues. Accident Analysis \& Prevention, 43, 2072-2084.

Mook, D. G. (1983). In defence of external invalidity. American Psychologist, April 379-387.

Morgan, J. F., Duley, A. R., \& Hancock, P. A. (2010). Driver responses to differing urban work zone configurations. Accident Analysis \& Prevention, 42(3), 978-985.

Näätänen, R., \& Summala, H. (1974). A model for the role of motivational factors in drivers' decision-making. Accident Analysis \& Prevention, 6(3-4), 243-261. 
Ng, A. W., \& Chan, A. H. (2007). The guessability of traffic signs: Effects of prospective-user factors and sign design features. Accident Analysis \& Prevention, 39(6), 1245-1257.

Norwegian Public Roads Administration (2011). Temaanalyse av trafikkulykker i tilknytning til vegarbeid. Basert på data fra dybdeanalyser av dødsulykker $i$ vegtrafikken 2005- 2009 [Theme analysis of traffic accidents in connection with work zones. Based on data from in-depth analysis of fatalities in road traffic 2005-2009]. Regional and Urban Planning, Southern Region: Norwegian Public Roads Administration.

Norwegian Public Roads Administration (2012). Arbeid på og ved veg: krav og retningslinjer til varsling og sikring. Håndbok 301. [Work on and by the roads: Requirements and guidelines. Handbook 301]. Directorate of Public Roads, Southern Region: Norwegian Public Roads Administration.

Oppenheim, I., \& Shinar, D. (2011). Human factors and ergonomics. In Porter, B. E. (Ed.) Handbook of Traffic Psychology (pp. 193-211). Academic Press.

Osman, M., Paleti, R., \& Mishra, S. (2018). Analysis of passenger-car crash injury severity in different work zone configurations. Accident Analysis \& Prevention, 111, 161-172.

Paulhus, D. L. (1984). Two-component models of socially desirable responding. Journal of Personality and Social Psychology, 46, 598 -609.

Paolo, P., \& Sar, D. (2012). Driving speed behaviour approaching road work zones on two-lane rural roads. Procedia-Social and Behavioral Sciences, 53, 672-681.

Pearson, M. R., Murphy, E. M., \& Doane, A. N. (2013). Impulsivity-like traits and risky driving behaviors among college students. Accident Analysis \& Prevention, 53, 142-148.

Petzoldt, T., Mair, C., Krems, J. F., Roßner, P., \& Bullinger, A. C. (2016). Psychologische Wirkungen von Arbeitsstellen auf die Verkehrsteilnehmer (No. 276). Accessed from: https://trid.trb.org/view/1453693

Phillips, R. O., Ulleberg, P., \& Vaa, T. (2011). Meta-analysis of the effect of road safety campaigns on accidents. Accident Analysis \& Prevention, 43(3), 1204-1218.

Qi, Y., Srinivasan, R., Teng, H., \& Baker, R. (2013). Analysis of the frequency and severity of rear-end crashes in work zones. Traffic injury prevention, 14(1), 61-72.

Rahman, M., Strawderman, L., Garrison, T., Eakin, D., Williams, C. C. (2017). Work zone sign design for increased driver compliance and worker safety. Accident Analysis \& Prevention, $106,67-75$.

Ram, T., \& Chand, K. (2016). Effect of drivers' risk perception and perception of driving tasks on road safety attitude. Transportation Research Part F: Traffic Psychology and Behaviour, $42,162-176$.

Rasmussen, J. (1983). Skills, rules, and knowledge; signals, signs, and symbols, and other distinctions in human performance models. IEEE Transactions On Systems, Man, And Cybernetics, 3, 257-266. 
Reason, J., Manstead, A., Stradling, S., Baxter, J., \& Campbell, K. (1990). Errors and violations on the roads: a real distinction? Ergonomics, 33(10-11), 1315-1332.

Richards, S. H. \& Dudek, C. L. (1986). Implementation of work-zone speed control measures. Accessed from: https://trid.trb.org/view/283799

Sagberg, F. (2005). Faktorer som påvirker bilisters kjørefart [Factors influencing driving speed]. TØI report, 765, 2005. Oslo, Norway: Institute of Transport Economics.

Sagberg, F., Selpi, Piccinini, G. F. B., \& Engström, J. (2015). A review of research on driving styles and road safety. Human Factors, 57(7), 1248-1275.

Shakouri, M., Punniaraj, K., Aghazadeh, F., Ikuma, L. H., \& Ishak, S. (2014). Effects of Varying Work Zone Configuration, Distances Between Traffic Signs and Individual Differences on Drivers' Perceived Workload (No. 14-1893). Assessed from: https://trid.trb.org/view/1288035

Shinar, D., \& Vogelzang, M. (2013). Comprehension of traffic signs with symbolic versus text displays. Transportation research part F: traffic psychology and behaviour, 18, 72-82.

Shinar, D., Dewar, R. E., Summala, H, \& Zakowska, L. (2003). Traffic sign symbol comprehension: A cross-cultural study. Ergonomics, 46(15), 1546-1565.

Silverstein, C., Schorr, J., \& Hamdar, S. H. (2014). Work zones vs. non-work zones: risk factors leading to rear-end and sideswipe collisions. Transportation Research Board 93rd Annual Meeting, 14-3840, Washington DC: Transportation Research Board.

Sjöberg, L. (1998). Worry and risk perception. Risk Analysis, 18(1), 85-93.

Slovic, P. (1987). Perception of risk. Science, 236(4799), 280-285.

Sullman, M. J. M., \& Taylor, J. E. (2010). Social desirability and self-reported driving behaviours: Should we be worried? Transportation Research Part F, 13, 215-221.

Summala, H. (1988). Risk control is not risk adjustment: The zero-risk theory of driver behaviour and its implications. Ergonomics, 31(4), 491-506.

Summala, H., \& Hietamäki, J. (1984). Drivers' immediate responses to traffic signs. Ergonomics, 27(2), 205-216.

Summala, H., \& Näätänen, R. (1974). Perception of highway traffic signs and motivation. Journal of Safety Research.

Summala, H., \& Pihlman, M. (1993). Activating a safety message from truck drivers' memory: an experiment in a work zone. Safety Science, 16(5-6), 675-687.

Theofilatos, A., Ziakopoulos, A., Papadimitriou, E., Yannis, G., \& Diamandouros, K. (2017). Meta-analysis of the effect of road work zones on crash occurrence. Accident Analysis \& Prevention, 108, 1-8. 
Turner, J. D., Simmons, C., \& Graham, J. (1997). High-visibility clothing for daytime use in work zones. Transportation Research Record: Journal of the Transportation Research Board, (1585), 1-8.

Ulleberg, P., \& Rundmo, T. (2003). Personality, attitudes and risk perception as predictors of risky driving behaviour among young drivers. Safety Science, 41(5), 427-443.

Ullman, G. L., Brewer, M. A., Bryden, J. E., Corkran, M. O., Hubbs, C. W., Chandra, A. K., \& Jeannotte, K. L. (2013). Traffic Law Enforcement Strategies for Work Zones. NCHRP Report 746. Transportation Research Board of the National Academies, Washington, DC.

Ullman, G., \& Brewer, M. (2014). Driver Perceptions of traffic-calming versus active enforcement efforts in work zones. Transportation Research Record: Journal of the Transportation Research Board, 2425, 25-31.

van der Molen, H. H., \& Bötticher, A. M. (1988). A hierarchical risk model for traffic participants. Ergonomics, 31(4), 537-555.

van Nes, N., Brandenburg, S., \& Twisk, D. (2010). Improving homogeneity by dynamic speed limit systems. Accident Analysis \& Prevention, 42(3), 944-952.

van Nes, N., Houtenbos, M., \& van Schagen, I. (2008). Improving speed behaviour: the potential of in-car speed assistance and speed limit credibility. IET Intelligent Transport Systems, 2(4), 323-330.

Wåhlberg, A., Barraclough, P., \& Freeman, J. (2017). Personality versus traffic accidents; metaanalysis of real and method effects. Transportation Research Part F: Traffic Psychology and Behaviour, 44, 90-104.

Walker, G., \& Calvert, M. (2015). Driver behaviour at roadworks. Applied ergonomics, 51, 1829.

Wang, J., Hughes, W., Council, F., \& Paniati, J. (1996). Investigation of highway work zone crashes: What we know and what we don't know. Transportation research record: Journal of the transportation research board, (1529), 54-62.

Wang, C., Dixon, K., \& Jared, D. (2003). Evaluating speed-reduction strategies for highway work zones. Transportation Research Record: Journal of the Transportation Research Board, (1824), 44-53.

Warner, H. W., \& Forward, S. (2016). The effectiveness of road safety interventions using three different messages: Emotional, factual or a combination of both messages. Transportation Research Part F: Traffic Psychology and Behaviour, 36, 25-34.

Weng, J.; \& Meng, Q. (2012). Effects of environment, vehicle and drivers' characteristics on risky driving behavior at work zones. Safety Science, 50, 1034-1042.

Weng, J., Meng, Q., \& Yan, X. (2014). Analysis of work zone rear-end crash risk for different vehicle-following patterns. Accident Analysis \& Prevention, 72, 449-457. 
Weng, J., Xue, S., Yang, Y., Yan, X., \& Qu, X. (2015). In-depth analysis of drivers' merging behavior and rear-end crash risks in work zone merging areas. Accident Analysis and Prevention, 77, 51-61.

Whiteside, S. P., \& Lynam, D. R. (2001). The five-factor model and impulsivity: Using a structural model of personality to understand impulsivity. Personality and Individual Differences, 30(4), 669-689.

Wickens, C. M., Mann, R. E., Stoduto, G., Butters, J. E., Ialomiteanu, A., \& Smart, R. G. (2012). Does gender moderate the relationship between driver aggression and its risk factors? Accident Analysis \& Prevention, 45, 10-18.

Wilde, G. (2013) Homeostasis Drives Behavioral Adaptation. In C. M. Rudin-Brown \& S. L. Jamson (Eds.), Behavioral Adaptation and Road Safety. Theory, Evidence and Action. (pp. 6186). Boca Raton, CRC Press.

Wilde, G. J. (1982). The theory of risk homeostasis: implications for safety and health. Risk Analysis, 2(4), 209-225.

Winter, J. C. F., \& Dodou, D. (2010). The Driver Behaviour Questionnaire as a predictor of accidents: A meta-analysis. Journal of Safety Research, 41(6), 463-470.

Wogalter, M. S. (1999). Factors influencing the effectiveness of warnings. In Zwaga, H., Boersema, T., \& Hoonhout, H. (Eds.). (1999). Visual information for everyday use: design and research perspectives. (pp. 93-110). CRC Press.

Wogalter, M. S. (2006). Purposes and scope of warnings. Handbook of warnings, 3-9.

Yang, H., Ozbay, K., Ozturk, O., \& Xie, K. (2015). Work zone safety analysis and modelling: a state-of-the-art review. Traffic injury prevention, 16(4), 387-396.

Yousif, S., Alterawi, M., \& Henson, R. R. (2014). Red light running and close following behaviour at urban shuttle-lane roadworks. Accident Analysis \& Prevention, 66, 147-157.

Yousif, S., Nassrullah, Z., \& Norgate, S. H. (2017). Narrow lanes and their effect on drivers' behaviour at motorway roadworks. Transportation research part F: traffic psychology and behaviour, 47, 86-100.

Zöller, I., Abendroth, B., \& Bruder, R. (2017). Driver behaviour validity in driving simulatorsAnalysis of the moment of initiation of braking at urban intersections. Transportation Research Part F: Traffic Psychology and Behaviour.

Zuckerman, M. (2007). Sensation seeking and risky driving, sports, and vocations. In Sensation seeking and risky behavior. (pp. 73-87). American Psychological Association. 


\section{APPENDIX I}

Questionnaires (in Norwegian) 


\section{QUESTIONNAIRE DATASET 1}

\section{Spørreundersøkelse om atferd i trafikken}

\section{Les dette før du besvare skjemaet}

\section{Hva vil vi oppnå?}

Formålet med denne unders $\varnothing$ kelsen er å finne ut mer om bilistenes atferd i forskjellige trafikksituasjoner. Vi er interesserte i dine erfaringer som bilist. Ved å besvare skjemaet gir du ditt bidrag til å få fram ny kunnskap om dette temaet. Derfor ber vi om din hjelp og dine synspunkter. Det er ingen «rette» eller «gale» svar på spørsmålene - det er dine vurderinger og erfaringer vi er interessert i.

\section{Hvem står bak?}

Denne undersøkelsen er et samarbeid mellom Statens vegvesen (Svv), Universitet i Oslo (UiO) og Transportøkonomisk Institutt (TØI). Den gjennomføres av doktorgradsstudent Renata Torquato Steinbakk (Svv), dr. Pål Ulleberg (UiO), dr. Knut Inge Fostervold (UiO) og Cand. psychol., Fridulv Sagberg (TØI).

\section{Om deltakelse i undersøkelsen}

Vi ber deg om å svare på spørreskjemaet, noe som vil ta ca. XX minutter av din tid. Det er frivillig å delta og du kan velge å avslutte underveis. Det er ingen konsekvenser forbundet med at du deltar eller ikke. Din deltakelse og svar skal på ingen måte ha noe virkning på ditt førerkort. Ved behandlingen av dataene framgår det ikke hvem som har gitt hvilke svar. Dine svar vil kun bli benyttet som del av en større gruppe av svar.

\section{Konfidensialitet}

Datainnsamlingen blir gjennomført av Respons analyse, og bare besvarelsene vil bli sendt til oss for analyse. Navn blir ikke registret i databasen. Datamaterialet vil bli anonymisert. All informasjon behandles konfidensielt.

\section{Har du spørsmål?}

Dersom du har spørsmål om undersøkelsen, kontakt gjerne prosjektleder Renata Steinbakk på e-post renata.steinbakk@vegvesen.no.

\section{På forhånd takk for hjelpen!}

Renata Torquato Steinbakk

Doktorgradsstudent

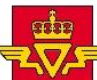

Statens vegvesen
Pål Ulleberg

Førsteamanuensis

$\mathrm{UiO}$ : Universitetet i Oslo
Fridulv Sagberg

Seniorforsker

เ๑i
Knut Inge Forstervold

Førsteamanuensis 
(Screening, singel, obligatorisk)

Har du førerkort?

$\mathrm{Ja}$

Nei (Avslutt)

Vise infoskriv om undersøkelsens formål, hvem som står bak etc. (er på eget skriv)

Infotekst: Du får nå se to korte videoer. Deretter skal vi spørre deg om din vurdering med tanke på farten du hadde valgt i de situasjonene som blir vist.

(Respondentene får se to videoer hver, video 1a eller 1b og video 2a eller 2b). Hvilke videoer og hvilken rekkefølge de blir vist i vil være helt tilfeldig, men vi sørger for at det er minimum 100 svar i hver kombinasjon av totalt 8 kombinasjoner).

Kombinasjoner:

1a-2a

$1 \mathrm{a}-2 \mathrm{~b}$

$1 \mathrm{~b}-2 \mathrm{a}$

$1 b-2 b$

2a-1a

$2 a-1 b$

2b-1a

$2 \mathrm{~b}-2 \mathrm{a}$

I tillegg skal det være to ulike instruksjonstekster per kombinasjon som vil tilsi at det blir 50 svar per instruksjonstekst per gruppe (Det er videre behov for å kunne skille mellom de 16 forskjellige kombinasjonene/batchene i datafilen slik at programmeringen vil ta hensyn til dette).

Instruksjon til gruppe 01: Forestill at det er du som kjører denne strekningen på en vanlig onsdag klokken 18.

Instruksjon til gruppe 02: Forestill at det er du som kjører denne strekningen på en vanlig søndag klokken 18.

(Visning av video 1)

1

(åpen, obligatorisk) - Teller som 1 spørsmål

Hva ville du anse som den mest behagelige farten for deg å kjøre i på den strekningen du så sist? $\mathrm{km} / \mathrm{t}$

\section{2}

(åpen, obligatorisk) - Teller som 1 spørsmål

Hvilken fart hadde du foretrukket å kjøre i på denne strekningen? $\mathrm{km} / \mathrm{t}$

3

(singel, obligatorisk) - Teller som 1 spørsmål 
Hva anser du som en fornuftig fartsgrense på denne strekningen?

30

40

50

60

70

80

Over 80

(Visning av video 2)

4

(åpen, obligatorisk) - Teller som 1 spørsmål

Hva ville du anse som den mest behagelige farten for deg å kjøre i på den strekningen du så sist? $\mathrm{km} / \mathrm{t}$

5

(åpen, obligatorisk) - Teller som 1 spørsmål

Hvilken fart hadde du foretrukket å kjøre i på denne strekningen? $\mathrm{km} / \mathrm{t}$

6

(singel, obligatorisk) - Teller som 1 spørsmål

Hva anser du som en fornuftig fartsgrense på denne strekningen?

30

40

50

60

70

80

Over 80

\section{7}

(singel, obligatorisk) - Teller som 1 spørsmål

La du merke til noen veiarbeidere på de to videoene du så i sted?

Ja, bare på den første videoen

$\mathrm{Ja}$, bare på den andre videoen

$\mathrm{Ja}$, på begge videoene

Nei, på ingen av videoene

8a

(singel matrise, randomiseres) - Teller som 9 spørsmål

Hvor stor betydning har følgende for ditt valg av hastighet ved et veiarbeidsområde?
a) Nedsatt fartsgrense
b) Fart på kjøretøyet foran deg
c) Fart på kjøretøyet bak deg
d) Fare for politikontroll
e) Veiforhold
f) Tidspress 
g) Synlig politikontroll

h) Skilt som viser din fart

i) Anleggsmaskiner ved veien

j) Blinkende lys på trafikkskilt

k) Vant til å kjøre i en bestemt fart

1) "Senk farten" skilt

m) Synlige veiarbeidere på stedet

n) Sikkerhet

o) Hensyn til passasjerer

p) Kjegler eller andre elementer på veibanen

q) Opplevelsen av at kjøretøyet bak deg ligger for nært

1 Svært liten betydning

2

3

4

5

6

7 Svært stor betydning

8a

(Åpen tekstboks) - Teller som 1 spørsmål

Er det annet du kommer på som er av stor betydning for ditt valg av hastighet ved et veiarbeidsområde?

9

(singel matrise, randomiseres) - Teller som 3 spørsmål

Generelt, hvordan opplever du vanligvis fartsgrensene som er satt ved veiarbeid i Norge?

a) 1 For lav -2-3-4-5-6-7 For høy

b) 1 Uforståelig -2-3-4-5-6-7 Forståelig

c) 1 Lite troverdig -2-3-4-5-6-7 Troverdig

d) 1 Unødvendig -2-3-4-5-6-7 Nødvendig

e) 1 Feil -2-3-4-5-6-7 Riktig

9

(singel matrise, randomiseres) - Teller som 2,5 spørsmål

Hvor sannsynlig mener du det er at:

a) en person på din alder skal bli skadet i en trafikkulykke?

b) du selv skal bli skadet i en trafikkulykke?

c) du selv skal bli skadet i en trafikkulykke ved et veiarbeidsområde?

d) du kan skade andre ved et veiarbeidsområde?

1 Svært usannsynlig

2

3

4

5

6

7 Svært sannsynlig 
(singel matrise, randomiseres) - Teller som 1,5 spørsmål

Hvor urolig og bekymret er du når du tenker på risikoen for at ...

... du selv kan bli skadet i en trafikkulykke ved et veiarbeidsområde?

... du kan skade andre ved et veiarbeidsområde?

1 Ikke bekymret i det hele tatt

2

3

4

5

6

7 Svært bekymret

11

(singel matrise, randomiseres) - Teller som 3,5 spørsmål

Hvor sannsynlig mener du det er at følgende hendelser inntreffer ved et veiarbeidsområde?

a) Påkjøringsulykker

b) Utforkjøringsulykker

c) Dødsulykker

d) Påkjøring av veiarbeidere

e) Politikontroll

f) Uforståelige/ forvirrende skilt

1 Svært usannsynlig

2

3

4

5

6

7 Svært sannsynlig

12

(singel matrise, randomiseres) - Teller som 9,5 spørsmål

Fra tid til annen bryter alle som kjører bil trafikkreglene eller gjør andre ting som vanligvis ikke oppfattes som korrekt. Hvor ofte forekommer det at du:

a) Tuter med hornet for å vise at du er irritert på en annen trafikant

b) Kjører så langt inn i et kryss der du har vikeplikt, at en fører som har forkjørsrett må stoppe og slippe deg fram

c) Kjører fortere enn fartsgrensen i et boligområde

d) Kjører selv om du mistenker at du kan være over grensen for alkohol på 0,2 promille

e) Blir sint på en annen bilfører og følger etter for å skjelle ut vedkommende

f) Fortsetter så langt fram som mulig i et kjørefelt du vet er stengt lenger framme, og presser deg inn i det andre kjørefeltet

g) Kjører forbi en saktekjørende bil på feil side

h) Akselererer så raskt som mulig når det blir grønt lys, for å komme foran bilen ved siden av deg

i) Kjører så tett innpå bilen foran at det ville bli vanskelig å stoppe i en nødsituasjon

j) Kjører inn i et lyskryss når du ser at lyset har skiftet til gult eller rødt, selv om du kunne klart å stanse

k) Blir provosert av en annen bilfører og viser din irritasjon på forskjellige måter 
1) Kjører bevisst over fartsgrensen på motorvei eller annen vei med høy standard

m) Bryter fartsgrensen i tettbygd strøk med $50 \mathrm{~km}$ sone (mer enn $10 \mathrm{~km}$ for fort)

n) Bryter fartsgrensen på landevei med $80-90 \mathrm{~km}$ sone (mer enn $10 \mathrm{~km}$ for fort)

o) Kjører forbi bilen foran deg selv om den kjører etter fartsgrensen

p) Kjører for nær bilen foran deg

q) Tøyer trafikkreglene litt for å komme deg frem

r) Ignorerer trafikkregler for å komme deg smidig frem i trafikken

1 Aldri

2 Svært sjelden

3 Av og til

4 Ganske ofte

5 Svært ofte

6 Nesten alltid

13

(singel matrise, randomiseres) - Teller som 6,5 spørsmål

De neste påstandene gjelder din kjøreatferd i forskjellige trafikksituasjoner. Vi ber deg ta stilling til om påstanden stemmer eller ikke ved å velge et nummer på skalaen.

a) Jeg bryr meg ikke om hva de andre sjåførene tenker om meg

b) Ved en forbikjøring har jeg aldri overskredet fartsgrensen eller kjørt over en heltrukken linje (sperrelinje)

c) Jeg følger alltid trafikkreglene, selv om det er lav sannsynlighet for å bli tatt i en kontroll

d) Selv om det ikke var politikontroller, ville jeg fortsatt ha fulgt fartsgrensene

e) Jeg har aldri overskredet fartsgrensen

f) Jeg er alltid sikker på hvordan jeg skal opptre i trafikksituasjoner.

g) Jeg holder alltid tilstrekkelig avstand til bilen foran meg

h) Jeg har aldri kjørt på trafikksignal når det akkurat har skiftet til rødt

i) Jeg angrer aldri på mine avgjørelser i trafikken

j) Jeg vet alltid hva jeg må gjøre i trafikken

k) Jeg beholder alltid roen og fornuften i trafikken

1) Jeg har aldri hatt lyst til å kjøre veldig fort

1 Ikke riktig

2

3

4 Noe riktig

5

6

7 Veldig riktig

14

(singel matrise, randomiseres) - Teller som 2,5 spørsmål

De neste påstandene handler om trafikk og bilkjøring. Vi ber deg om å ta stilling til om du er enig eller uenig i dem.

a) Ofte er det slik at jo bedre kjøreferdigheter en sjåfør har, jo fortere kan hun eller han tillate seg å kjøre

b) Det er helt i orden å kjøre over fartsgrensen hvis trafikkforholdene er bra

c) Noen ganger må man tøye reglene for å komme seg fram i trafikken

d) Det er viktigere å bidra til fremkommelighet i trafikken enn å alltid kjøre lovlig 

1 Svært uenig
2 Delvis uenig
3 Både/og
4 Delvis enig
5 Helt enig

\section{5}

(singel matrise, randomiseres) - Teller som 8,5 spørsmål

Vi er nå interessert i hvordan du er som person. Vurder hvor godt hver av påstandene nedenfor passer for deg.

a) Jeg liker å stoppe opp å tenke gjennom ting før jeg gjør dem

b) Når jeg er oppskaket, handler jeg ofte uten å tenke

c) Når jeg har det dårlig, gjør jeg ofte ting som jeg angrer på senere for å føle meg bedre her og nå

d) Jeg ville gjerne lære meg å fly et fly

e) Jeg liker ganske godt å ta sjanser

f) Min tankegang er vanligvis grundig og målrettet

g) Når jeg først har kommet i gang med noe, hater jeg å avslutte det

h) Jeg liker jevnt over å se at ting blir gjort helt ferdig

i) Når jeg føler meg avvist, sier jeg ofte ting jeg angrer meg på senere

j) Uferdige oppgaver plager meg virkelig

k) Jeg pleier å sette pris på og følge en rasjonell, 'fornuftig' tilnærming til ting

1) Noen ganger når jeg har det dårlig, er det som om jeg ikke klarer å slutte med det jeg driver med, selv om det får meg til å føle meg verre

m) Jeg ønsker nye erfaringer og opplevelser velkomne, selv om de er litt skremmende og uvanlige

n) Jeg fullfører det jeg begynner på

o) Jeg tenker meg som regel godt om før jeg gjør noe

p) Jeg ville like følelsen av å kjøre veldig fort på ski ned en bratt fjellside

1 Svært uenig

2 Delvis uenig

3 Delvis enig

4 Helt enig

16

(singel matrise, randomsieres) - Teller som 6,5 spørsmål

Vi er nå interessert $\mathrm{i}$ hvordan du er som person. Vurder hvor godt hver av påstandene nedenfor passer for deg.

a) Jeg ser på meg selv som en person som gjerne er positivt innstilt til andre

b) Det er helt i orden å omgå lover og regler så lenge du ikke direkte bryter dem

c) De fleste mennesker jeg kjenner, liker meg

d) Noen ting kan være galt å gjøre selv om det er lovlig

e) Jeg forsøker som regel å være hensynsfull og omtenksom

f) Det er helt i orden å gjøre alt du ønsker så lenge du ikke kommer i vanskeligheter

g) Noen mennesker ser på meg som kald og beregnende

h) Hvis noe fungerer, er det mindre viktig om det er rett eller galt

i) Noen mennesker synes jeg er egoistisk

j) Jeg forsøker å være høflig mot alle jeg møter

k) Jeg strekker meg langt for å hjelpe andre mennesker hvis jeg kan

1) Jeg er ikke kjent for min gavmildhet 

1 Svært uenig
2 Delvis uenig
3 Delvis enig
4 Helt enig

\section{Demografi}

1

(singel, obligatorisk) - Teller som 1 spørsmål

Er du ...

Mann

Kvinne

2

(4 siffer, obligatorisk, kodes om til fylker og regioner) - Teller som 1 spørsmål Hvilket år er du født?

3

Hvilken fylke og region bor du?

4

(4 siffer, obligatorisk) - Teller som 1 spørsmål

Hvilket år fikk du førerkort for bil første gang?

\section{5}

(singel, obligatorisk) - Teller som 1 spørsmål

Omtrent hvor ofte kjører du bil?

5-7 dager i uka

3-4 dager i uka

1-2 dager i uka

1-3 dager per måned

Sjeldnere

Har sluttet å kjøre bil

\section{6}

(singel, obligatorisk) - Teller som 1 spørsmål

Omtrent hvor mange kilometer kjørte du sist år? (Prøv å svare så godt du kan)

Mindre enn $4000 \mathrm{~km}$

$4000-6000 \mathrm{~km}$

$6000-8000 \mathrm{~km}$

$8000-10000 \mathrm{~km}$

$10000-12000 \mathrm{~km}$

$12000-14000 \mathrm{~km}$

$14000-16000 \mathrm{~km}$

$16000 \mathrm{~km}$ eller mer 
Vet ikke

7

(singel, obligatorisk) - Teller som 1 spørsmål

Har du i løpet av det siste 5 år vært involvert i trafikkulykker som bilfører?

Aldri

Én gang

Flere ganger

8

(singel, obligatorisk) - Teller som 1 spørsmål

Hva er din høyeste fullførte utdanning?

Grunnskole

Videregående skole

Universitet/høyskole

9

(Åpen, obligatorisk) - Teller som 1 spørsmål

Hvilket bilmerke kjører du vanligvis?

(Angi bare hovedmerke)

Årsmodell?

10

(singel, obligatorisk) - Teller som 1 spørsmål

Hvordan vil du beskrive din egen dyktighet som sjåfør?

0 Svært dårlig

1

2

3

4

5

6

7

8

9

10 Svært god

11

(singel, obligatorisk) - Teller som 1 spørsmål

I løpet av den siste måneden, hvor ofte har du kjørt på steder hvor det foregår veiarbeid?

5-7 dager i uka

3-4 dager i uka

1-2 dager i uka

1-3 ganger i løpet av siste måned

Har ikke kjørt på steder hvor det er veiarbeid 


\section{QUESTIONNAIRE DATASET 2}

\section{Spørreundersøkelse om atferd i trafikken}

\section{Les dette før du besvare skjemaet}

\section{Hva vil vi oppnå?}

Formålet med denne undersøkelsen er å finne ut mer om bilistenes atferd i forskjellige trafikksituasjoner. Vi er interesserte i dine erfaringer som bilist. Ved å besvare skjemaet gir du ditt bidrag til å få fram ny kunnskap om dette temaet. Det er ingen «rette» eller «gale» svar på spørsmålene - det er dine vurderinger og erfaringer vi er interessert i.

\section{Hvem står bak?}

Denne undersøkelsen er et samarbeid mellom Statens vegvesen (Svv), Universitet i Oslo (UiO) og Transport $\varnothing$ konomisk Institutt (TØI). Den gjennomføres av doktorgradsstudent Renata Torquato Steinbakk (Svv), dr. Pål Ulleberg (UiO), dr. Knut Inge Fostervold (UiO) og Cand. psychol., Fridulv Sagberg (TØI).

\section{Om deltakelse i undersøkelsen}

Vi ber deg om å svare på spørreskjemaet, noe som vil ta ca. 10 minutter av din tid. Det er frivillig å delta og du kan velge å avslutte underveis. Det er ingen konsekvenser forbundet med at du deltar eller ikke. Din deltakelse og svar skal på ingen måte ha noe virkning på ditt førerkort. Ved behandlingen av dataene framgår det ikke hvem som har gitt hvilke svar. Dine svar vil kun bli benyttet som del av en større gruppe av svar.

\section{Konfidensialitet}

Datainnsamlingen blir gjennomført av Respons Analyse, og bare besvarelsene vil bli sendt til oss for analyse. Datamaterialet vil bli anonymisert. All informasjon behandles konfidensielt.

\section{Har du spørsmål?}

Dersom du har spørsmål om undersøkelsen, kontakt gjerne prosjektleder Renata Steinbakk på e-post renata.steinbakk@vegvesen.no.

\section{På forhånd takk for hjelpen!}

Renata Torquato Steinbakk

Doktorgradsstudent

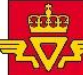

Statens vegvesen
Pål Ulleberg

Førsteamanuensis

$\mathrm{UiO}$ : Universitetet i Oslo

Knut Inge Forstervold

Førsteamanuensis

$\mathrm{UiO}$ : Universitetet i Oslo 
Screening (singel, obligatorisk)

\section{Har du førerkort?}

Ja

Nei (Avslutt)

Infotekst: Du får nå se 10 ulike bilder tatt i veiarbeidsområder. Så spør vi deg om hvor fort du hadde foretrukket å kjøre i denne situasjonen.

\section{Fartsvalg}

(Respondentene får se 10 bilder, i tilfeldig rekkefølge, samt ett spørsmål)

(Visning av bilde 1 til 10, randomiseres) (Åpen, obligatorisk)

Hvilken fart hadde du foretrukket å kjøre på denne strekning? $\mathbf{k m} / \mathbf{t}$

Self-assessment of driving ability (singel matrise, randomiseres)

Her følger en del påstander om hvordan det kan oppleves å være bilfører. Hvor riktige er disse påstandene for $\mathrm{deg}$ ?

a) Jeg føler meg sikker på at jeg vet hva slags situasjoner og handlinger som kan være farlige

b) Det er sjelden at farlige situasjoner kommer brått på meg når jeg kjører bil

c) Jeg føler meg sikker på at jeg kan håndtere uventede situasjoner på vegen

d) Jeg har lavere ulykkesrisiko enn den gjennomsnittlige bilføreren

e) Når jeg kjører bil vet jeg nøyaktig hvor jeg har bilen

f) Når jeg kjører bil er det som om jeg har direkte kontakt med underlaget

g) Når jeg oppdager en trang passasje et stykke frem på vegen vet jeg umiddelbart om det er plass nok til min bil

h) Ved behov for rask bremsing vet jeg nøyaktig hvor jeg kommer til å stoppe med den farten jeg har

i) Når jeg kjører bil kjennes det som om jeg blir ett med bilen

j) Ved lukeparkering kan jeg parkere raskt og nøyaktig selv med minimal luke

k) Ved rygging kan jeg rygge raskt og presist inn i en vanlig garasje

1) Jeg har ingen problemer med å rygge bare ved å se i speilene

m) Jeg er god til å kjøre med høy sikkerhet i trafikken

n) Mine kjøreferdigheter er helt på topp

o) Jeg er en mester til å kjøre bil på glatt føre

p) Jeg er svært god til å kjøre fort dersom det trengs

q) Ved ufrivillig sladd vet jeg presist hvordan jeg må justere med rattet for å rette opp bilen

r) Jeg er svært god til å forutse hva som kommer til å skje

s) Jeg er svært god til å kjøre bil i mørket

t) Jeg er svært god til å komme effektivt fram i tett trafikk

u) Jeg gjør alltid riktige vurderinger av luker i tett trafikk

v) Jeg kjører slik at jeg alltid unngår å havne i farlige situasjoner

1 Helt riktig

2 Mest riktig

3. Både/og

4. Mest feil 


\section{Helt feil}

Personlighetstrekk: Normlessness (singel matrise, randomiseres)

\section{Vi er nå interessert i hvordan du er som person. Vurder hvor godt hver av påstandene nedenfor passer for deg.}

a) Det er helt i orden å gjøre alt du ønsker så lenge du ikke kommer i vanskeligheter

b) Det er helt i orden å omgå lover og regler så lenge du ikke direkte bryter dem

c) Hvis noe fungerer, er det mindre viktig om det er rett eller galt

d) Noen ting kan være galt å gjøre selv om det er lovlig
1. Helt enig
2. Litt enig
3. Både/ og
4. Litt uenig
5. Helt uenig

Personlighetstrekk 2: Perseverance (singel matrise, randomiseres)

a) Jeg liker jevnt over å se at ting blir gjort helt ferdig

b) Uferdige oppgaver plager meg virkelig

c) Når jeg først har kommet i gang med noe, hater jeg å avslutte det

d) Jeg fullfører det jeg begynner på

1 Svært enig

2 Litt enig

3 Litt uenig

4 Helt uenig

\section{Personlighetstrekk 03: negative urgency (singel matrise, randomiseres)}

a) Når jeg har det dårlig, gjør jeg ofte ting som jeg angrer på senere for å føle meg bedre her og nå

b) Noen ganger når jeg har det dårlig, er det som om jeg ikke klarer å slutte med det jeg driver med, selv om det får meg til å føle meg verre

c) Når jeg er oppskaket, handler jeg ofte uten å tenke

d) Når jeg føler meg avvist, sier jeg ofte ting jeg angrer meg på senere

\section{Svært enig}

2 Litt enig

3 Litt uenig

4 Helt uenig

\section{Demografi}

1 (singel, obligatorisk)

\section{Er du ...}

Mann 
Kvinne

2 (4 siffer, obligatorisk)

Hvilket år er du født?

3 (4 siffer, obligatorisk)

Hvilket år fikk du førerkort for bil første gang?

4 (singel, obligatorisk)

Omtrent hvor mange kilometer kjørte du sist år? (Prøv å svare så godt du kan)

Mindre enn $4000 \mathrm{~km}$

$4000-6000 \mathrm{~km}$

$6000-8000 \mathrm{~km}$

$8000-10000 \mathrm{~km}$

$10000-12000 \mathrm{~km}$

$12000-14000 \mathrm{~km}$

$14000-16000 \mathrm{~km}$

$16000 \mathrm{~km}$ eller mer

Vet ikke

5 (singel, obligatorisk)

I løpet av den siste måneden, hvor ofte har du kjørt på steder hvor det foregår veiarbeid?

5-7 dager i uka

3-4 dager i uka

1-2 dager i uka

1-3 ganger i løpet av siste måned

Har ikke kjørt på steder hvor det er veiarbeid

6 (singel matrise, randomiseres)

Hva slags informasjon synes du det hadde vært nyttig å få ved vegarbeidsområder?

a) Lengden på arbeidsområdet $\mathrm{i}$ kilometer

b) Lengden på arbeidsområdet i minutter

c) Forsinkelse i minutter

d) Type arbeid som foregår

e) Informasjon om entreprenører for prosjektet

f) Årsak til arbeidet

g) Varigheten av arbeidet

h) Informasjon om det er veiarbeidere og/eller maskiner i aktivitet i øyeblikket

1. Svært nyttig

2. Nyttig

3. Verken/ eller

4. Unyttig

5. Svært unyttig 


\section{APPENDIX II}

Coding of the pictures from dataset 2 


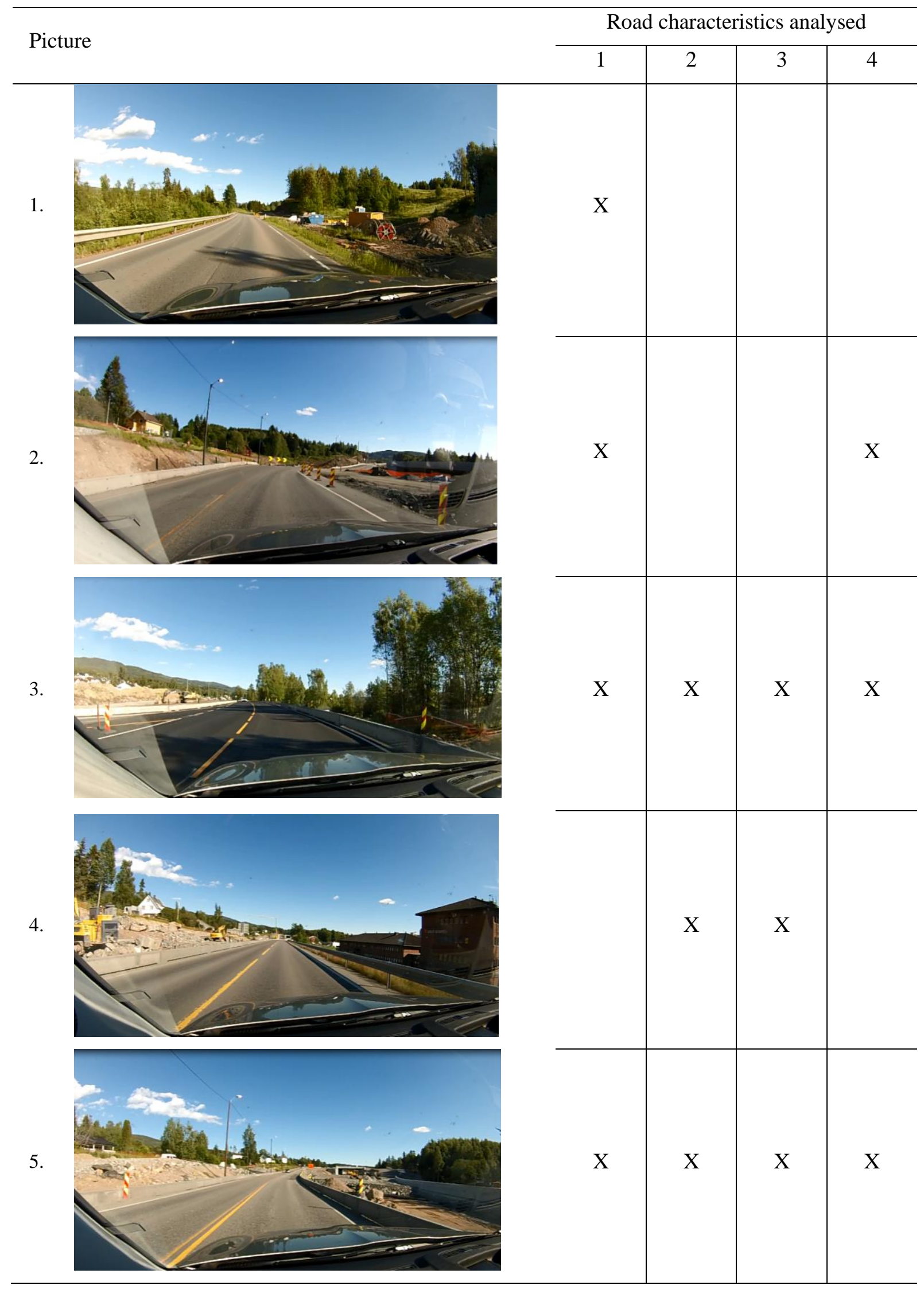




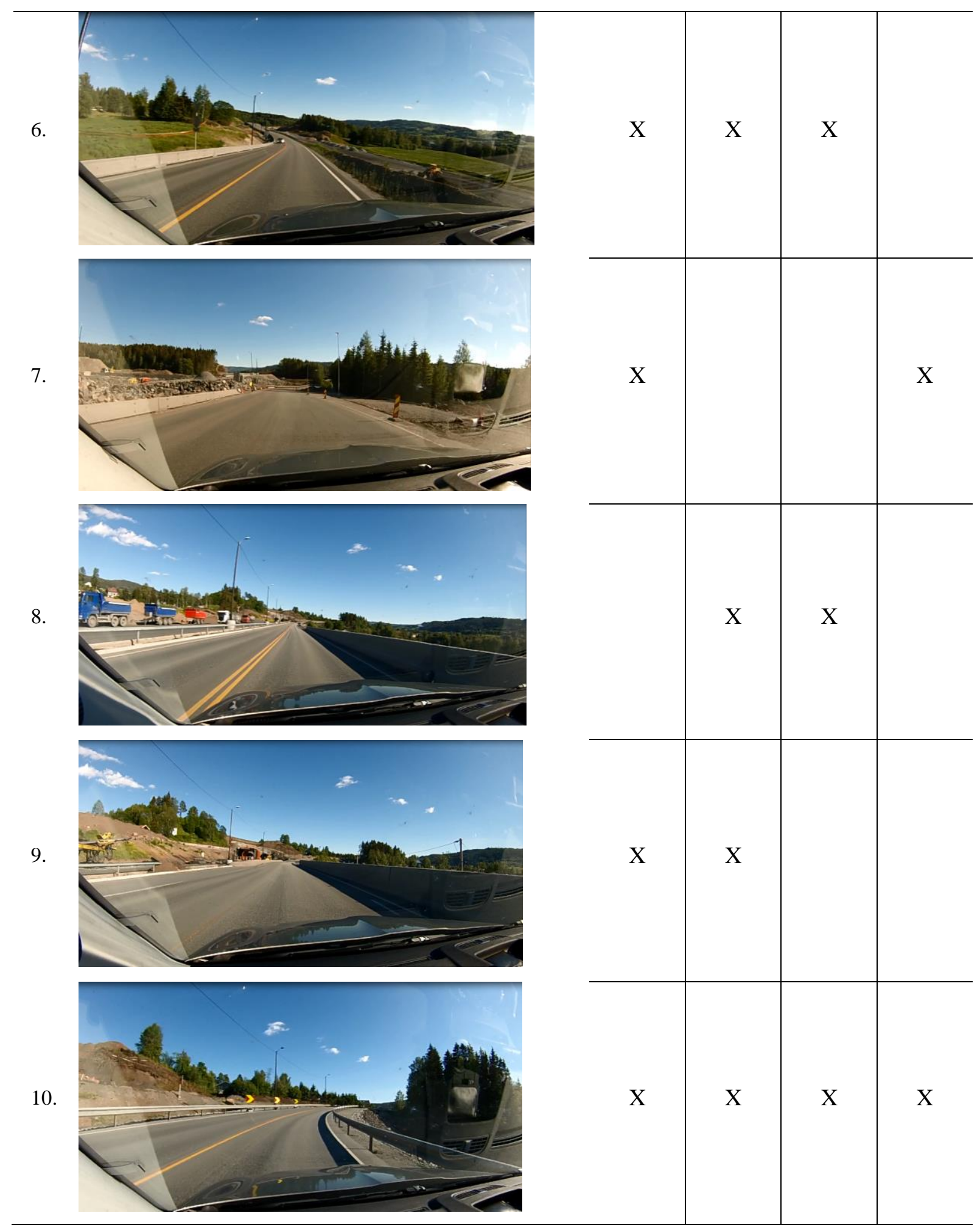

Note. $1=$ curve; 2 =guardrail, $3=$ roadmarking, 4=delineators 


\section{APPENDIX III}

Additional analysis 
The questionnaire used in this thesis had several questions that were of a more exploratory nature and were therefore not analysed in the papers. Further analyses were performed for those questions and are presented here.

\section{ASSESSMENT OF RISK FOR WORK ZONES}

Risk assessment was a variable from the first dataset that formed the basis for paper I and II. It was measured by asking participants to evaluate the probability of the following situations for roadworks: rear-end collisions, off-road collisions, fatal collisions, running down road workers, and police control. The items ranged from to "not probable at all" to "very probable" on a seven-point Likert-type scale.

The overall mean for risk assessment was $\mathrm{M}=3.70(\mathrm{SD}=1.07)$. The means for the subscales were: rear-end collisions $(M=4.50 ; \mathrm{SD}=1.4)$; off-road collisions $(\mathrm{M}=3.41$; $\mathrm{SD}$ $=1.4)$; fatal collisions $(M=3.20 ; S D=1.5)$; running down road workers $(M=4.11 ; S D=$ $1.5)$, and police control $(M=3.28 ; S D=1.5)$. There was a significant difference between gender groups, where females assessed those types of risks as more probable than males. Those differences were for the mean scores for rear-end collisions $\left(t_{(810)}=2.03, p<0.05\right.$. Mean difference $=0.20,95 \% \mathrm{CI}: 0.40$ to $\left.0.01 ; \eta^{2}=0.005\right)$; off-road collisions $\left(t_{(805)}=3.76, p<\right.$ 0.001 . Mean difference $=0.38,95 \%$ CI: 0.58 to $\left.0.18 ; \eta^{2}=0.01\right)$; fatal collisions $(t(807)=3.00$, $p<0.01$. Mean difference $=0.30,95 \%$ CI: 0.51 to $\left.0.10 ; \eta^{2}=0.01\right)$; running down road workers $\left(t(809)=3.23, p<0.01\right.$. Mean difference $=0.35,95 \%$ CI: 0.56 to $\left.0.13 ; \eta^{2}=0.01\right)$; and police control $\left(t(809)=2.50, p<0.05\right.$. Mean difference $=0.27$, 95\% CI: 0.49 to $0.06 ; \eta^{2}=$ 0.007).

There were no significant differences in risk assessment scores for those who were involved in a crash as a driver in the past 5 years. There was a significant difference between age groups where the group above 56 years had significantly lower mean scores compared to the group 40-55 years for all scores. Those differences for the mean scores were for rear-end collisions $\left(F_{(3,808)}=3.21, p<0.05 ; \eta^{2}=0.01\right)$; off-road collisions $\left(F_{(3,803)}=3.89, p<0.01\right.$; $\left.\eta^{2}=0.01\right)$; fatal collisions $\left(F_{(3,805)}=3.01, p<0.05 ; \eta^{2}=0.01\right)$; and police control $\left(F_{(3,807)}=\right.$ $\left.4.00, p<0.01 ; \eta^{2}=0.01\right)$. There was no difference in means scores for running down road workers. There were no significant differences in mean scores of risk assessments for groups based on region of residence or driving frequency. For the different frequencies of driving through work zones, there was a significant difference only for scores for police control $\left(F_{(3}\right.$, 807) $\left.=3.22, p<0.05 ; \eta^{2}=0.01\right)$. Those who drove through work zones 5-7 days per week 
assessed the risk of police control $(\mathrm{M}=3.00, \mathrm{SD}=1.5)$ to be lower than those who drove through work zones $1-4$ days per week $(\mathrm{M}=3.32, \mathrm{SD}=1.5), 1-3$ days per month $(\mathrm{M}=3.28$, $\mathrm{SD}=1.5)$, or never $(\mathrm{M}=3.65, \mathrm{SD}=1.7)$.

\section{ATTITUDES TOWARDS POSTED SPEED LIMITS FOR WORK ZONES}

Attitudes towards posted speed limits for work zones were also from the first dataset. Such attitudes were measured by asking how participants experienced posted speed limits for roadworks in Norway. Five bipolar adjectives were presented on a seven-point semantic differential-type scale: Too low-Too high; Incomprehensible-Comprehensible, Not credibleCredible; Unnecessary-Necessary; Wrong-Right.

The overall mean for attitudes towards posted speed limits for work zones was $\mathrm{M}=5.05$ ( $\mathrm{SD}=1.2$ ) indicating a quite positive attitude. The means of the subscales were: value $(\mathrm{M}=$ 4.00; $\mathrm{SD}=1.0)$; comprehensibility $(\mathrm{M}=5.48 ; \mathrm{SD}=1.5)$; credibility $(\mathrm{M}=5.07 ; \mathrm{SD}=1.5)$; necessity $(M=5.55 ; S D=1.5)$; and correctness $(M=5.22 ; S D=1.4)$.

There was a significant difference between gender groups for the means of evaluation of speed limits on work zone. Females compared to males judged speed limits as having a higher value (males: $\mathrm{M}=3.88 ; \mathrm{SD}=1.0$; females: $\mathrm{M}=4.03$; $\mathrm{SD}=1.0 ; t(806)=-2.27, p<0.01$. Mean difference $=-0.15,95 \% \mathrm{CI}:-0.71$ to $-0.30 ; \eta^{2}=0.006$ ); more understandable (males: $\mathrm{M}=5.24 ; \mathrm{SD}=1.6$; females: $\mathrm{M}=5.75 ; \mathrm{SD}=1.3 ; t(806)=-4.90, p<0.001$. Mean difference $=$ $-0.51,95 \% \mathrm{CI}:-0.71$ to $-0.30 ; \eta^{2}=0.02$ ); more credible (males: $\mathrm{M}=4.81$; $\mathrm{SD}=1.6$; females: $\mathrm{M}=5.35 ; \mathrm{SD}=1.4 ; t_{(809)}=-4.93, p<0.001$. Mean difference $=-0.53,95 \% \mathrm{CI}:-0.74$ to -0.3 ; $\eta^{2}=0.03$ ); more necessary (males: $\mathrm{M}=5.34 ; \mathrm{SD}=1.5$; females: $\mathrm{M}=5.78 ; \mathrm{SD}=1.4 ; t$ (806) $=$ $-4.30, p<0.001$. Mean difference $=-0.44,95 \% \mathrm{CI}:-0.64$ to $-0.24 ; \eta^{2}=0.02$ ); and more correct (males: $\mathrm{M}=5.00 ; \mathrm{SD}=1.5$; females: $\mathrm{M}=5.46 ; \mathrm{SD}=1.3 ; t(806)=-4.45, p<0.001$. Mean difference $=-0.45,95 \% \mathrm{CI}:-0.65$ to $-0 ; \eta^{2}=0.02$ ). There were no significant differences on scores of risk assessments for those who were involved in a crash in the past 5 years. There was a significant difference between age groups on speed limit assessments $\left(F_{(3,812)}=3.72, p\right.$ $\left.<0.05 ; \eta^{2}=0.01\right)$. The age group above 56 years had a more positive attitude towards speed limits $(M=5.23 ; S D=1.2)$ compared to the age group 26-39 years $(M=4.86 ; S D=1.2)$. There were no significant differences for the means of assessments of speed limits between groups in terms of region of residence. Between the frequency of driving groups, there was a significant difference only for scores on comprehensibility $\left(F_{(3,804)}=2.82, p<0.05 ; \eta^{2}=0.01\right)$ and 
credibility $\left(F_{(3,807)}=3.11, p<0.05 ; \eta^{2}=0.01\right)$, but not on scores for value, necessity, or correctness. The mean score of understandability for the group who drove through a work zone 5-7 days a week $(\mathrm{M}=5.39, \mathrm{SD}=1.5)$ was significantly lower compared to the group that seldom drove through a work zone $(\mathrm{M}=5.95, \mathrm{SD}=1.0)$. The mean scores of credibility for the group who drove through a work zone 5-7 days a week $(\mathrm{M}=4.97, \mathrm{SD}=1.6)$ was significantly lower compared to the group that seldom drove through a work zone $(\mathrm{M}=5.62, \mathrm{SD}=1.4)$. Between the frequency of driving in work zones groups, there was a significant difference only for scores on credibility $\left(F_{(3,807)}=3.17, p<0.05 ; \eta^{2}=0.01\right)$ and not for scores on value, understandability, necessity, or correctness. The mean score on credibility for the group who drove through work zones $1-4$ days per week $(M=4.91, S D=1.6)$ was significantly lower compared to the group that had not driven through work zone in the past month $(\mathrm{M}=5.45, \mathrm{SD}$ $=1.4)$.

\section{SPEED PREFERENCE FOR FOUR WORK ZONE SCENARIOS}

\section{Urban road}

The overall average preferred speed for the urban scenario was $60 \mathrm{~km} / \mathrm{h}(\mathrm{SD}=12 \mathrm{~km} / \mathrm{h})$. That means respondents preferred to drive on average $10 \mathrm{~km} / \mathrm{h}$ faster than the $50 \mathrm{~km} / \mathrm{h}$ posted speed limit. Although there was a significant difference between the stated comfortable and preferred speed, the effect size was small (comfortable speed: $M=59.5 \mathrm{~km} / \mathrm{h} ; \mathrm{SD}=12 \mathrm{~km} / \mathrm{h}$ and preferred speed: $\mathrm{M}=60 \mathrm{~km} / \mathrm{h} ; \mathrm{SD}=12 \mathrm{~km} / \mathrm{h} ; t_{(821)}=-4.07, p<0.001$; mean difference $=-0.84,95 \% \mathrm{CI}:-1.25$ to $\left.-0.43 ; \eta^{2}=0.02\right)$.

There was a significant difference in mean speeds for the scenarios without activity $(\mathrm{M}$ $=55 \mathrm{~km} / \mathrm{t} ; \mathrm{SD}=11)$ and with activity $(\mathrm{M}=65 \mathrm{~km} / \mathrm{t} ; \mathrm{SD}=11 ; t(813)=-12.98, p<0.001)$. The magnitude of the differences in the means was large (mean difference $=-10.21,95 \% \mathrm{CI}:-11.76$ to $-8.67 ; \eta^{2}=0.17$ ). There were no significant differences between groups for preferred mean speeds for either of the videos. There were no significant mean differences in preferred speeds between the different expectancy groups for the videos. For this reason, this variable was not used on further analysis.

As can be seen in figure 1 , for the scenario with activity $51 \%$ preferred speeds of 50 $\mathrm{km} / \mathrm{h}$ or below, while $49 \%$ preferred speeds above $50 \mathrm{~km} / \mathrm{h}$. For the scenario without activity, $16 \%$ preferred $50 \mathrm{~km} / \mathrm{h}$ or below and $84 \%$ preferred a speed above $50 \mathrm{~km} / \mathrm{h}$. 


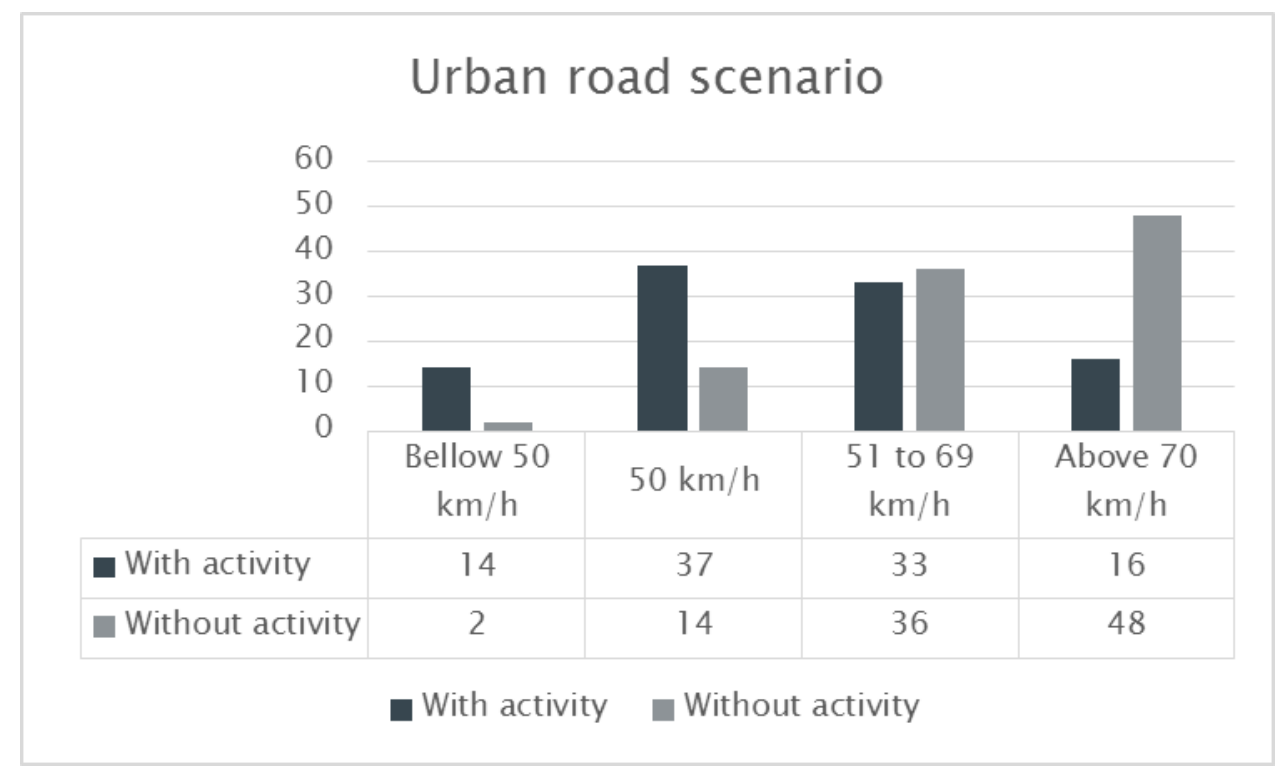

Figure 1. Frequency (\%) of drivers' preferred speeds for urban road scenarios with $50 \mathrm{~km} / \mathrm{h}$ speed limits

\section{Rural road}

The overall average preferred speed for the rural road was $65 \mathrm{~km} / \mathrm{h}(\mathrm{SD}=13 \mathrm{~km} / \mathrm{h}), 5$ $\mathrm{km} / \mathrm{h}$ less than the $70 \mathrm{~km} / \mathrm{h}$ posted speed limit. Although there was a significant difference between the stated comfortable speed and preferred speed, the effect size was small (comfortable speed: $\mathrm{M}=63 ; \mathrm{SD}=12 \mathrm{~km} / \mathrm{h}$ and preferred speed: $\mathrm{M}=65 \mathrm{~km} / \mathrm{h} ; \mathrm{SD}=13$ $\mathrm{km} / \mathrm{h} ; t(821)=-4.81, p<0.001 ;$ mean difference $=-1.13,95 \% \mathrm{CI}:-1.59$ to $\left.-0.67 ; \eta^{2}=0.03\right)$. There was a significant difference in mean speeds for the scenario without activity $(M=68$ $\mathrm{km} / \mathrm{t} ; \mathrm{SD}=13 \mathrm{~km} / \mathrm{h})$ and with activity $\left.(\mathrm{M}=61 \mathrm{~km} / \mathrm{t} ; \mathrm{SD}=12 \mathrm{~km} / \mathrm{h}) ; t_{(813)}=-8.42, p<0.001\right)$. The magnitude of the differences in the means was moderate (mean difference $=-7.33,95 \%$ CI: -9.03 to $\left.-5.62 ; \eta^{2}=0.08\right)$.

For the scenario without activity, there was only a significant difference between groups of regions of residence $\left(F_{(4,400)}=3,69 ; p<0.05, \eta^{2}=0.03\right)$. Those living in region North had significantly higher means $(\mathrm{M}=63.77 \mathrm{~km} / \mathrm{h}, \mathrm{SD}=12 \mathrm{~km} / \mathrm{h})$ compared to region South $(\mathrm{M}=$ $53.25 \mathrm{~km} / \mathrm{h}, \mathrm{SD}=8 \mathrm{~km} / \mathrm{h})$ and region East $(\mathrm{M}=61.79 \mathrm{~km} / \mathrm{h}, \mathrm{SD}=12 \mathrm{~km} / \mathrm{h})$, but the effect size was small. For the scenario without activity, there was only a significant difference between age groups $\left(F_{(4,406)}=2,93 ; p<0.01, \eta^{2}=0.02\right)$. The group aged 56 years and above had higher mean speeds $(M=70.30 \mathrm{~km} / \mathrm{h}, \mathrm{SD}=13 \mathrm{~km} / \mathrm{h})$ compared to the groups 18 to 25 years $(\mathrm{M}=$ $64.64 \mathrm{~km} / \mathrm{h}, \mathrm{SD}=12 \mathrm{~km} / \mathrm{h})$ and 40 to 55 years $(\mathrm{M}=66.46 \mathrm{~km} / \mathrm{h}, \mathrm{SD}=12 \mathrm{~km} / \mathrm{h})$, but the effect 
size was small. There were no significant mean differences on preferred speeds between the different expectancy groups for the videos. For this reason, this variable was not used on further analysis.

Figure 2 presents the frequency for different preferred speeds. For the scenario with activity, $87 \%$ preferred speeds of $70 \mathrm{~km} / \mathrm{h}$ or below and $13 \%$ preferred speeds above $70 \mathrm{~km} / \mathrm{h}$. For the scenario without activity, $67 \%$ preferred $70 \mathrm{~km} / \mathrm{h}$ or below and $33 \%$ preferred speeds above $70 \mathrm{~km} / \mathrm{h}$.

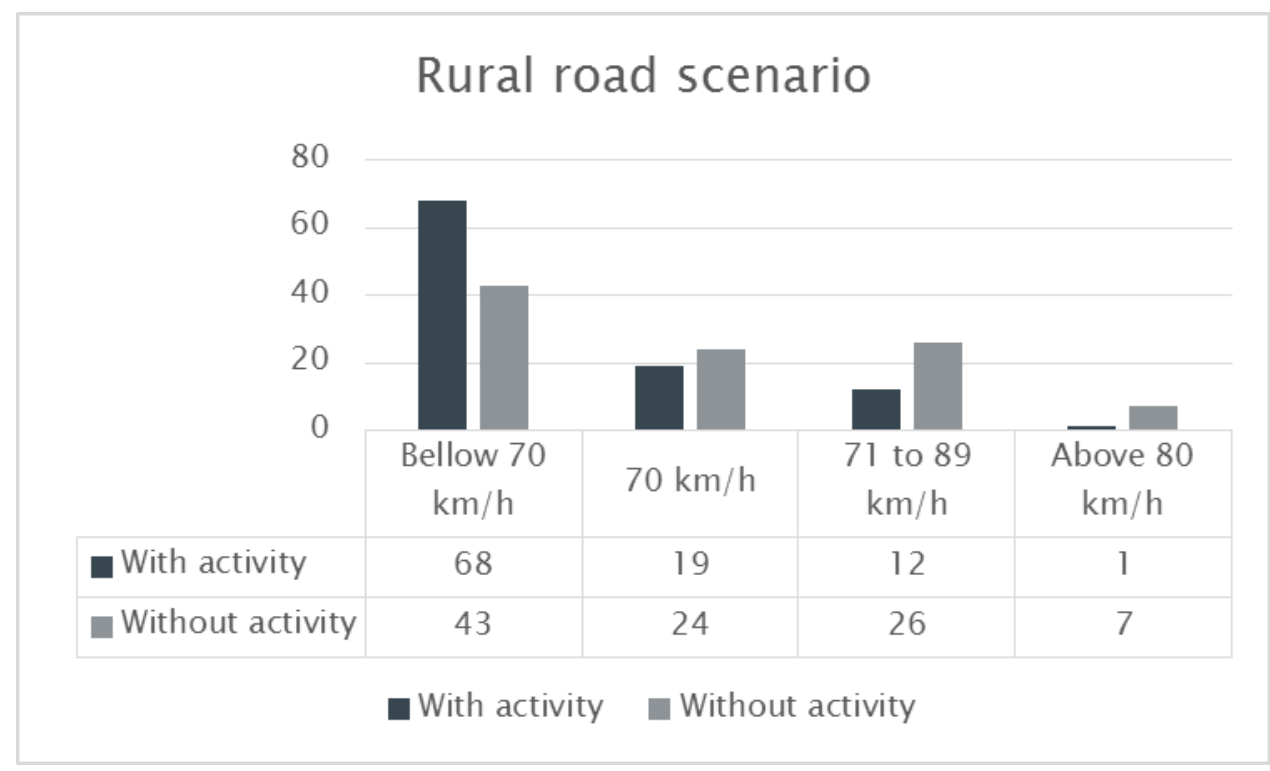

Figure 2. Frequency (\%) of drivers' preferred speeds for rural road scenarios with 70 $\mathrm{km} / \mathrm{h}$ speed limits

\section{USEFULNESS OF DIFFERENT TYPES OF INFORMATION FOR WORK ZONES}

The usefulness of different types of information for work zones was a question from dataset 2. Participants were asked how useful they thought it was to receive different types of information at a work zone. Eight types of information were given, and participants indicated their response on a five-point scale ranging from "useless" to "very useful". The types of information were length of the work zone in kilometres, length of the work zone in minutes, delay in minutes, type of roadwork, information about the contractor of the project, reason for the roadwork, duration of the roadwork, and information about whether there are road workers and/or machinery present. 
As shown in Table 4, the type of information the drivers evaluated as most useful was information about active road workers and/or machinery followed by the length of the work zone in kilometres. The less useful was regarding the contractor of the project.

The mean usefulness of information for a work zone was $3.53(\mathrm{SD}=0.57)$, which indicates that drivers evaluate the additional information for a work zone as neutral, e.g. neither useless nor useful. There were significant differences between groups of drivers and how they evaluated the usefulness of information, but the differences were very small. Female drivers $(M$ $=3.62 ; \mathrm{SD}=0.54)$ and drivers with an age from 35 to 54 years $(M=3.57 ; \mathrm{SD}=0.50)$ evaluated the information as slightly more useful. No differences were found between level of selfassessment of driving skills, work zone exposure, and the evaluation of the usefulness of information.

Table 4. Value of information about the work zone's characteristics

\begin{tabular}{lll}
\hline Type of information & Mean & SD \\
\hline Information about whether there are active road workers and/or & 4.13 & 0.93 \\
machinery present & & \\
Length of the work zone in kilometres & 4.11 & 0.81 \\
Duration of the roadwork & 3.94 & 0.88 \\
Delay in minutes & 3.75 & 0.98 \\
Kind of roadwork & 3.62 & 0.96 \\
Length of the work zone in minutes & 3.21 & 1.00 \\
Reason for the roadwork & 3.32 & 1.00 \\
Information about the contractor of the project & 2.23 & 1.00 \\
\hline Note. 1= Very useless to 5 = very useful & &
\end{tabular}




\section{ERRATA}

In the paper I, entitled "Analysing the influence of visible roadwork activity on drivers' speed choice at work zones using a video-based experiment", published in 2017, the following correction should be made. Page 57, Figure 1, the legend to graph should read "Built-up area" and "Country area". Corrected figure is presented below.

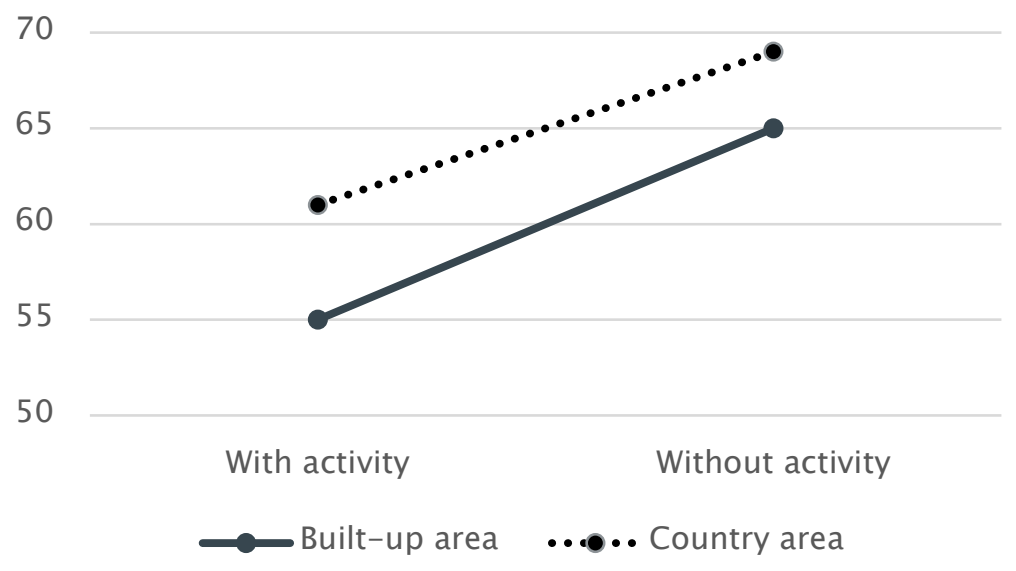

Fig. 1. Main effects of road area and roadwork activity on preferred speeds $(\mathrm{km} / \mathrm{h})$

In the paper III, entitled 'Effects of roadwork characteristics and drivers' individual differences on speed preferences in a rural zone", published in 2019, the following correction should be noted. Page 4, Column 1, Line 7, should read “... difference between the preferred speed and the actual speed limit ..." 
PAPERS I, II AND III 

I 



\title{
Analysing the influence of visible roadwork activity on drivers' speed choice at work zones using a video-based experiment
}

\author{
Renata Torquato Steinbakk ${ }^{\mathrm{a}, \mathrm{b}, *}$, Pål Ulleberg ${ }^{\mathrm{a}}$, Fridulv Sagberg ${ }^{\mathrm{c}}$, Knut Inge Fostervold ${ }^{\mathrm{a}}$ \\ ${ }^{a}$ Department of Psychology, University of Oslo, Forskningsveien 3A, 0373 Oslo, Norway \\ ${ }^{\mathrm{b}}$ Norwegian Public Roads Administration, Brynsengfaret 6A, 0667 Oslo, Norway \\ ${ }^{\mathrm{c}}$ Institute of Transport Economics, Gaustadalléen 21, 0349 Oslo, Norway
}

\section{A R T I C L E I N F O}

\section{Article history:}

Received 4 April 2016

Received in revised form 5 August 2016

Accepted 4 October 2016

\section{Keywords:}

Driver behaviour

Roadworks

Speed preference

Video-based experiment

\begin{abstract}
A B S T R A C T
The present study used a video-based experimental design to investigate the influence of visible roadwork activity on speed preferences at work zones. Four videos from real work zones in Norway were used. Two roadwork areas were filmed at two moments - with and without visible roadwork activity. A total of 815 drivers watched two videos and answered a questionnaire online. Participants stated speed preferences for both videos and then evaluated the influence of 17 common work zone elements on their speed choice. The results showed lower preferred speeds for the videos with visible roadwork activity. The elements considered by drivers to influence their speed included speed regulation (e.g. speed limit signs), transient motives (e.g. time pressure), flow pressure (e.g. speed of the rear driver) and situational conditions (e.g. road situation). Results from the regression analysis showed that visible roadwork activity was the strongest predictor of lower preferred speeds. Speed regulation and transient motives were also significant predictors of preferred speeds. Those who considered speed regulation more important to influence their speed choice at work zones were likely to state lower preferred speeds, while those who considered transient motives as more important were likely to state higher preferred speeds. These findings support the hypothesis that visible roadwork activity is an important factor for lower speed preferences at work zones. The main practical implication is that road authorities should consider various countermeasures to achieve safe driving speeds at work zones, not only roadworks warning signs.
\end{abstract}

(c) 2016 Elsevier Ltd. All rights reserved.

\section{Introduction}

Work zones are quite hazardous road situations, in which fatality risks are twice as high compared to non-work zones (Silverstein, Schorr, \& Hamdar, 2014). Most of the collisions occur during clear weather, daylight conditions, dry surface and straight highways with high posted speed limits (Akepati \& Dissanayake, 2011; Silverstein et al., 2014). Common risk behaviours include exceeding posted speed limits, abrupt deceleration and close following (Advanced Research on Road Work Zone Safety Standards in Europe Consortium [ARROWS], 1998; Høye, Elvik, Sørensen, \& Vaa, 2012; Silverstein et al., 2014; Weng, Xue, Yang, Yan, \& Qu, 2015). Differing from other sites, risk behaviours such as extreme speeds and drunk

\footnotetext{
* Corresponding author at: Norwegian Public Roads Administration, Brynsengfaret 6A, 0667 Oslo, Norway.

E-mail addresses: renata.steinbakk@vegvesen.no (R.T. Steinbakk), pal.ulleberg@psykologi.uio.no (P. Ulleberg), fs@toi.no (F. Sagberg), k.i.fostervold@ psykologi.uio.no (K.I. Fostervold).
} 
driving are not the typical crash factors at work zones (Akepati \& Dissanayake, 2011; Norwegian Public Roads Administration, 2011).

Previous studies have primarily focused on work zone driving behaviours such as speeding and lane changing (e.g. Finley, Jenkins, \& McAvoy, 2015; Morgan, Duley, \& Hancock, 2010; Weng et al., 2015). Relatively little research has so far been done on drivers' perceptions and motivation regarding speed choice at work zones (Blackman, Debnath, \& Haworth, 2014a). Since low speed limit compliance is an important safety issue, supplementary studies focusing on the contributing factor of drivers' speed choice at roadworks are urged.

\subsection{Speed compliance at work zones}

At many work zones, drivers need to relate to new elements on the road such as workers, work machinery and/or new traffic design. Deviation of drivers' expectancies is allegedly a reason for increased crash risk at work zones (Conference of European Directors of Roads [CEDR], 2013). Several studies show that when the environment does not conform to driver expectancies, it can obstruct an appropriate understanding of the situation, increasing the chance of missing relevant information and resulting in increased reaction times (e.g. Bhagavathula \& Gibbons, 2013; Borowsky, Shinar, \& Parmet, 2008; Martens, 2011; Martens \& Fox, 2007). To prevent drivers from being taken by surprise by roadwork activities, and to regulate their behaviours, traffic signs are used. Nevertheless, low effects of traffic sign on speeds are well documented in the literature. Roadworks warning signs alone were found to be ineffective to improve traffic safety in the form of reduced speed (e.g. Finley et al., 2015; Gupta, Singh, \& Tiwari, 2014; Haworth, Symmons, \& Mulvihill, 2002; Hildebrand, Wilson, \& Copeland, 2003). Drivers' failure to notice the traffic signs could be a reason for it, since a previous study has indicated that traffic signs are not always seen by drivers (Costa et al., 2014). Changes in traffic countermeasures, such as signs and road markings, are often not perceived, especially if drives were not looking for a change, if they were familiar with the route and if the changes were small (Martens \& Fox, 2007; Martens, 2011). On the other hand, only a few drivers stated that they did not notice warning signs when approaching the work zones (Haworth et al., 2002). In the field study by Costa et al. (2014), roadworks warning signs were one of the most frequent signs looked at by drivers (36\% of 8 signs) when driving on an unfamiliar road. Ineffectiveness of roadworks warning signs does not appear to be a problem related to understanding either; the symbol was one of the most correctly understood by drivers in different countries (e.g. Ben-Bassat \& Shinar, 2006; Kirmizioglu \& Tuydes-Yaman, 2012; Shinar, Dewar, Summala, \& Zakowska, 2003). Therefore, we can presume that the roadworks' warning signs are conspicuous enough, but due to motivational reasons, they are not effective for promoting safe driving speeds at work zones. Motivation to comply with traffic signs was discussed by Summala and Hietamäki (1984), who suggested that drivers rely more on their own experience and expectations since the symbolic information on warning signs is often ambiguous or redundant. Due to low expectancy of encountering the corresponding object on the road (e.g. crossing children, animals on the road, road workers, etc.), the significance of warning signs is often lost, thus the motivation to comply is quite small. Motivation to comply with mandatory signs is supposed to be higher since the consequences for not obeying them are greater (e.g. a fine) (Summala \& Hietamäki, 1984). Mandatory signs, such as speed limits were found to be more effective in reducing main speeds than just warning signs at work zones (e.g. Finley et al., 2015; Gupta et al., 2014; Haworth et al., 2002; Hildebrand et al., 2003). Yet, speeding over the posted limit remains one of the most common risk behaviours at those areas (ARROWS, 1998; Høye et al., 2012). One reason is the low credibility of speed limits. Goldenbeld and van Schagen (2007) have discussed the aspect of the credibility of speed limits and suggested that the larger the difference between preferred speeds and the posted speed limit, the lower the speed limit's credibility. Thus, drivers who perceive a posted speed limit as not credible may ignore the limit and choose for themselves what speed is appropriate. When driving at a work zone, drivers do not always perceive a reason to reduce their speed. Consequently, they tend to choose a speed they find appropriate for the situation regardless of the reduced posted speed limits (Haworth et al., 2002; Ullman \& Brewer, 2014). Drivers also stated that they were willing to comply with speed limits at work zones if they perceived the speed limits to be justified (Blackman, Debnath, \& Haworth, 2014b). Visible roadwork activity seems to be an important factor for speed limit credibility. In a field study, Benekohal and Wang (1994) found that drivers travelled at different speeds through the work zone, with average speeds gradually decreasing before the work activity area and increasing after passing it. Akepati and Dissanayake (2011) showed an increased frequency of abrupt deceleration towards the onset of a work activity area compared to the advance warning and termination area. Blackman et al. (2014b) found significantly lower mean speeds when showing photographs of work zones that depicted workers and machinery present when compared to the same work sections without any visible activity. In another field study, Finley et al. (2015) found that when the first speed limit sign was within view of the work zone condition, there was a greater decrease in average speeds and in speed variance.

Given the importance of characteristics of the road environment for speed choice and traffic signs credibility (e.g. Goldenbeld \& van Schagen, 2007; Summala \& Hietamäki, 1984), a better understanding of speed choice at roadworks could help the planning of countermeasures in those areas. The present study utilised videos of real work zones at two different moments (i.e. with and without visible roadwork activity) aiming to investigate the effects of roadwork activity on drivers' preferred speeds. The secondary aim was to analyse drivers' assessments of elements that influence their speed choice at work zones and their effects on speed preferences. 


\section{Method}

\subsection{Participants and procedure}

Participants were randomly drawn from an existing panel at the independent survey bureau Respons Analyse and invited to participate by e-mail. Only those who had a valid driving licence had the opportunity to participate on this online-based experiment. In total, 822 Norwegian drivers were recruited. As a reward for their participation, those who answered the questionnaire took part in a lottery to win a gift voucher. First, the informed consent was presented, which contained the objective of the study and contact information. The participants were also informed that their participation in no way would have any consequence for their driving licence. It was emphasised that the data collected would be anonymised and impossible to retrace to the individual. After reading the informed consent and agreeing to participate, the participants watched two videos and answered the questionnaire. Seven participants were excluded from further analysis since they stated that they had stopped driving. The total number of respondents was therefore 815 . Fifty-two percent of the respondents were male $(N=421)$, and 48 percent female $(N=394)$. The majority had completed university/college (62\%) followed by those who had completed high school (34\%). Their age ranged from 18 to 70 years $(M=45.7 ; S D=13.0)$, and they had held a driving licence for 26 years on average $(S D=13.0)$. The majority drove almost every day $(66 \%)$ and had an annual mileage of over $16000 \mathrm{~km}$ (25\%), followed by those who reported driving $4000 \mathrm{~km}$ to $8000 \mathrm{~km}$ (22.6\%). The majority also reported that they drive through work zones weekly (54.5\%). The minority reported that they had been involved in a car crash as driver in the past 5 years $(13.4 \%)$.

\subsection{Materials}

Four videos of real two-lane work zones located in Norway were used (approx. $30 \mathrm{~s}$ each). One work zone was located in a built-up area and another in a country area. Screenshots and road characteristics of the videos can be seen in Table 1 . The videos did not show sections with sharp curves and/or sight obstructions, since these road characteristics have been shown to influence self-reported speed choices (Goldenbeld \& van Schagen, 2007). The videos were taken late summer, without rain or snow, when higher speeds and crashes at work zones are more frequent (Akepati \& Dissanayake, 2011; Silverstein et al., 2014). The videos were taken from the perspective of the driver. Existing posted speed limit signs along the route were censored and participants did not receive any information about the speed limits.

\subsection{Design}

This study comprised an online video-based experiment with repeated measure design. The manipulated conditions were expectancy and presence of roadwork activity. The expectancy variable was manipulated on the information given to the participants before they watched the videos (e.g. "imagine that it is you driving alone on this road on a typical Wednesday at $6 \mathrm{pm}$ " or "imagine that it is you driving alone on this road on a typical Sunday at $6 \mathrm{pm}$ "). For this variable, expectations to

Table 1

Screenshots of the work zone videos and road characteristics for each video.

\begin{tabular}{|c|c|c|c|}
\hline Location & With activity & Without activity & Road characteristics \\
\hline $\begin{array}{l}\text { Built-up } \\
\text { area }\end{array}$ & & & $\begin{array}{l}\text { Roadworks on the left side, dawn } \\
\text { filming, bright sky, no car queue }\end{array}$ \\
\hline $\begin{array}{c}\text { Country } \\
\text { area }\end{array}$ & & & $\begin{array}{l}\text { Roadworks on the right side, day } \\
\text { filming, cloudy sky, some car queue }\end{array}$ \\
\hline
\end{tabular}


encounter ongoing roadworks were anticipated to be higher when driving on a weekday during ordinary working hours (Wednesday at $6 \mathrm{pm}$ ) than on weekends outside ordinary working hours (Sunday at $6 \mathrm{pm}$ ). Participants received the same instructions for both videos. The variable presence of roadwork activity was manipulated on the videos, which depicted either the presence of workers/work machinery or no visible activity. Roadworks warning signs were depicted in the beginning of each video.

To rule out order effects, participants watched two videos, one of each area, in a randomized order. About 50 participants were randomly assigned to each group of the $2 \times 2 \times 2 \times 2$ experimental design. After watching each video, participants were asked about their speed preferences, and they completed a questionnaire online with the measures presented in the next section.

\subsection{Measures}

\subsubsection{Speed choice}

Participants needed to state, in kilometres per hour, the speed they would have chosen, for each video. Two different aspects of speed choice were collected: (a) most comfortable speed and (b) preferred speed.

\subsubsection{Assessment of elements on speed choice at work zones}

A set of 17 items comprising work zone situations/elements was used to assess drivers' perception of elements that influence their speed at work zones. Seven items concerned drivers' evaluation of the likelihood of work zones' features to affect speed, adapted from Blackman et al. (2014a) (i.e. flashing light on a traffic sign, sign that shows your speed, "slow down" traffic signs, reduced posted speed limits, visible police control, visible road workers and cones or other elements on the road). Six items were related to motivation to speed from Sagberg (2005) (i.e. time pressure, safety, consideration to passengers, road situation, risk of police control and being used to drive at a particular speed). Three items concerned the behaviour of other drivers (i.e. speed of the rear-driver, speed of the vehicle ahead and experiencing that the rear vehicle is too close) and one item about the presence of roadwork vehicles (i.e. roadworks' vehicle by the road). The participants stated how important these elements were for their speed choice at work zones. The response format for each item ranged from "not important at all" to "very important" on a seven-point scale. The items were presented in a randomized order to avoid possible primacy and recency effects.

\subsubsection{Driver characteristics}

The personal characteristics comprised gender, age, level of education, region of residence, accidents as driver in the past 5 years, driving frequency, kilometres driven last year and frequency of driving at roadworks.

\subsection{Statistical analysis}

A mixed between-within subjects ANOVA was performed to assess the impact of expectancy and road activity on preferred speeds, and to compare mean differences between scenarios. The within-subject independent variable was road area ("built-up area" and "country area"). The between-subject independent variables were expectancy ("high expectancy" and "low expectancy") and roadwork activity ("visible roadwork activity" and "no visible roadwork activity"). Effect sizes - eta squared $\left(\eta^{2}\right)$ - were calculated and classified according to Cohen (1988) as small $\left(\eta^{2}=0.01\right)$, medium $\left(\eta^{2}=0.06\right)$ or large $\left(\eta^{2}=0.14\right)$.

All items with work zone elements were included in a factor analysis. The Kaiser-Meyer-Olkin value was 0.82, exceeding the recommended value, and the Bartlett's test of Sphericity was $p<0.001$, supporting the factorability of the correlation matrix. A factor analysis using a principal axis factoring with Oblimin rotation was performed. Means, standard deviations and Cronbach's alpha were calculated for the obtained factors.

One hierarchical multiple regression analysis was performed in order to test the interaction effects; regressing preferred speeds onto age, road area, roadwork activity, expectancy and factors for speed choice. Gender, annual mileage and number of crashes were included in preliminary analyses but did not show significant relationship to preferred speed and were therefore not included in the following analyses. These excluded variables were previously also found not to have a significant effect on preferred speeds (Goldenbeld \& van Schagen, 2007). Road area, roadwork activity and expectancy variables were entered in the second step, and the factors assessed to influence drivers' speed choices at work zones were entered in the final step.

\section{Results}

\subsection{Speed choice for different work zone areas}

Preferred speed for the built-up area correlated positively with preferred speed for the country area. The higher the preferred speed for the built-up area, the higher the preferred speed for the country area $(r=0.39 ; p<0.01)$. 
3.1.1. Built-up area $(50 \mathrm{~km} / \mathrm{h}$ speed limit)

There was a significant difference between the stated comfortable and preferred speed; however, the effect size was small (comfortable speed: $M=59.5 \mathrm{~km} / \mathrm{h} ; S D=12.0$ and preferred speed: $M=60 \mathrm{~km} / \mathrm{h} ; S D=12.0 ; t{ }_{(821)}=-4.07, p<0.001$; $\left.\eta^{2}=0.02\right)$. In further analyses, only preferred speed was used due to its high correlation with comfortable speed $(r=0.88$; $p<0.01)$.

\subsubsection{Country area $(70 \mathrm{~km} / \mathrm{h}$ speed limit)}

There was a significant difference between the stated comfortable speed and preferred speed; however, the effect size was small (comfortable speed: $M=63 \mathrm{~km} / \mathrm{h} ; S D=12 \mathrm{~km} / \mathrm{h}$ and preferred speed: $M=65 \mathrm{~km} / \mathrm{h} ; \quad S D=13 \mathrm{~km} / \mathrm{h}$; $\left.t_{(821)}=-4.81, p<0.001 ; \eta^{2}=0.03\right)$. In further analyses, only preferred speed was used due to its high correlation with comfortable speed $(r=0.86 ; p<0.01)$.

\subsection{Effect of road area, expectancy and roadwork activity on preferred speeds}

The results of the repeated measure ANOVA showed a significant effect of road area on preferred speeds (Wilks' $\lambda=0.89$, $\left.F_{(1,807)}=92.62, p<0.001\right)$. Speed preference was higher for the country area $(M=64.5 \mathrm{~km} / \mathrm{h}, S D=12.9)$ compared to preferred speed for the built-up area $(M=60.39 \mathrm{~km} / \mathrm{h}, S D=12.3)$. The magnitude of the differences in the means was moderate $\left(\eta^{2}=0.10\right)$. There was a significant effect of roadwork activity on preferred speed for the built-up area (Wilks' $\lambda=0.82$, $\left.F_{(1,807)}=169.33, p<0.001\right)$, where mean speeds for the video with visible roadwork activity were lower $(M=55.31 \mathrm{~km} / \mathrm{h}$; $S D=10.94)$ compared to the video without visible roadwork activity $(M=65.77 \mathrm{~km} / \mathrm{h} ; S D=10.90)$. The effect size was large $\left(\eta^{2}=0.17\right)$, indicating a substantial difference in the preferred speed scores for the videos with and without visible roadwork activity. For the country area there was also a significant effect of visible roadwork activity (Wilks' $\lambda=0.91, F_{(1,807)}=79.33$, $p<0.001)$, where mean speeds for the scenario with roadwork activity were lower $(M=61 \mathrm{~km} / \mathrm{h} ; S D=12 \mathrm{~km} / \mathrm{h})$ compared to the scenario without visible roadwork activity $(M=68.89 \mathrm{~km} / \mathrm{h} ; S D=12.78)$. The magnitude of the differences in the means was moderate $\left(\eta^{2}=0.08\right)$. There was no significant effect for the expectancy variable (Wilks' $\left.\lambda=1.0 ., F_{(1,807)}=0.15, p>0.05\right)$. The results did not show a significant interaction between area, expectancy and roadwork activity $\left(F_{(1,807)}=0.07, p>0.05\right)$.

As Fig. 1 shows, the preferred speeds were higher for the country area compared to the built-up area, and lower for the scenarios with visible roadwork activity for both areas.

\subsection{Influence of roadworks elements on speed choice at work zones}

A principal axis factoring analysis with Oblimin rotation with the set of 17 items revealed the presence of four factors with eigenvalues above Kaiser's criterion of one, which, in combination explained $45 \%$ of the variance. An inspection of the scree plot revealed an inflexion after the forth factor, and a Parallel analysis using Monte Carlo PCA also suggested four factors. Three items loaded below the value of 0.40 and were therefore excluded from further analysis. The item "consideration to passengers" was also excluded since it did not correspond with the other items that loaded on the fourth factor.

Another factor analysis with a fixed number of four factors was performed, without the excluded items, explaining $49 \%$ of the total variance $(23 \%, 16 \%, 6 \%$ and $4 \%$, respectively). The first factor represented traffic signs and elements intended to regulate speed and was named "Speed regulation". The second factor had items related to fear of getting a ticket and time pressure, which represent temporary motivations related to speeding and was named "Transient motives". The third factor represented speed of rear driver and was named "Flow pressure". The fourth factor represented crash risk elements related to particular work zone situations and was named "Situational conditions". The set of items and the results of the factor analysis are presented in Table 2.

The elements regarded to be most important for speed choice (i.e. with the highest mean scores) were "visible road workers", followed by "safety" and "road situation". The least important was "speed of the rear vehicle". The factor situational conditions, followed by speed regulation, had higher mean scores. The correlations between the factors showed that the more important situational conditions was evaluated, the more important speed regulation $(r=0.54 ; p<0.01)$ was rated. The more

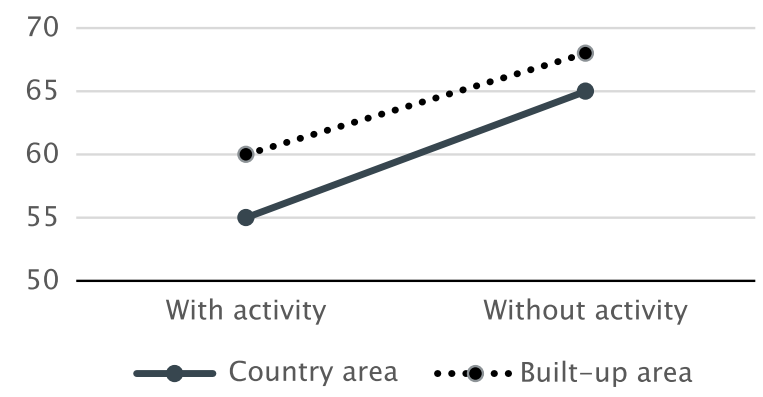

Fig. 1. Main effects of road area and roadwork activity on preferred speeds $(\mathrm{km} / \mathrm{h})$. 
Table 2

Results of factor analysis, standardised factor loadings, means and standard deviations for each item $(N=815)$.

\begin{tabular}{|c|c|c|c|c|c|c|c|}
\hline \multirow{2}{*}{$\begin{array}{l}\text { Item } \\
\text { Pattern matrix }\end{array}$} & \multicolumn{4}{|l|}{ Factor } & \multirow[t]{2}{*}{ Communalities } & \multirow[t]{2}{*}{ Mean } & \multirow[t]{2}{*}{$S D$} \\
\hline & 1 & 2 & 3 & 4 & & & \\
\hline \multicolumn{8}{|l|}{ Factor 1 - Speed regulation } \\
\hline Flashing light on a traffic sign & .72 & & & & .54 & 5.29 & 1.46 \\
\hline Sign that shows you speed & .60 & & & & .39 & 4.71 & 1.75 \\
\hline “Slow down” traffic sign & .58 & & & & .48 & 4.96 & 1.47 \\
\hline Reduced posted speed limits & .41 & & & & .24 & 5.87 & 1.27 \\
\hline \multicolumn{8}{|l|}{ Factor 2 - Transient motives } \\
\hline Visible police control & & .93 & & & .81 & 5.04 & 2.09 \\
\hline Risk of police control & & .75 & & & .57 & 3.97 & 1.98 \\
\hline Time pressure & & .42 & & & .33 & 3.35 & 1.50 \\
\hline \multicolumn{8}{|l|}{ Factor 3 - Flow pressure } \\
\hline Speed of the rear vehicle & & & .73 & & .51 & 2.88 & 1.65 \\
\hline Experience that the rear vehicle is too close & & & .73 & & .56 & 3.59 & 1.86 \\
\hline \multicolumn{8}{|l|}{ Factor 4 - Situational conditions } \\
\hline Safety & & & & .73 & .58 & 6.12 & 0.99 \\
\hline Road situation & & & & .66 & .39 & 6.10 & 1.00 \\
\hline Visible road workers & & & & .55 & .43 & 6.19 & 1.06 \\
\hline Cones or other elements on the road & & & & .40 & .51 & 5.72 & 1.23 \\
\hline \multicolumn{8}{|l|}{ Excluded } \\
\hline Roadworks vehicles by the road & & & & & & 5.48 & 1.37 \\
\hline Speed of the vehicle ahead & & & & & & 4.47 & 1.86 \\
\hline Consideration to passengers & & & & & & 5.07 & 1.65 \\
\hline Used to drive at a particular speed & & & & & & 3.27 & 1.65 \\
\hline Cronbach's alpha & 0.70 & 0.75 & 0.70 & 0.75 & & & \\
\hline Mean $(S D)$ & $5.20(1.07)$ & $4.11(1.54)$ & $3.23(1.54)$ & $6.03(0.82)$ & & & \\
\hline
\end{tabular}

Notes. All items had a seven-point type scale ranging from $1=$ very little important to $7=$ very important. Loadings less than 0.4 have been omitted for clarity's sake. Extraction method Principal Axis Factoring with Oblimin rotation.

Table 3

Predicting preferred speeds for different work zone road areas.

\begin{tabular}{|c|c|c|c|c|c|c|c|c|}
\hline Road type & Block & Predictors & $R^{2}$ & $\Delta R^{2}$ & $B$ & $S E$ & Standardised $\beta$ & $t$ \\
\hline \multirow[t]{7}{*}{ Built-up area } & 1 & Age & 0.00 & 0.00 & 0.06 & 0.03 & 0.06 & 1.98 \\
\hline & \multirow[t]{2}{*}{2} & Roadwork activity $^{\mathrm{a}}$ & 0.17 & 0.17 & 10.03 & 0.77 & 0.40 & $12.93^{* *}$ \\
\hline & & Expectancy $^{\mathrm{a}}$ & & & -0.03 & 0.77 & -0.01 & -0.49 \\
\hline & \multirow[t]{4}{*}{3} & Speed regulation & 0.20 & 0.03 & -1.33 & 0.44 & -0.11 & $-3.02^{*}$ \\
\hline & & Transient motives & & & 1.05 & 0.26 & 0.13 & $4.00^{* * *}$ \\
\hline & & Flow pressure & & & -0.13 & 0.26 & -0.01 & -0.50 \\
\hline & & Situational conditions & & & -0.53 & 0.56 & -0.03 & -0.95 \\
\hline \multirow[t]{7}{*}{ Country area } & 1 & Age & 0.00 & 0.00 & 0.07 & 0.03 & 0.07 & 2.11 \\
\hline & \multirow[t]{2}{*}{2} & Roadwork activity ${ }^{\mathrm{a}}$ & 0.08 & 0.08 & 7.29 & 0.85 & 0.28 & $8.54^{* *}$ \\
\hline & & Expectancy $^{\mathrm{a}}$ & & & -0.04 & 0.85 & 0.00 & -0.05 \\
\hline & \multirow[t]{4}{*}{3} & Speed regulation & 0.12 & 0.05 & -1.91 & 0.48 & -0.15 & $-3.94^{* *}$ \\
\hline & & Transient motives & & & 1.24 & 0.28 & 0.14 & $4.30^{* *}$ \\
\hline & & Flow pressure & & & -0.38 & 0.29 & -0.04 & -1.33 \\
\hline & & Situational conditions & & & -0.35 & 0.61 & -0.02 & -0.58 \\
\hline
\end{tabular}

a $1=$ Yes and $2=$ No.

${ }^{*} p<0.05$.

** $p<0.001$.

important flow pressure was rated, the more important the transient motives $(r=0.27 ; p<0.01)$. Flow pressure also correlated with speed regulation $(r=0.16, p<0.01)$ and situational conditions $(r=0.08, p<0.01)$. The remaining factors were not correlated.

\subsection{The effects of drivers' characteristics, road area, roadwork activity and roadworks factors on preferred speed}

Hierarchical multiple regression analysis regressed preferred speeds onto age, road area, roadwork activity and the four factors regarded as important for drivers' speed choice at work zones. The results are shown in Table 3.

For the built-up area, the total variance explained by the model as a whole was $20.6 \%$ of the variance in preferred speed $\left(F_{(7,806)}=29.84, p<0.001\right)$. For the country area, the total variance explained by the model as a whole was $12.9 \%$ of the variance in preferred speed $\left(F_{(7,806)}=17.02, p<0.001\right)$. Roadwork activity, speed regulation and transient motives were signif- 
icant predictors for both road types, where roadwork activity was the strongest predictor of preferred speeds. The absence of visible roadwork activity was more likely to produce higher preferred speeds. Those who considered speed regulation more important to their speed choice at work zones were less likely to have higher preferred speeds, while those who considered transient motives as more important were more likely to have higher preferred speeds.

\section{Discussion}

Previous studies on driver behaviour at work zones have focused mainly on actual driving without an attempt to understand the determinants of speed choice. To our knowledge, the present study is the first to analyse the influence of roadwork activity on drivers' preferred speeds with the use of videos and the effects of drivers' evaluation of elements that influence their speed choices on those areas. The results support an early study by Blackman et al. (2014b) who found an effect of visible roadwork activity on drivers' speed choices utilising photographs of work zones. A particular strength of the present study is the better ecological validity of results compared to the use of photographs.

The findings corroborate previous literature that warning signs are not always adequate to achieve safe speed choices. Drivers prefer lower speeds when they perceive a reason to do so, which in the present study was visible roadwork activity. Blackman et al. (2014b) indicated that drivers had the perception that when no roadwork was present the traffic signs delivered inaccurate information, frustrating them and undermining the effectiveness of reduced speed limits. Mean preferred speeds for roads with visible roadwork activity were lower compared to the videos without visible roadwork activity. Since participants were not aware of the existing speed limits during the experiment, it is reasonable to assume that particularities of the road environment influenced the participants' speed range choice. Furthermore, the assumption that road environment has an influence on credibility of speed limits (Goldenbeld \& van Schagen, 2007) was also supported by our findings. For the videos without visible roadwork activity, drivers stated that they would prefer speeds $7-10 \mathrm{~km} / \mathrm{h}$ faster than the reduced posted speed limits. Preferred speed for the built-up area was found to be higher than the posted speed limits, while it was lower for the country area. For the country area, roadwork activity was taking place closer to the driver. Activity closer to the driver may also result in lower speeds, probably due to increased risk perception. As suggested by Lawton, Parker, Stradling and Manstead (1997), drivers make judgements about the reasonableness of a speed limit based on the negative consequences associated with speeding in a particular context (such as seriousness of offence, risk and annoyance to other road users). Although preliminary, we can assume that proximity of the roadwork activity could make the posted speed limit more credible. Nevertheless, it is important to highlight that visible roadwork activity is not always a guarantee of safe speed choices. Road workers still perceive excessive vehicle speeds as the most common hazard for them (Debnath, Blackman, \& Haworth, 2015), supporting the notion that speed limits should be reinforced in different ways.

As previous studies have pointed out, different aspects of speed choice vary among traffic situations (Sagberg, 2005). An example is that speed considered safe does not always correspond to preferred speeds or speed choice (Ahie, Charlton, \& Starkey, 2015; Goldenbeld \& van Schagen, 2007). For this reason, two different aspects of speed choice were collected in the present study, i.e. comfortable and preferred speeds. At work zones, it is reasonable to assume that comfortable speeds would be low due to unusual road conditions. The results showed that participants preferred to drive up to $5 \mathrm{~km} / \mathrm{h}$ faster than the speed they considered most comfortable. This means that drivers consider most comfortable speeds to be lower than their preferred speeds, but this difference was not large. One explanation is that, the participants were not aware of the difference between these two aspects, since they did not receive a definition of comfortable speeds. Future studies can investigate different aspects of speed choices at work zones and their potential effects on driving speeds.

The regression analysis suggested that predictors of speed preference were roadwork activity, speed regulation and transient motives, with visible roadwork activity being the strongest predictor. Those who considered speed regulation as an important factor to influence their speed choice were less likely to state higher preferred speeds for the work zones areas. Sagberg (2005) also found that drivers who evaluated speed limits as important for their speed choice drove slower than those who thought it was less important. These findings highlight the importance of individual traffic safety orientation since it has an effect on actual speeds. Transient motives, which represent temporary motivations, was also a factor found to be a significant predictor. The risk of police control at work zones is quite low, thus the fear of getting a ticket is not necessarily a long-lasting motivation to choose lower speeds in those areas. In addition, studies have shown that effectiveness of enforcement depends on several factors other than its presence, such as swiftness, severity, and certainty of the punishment given for the violation (e.g. Ullman \& Brewer, 2014). Another transient motive that could have an effect on speed preferences at work zones, and thus should be further studied, is purpose of travel (e.g. travel to work).

The present study failed to find an effect of expectancy on speed preference or interaction effects with other variables. There was no significant mean speed differences between those who received the instruction that the driving scene was on a Wednesday (were the expectancy for roadworks should be higher) and the instruction that the scene was on a Sunday for any of the videos. One hypothesis is that the actual road situation is more important for speed choices at work zones than the expectation of encountering roadwork activity. Another explanation why we did not find any effects could be that expectations have more influence on reaction times such as braking (e.g. Bhagavathula \& Gibbons, 2013) rather than on speed choices. Besides, it cannot be rule out that the participants did not pay attention to the instructions, in which case the manipulation was not effective at all. Further studies utilising different manipulations for expectancy are consequently needed to establish how expectancy influences driving behaviours at work zones. 


\subsection{Study's limitations and future studies}

Drivers' speed choice has previously been studied using different methods, such as description of scenarios (e.g. Lawton et al., 1997), actual road photographs (e.g. Goldenbeld \& van Schagen, 2007) or actual roadworks' photographs (e.g. Blackman et al., 2014b). The present study aimed to increase the ecological validity of studies on speed choice at work zones using real videos. Still, it has some limitations that should be acknowledged.

Firstly, there is the issue related to the external validity of videos to study speed choice. Videos have limited information compared to the actual driving, such as auditory and kinaesthetic cues. Still, videos provide a richer environmental context where participants do not need to imagine the situation, as is the case when using questionnaires only. Videos also provide more realistic visual information of the actual driving compared to the use of photographs, since the driving task is based on a continuous changing of views (Goldenbeld \& van Schagen, 2007). Videos is a method that has previously been validated to study drivers' speed choice, and it is supposed to have good ecological validity (e.g. Horswill \& McKenna, 1999; Lehtonen, Havia, Kovanen, Leminen, \& Saure, 2015). The videos used in this study were filmed at two different moments at the same section (i.e. one with and one without visible roadwork activity). The same section was used to minimise potential influence of road area surroundings to compare those scenarios. Nevertheless, it was impossible to maintain all variables constant, such as the presence of clouds, car queue, etc. However, current results confirm the findings of other studies about actual speeds; thus, it is reasonable to assume that videos is a method for providing reasonable validly results to study drivers' speed preferences. Future research could validate the use of videos comparing results with real life observations.

This study was based on a limited number of work zones - one from a built-up area and one from a country area. Work zones vary greatly, requiring different types of warning and safety measures. The positive correlation found between preferred speed for built-up and country areas indicates that speeding at work zones may be a widespread problem and not only a situational problem. However, the generalizability of those findings are limited since only two work zones were used and the correlation was moderate. A larger number of work zones could be investigated to assess this assumption. Future research could also explore the novelty effects of countermeasures at work zones, since novelty of roadwork activity may also have produced lower mean speed without long-lasting effects.

Another issue is related to the manner in which the variable preferred speeds was collected. Participants were asked to give a speed they would prefer after having watched the videos, i.e. the speed for the entire road section. Speed can vary throughout the work zone, often with higher speed at the beginning and a decreasing speed towards the onset of the activity area (Benekohal \& Wang, 1994). Yet, initial speeds were found to be related to speeds in the roadwork activity area, where drivers with higher initial speeds kept higher speeds throughout the work zone. In the present study, we only asked about speed preference for the entire work zone section. The results provided a good indication of preferred speed for different work zone scenarios (i.e. with and without roadwork activity); however, future research could enhance the findings by including different speed aspects (e.g. safe speeds, fun speeds) as well as using different methods to collect speed (e.g. pressing a button; asking for speed choice in different parts of the video, etc.).

Lastly, self-reports should always be analysed in a critical light. Nevertheless, as pointed out by Goldenbeld and van Schagen (2007), even though participants may over or underestimate their preferred speed compared to real driving, their answers may be valid in terms of change in speed due to characteristics of road scenes, as showed by the large effect observed for scenarios with visible roadwork activity. In addition, previous studies have found a relation between selfreported preferable speed and actual speed, suggesting that speed preference is a good indicator of drivers' actual speeds (e.g. Ahie et al., 2015; Sagberg, 2005). It is worth to mentioning that a considerable amount of speed variance was not explained by the variables in this study, which is not uncommon for psychological experiments. This suggests that other variables, such as individual differences, should be further investigated to improve the practical implication of the findings.

Although generalisability of current results should be carried out with caution, it still provides important indicators of what influences drivers' speeds at work zones. Future research could validate and enrich the current findings by providing additional empirical evidence.

\section{Conclusions and implications}

The present study addressed the importance of understanding the influence of work zone elements on drivers' speed choice. The knowledge provided has strong practical utility and can be used as indicators to increase work zone safety through the planning and use of appropriate countermeasures. Some practical implications of the insights acquired include:

(a) Aspects of work zone, such as warning signs and guardrails (that were present in all videos), may not always influence drivers to choose safe speeds. In order to regulate driving speeds, temporary speed limits may be necessary.

(b) There was a large speed variation for the videos, even in the visible roadwork activity videos. CEDR (2013), pointed out that high speed variance can occur without any regulations (e.g. posted speed limits), which was corroborated by this study. Posted speed limits could decrease speed variance, for this reason other speed management countermeasures may still be necessary to decrease speed variations, even when the speed limits are kept. Speed cameras before the 
activity area could be a possible solution. If drivers enter the work zone at a lower speed, there is a probability that they will maintain lower speeds throughout the entire area. Speed cameras that measure average speeds can be used to maintain the relevance of speed limits at long work zones.

(c) Situational conditions and transient motives were found to be predictors of speed preferences, where visible roadwork activity was the strongest predictor of lower speed preferences. Nevertheless, a large amount of speed variance was not explained by the variables in this study. Road planners need to take into account that other variables, such as individual differences, may play a role in speed preferences and are not possible to control or regulate in the traffic environment. Consequently, supplementary strategies such as traffic safety campaigns may be necessary to enhance safety at work zones.

(d) According to European standards for work zones, practitioners should choose posted speed limits that are reasonable and justifiable (ARROWS, 1998). To improve speed limit compliance, drivers need to perceive the reasons to do so. In this sense, work zones can pose an extra challenge since the reasons for a reduced speed limit is not always apparent to the drivers. Graphic-aided message signs that display current facts of roadwork activity and/or variable speed limits that change when no work is being carried out could increase speed limit compliance at a particular work zone. In places where no roadwork activity is taking place, this could be achieved either by improving drivers' perceptions through environmental changes (e.g. traffic calming countermeasures), or by providing accurate information to drivers using traffic signs.

\section{Acknowledgments}

The author wishes to thank the Norwegian Public Roads Administration for funding the study. Thanks to the anonymous reviewers for very instructive comments and suggestions. Also thanks to Nevjard Guttormsen for his help with the data collection, Morten Hafting for the videos and Ann-Kristin Gjelsten for her help in proofreading the manuscript.

\section{Appendix A. Supplementary material}

Supplementary data associated with this article can be found, in the online version, at http://dx.doi.org/10.1016/j.trf. 2016.10.003.

\section{References}

Advanced Research on Road Work Zone Safety Standards in Europe Consortium (1998). Road work zone safety practical handbook Final report for publication. National Technical University Athens.

Ahie, L. M., Charlton, S. G., \& Starkey, N. J. (2015). The role of preference in speed choice. Transportation Research Part F: Traffic Psychology and Behaviour, 30, $66-73$.

Akepati, S., \& Dissanayake, S. (2011). Characteristics and contributory factors of work zone crashes. In 90th Transportation research board annual meeting, 11 3769. Washington DC: Transportation Research Board.

Ben-Bassat, T., \& Shinar, D. (2006). Ergonomic guidelines for traffic sign design increase sign comprehension. Human Factors, 48, $182-195$.

Benekohal, R. F., \& Wang, L. (1994). Relationship between initial speed and speed inside a highway work zone. Transportation Research Record, $1442,41-48$. Bhagavathula, R., \& Gibbons, R. B. (2013). Role of expectancy, motion and overhead lighting on nighttime visibility. Proceedings of the human factors and ergonomics society annual meeting (Vol. 57(1), pp. 1963-1967). SAGE Publications.

Blackman, R. A., Debnath, A. K., \& Haworth, N. (2014a). Work zone items influencing driver speeds at roadworks: Worker, driver and expert perspectives. In ARSRPE conference paper database. Accessed from <http://arsrpe.acrs.org.au/index.cfm?action=main.paper\&id=2932>.

Blackman, R. A., Debnath, A. K., \& Haworth, N. L. (2014b). Influence of visible work activity on drivers' speed choice at roadworks. In Proceedings of the 2nd occupational safety in transport conference, CARRS-Q(pp. 1-10). Queensland University of Technology. Accessed from: <http://eprints.qut.edu.au/76277/>.

Borowsky, A. Shinar, D. \& Parmet, Y. (2008). Sign location, sign recognition, and driver expectancies. Transportation Research Part F, 11, 459-465.

Cohen, J. (1988). Statistical power analysis for the behavioral sciences. Hillsdale, NJ: Lawrence Erlbaum Associates.

Conference of European Directors of Roads. (2013). State of the art on speed management methods, deliverable D2.1. ASAP - appropriate speed saves all people. In The transnational road research programme call 2012: Safety.

Costa, M., Simone, A., Vignali, V., Lantieri, C., Bucchi, A., \& Dondi, G. (2014). Looking behavior for vertical road signs. Transportation Research Part F, 23, $147-155$.

Debnath, A. K., Blackman, R., \& Haworth, N. (2015). Common hazards and their mitigating measures in work zones: A qualitative study of worker perceptions. Safety Science, 72, 293-301.

Finley, M. D., Jenkins, J., \& McAvoy, D. S. (2015). Motorists' speed response to non-variable and variable work zone speed limits and other work zone conditions. In 94th Transportation research board annual meeting 15-3214. Washington DC: Transportation Research Board.

Goldenbeld, C., \& van Schagen, I. (2007). The credibility of speed limits on $80 \mathrm{~km} / \mathrm{h}$ rural roads: The effects of road and person(ality) characteristics. Accident Analysis and Prevention, 39, 1121-1130.

Gupta, S., Singh, Y., \& Tiwari, G. (2014). Driver behaviour and warning signs in highway work zones. In Transportation research board annual meeting 2014, 14-5728. Washington DC: Transportation Research Board.

Haworth, N., Symmons, M., \& Mulvihill, C. (2002). Safety of small workgroups on roadways Report 195. Victoria, Australia: Monash University Accident Research Centre.

Hildebrand, E. D., Wilson, F. R., \& Copeland, J. J. (2003). Speed management strategies for rural temporary work zones. In Proceedings of the Canadian multidisciplinary road safety conference XIII.

Horswill, M. S., \& McKenna, F. P. (1999). The development, validation, and application of a video-based technique for measuring an everyday risk-taking behavior: Drivers' speed choice. Journal of Applied Psychology, 84(6), 977-985.

Høye, A., Elvik, E., Sørensen, M. W. J., \& Vaa, T. (2012). Vegarbeidsvarsling. In Trafikksikkerhetshåndboken [The handbook of Traffic Safety]. Oslo: Institute of Transport Economics. Acessed from http://tsh.toi.no/.

Kirmizioglu, E., \& Tuydes-Yaman, H. (2012). Comprehensibility of traffic signs among urban drivers in Turkey. Accident Analysis and Prevention, 45, $131-142$. 
Lawton, R., Parker, D., Stradling, S. G., \& Manstead, A. S. (1997). Self-reported attitude towards speeding and its possible consequences in five different road contexts. Journal of Community and Applied Social Psychology, 7, 153-165.

Lehtonen, E., Havia, V., Kovanen, A., Leminen, M., \& Saure, E. (2015). Evaluating bicyclists' risk perception using video clips: Comparison of frequent and infrequent city cyclists. Transportation Research Part F: Traffic Psychology and Behaviour.

Martens, M. H. (2011). Change detection in traffic: Where do we look and what do we perceive? Transportation Research Part F, 14, $240-250$.

Martens, M. H., \& Fox, M. R. J. (2007). Do familiarity and expectations change perception? Drivers' glances and response to changes. Transportation Research Part $F, 10,476-492$.

Morgan, J. F., Duley, A. R., \& Hancock, P. A. (2010). Driver responses to differing urban work zone configurations. Accident Analysis and Prevention, 42, 978-985.

Norwegian Public Roads Administration. (2011). Temaanalyse av trafikkulykker i tilknytning til vegarbeid. Basert på data fra dybdeanalyser av dødsulykker i vegtrafikken 2005-2009 [Theme analysis of traffic accidents in connection with work zones. Based on data from in-depth analysis of fatalities in road traffic 2005-2009]. Norwegian Public Roads Administration.

Sagberg, F. (2005). Factors influencing driving speed Report 765/2005. Oslo: Institute of Transport Economics.

Shinar, D., Dewar, R. E., Summala, H. \& Zakowska, L. (2003). Traffic sign symbol comprehension: A cross-cultural study. Ergonomics, 46(15), 1546-1565.

Silverstein, C. Schorr J. \& Hamdar, S. H. (2014). Work zones vs. non-work zones: Risk factors leading to rear-end and sideswipe collisions. In Transportation research board 93rd annual meeting. Washington DC: Transportation Research Board.

Summala, H., \& Hietamäki, J. (1984). Drivers' immediate responses to traffic signs. Ergonomics, 27(2), 205-216.

Ullman, G. L., \& Brewer, M. A. (2014). Driver perceptions of traffic calming versus active enforcement efforts in work zones. Transportation Research Record: Journal of the Transportation Research Board, 2425, 25-31.

Weng, J., Xue, S., Yang, Y., Yan, X., \& Qu, X. (2015). In-depth analysis of drivers' merging behavior and rear-end crash risks in work zone merging areas. Accident Analysis and Prevention, 77, 51-61. 


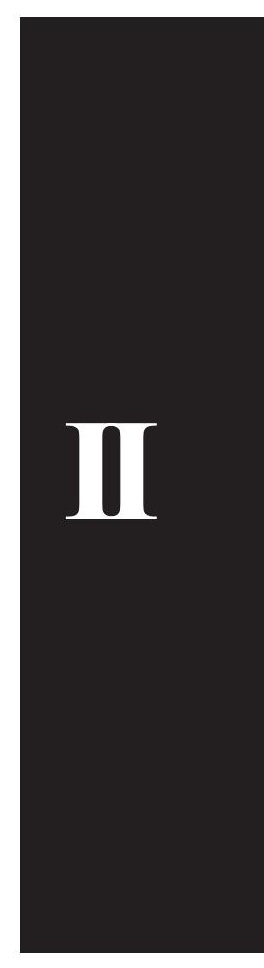





\title{
Speed preferences in work zones: The combined effect of visible roadwork activity, personality traits, attitudes, risk perception and driving style
}

\author{
Renata Torquato Steinbakk ${ }^{\mathrm{a}, \mathrm{b}, *}$, Pål Ulleberg ${ }^{\mathrm{a}}$, Fridulv Sagberg ${ }^{\mathrm{c}}$, Knut Inge Fostervold ${ }^{\mathrm{a}}$ \\ a Department of Psychology, University of Oslo, Forskningsveien 3A, 0373 Oslo, Norway \\ ${ }^{\mathrm{b}}$ Norwegian Public Roads Administration, Brynsengfaret 6A, 0667 Oslo, Norway \\ ${ }^{\mathrm{c}}$ Institute of Transport Economics, Gaustadalléen 21, 0349 Oslo, Norway
}

\section{A R T I C L E I N F O}

\section{Article history:}

Received 25 May 2018

Received in revised form 6 January 2019

Accepted 30 January 2019

\section{Keywords:}

Speed preference

Driver behaviour

Roadworks

Personality traits

Social-cognitive variables

\begin{abstract}
A B S T R A C T
One of the most common safety issues at work zones is high speed variation. Nevertheless, few studies have addressed psychological variables to deepen the understanding of drivers' speed choice in work zones. The present study examined whether work zones represent a type of situation that may trigger the expression of certain personality traits resulting in large individual differences in speed preferences. An additional aim was to study whether the expected relationship between personality traits and speed in work zones was dependent upon the presence of visible roadwork activity. Four sub-scales of the UPPSImpulsivity scale (perseverance, premeditation, negative urgency and sensation seeking), a measure of altruism and a measure of normlessness were chosen for this purpose. A video-based experiment of real work zones was used where drivers $(N=815)$ stated their preferred speed in conditions with and without roadwork activity present. Afterwards, they answered an online questionnaire with the study variables. The presence of roadwork activity was the strongest predictor for speed, resulting in a relatively large reduction in preferred speed. The effect of roadwork activity was also found to moderate the relationship between normlessness and speed as well as perseverance and speed, suggesting that the presence of this contextual factor to some extent influences the relation between personality traits and preferred speed. A serial mediation model showed that sensation seeking, altruism and normlessness had weak, but statistically significant indirect effects on preferred speed in work zone through attitudes towards speeding. Negative urgency had an indirect effect on preferred speed through risk perception, but in the opposite direction as expected. The practical implications such as in planning countermeasures are discussed, as well as in interventions targeting attitudes and risk perception specific for work zones. (c) 2019 Elsevier Ltd. All rights reserved.
\end{abstract}

\section{Introduction}

Roadworks present alterations of road characteristics and traffic conditions where drivers often need to adjust their behaviours to deal with the new traffic demands. The typical risky behaviours in those areas were exceeding posted speed limits,

\footnotetext{
* Corresponding author at: Norwegian Public Roads Administration, Brynsengfaret 6A, 0667 Oslo, Norway.

E-mail addresses: renata.steinbakk@vegvesen.no (R.T. Steinbakk), pal.ulleberg@psykologi.uio.no (P. Ulleberg), fs@toi.no (F. Sagberg), k.i.fostervold@ psykologi.uio.no (K.I. Fostervold).
} 
abrupt deceleration and close following (Akepati \& Dissanayake, 2011; Høye, Elvik, Sørensen, \& Vaa, 2012; Silverstein, Schorr, \& Hamdar, 2015; Weng, Xue, Yang, Yan, \& Qu, 2015), which suggest that drivers do not always adjust their behaviours to the work zones' characteristics. Furthermore, high speed variance is one of the main safety concerns at work zones, where the safest work zones are those with the smallest speed variance (Conference of European Directors of Roads [CEDR], 2013).

As for driving speeds at work zones, drivers report to often choose a speed they find appropriate for the current situation, yet not always in accordance with the posted speed limits (Haworth, Symmons, \& Mulvihill, 2002; Ullman \& Brewer, 2014). A situation that influences this evaluation of appropriate speeds is visible roadwork activity, such as the presence of workers, machines or something else that indicates that roadwork activity is ongoing at the site. Previous studies found that drivers preferred lower speeds on roads with roadwork activity (Blackman, Debnath, \& Haworth, 2014; Steinbakk, Ulleberg, Fostervold, \& Sagberg, 2017). However, not all drivers respond in the same way, which is evidenced by the high speed variance found, even when roadwork activity was present. These different responses will have an impact on crash risks, moreover corroborated by the results from Akepati and Dissanayake (2011) that found an increase in the frequency of crashes towards the onset of work activity areas. For this reason, it would be necessary to identify the sources of drivers' different reactions to roadwork activity. Since few studies have addressed the issue of speeding and high speed variance at work zones from a psychological perspective, it would be noteworthy to investigate drivers' individual differences on speed preferences at work zones in terms of personality traits, attitudes, risk perception and driving style.

\subsection{Personality traits, attitudes, risk perception and driving style}

As argued by Näätänen and Summala (1974), the drivers come into the traffic with different types of motivations that, among other factors, are influenced by their personality. The construct personality trait is a latent variable that has been described as a basic disposition that contribute to the development of habits, attitudes and skills which explain the consistency of patterns of thoughts, feelings and actions (McCrae \& Costa, 1995). It should be noted that personality is more than traits. The construct also encapsulates motivation (e.g. motives, defences, psychic structure) and cognition (e.g. beliefs, values, attitudes, self-concept), components that has been regarded as more situation-dependent (McAdams \& Pals, 2006). Thus, individuals are believed to act in relation to conscious and/or unconscious goals. In this way, individual behaviour can be regarded as intentional and partly shaped by how a person perceives a specific situation.

Personality traits have moreover showed to influence how drivers perceive and interpret different traffic situations (e.g. Loo, 1979; Goldenbeld \& van Schagen, 2007), and influence the choices drivers' make while driving. Although the study of personality traits can give us important insights about driving behaviour, there are still some challenges related to its practical applications. Therefore, it would be valuable to investigate other behavioural determinants that are believed to be more open to influence and change, such as attitudes and risk perceptions. Attitudes were showed to mediate the effects of personality traits on violations, lapses and errors (Lucidi, Mallia, Lazuras, \& Violani, 2014) and have direct effects on risky behaviours (Ulleberg \& Rundmo, 2003). Furthermore, several studies found that drivers who had a more positive attitude towards safety perceived higher risks in traffic (e.g. Ulleberg \& Rundmo, 2003; Lucidi et al., 2014). As for risk perception, Ulleberg and Rundmo (2003) found that it is negatively correlated to risk taking behaviour, where those with a higher perception of risk, reported lower risky behaviours. It is reasonable to assume that positive attitudes towards speeding and lower perception of risks would explain higher preferred speeds at work zones. The habitual way the driver drives may predict how they will react in other traffic situations. As underlined by Sagberg, Piccinini, and Engström (2015) driving style is "an habitual way of driving (...) that tends to occur in a consistent way across driving occasions for a give driver and that may include both automatized skills and more consciously controlled behaviour" (p. 1251). Risky behaviours committed systematically in form of violations could be qualified as a driving style. For this reason, it would be also interesting to explore if driving style, in form of frequency of committed violations, have an effect on preferred speeds at work zones. We can assume that those who commit violations more often (especially speed violations) will prefer higher speeds at work zones.

Personality traits have been showed to have both direct and indirect effects on driving behaviours through other determinants (Lucidi et al., 2014; Machin \& Sankey, 2008; Ulleberg \& Rundmo, 2003). However, whether the expected relationship between personality traits and driving outcomes is dependent upon the presence of a particular situation is yet to be explored. Thus, the present study aimed to study both direct and indirect effects of personality traits, as well as the moderating effects of visible roadwork activity on preferred speeds.

\subsubsection{Moderating effects of visible roadwork activity}

In order to manifest as behaviour, personality depends on the strength of the situation (i.e. if the situation allows the trait to express itself) and upon something that triggers the expression of the trait (Judge \& Zapata, 2014). It is reasonable to assume that work zones represent a type of situation that may trigger the expression of certain personality traits resulting in large individual differences on speed preferences. One possibility is that the relationship between personality traits and speed at work zones is dependent upon contextual factors such as the presence (or absence) of roadwork activity, meaning that visible activity act as a moderator in this context. We hypothesize that the personality traits impulsivity, normlessness and altruism are of particular relevance in the work zones setting. We can assume that work zones and their possible adverse effects (e.g. delays, congestions and lowered speeds) may trigger risky behaviours for some drivers due to their higher disposition to behave impulsively. Drivers that score high on normlessness may be more prone to ignore the implicit and 
explicit rules at work zones preferring higher speeds, while drivers scoring high on altruism are expected to show more active concern for other, in this case roadworkers, preferring lower speeds. Although the relationship between these traits and driving behaviour in general has been demonstrated in a larger range of studies (see e.g. Bachoo, Bhagwanjee, \& Govender, 2013; Delhomme, Chaurand, \& Paran, 2012; Goldenbeld \& van Schagen, 2007; Jonah, 1997; Loo, 1979; Lucidi et al., 2014; Machin \& Sankey, 2008; Mallia, Lazuras, Violani, \& Lucidi, 2015; Pearson, Murphy, \& Doane, 2013; Ulleberg \& Rundmo, 2003), possible moderating effects of contextual factors and on the relationship between traits and driving behaviour are rarely studied.

Impulsivity can be separated into four sub-scales; (lack of) perseverance, (lack of) premeditation, (negative) urgency and sensation seeking (Cyders, Littlefield, Coffey, \& Karyadi, 2014; Whiteside \& Lynam, 2001). Perseverance refers to the "individual's ability to remain focused on a task that may be boring or difficult" (Whiteside \& Lynam, 2001, p. 685). Driving at a reduced speed in a work zone can be easily experienced as boring, which may cause drivers scoring low on perseverance to prefer higher speed, even in the presence of roadwork activity. Premeditation is defined as the "tendency to think and reflect on the consequences of an act before engaging in that act" (Whiteside \& Lynam, 2001; p. 685). This tendency is of particular relevance in work zones because drivers have to evaluate the consequences of, for instance, not reduce speed in work zones. Negative urgency refers to the "tendency to experience strong impulses, frequently under conditions of negative affect (Whiteside \& Lynam, 2001; p. 685). Drivers scoring high on negative urgency can be expected to be less motivated to reduce speed in the presence of roadwork activity, due to the strong impulse to drive as usual which overrides the desire to reduce speed. Sensation seeking refers to the "tendency to enjoy and pursue activities that are exiting and openness to trying new experiences that may or may not be dangerous" (Whiteside \& Lynam, 2001; p. 686). High sensation seekers have been found to be less influenced by road features in their speed preferences (Goldenbeld \& van Schagen, 2007). Thus, we can expect that the enjoyment of high speeds may outweigh the wish to reduce speeds at work zones, also in the presence of roadwork activity. Normlessness is originally defined as "the individual's belief that it is acceptable to do whatever [one] can get away with" (Kohn \& Schooler, 1983, p. 87). Individuals scoring high on normlessness have been found to frequently violate traffic rules due to their lower barriers towards socially unapproved behaviours (Ulleberg \& Rundmo, 2003). Drivers scoring high on this trait can be expected to prefer higher speeds in work zones, since they are not very concerned with traffic rules, whether implicit or explicit. It should be noted that the contents of the items intended to measure normlessness were proposed by Kohn and Schooler (1983). The items cover a direction from strict rule obedience to a more independent evaluation of whether one should follow rules or not. For drivers scoring high on normlessness, the presence of roadwork activity may represent a credible stimulus for speed reduction, thus triggering rule obedience in this specific situation. The trait Altruism refers to the "active concern for others' welfare as shown in generosity, consideration of others and willingness to assist others in need of help" (McCrae \& Costa, 1997; p. 18). The predisposition to be considerate towards others (in this case towards roadworkers) may cause drivers scoring high on altruism to have a lower speed preference when faced with roadwork activity.

\subsubsection{Indirect effects of personality traits on speed preferences at work zones}

Both Sümer (2003) and Ulleberg and Rundmo (2003) have suggested a mediation model that explained the relationship between personality traits and risky behaviours as being of an indirect nature, where factors such as attitudes and risk perception act as mediators in the trait-behaviour relationship. Support for this kind of mediation model has been found in many studies (e.g. Bachoo et al., 2013; Lucidi et al., 2014; Pearson et al., 2013; Machin \& Sankey, 2008; Mallia et al., 2015; Ulleberg \& Rundmo, 2003). For instance, negative urgency, sensation seeking and normlessness were linked to negative attitudes towards traffic safety and low perception of risk, which in turn were related to risky driving and speeding. Perseverance, premeditation and altruism were linked to a more favourable attitude towards traffic safety and higher risk perception, which in turn were related to less risk taking and less speeding.

Accounting for the influence of personality traits on attitudes and risk perceptions would increase the accuracy of prediction on how drivers may behave (Vaa, 2007, 2014) and, in our case, improve our prediction of drivers' speed choice at work zones. In the present study, a serial multiple mediation model was proposed. It was hypothesized that personality traits indirectly influence preferred speed at work zones through their influence on attitudes towards speeding and risk perception, which in turn influence driving style and again speed preference.

\subsection{Aims of the study}

Previous research suggests that speeding and large variation in speed are major problems at work zones, even in the presence of roadwork activity. Our main research questions were whether individual differences can be accounted as significant sources of speed heterogeneity at work zones, or whether work zones represents a situation where the influence of contextual factors is too strong to allow traits to express themselves in terms of speed preference. The specific objectives of the study were to:

(1) Investigate the influence of Impulsivity traits, Altruism and Normlessness on preferred speed at work zones and the moderation effect of visible roadwork activity.

(2) Examine the effects of Impulsivity traits, Altruism and Normlessness on speed preferences in work zones as mediators through attitudes towards speeding, risk perception and driving style. 


\section{Method}

\subsection{Participants and procedures}

Eight-hundred and twenty-two Norwegian drivers were recruited online to participate in the present study. Participants were randomly drawn from an existing panel at the independent survey bureau Respons Analyse and invited to participate by e-mail. Only those who had a valid driving licence had the opportunity to answer the questionnaire. Panel members who agreed to answer the questionnaire, took part in a lottery to win a gift voucher. First, the informed consent was presented, which contained the objective of the study and contact information. The participants were also informed that their participation in no way would have any consequence for their driving licence. It was emphasised that the data collected would be anonymised and impossible to retrace to the individual. After reading the informed consent and agreeing to participate, the participants watched two videos online and answered the questionnaire. Seven participants were excluded from further analysis since they stated to have stopped driving. Total number of respondents was therefore 815 drivers. Fifty-two percent of respondents were male $(N=421)$ and $48 \%$ females $(N=394)$. Their age ranged from 18 to 70 years $(M=45.7 ; S D=13.0)$ and they held a driving licence for 26 years on average $(S D=13.0)$. The majority drove almost every day (66\%). Fifty-nine percent had an annual mileage between $4000 \mathrm{~km}$ and 16,000 km and 25\% had driven annually 16,000 km or more. Males stated to have driven annually more often than females $\left(t_{(813)}=5.73, p<0.001 ; \eta^{2}=0.19\right)$. The majority reported to drive through work zones weekly (54.5\%) and only $13.4 \%$ reported to have been involved in a car crash as a driver during the past 5 years.

\subsection{Design}

The current study comprised of an online video-based experiment with repeated measure design. The videos were presented to participants in a counterbalanced randomized order to avoid order effects (such as practice or fatigue). The order of the videos was counterbalanced, i.e. the participants were separated into different groups, where each group watched the same videos, but in reverse order. About 50 participants were randomly assigned to each group of the $2 \times 2 \times 2 \times 2$ experimental design (total $N=815$ ). After watching a video, participants were asked about their speed preferences for each road depicted. Later, they completed an online questionnaire to assess the independent variables of this study, as described in Section 2.4.

\subsection{Materials}

Four videos (approx. $30 \mathrm{~s}$ each) from actual work zones located in Norway were used. One work zone was located in a built-up area and another in a country area. Each section was filmed at two moments: with and without visible roadwork activity. Visible roadwork activity consisted of machinery and roadworkers. The videos were taken from the perspective of the driver and participants were encouraged to imagine themselves driving on the road depicted without having any information about the speed limits. All videos depicted a work zone warning sign at the beginning. Screenshot of one of the videos can be seen in Fig. 1. For a better description of the roads, see Steinbakk et al., 2017.

\subsection{Measures}

\subsubsection{Speed preference}

The dependent variable of this study was preferred speed. It was collected by asking participants the question: "At what speed would you prefer to drive on this road section?" The question was presented with the videos. The preferred speed were indicated in kilometres per hour.

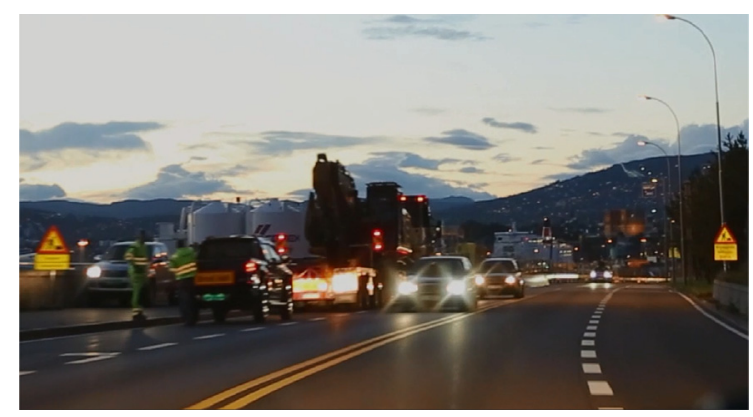

Fig. 1. Screenshot of the built-up area video with roadwork activity. 


\subsubsection{Personality traits}

The personality traits collected were impulsivity traits (perseverance, premeditation, negative urgency, sensation seeking), altruism and normlessness. The first four traits were assessed using scales from the UPPS-P, a short version of the UPPS Impulsive Behavior Scale (Cyders et al., 2014; Whiteside \& Lynam, 2001). Each subscale comprised of four items, with a total of 16 items measured on a four-point scale ranging from "strongly disagree" to "strongly agree". Altruism was assessed using facets of the NEO-Personality Inventory Revised (NEO-PI-R, Costa, McCrae, \& Dye, 1991) and consisted of eight items on a five-point scale ranging from "strongly disagree" to "strongly agree". Normlessness was assessed using the scale by Kohn and Schooler (1983) and consisted of four items measured on a five-point scale ranging from "strongly disagree" to "strongly agree".

\subsubsection{Attitude towards speeding}

Attitudes were measured by two scales, i.e. speeding and traffic flow vs. rule obedience (Ulleberg \& Rundmo, 2003). The scales consisted of four items on a five-point scale ranging from "strongly disagree" to "strongly agree".

\subsubsection{Risk perception}

Risk perception was measured with items by Ulleberg and Rundmo (2003). First, the respondents were asked to judge the probability of one person of their age being involved in a traffic crash, the probability of them being involved in a traffic crash and probability for them to be involved in a traffic crash at a work zone. Those three items were measured on a five-point scale ranging from to "not probable at all" to "very probable". Last, respondents were asked how worried and concerned they were regarding being hurt and hurting other in a traffic crash at a work zone. The items were assessed on a five-point scale ranging from to "not worried at all" to "very worried".

\subsubsection{Driving style}

To assess risky driving style, the Ordinary Violations scale (from the Driver Behavior Questionnaire by Reason, Manstead, Stradling, Baxter, \& Campbell, 1990) and Aggressive Violations scale (by Lawton, Parker, Stradling, \& Manstead, 1997) were used. The number of items were nine and three, respectively, measured on a six-point scale ranging from "never" to "almost always". Speeding and rule violations items (from Ulleberg \& Rundmo, 2003) were also used. These consist of six items measured on a six-point scale ranging from "never" to "almost always".

\subsubsection{Social desirable response}

In order to control for possible effects of socially desirable response of self-reported driving behaviours, the Driver Social Desirability Scale (DSDS - Lajunen, Corry, Summala, \& Hartley, 1997) was used. One of the authors authorized the use of the scale. The scale was translated from English to Norwegian using back-translation procedures. The overall scale comprised of twelve items, divided on two subscales: Driver Impression Management (DIM) and Driver Self-Deception (DSD). The items were measured on a seven-point scale ranging from "not true" to "very true". A preliminary analysis revealed that the variable Driver Impression Management (DIM) was significantly related to preferred speeds (built-up: $r=-0.20$; Country: $r=-0.22)$, attitudes towards speeding $(r=-0.44)$ and risky driving style $(r=-0.62)$. For this reason, it was decided to exclude participants who scored over two standard deviations above the DIM mean, as proposed by Lajunen et al. (1997). Thirty-five participants were therefore discarded from further analysis, reducing the total sample from 815 participants to 780 participants.

\subsection{Statistical analysis}

Data was analysed using IBM SPSS version 24 and Mplus version 7.4. Possible moderating effects of visible roadwork activity upon the relationship between personality traits and preferred speed were estimated using hierarchical multiple regression analysis. Product terms between each personality trait and presence or absence of roadwork activity were constructed to test for possible moderator effects. To avoid problems with multicollinearity, each independent variable was mean centred before product terms were calculated.

Structural equation modelling (SEM) was used to estimate a serial mediation model, describing the hypothesised relationship (see Fig. 4) between personality traits, attitudes, risk perception, driving style and preferred speeds at work zones for built-up and country areas. The fit of the model was evaluated using several $\chi 2$ goodness-of fit-statistics; the comparative fit index (CFI), the root mean square error of approximation (RMSEA) and the standardized root mean squared residual (SRMR). As a general rule, a CFI above 0.95 , and a RMSEA/SRMR below 0.06 indicates a very good fit between the model and the data, whereas a RMSEA below 0.08, SRMR below 0.09 and a CFI above 0.90 is conventionally regarded as a reasonable fit (Hu \& Bentler, 1999; Loehlin, 1998). As recommended by Preacher and Hayes (2008), 95\% confidence intervals for each indirect effect was estimated on the basis of bootstrapped standard errors. 


\section{Results}

Table 1 shows the number of items, mean scores and reliability for all subscales. Most scales demonstrated moderate reliability, but some of the personality scales had a rather low alpha value, especially the normlessness scale $(\alpha=0.48)$ and the perseverance scale $(\alpha=0.43)$. Further analysis indicated that if the item "once I get going on something, I hate to stop" was deleted, the alpha value of the perseverance scale would increase to 0.57 . However, it was decided to maintain all items of this scale in order to keep the scale in the original format.

The rather low alpha values were not ideal, but was probably caused by the use of short-forms of the UPPS-Impulsivity scale and the normlessness scale. The coefficient alpha is heavily dependent upon the number of items within the scale. A high alpha coefficient on short-scales usually means that the items have very similar wording and will thus not capture the heterogeneity of the construct intended to be measured. Acknowledging that alpha values ideally should have been higher, we decided to include the scales in their present form to capture the heterogeneity of the constructs. The authors would like to pinpoint that standards for acceptable reliability, such 0.50 (Nunnally, 1967; p. 226) or 0.70 (Nunnally, 1978; p. 245) are conventions, and not clear cut-off criteria (for a discussion, see Pedhazur \& Schmelkin, 1991; p. 109-110).

Among all personality traits, the mean scores for negative urgency was the lowest and altruism was the highest. The standard deviations were small, which indicates a quite homogeneous group of drivers. As for their attitudes, participants reported a more negative attitude towards speeding. They tended to perceive the risk of a traffic accident as higher compared to the risk of an accident on a work zone. Participants reported more often speeding and rule violations, but their frequencies were quite low. Participants preferred higher speeds for the country area without visible activity $(68.5 \mathrm{~km} / \mathrm{h})$, and lower speeds for the built-up area with visible activity $(55.5 \mathrm{~km} / \mathrm{h}$ ). The standard deviations were quite high (from 11 to $13 \mathrm{~km} /$ h), which indicates a large heterogeneity of preferred speeds for the different work zones.

To simplify the correlation matrix, mean scores were computed for risk perception, attitudes towards speeding and driving style. Since participants evaluated the probability of getting hurt in a traffic accident as more probable compared to getting hurt in an accident on work zones $\left(t(813)=22.52 ; p<0.001\right.$; eta $\left.{ }^{2}=0.38\right)$, for risk perception scores only questions specific for work zones' risks were computed.

Table 2 displays correlation between the variables in the study. The personality traits were not related to preferred speed, but some were weakly correlated with attitudes towards speeding, risk perception and driving style. Drivers who scored higher on sensation seeking and normlessness tended to have more positive attitude towards speeding and reported a more risky driving style. Those who scored higher on altruism had a more negative attitude towards speeding and reported a less risky driving style in terms of number of violations committed. Those who scored higher on negative urgency tended to perceive risks for work zones as higher and reported a riskier driving style. Attitudes and risk perception were, on the other

Table 1

Number of items, mean scores, standard deviations, Cronbach alpha values of variables.

\begin{tabular}{|c|c|c|c|c|}
\hline Measures & Number of items & Mean & SD & Reliability measures $(\alpha)$ \\
\hline \multicolumn{5}{|l|}{ Personality traits } \\
\hline Perseverance & $4^{\mathrm{a}}$ & 3.07 & 0.46 & 0.43 \\
\hline Premeditation & $4^{\mathrm{a}}$ & 3.24 & 0.47 & 0.74 \\
\hline Negative Urgency & $4^{\mathrm{a}}$ & 1.90 & 0.60 & 0.72 \\
\hline Sensation seeking & $4^{\mathrm{a}}$ & 2.25 & 0.66 & 0.62 \\
\hline Normlessness & $4^{\mathrm{b}}$ & 2.40 & 0.50 & 0.48 \\
\hline Altruism & $8^{\mathrm{b}}$ & 3.74 & 0.42 & 0.55 \\
\hline Attitude towards speeding & 4 & 2.53 & 0.81 & 0.74 \\
\hline Traffic flow vs. rule obedience & $2^{\mathrm{b}}$ & 2.67 & 0.95 & $.65^{\mathrm{f}}$ \\
\hline Speeding & $2^{\mathrm{b}}$ & 2.39 & 0.90 & $.60^{\mathrm{f}}$ \\
\hline Risk perception (work zone) & $4^{\mathrm{e}}$ & 3.23 & 1.28 & 0.78 \\
\hline Subjective judgments (traffic accident) & $2^{\mathrm{c}}$ & 4.11 & 1.37 & $.75^{\mathrm{f}}$ \\
\hline Subjective judgments (accident on a work zone) & $2^{\mathrm{c}}$ & 3.08 & 1.44 & $.78^{\mathrm{f}}$ \\
\hline Affective aspect (accident on a work zone) & $2^{\mathrm{c}}$ & 3.39 & 1.55 & $.79^{\mathrm{f}}$ \\
\hline Driving style & 18 & 2.02 & 0.46 & 0.85 \\
\hline Aggressive violations & $3^{\mathrm{d}}$ & 1.75 & 0.60 & 0.60 \\
\hline Ordinary violations & $9^{d}$ & 1.94 & 0.47 & 0.70 \\
\hline Speeding and rule violations & $6^{\mathrm{d}}$ & 2.37 & 0.64 & 0.76 \\
\hline Driver Social Desirable Scale & 12 & 3.89 & 0.86 & 0.75 \\
\hline Driver Impression Management & $7^{c}$ & 3.57 & 1.17 & 0.70 \\
\hline Driver Self-Deception & $5^{c}$ & 4.35 & 1.05 & 0.66 \\
\hline \multicolumn{5}{|l|}{ Preferred speeds } \\
\hline Built-up area - visible activity & - & 55.51 & 10.85 & - \\
\hline Built-up area - without visible activity & - & 65.80 & 11.51 & - \\
\hline Country area - visible activity & - & 61.20 & 12.00 & - \\
\hline Country area - without visible activity & - & 68.42 & 12.60 & - \\
\hline
\end{tabular}

Note. a. range 1-4; b. range 1-5; c. range 1-7; d. range 1-6; e. just for the work zone items; f. correlation coefficient. 
Table 2

Correlations between personality traits, attitude towards speeding, traffic risk perception, driving style and preferred speeds for both road types $\mathrm{N}=780$.

\begin{tabular}{|c|c|c|c|c|c|c|c|c|c|}
\hline & $X_{1}$ & $X_{2}$ & $X_{3}$ & $X_{4}$ & $X_{5}$ & $X_{6}$ & $M_{1 a}$ & $M_{1 b}$ & $M_{2}$ \\
\hline$X_{1}$ Perseverance & & & & & & & & & \\
\hline$X_{2}$ Premeditation & $0.211^{* *}$ & & & & & & & & \\
\hline$X_{3}$ Negative Urgency & 0.047 & $-0.230^{* *}$ & & & & & & & \\
\hline$X_{4}$ Sensation seeking & -0.013 & $-0.088^{*}$ & 0.006 & & & & & & \\
\hline$X_{5}$ Altruism & $0.094^{* *}$ & $0.191^{* *}$ & $-0.242^{* *}$ & -0.021 & & & & & \\
\hline$X_{6}$ Normlessness & 0.030 & $-0.108^{* *}$ & $0.190^{* *}$ & $0.297^{* * *}$ & $-0.178^{* *}$ & & & & \\
\hline$M_{1 a}$ Attitude towards speeding & -0.019 & -0.048 & -0.003 & $0.218^{* * *}$ & $-0.169^{* *}$ & $0.380^{* *}$ & & & \\
\hline$M_{1 b}$ Risk perception WZ & 0.062 & 0.046 & $0.184^{* *}$ & $-0.095^{* *}$ & 0.007 & $-0.075^{*}$ & $-0.194^{* *}$ & & \\
\hline$M_{2}$ Driving style & -0.059 & $-0.156^{* *}$ & $0.118^{* *}$ & $0.244^{* * *}$ & $-0.225^{* *}$ & $0.253^{* *}$ & $0.481^{* *}$ & $-0.076^{*}$ & \\
\hline$Y_{1}$ Preferred speed Built-up area & -0.008 & -0.043 & -0.022 & 0.066 & -0.050 & 0.078 & $0.151^{* *}$ & $-0.126^{* *}$ & $0.180^{* *}$ \\
\hline$Y_{2}$ Preferred speed Country area & -0.021 & $-0.074^{*}$ & -0.068 & 0.064 & -0.019 & 0.056 & $0.208^{* *}$ & $-0.165^{* *}$ & $0.177^{* *}$ \\
\hline
\end{tabular}

hand, related to preferred speed and risky driving style. Those who had a more positive attitude towards speeding reported a riskier driving style and preferred higher speed for both work zones areas. Those scoring higher on risk perception, reported a less risky driving style and had lower preferred speeds for both areas. The preferred speeds for the work zone areas were correlated where those who preferred higher speeds in the built-up area, also preferred higher speeds in the country area.

\subsection{Moderating effects of visible road work activity}

In order to test whether the effects of personality traits upon preferred driving speed at work zones were moderate by the presence of roadwork activity, two multiple regression analyses were performed. Table 3 shows the results of the regression analysis for both work zone areas. Drivers' age, gender, annual mileage and roadwork activity were included as predictors in block 1 . The results showed that roadwork activity was a strong predictor for preferred speed for both work zone areas.

Table 3

Regression analysis for both work zone types $\mathrm{N}=780$.

\begin{tabular}{|c|c|c|c|c|}
\hline & \multicolumn{2}{|c|}{ Preferred speed, built-up area $\left(Y_{1}\right)$} & \multicolumn{2}{|c|}{ Preferred speed, country area $\left(Y_{2}\right)$} \\
\hline & $b$ & $\beta$ & $b$ & $\beta$ \\
\hline Intercept & $59.33^{* * * *}$ & & $61.05^{* * *}$ & \\
\hline Age $^{\mathrm{a}}$ & 0.05 & 0.05 & 0.05 & 0.05 \\
\hline Gender & 0.77 & 0.03 & $2.52^{* * *}$ & 0.10 \\
\hline Annual mileage & 0.05 & 0.01 & 0.03 & 0.01 \\
\hline $\begin{array}{l}\text { Experimental manipulation } \\
\text { Roadwork present, built-up area }{ }^{\mathrm{a}}\left(X_{7}\right)^{\mathrm{b}} \\
\text { Roadwork present, country area }{ }^{\mathrm{b}}\left(X_{8}\right)^{\mathrm{b}} \\
R^{2}\end{array}$ & $\begin{array}{l}-10.38^{* * *} \\
0.179^{* * *}\end{array}$ & -0.42 & $\begin{array}{l}-7.31^{* * * *} \\
0.088^{* * *}\end{array}$ & -0.28 \\
\hline \multicolumn{5}{|l|}{ Personality traits } \\
\hline Perseverance $\left(X_{1}\right)$ & -0.35 & -0.01 & -0.20 & -0.01 \\
\hline Premeditation ${ }^{\mathrm{a}}\left(X_{2}\right)$ & -0.91 & -0.04 & -1.62 & -0.06 \\
\hline Negative urgency a $\left(X_{3}\right)$ & -0.50 & -0.02 & $-2.03^{*}$ & -0.09 \\
\hline Sensation seeking a $\left(X_{4}\right)$ & 0.65 & 0.04 & 1.22 & 0.06 \\
\hline Normlessness $^{\text {a }}\left(X_{5}\right)$ & $2.23^{*}$ & 0.09 & $1.90^{*}$ & 0.07 \\
\hline Altruism ${ }^{\mathrm{a}}\left(X_{6}\right)$ & -1.56 & -0.05 & -1.05 & -0.03 \\
\hline$R^{2}$ & $192^{* * *}$ & & $0.107^{* * *}$ & \\
\hline$\Delta R^{2}$ & 0.013 & & $0.019^{*}$ & \\
\hline \multicolumn{5}{|l|}{ Interaction effects } \\
\hline Roadwork present ${ }^{*} X_{1}$ & 1.85 & 0.03 & $-5.33^{* *}$ & -0.09 \\
\hline Roadwork present ${ }^{*} X_{2}$ & 3.55 & 0.07 & 1.99 & 0.04 \\
\hline Roadwork present $* X_{3}$ & 2.48 & 0.06 & -1.92 & -0.04 \\
\hline Roadwork present ${ }^{*} X_{4}$ & 2.44 & 0.07 & 1.51 & 0.04 \\
\hline Roadwork present $* X_{5}$ & $-4.78^{* *}$ & -0.10 & 1.66 & 0.03 \\
\hline Roadwork present $* X_{6}$ & -0.83 & -0.01 & 0.35 & 0.01 \\
\hline$R^{2}$ & $0.208^{* * *}$ & & $0.121^{* * * *}$ & \\
\hline$\Delta R^{2}$ & $0.016^{*}$ & & 0.014 & \\
\hline
\end{tabular}

Notes. a Variables are mean centered; $\mathrm{b}-0.50=$ no, $0.50=$ yes.

$\mathrm{p}<0.05$.

** $\mathrm{p}<0.01$.

${ }^{* * *} \mathrm{p}<0.001$. 
Preferred speeds were $10.4 \mathrm{~km} / \mathrm{h}$ lower for the built-up area, and $7.3 \mathrm{~km} / \mathrm{h}$ lower for the country area when there was roadwork activity present. Age and annual mileage had no significant effects upon speeds, but females reported significantly less preferred speeds at work zones for the country area. For the built-up area, the model predicted $20.8 \%$ of the variance in preferred speed $(F(11,801)=21.88 ; p<0.001)$. For the country area, $12.1 \%$ of the variance in preferred speed was predicted $(F$ $(11,801)=15.42 ; p<0.001)$.

The personality traits were in general weakly related to preferred speed. Only negative urgency and normlessness had significant main effects upon preferred speed. Negative urgency had an effect in the opposite direction as expected: drivers scoring high on negative urgency preferred to drive at lower speed in the country work zone area. Normlessness was the only trait to have an effect upon preferred speed for both built-up and country areas. As expected, drivers scoring high on normlessness tended to prefer to drive at higher speed in both work zone areas. However, the significant interaction effect between normlessness and roadwork activity for the built-up area $(b=-4.78, p<0.01)$, suggested that the effect of normlessness was dependent upon whether roadwork activity was present or not. As illustrated in Fig. 2, when the score on normlessness increased, preferred speed also increased when there was no visible roadwork activity. The opposite effect occurred when roadwork activity was present, i.e. preferred speed decreased as the level of normlessness increased.

A significant interaction effect between perseverance and roadwork activity for the country area was also found $(b=-5.33, p=0.01)$. The interaction effect is illustrated in Fig. 3 and demonstrates that perseverance had an effect upon preferred speed only in the condition were roadwork activity was present. The higher the score on perseverance, the lower the preferred speed was in this condition. When there was no visible roadwork activity, there were not found any effects of perseverance on preferred speeds for the country area.

\subsection{Indirect effects of personality traits on preferred speed}

A SEM analysis was performed in order to investigate whether the hypothesized effect of personality traits upon speed preferences were mediated through attitudes, risk perception and driving style as presented in Fig. 4.

The results of the serial mediation model are presented in Fig. 5 and Tables 4 and 5. Only significant paths $(p<0.01)$ were shown in the figure. Perseverance had no significant relationship with either attitudes, risk perception or preferred speed and was excluded from the model. The exclusion of this variable resulted in only trivial changes in the parameters, and the final model demonstrated a very close fit to the data: $\chi^{2}(20)=16.34, \mathrm{CFI}=1.00$; RMSEA $=0.000\left(\mathrm{Cl}_{95}[0.000,0.024]\right)$, SRMR $=0.013$. The path model showed that a total of $23 \%$ of the variance in attitudes towards speeding were explained

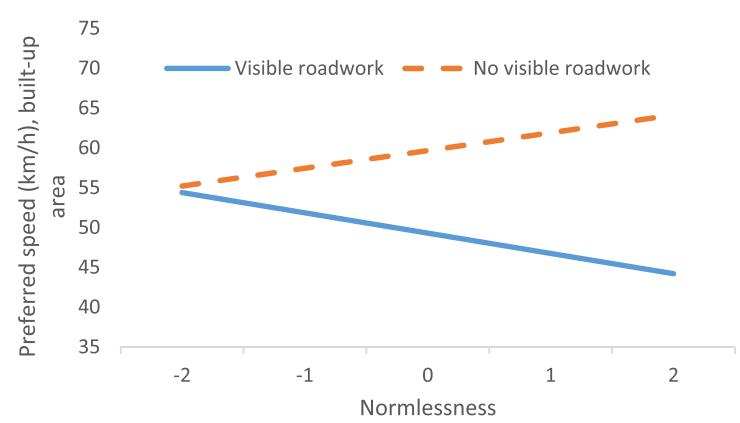

Fig. 2. Regression slopes illustrating the moderating effect of visible roadwork activity on the relationship between normlessness on preferred speed for the built-up area. Normlessness and roadwork activity are mean centred $(\mathrm{N}=780)$.

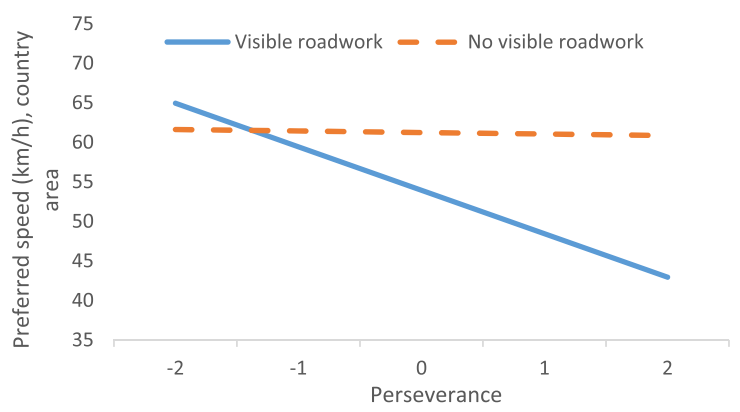

Fig. 3. Regression slopes illustrating the moderating effect of visible roadwork activity on the relationship between perseverance and preferred speed for the country area. Perseverance and roadwork activity are mean centred $(\mathrm{N}=780)$. 
by the traits premeditation, negative urgency, sensation seeking normlessness and altruism. A total of $6 \%$ of variance in risk perception for work zones was explained by premeditation, negative urgency and normlessness. The model explained $23 \%$ of the total variance in preferred speed for the built-up area and 15\% in preferred speed for the country area. Since no direct effects from the personality traits on preferred speed were included in the model, the excellent fit of the model suggests that the effects of personality traits were of an indirect nature.

The results of the tests of the indirect effects using bootstrapping can be seen in Tables 4 and 5. It showed weak, but significant indirect effects of sensation seeking, normlessness and altruism on speed preferences for the built-up and country area. For the country area, all the above mentioned traits plus negative urgency also showed weak, but significant indirect effects on speed preference. High scores on sensation seeking and normlessness were associated with more positive attitudes towards speeding, which in turn was related to higher preferred speed for both areas. High scores on altruism was, on the other hand, related to less positive attitudes towards speeding, which in turn was related to less preferred speed for both area. Negative urgency had an indirect effect on preferred speed through risk perception, but only for the country area. High scores on negative urgency were associated with increased risk perception, which in turn was related to a lower preferred speed.

\section{Discussion}

The present study is to our knowledge the first attempt to investigate the direct and indirect effects of personality traits, mediating effects of social-cognitive variables, as well as the moderator effects of visible roadwork activity on drivers' speed preferences at work zones. The results confirm previous studies about the mediating role of attitudes and risk perception on risk behaviours (Lucidi et al., 2014; Machin \& Sankey, 2008; Mallia et al., 2015; Ulleberg \& Rundmo, 2003). Sensation seeking, normlessness and altruism were the personality traits that had significant indirect effects upon preferred speeds for both built-up and country areas, through attitudes towards speed limits. Meanwhile, negative urgency had indirect effects upon preferred speeds through risk perception, but only for the country area. Hence, we could support the assumption that personality traits primarily influences behaviour through affecting behavioural determinants. However, it is important to note that the effects of the personality traits upon preferred speed could be described as rather moderate.

Attitudes towards speeding showed direct effects, being significant predictors of preferred speeds for both work zone areas. The personality trait variables accounted for $23 \%$ of the total variance in the attitude measure, which suggest that attitudes also had an independent effect on speed preferences predicting additional variance in behaviour. An interesting finding was that participants evaluated the probability of getting hurt in a traffic accident as higher compared to getting hurt in an accident at work zones. This is conflicting to accident analysis that point out that work zones have twice as high the number of crashes, as well as more serious crashes compared to non-work zones (Høye, Phillips, \& Hesjevoll, 2015; Silverstein et al., 2015). Results also point to risk perception as one of the significant predictors for speed preferences at the work zones. Since drivers appear not to have accurate knowledge of risks at work zones, information campaigns focusing on potential risks may be necessary.

Furthermore, the findings showed that the traits of sensation seeking and normlessness were positively associated with a more positive attitude towards speeding and a riskier driving style (in form of reported committed violations). As pointed out by Vaa (2007), personality traits reflect a deeper motivation that steer drivers' motives and behaviour. For individuals scoring high on sensation seeking, speeding behaviour can be an expression of a motivation to have fun and excitement.

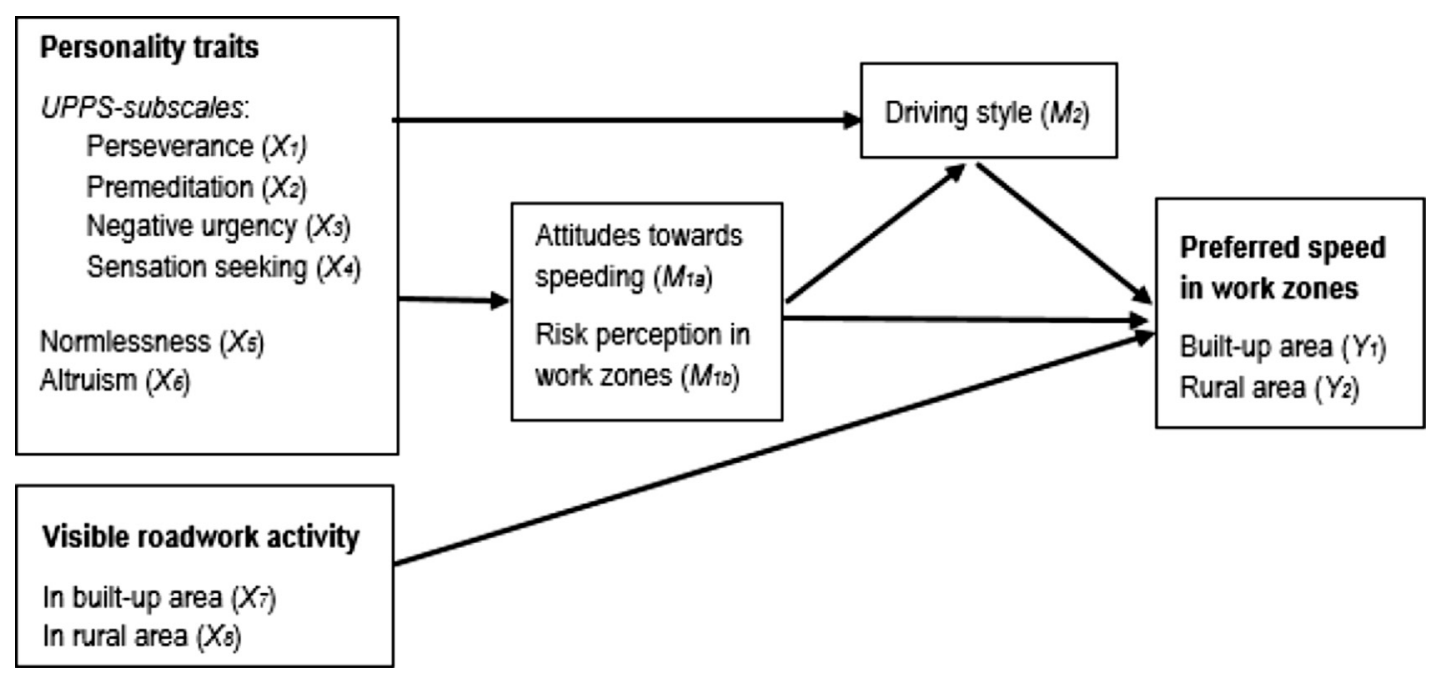

Fig. 4. Conceptual model representing a serial multiple mediation model. 


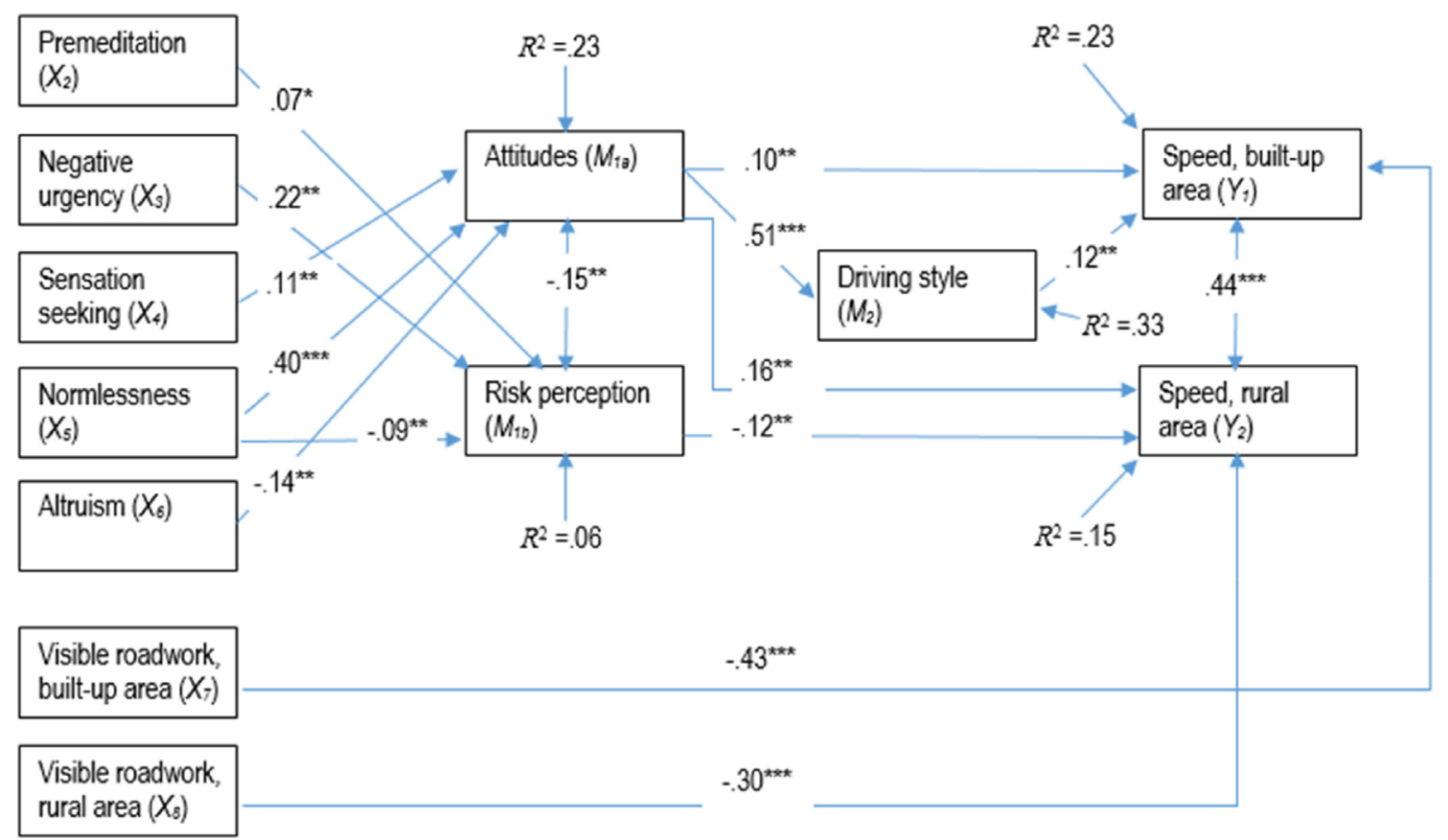

Fig. 5. Path diagram of the relationship between personality traits, attitudes, risk perception, driving style, visible roadwork activity and speed preferences at work zone for the built-up and country areas. Standardized coefficients presented $(\mathrm{N}=780) .{ }^{*} \mathrm{p}<0.05,{ }^{* *} \mathrm{p}<0.01,{ }^{* * *} \mathrm{p}<0.001$.

The individuals scoring higher on normlessness may have an intentional disdain of existing implicit and explicit rules where their personal goals may become more important than obeying those. The significant positive correlation between sensation seeking and normlessness indicate that drivers that tend to pursue exiting activities (such as driving at high speeds), tend to have a higher acceptance to get around the rules in order to fulfil this pursuit. Since traffic laws restrict the behaviours of drivers to some extent, to pursue excitement in driving, drivers scoring high on sensation seeking will inevitably break some traffic rules. This assumption can be corroborated by the results of Goldenbeld and van Schagen (2007) who found that high scores on sensation seeking were positively related to number of speeding tickets. For the built-up area, an interaction effect was found between normlessness, presence of roadwork activity and speed preference. Drivers who scored low on normlessness preferred lower speed for both conditions (visible and no visible roadwork activity). However, drivers scoring high on this trait preferred lower speeds only when there was visible roadwork activity. These results point to the fact that the presence of roadwork activity represented a credible stimulus for speed reduction, especially for drivers who scored high on normlessness.

An interaction effect was also found between perseverance, visible roadwork activity and preferred speeds for the country area. Drivers who scored low on perseverance preferred higher speeds for both scenarios (visible and no visible roadwork activity). Interestingly, preferred speeds for drivers with lower perseverance scores were even higher at the roadwork activity scenarios. We can hypothesize that drivers low on perseverance may experience driving through a work zone as boring and that they will not be eager to lower their speeds even in the presence of roadwork activity. Since this trait has something to do with the ability to deal with activities that can be boring or difficult, it is reasonable to assume that the drivers that scored low on this trait may choose higher speeds to "get over with" the work zone as quickly as possible. Drivers scoring high on perseverance preferred lower speeds, but only when there was roadwork activity present. When no roadwork activity was present, they also preferred higher speeds. This can be an indication that this particular trait will only manifest as a behaviour when the situation allows its expression (in this case, the presence of roadwork activity which acted as a moderator). Moreover, the results showed that visible roadwork activity acted as a moderator also between normlessness and preferred speeds. These results corroborate our assumption that work zones represent a situation that trigger the expression of certain personality traits explaining the source of speed heterogeneity at work zones. Thus, we can assume that the presence of roadwork activity in itself will not guarantee lower speeds and that other countermeasures will be necessary to force most drivers to reduce speeds.

We could not corroborate our hypothesis that drivers scoring high on altruism would have lower preferred speeds in the presence of roadwork activity. However, we found that altruism had indirect effects on preferred speeds through attitudes for both work zone areas. This finding was contrary to the study of Ulleberg and Rundmo (2003) who found direct effects of this trait on risky behaviours. However, our findings is in accordance with the results by Mallia et al. (2015) and Lucidi et al. 


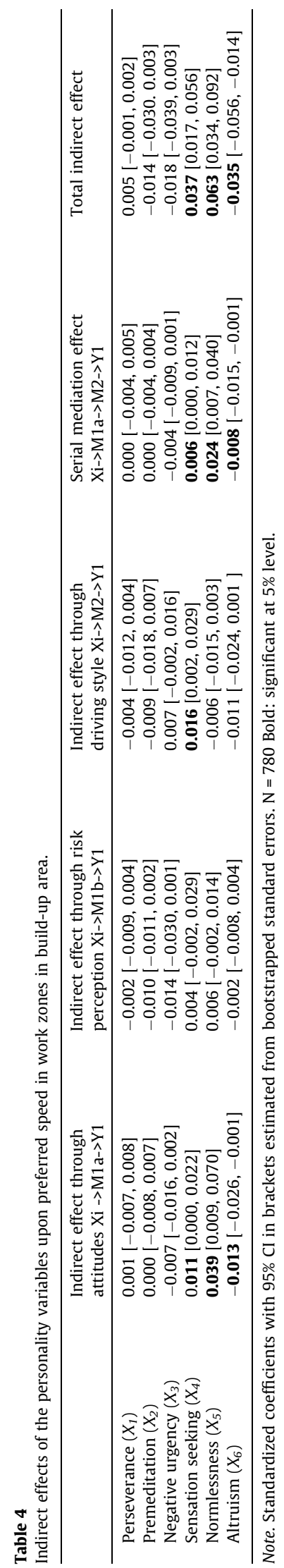




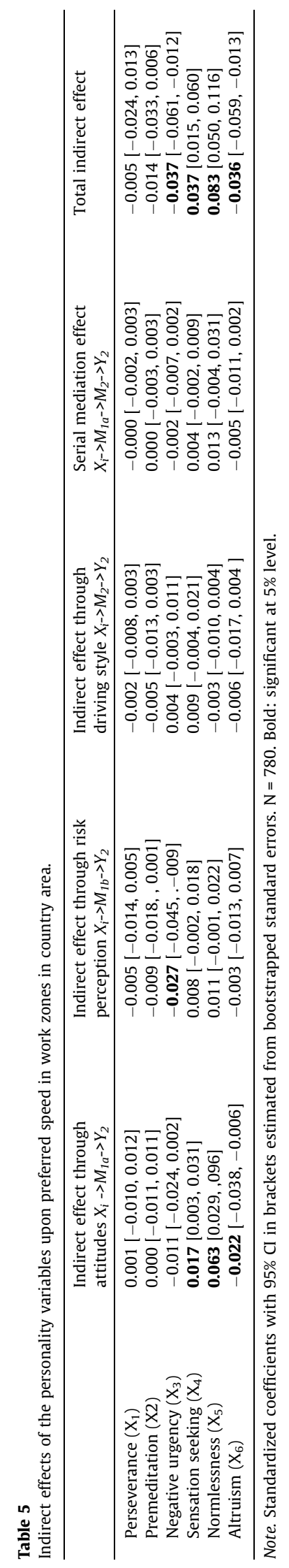


(2014) who also found only indirect effects of this trait on driving behaviour. One possible explanation for those different results is the particularity of samples. Ulleberg and Rundmo (2003) analysed a sample of young drivers while other studies utilized a sample of much older drivers. This could suggest that personality traits affect behaviours in different ways for different groups of drivers with personality having less direct influence on the behaviour of older drivers. High scores on altruism were associated with a more negative attitude towards speeding and a less risky driving style supporting prior findings (e.g. Machin \& Sankey, 2008; Mallia et al., 2015; Ulleberg \& Rundmo, 2003). Drivers scoring high on altruism have more concern for other traffic users which is reflected in less risky driving behaviour. Since interaction effects were not found between altruism and roadwork activity on speed preferences, we can assume that this trait is not dependent on this particular situation to be manifested.

Drivers scoring high on the negative urgency trait preferred lower speeds, which was the opposite of what was expected. However, this trait showed a positive relationship with risk perception, where high scores on negative urgency were associated with high scores on risk perception, having indirect effects on preferred speeds through risk perception. Negative urgency is a facet of the domain neuroticism which is associated with negative emotional states such as anxiety, fear and frustration (Whiteside \& Lynam, 2001). We can assume that drivers scoring high on negative urgency may be more prone to experience negative emotions such as fear or worry at country work zones and, as a consequence prefer lower speeds. Since negative urgency and risk perception only had an effect on preferred speeds at the country work zone, this suggests that a country work zone may incite lower speed preferences for drivers scoring high on negative urgency, probably due to higher risks perceived.

It would be reasonable to assume that drivers who usually have a riskier driving style, in form of committing more often speed violations, would also prefer higher speed at work zones. On the other hand, work zones are specific road situations that reduce drivers' possibility to drive as they would usually drive. A work zone may often impose limits on driving (for example, car queues or narrower lanes) that force drivers to drive in accordance with the road situation. Our results showed that risky driving style was found to have a positive correlation with speed preferences for both work zones, but this correlation was weak. Driving style only showed direct effects on preferred speeds for the built-up area, but this effect was small ( $\beta=0.12$ ). This variable was found to mediate the effects of sensation seeking on preferred speeds in the built-up area, but also presented small total effects. The current results supports the assumption that "behaviour selection is strongly determined by current driving situations, which creates opportunities or constraints for action" (Sagberg et al., 2015, p.1253). Thus, we can assume that drivers' speed preferences at work zones are to a lesser extent influenced by their usual driving style and more dependent on the situation - such as whether visual roadwork activity is present or not.

\subsection{Limitations and future research}

The present study has some limitations that should be noted. The limitations related to the use of videos and generalizability were discussed more thoroughly in a previous paper (i.e. Steinbakk et al., 2017). Furthermore, asking drivers about the speeds they prefer or their self-nominated speeds may not necessary be the same as the speeds they would drive at a work zones (e.g. Debnath, Blackman, \& Haworth, 2015). Still, as pointed by Debnath et al. (2015), self-nominated speeds can provide valuable contribution to understand drivers' individual differences on speed choice at work zones.

The rather low percentage of explained variance in speed preference for both videos in the present study (15-23\%) suggest that a large amount of speed preference for work zones is still unknown and probably dependent upon other situational factors. This low amount of explained variance is quite common within traffic safety research and we did not expect that general measures such as personality traits, attitudes and driving style would predict much of the variance in very specific measures such a preferred speed in a work zone. Future research might address other significant variables to explain speed preferences on work zones.

Common method variance (see Podsakoff, MacKenzie, \& Podsakoff, 2012) may also represent a limitation although its importance has been discussed (Spector \& Brannick, 2009).

One of the most important limitations is related to the relatively low alpha coefficient values on some of the scales intendent to measure personality traits, probably due to the use of short-scale measurement. The low reliability suggest that the scales are "contaminated" by measurement error, resulting in an underestimation of the strength of relationship between the scales used in this study (see e.g. Nunnally, 1991, p. 256-258). Thus, more reliable measurement would probably have increased the strength of the interaction effects between perseverance, normlessness and visible roadwork activity detected in the present study, as well as increasing the strength of the effects detected in the multiple mediation model. A suggestion for future research is thus to avoid the use of short-scale measurement in favour of more comprehensive measurement of the personality traits of interest.

This study has focused on preferred speed as an indicator of risk driving at work zones. However, other behaviours should also be taken into account when discussing safety at work zones. Some examples of other risky behaviour at work zones are merging behaviour (Weng et al., 2015) and lane position (Summala \& Pihlman, 1993). It would be also interesting to investigate the speed preferences between different groups of road users, since it could also be a source of speed heterogeneity at work zones (e.g. Debnath et al., 2015). 
Our results showed significant effects of normlessness on speed preference, thus this is a personality trait that could be investigated further in future studies. For instance, Domenichini, La Torre, Branzi, and Nocentini (2017) found that perceptual treatments that increased the optical density of the field of view led to significant speed reductions and more homogenization of speeds at work zones. Perceptual treatments could be a countermeasure that have the potential to influence drivers scoring high on normlessness, thus other studies are necessary to investigate its potential to affect drivers scoring high on this trait.

\subsection{Implication of the findings}

At a theoretical level, the present study gives an important insight into the understanding of drivers' speed preferences at work zones. Our results confirmed that personality traits have direct effects on attitudes, risk perception and driving style as well as indirect effects on preferred speeds at work zones. Even though the results showed low values of explained variance, it strengthens the hypothesis that some personality traits will depend on contextual factors to be manifested as behaviour (see also Judge \& Zapata, 2014). Identifying the role of personality traits provide an explanation to why drivers react differently on same situation, and why large speed variances occurs in traffic. The knowledge provided is valuable when planning countermeasures, highlighting the importance of targeting interventions and using various types of methods to reach as many drivers as possible.

At a practical level, we can determine that the work zone warning traffic sign alone is not enough to motivate all drivers to select safe speeds. Drivers may lack the motivation to comply with traffic signs when they do not see a reason to do so (Summala \& Hietamäki, 1984). Moreover, some drivers may present contrary expected behaviours even when there is a reason to comply, as was the case for drivers who scored lower on perseverance preferring higher speed for visible roadwork activity area. Their motivations (for instance, not get bored, get over with the work zone as soon as possible, etc.) can override the motivation to prefer lower speeds. From a policy point of view, it may be necessary to use a combination of warning and traffic calming countermeasures at work zones to influence the largest number of drivers. Dependent on drivers' motivations, a high variation in speed will occur. Countermeasures aiming to instigate safer driving behaviour are most likely to succeed in diminishing crashes at work zones (Silverstein et al., 2015), since it forces drivers to a certain speed level not depending on their motivation to comply with signs and regulations. A possible way to influence drivers' motivation is using informational signs that display an information either about the cause, time of completion or length of ongoing roadwork. Those different types of information could be tested to establish if they increase acceptance towards work zone regulations in form of speed compliance. Still, informational signs should be carefully planned to not increase drivers' workload, which in turn could contribute to failure in perceiving relevant information from other warning and regulatory signs. Another practical implication of this study regards safety campaigns. Attitudes and risk perception provide "points of attack" for interventions. The present study showed that attitudes towards speeding had an indirect effect on preferred speeds. Thus, targeting attitudes could have the potential to affect speed preferences at work zones as well (see also Iversen, 2004). Even if there is some evidence that safety campaigns may be less effective in reducing speeds at work zones, they may influence other behaviours such as increased awareness (Summala \& Pihlman, 1993). Informing about the risks linked to work zones have also the potential to influence speed preferences at work zones. The nature of the message used should be adjusted to reach different types of drivers. According to our results, interventions should especially focus on attitudes toward driving speeds among drivers who are sensation seekers and normless.

\section{Conclusion}

The knowledge provided by this study is valuable with a view to increase the effects of interventions at work zones. The assumption that personality traits can explain, to some extent, speed variation at work zones could be supported. Personality traits help to predict risky driver behaviour at work zones on a more global perspective, making possible inferences about the motivation underlying this behaviour. The results also highlight the importance of environmental factors (in this case, visible roadwork activity) in speed preferences. It was revealed to have a more important role in predicting lower speed preferences at work zones than other variables, moreover also interacting with some personality traits having diverse effects on preferred speeds. Efforts to increase work zones' safety can take into account the motivations drivers have to prefer higher speeds, but should also concentrate on physical measures in the traffic environment to induce and motivate safer driving speeds. More research is needed to investigate other variables that can explain the variance on speeds and effective measures to reduce this variance at work zones for different type of drivers.

\section{Acknowledgments}

This research was supported by the Norwegian Public Roads Administration. The authors would like to thank Truls Vaa for the valuable discussions and suggestions to improve the manuscript. 


\section{References}

Akepati, S. R., \& Dissanayake, S. (2011). Characteristics and contributory factors of work zone crashes. In Transportation Research Board 90th Annual Meeting (pp. 11-3769). Washington DC: Transportation Research Board.

Bachoo, S., Bhagwanjee, A., \& Govender, K. (2013). The influence of anger, impulsivity, sensation seeking and driver attitudes on risky driving behaviour among post-graduate university students in Durban, South Africa. Accident Analysis and Prevention, 55, 67-76.

Blackman, R. A., Debnath, A. K., \& Haworth, N. L. (2014). Influence of visible work activity on drivers' speed choice at roadworks. In Proceedings of the 2nd occupational safety in transport conference, CARRS-Q (pp. 1-10). Queensland University of Technology. Accessed from: <http://eprints.qut.edu.au/ $76277 />$.

Conference of European Directors of Roads (2013). State of the art on speed management methods, deliverable D2.1.ASAP - appropriate speed saves all people. In The Transnational Road Research Programme Call 2012: Safety (pp. 1-82).

Costa, P. T., McCrae, R. R., \& Dye, D. A. (1991). Facet scales for agreeableness and conscientiousness: A revision of the NEO Personality Inventory. Personality and Individual Differences, 12(9), 887-898.

Cyders, M. A., Littlefield, A. K., Coffey, S., \& Karyadi, K. A. (2014). Examination of a short English version of the UPPS-P Impulsive Behavior Scale. Addictive Behaviors, 39(9), 1372-1376.

Debnath, A. K., Blackman, R., \& Haworth, N. (2015). A comparison of self-nominated and actual speeds in work zones. Transportation Research Part F: Traffic Psychology and Behaviour, 35, 213-222.

Delhomme, P., Chaurand, N., \& Paran, F. (2012). Personality predictors of speeding in young drivers: Anger vs. sensation seeking. Transportation Research Part F: Traffic Psychology and Behaviour, 15(6), 654-666.

Domenichini, L., La Torre, F., Branzi, V., \& Nocentini, A. (2017). Speed behaviour in work zone crossovers. A driving simulator study. Accident Analysis \& Prevention, 98, 10-24.

Goldenbeld, C., \& van Schagen, I. (2007). The credibility of speed limits on 80 km/h rural roads: The effects of road and person(ality) characteristics. Accident Analysis and Prevention, 39, 1121-1130.

Haworth, N., Symmons, M., \& Mulvihill, C. (2002). Safety of small workgroups on roadways. Report 195. Monash University Accident Research Centre Victoria, Australia.

Høye, A., Elvik, E., Sørensen, M. W. J., \& Vaa, T. (2012). Trafikksikkerhetshåndboken. [The Handbook of Traffic Safety]. Institute of Transport Economics, Oslo. Retrieved from <http://tsh.toi.no/doc647.htm\#anchor_22006-50>.

Høye, A., Phillips, R., \& Hesjevoll, I. S. (2015). Evaluering av E18 Gulli-Langåker: Trafikantenes sikkerhet i anleggsperioden [Evaluation of E18 Gulli-Langåker: Road safety during the construction period]. TØI report 1445. Oslo, Norway: Institute of Transport Economics.

Hu, L. T., \& Bentler, P. M. (1999). Cutoff criteria for fit indexes in covariance structure analysis: Conventional criteria versus new alternatives. Structural Equation Modeling: A Multidisciplinary Journal, 6(1), 1-55.

Iversen, H. (2004). Risk-taking attitudes and risky driving behaviour. Transportation Research Part F: Traffic Psychology and Behaviour, 7, $135-150$.

Jonah, B. A. (1997). Sensation seeking and risky driving: A review and synthesis of the literature. Accident Analysis and Prevention, $29(5), 651-665$.

Judge, T., \& Zapata, C. (2014). The person-situation debate revisited: Effect of situation strength and trait activation on the validity of the big five personality traits in predicting job performance. Academy of Management Journal, amj, 58(4), 1149-1179.

Kohn, M. L., \& Schooler, C. (1983). Work and personality: An inquiry into the impact of social stratification. New Jersey: Ablex Publishing Corporation.

Lajunen, T., Corry, A., Summala, H., \& Hartley, L. (1997). Impression management and self-deception in traffic behaviour inventories. Personality and Individual Differences, 22(3), 341-353.

Lawton, R., Parker, D., Stradling, S. G., \& Manstead, A. S. R. (1997). The role of affect in predicting social behaviours: The case of road traffic violations. Journal of Applied Social Psychology, 27(14), 1258-1276.

Loehlin, J. C. (1998). Latent variable models: An introduction to factor, path, and structural analyses (3rd ed.). London: Lawrence Erlbaum Associates.

Loo, R. (1979). Role of primary personality factors in the perception of traffic signs and driver violations and accidents. Accident Analysis and Prevention, 11 $125-127$.

Lucidi, F., Mallia, L., Lazuras, L., \& Violani, C. (2014). Personality and attitudes as predictors of risky driving among older drivers. Accident Analysis and Prevention, 72, 318-324.

Machin, M. A., \& Sankey, K. S. (2008). Relationships between young drivers' personality characteristics, risk perceptions and driving behaviour. Accident Analysis and Prevention, 40(2), 541-547.

Mallia, L., Lazuras, L., Violani, C., \& Lucidi, F. (2015). Crash risk and aberrant driving behaviors among bus drivers: The role of personality and attitudes towards traffic safety. Accident Analysis and Prevention, 79, 145-151.

McAdams, D. P., \& Pals, J. L. (2006). A new Big Five: Fundamental principles for an integrative science of personality. American Psychologist, 61(3), 204-217.

McCrae, R. R., \& Costa Jr, P. T. (1997). NEO-PI-R: Professional manual (pp. 14-18).

McCrae, R. R., \& Costa, P. T. (1995). Trait explanations in personality psychology. European Journal of Personality, 9, $231-252$.

Näätänen, R., \& Summala, H. (1974). A model for the role of motivational factors in drivers' decision-making. Accident Analysis and Prevention, 6(3), 243-261.

Nunnally, J. (1967). Psychometric theory. New York: McGraw-Hill.

Nunnally, J. (1978). Psychometric theory (2 ed). New York: McGraw-Hill.

Nunnally, J. (1991). Psychometric theory (3 ed). New York: McGraw-Hill.

Pearson, M. R., Murphy, E. M., \& Doane, A. N. (2013). Impulsivity-like traits and risky driving behaviors among college students. Accident Analysis and Prevention, 53, 142-148.

Pedhazur, E. J., \& Schmelkin, L. P. (1991). Measurement, design and analysis. An integrated approach. London: Laurence Erlbaum Associates.

Podsakoff, P. M., MacKenzie, S. B., \& Podsakoff, N. P. (2012). Sources of method bias in social science research and recommendations on how to control it. Annual Review of Psychology, 63, 539-569.

Preacher, K. J., \& Hayes, A. F. (2008). Asymptotic and resampling strategies for assessing and comparing indirect effects in multiple mediator models. Behavior Research Methods, 2008(40), 879-891.

Reason, J., Manstead, A., Stradling, S., Baxter, J., \& Campbell, K. (1990). Errors and violations on the roads: A real distinction? Ergonomics, 33, $1315-1332$.

Sagberg, F., Piccinini, F. B., \& Engström, J. (2015). A review of research on driving styles and road safety. Human Factors, 57(7), $1248-1275$.

Silverstein, C., Schorr, J., \& Hamdar, S. H. (2015). Work zones vs. non-work zones: risk factors leading to rear-end and sideswipe collisions. In Transportation Research Board 93rd Annual Meeting, 14-3840, Washington DC: Transportation Research Board.

Spector, P. E., \& Brannick, M. T. (2009). Common method variance or measurement bias? The problem and possible solutions. In D. Buchanan \& A. Bryman (Eds.), The Sage Handbook of organizational research methods (pp. 346-362). London: Sage.

Steinbakk, R. T., Ulleberg, P., Fostervold, K. I., \& Sagberg, F. (2017). Analysing the influence of visible roadwork activity on drivers' speed choice at work zones using a video-based experiment. Transportation Research Part F: Traffic Psychology and Behaviour, 44, 53-62.

Sümer, N. (2003). Personality and behavioral predictors of traffic accidents: Testing a contextual mediated model. Accident Analysis \& Prevention, 35(6), 949-964.

Summala, H., \& Hietamäki, J. (1984). Drivers' immediate responses to traffic signs. Ergonomics, 27(2), 205-216.

Summala, H., \& Pihlman, M. (1993). Activating a safety message from truck drivers' memory: An experiment in a work zone. Safety Science, 16(5-6), $675-687$.

Ulleberg, P., \& Rundmo, T. (2003). Personality, attitudes and risk perception as predictors of risky driving behaviour among young drivers. Safety Science, 41 (5), 427-443. 
Ullman, G., \& Brewer, M. (2014). Driver Perceptions of trafficcalming versus active enforcement efforts in work zones. Transportation Research Record: Journal of the Transportation Research Board, 2425, 25-31.

Vaa, T. (2007). Modelling driver behaviour on basis of emotions and feelings: Intelligent transport systems and behavioural adaptations. In Modelling driver behaviour in automotive environments (pp. 208-232). London: Springer.

Vaa, T. (2014). From Gibson and Crooks to Damasio: The role of psychology in the development of driver behaviour models. Transportation Research Part F: Traffic Psychology and Behaviour, 25, 112-119.

Weng, J., Xue, S., Yang, Y., Yan, X., \& Qu, X. (2015). In-depth analysis of drivers' merging behavior and rear-end crash risks in work zone merging areas. Accident Analysis and Prevention, 77, 51-61.

Whiteside, S. P., \& Lynam, D. R. (2001). The five factor model and impulsivity: Using a structural model of personality to understand impulsivity. Personality and Individual Differences, 30(4), 669-689. 


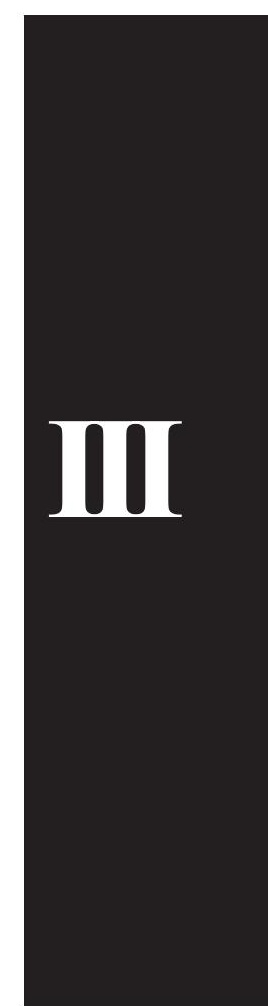





\title{
Effects of roadwork characteristics and drivers' individual differences on speed preferences in a rural work zone
}

\author{
Renata Torquato Steinbakk ${ }^{\mathrm{a}, \mathrm{b}, *}$, Pål Ulleberg ${ }^{\mathrm{a}}$, Fridulv Sagberg ${ }^{\mathrm{c}}$, Knut Inge Fostervold ${ }^{\mathrm{a}}$ \\ ${ }^{a}$ Department of Psychology, University of Oslo, Forskningsveien 3A, 0373, Oslo, Norway \\ ${ }^{\mathrm{b}}$ Norwegian Public Roads Administration, Brynsengfaret 6A, 0667, Oslo, Norway \\ ${ }^{\mathrm{c}}$ Institute of Transport Economics, Oslo, Norway, Gaustadalléen 21, 0349, Oslo, Norway
}

\section{A R T I C L E I N F O}

\section{Keywords:}

Roadwork

Speed preferences

Self-assessment of driving skills

Personality traits

\begin{abstract}
A B S T R A C T
Work zone safety from a psychological perspective has received little attention in scientific literature. Therefore, the present study aims to explore the influence of roadwork characteristics and drivers' individual differences in terms of personality traits and self-assessment of driving skills on speed preferences in a rural work zone. Eight hundred forty-five Norwegian drivers stated their preferred speed for ten pictures of a rural work zone with a $50 \mathrm{~km} / \mathrm{h}$ reduced speed limit without knowing the speed limit. The results showed that the preferred speeds were greater than the actual reduced speed limit for all pictures. The standard deviations were quite high (from 11 to $14 \mathrm{~km} / \mathrm{h}$ ), indicating that drivers have a rather high variation in preferred speeds. A multilevel model was used to analyse the effects of the variables on speed preference. The results indicated that preferred speeds increased with age, higher scores on the normlessness scale, and higher self-assessment of own driving skills. As for the roadwork characteristics, speed increased with the presence of road markings by $11 \mathrm{~km} / \mathrm{h}$, while it decreased by $9 \mathrm{~km} / \mathrm{h}$ with the presence of road delineators and by $5 \mathrm{~km} / \mathrm{h}$ with barriers. Implications for respect for the reduced speed limits in work zones were discussed, and recommendations of other countermeasures were presented.
\end{abstract}

\section{Introduction}

Speed is an important risk factor when it comes to traffic safety. It is well established in the literature that high speed increases the probability of a crash and intensifies injury severity (Aarts and van Schagen, 2006; Elander et al., 1993; Elvik, 2013). The same issue applies to safety in work zones, in which a high number of speed violations and wide speed variance represent the main risk factors (Advanced Research on Road Work Zone Safety Standards in Europe Consortium, 1998; Akepati and Dissanayake, 2011; Bai et al., 2010; Silverstein et al., 2014). Crash severity in work zones was also found to be higher compared to other roads (Høye et al., 2015; Qi et al., 2013; Wang et al., 1996). Since high speeds are a considerable issue concerning work zone safety, it is valuable to obtain a deeper understanding of how different factors may affect driving speed.

\subsection{Speed choice and speed limit credibility in work zones}

Drivers' speed choice is not always an objective rational decision. As pointed out by Elvik (2010), drivers tend to ignore the environmental impacts of speed, perceive incorrectly the relationship between speed and travel time, and underestimate the increase in risks associated with increased speeds. Elvik furthermore argued that if posted speed limits did not exist, mean speeds would be higher due to the wide spectrum of drivers' speed preferences. According to him, the lack of objective rationality in drivers' speed choices is a strong argument for the use of posted speed limits to guide and regulate this choice. Posted speed limits are thus an important traffic safety measure, as they stipulate the highest safe speed for a road section for all drivers, independently of their speed preferences.

However, disregard for traffic signs, particularly speed limits signs, was a risk behaviour found to be associated with severe crashes in work zones (Li and Bai, 2009). Several studies on speed choice in work zones demonstrated that most drivers drove at speeds over the posted speed limits (e.g. Bai et al., 2010; Debnath et al., 2014, 2015; Domenichini et al., 2017; Finley et al., 2015; Ullman and Brewer, 2014; Rahman et al., 2017). One explanation of why speed limit compliance is so low in work zones is that drivers only adapt their speed when they see a

\footnotetext{
* Corresponding author at: Norwegian Public Roads Administration, Brynsengfaret 6A, 0667, Oslo, Norway. Tel.: + 4748281647.

E-mail addresses: renata.steinbakk@vegvesen.no (R.T. Steinbakk), pal.ulleberg@psykologi.uio.no (P. Ulleberg), fs@toi.no (F. Sagberg), k.i.fostervold@psykologi.uio.no (K.I. Fostervold).
} 
reason for it. Summala and Hietamäki (1984) argued that sign compliance is a matter of motivation, with drivers relying more often on their own experience, expectations, and context than on traffic signs when adapting their driving behaviours. This assumption is supported by many studies, which have demonstrated that drivers were more compliant with posted speed limits near work activity areas at which roadworkers, machinery and work activity are often present (Benekohal et al., 1992; Benekohal and Wang, 1994; Debnath et al., 2014; Finley et al., 2015; Paolo and Sar, 2012). Additionally, the reduced speed limits in short-term work zones seem to be more effective compared to speed limits in long-term work zones (Hou et al., 2013). The authors suggested that since short-term work zones are shorter in duration, drivers are more likely to see roadworkers present at the area and are therefore more motivated to comply with the posted speed limits. Yet, it is necessary to mention that even though speed reductions were more often observed in situations in which the speed limits were more credible (i.e., near roadwork activity), an increase in speed variance was nevertheless also observed (Debnath et al., 2014; Finley et al., 2015), which may be due to drivers' different reactions to traffic signs and work zone elements. One example of how drivers react differently in the same situation can be seen in a field study conducted by Benekohal et al. (1992) in which the speed profile patterns of drivers in one work zone were observed. The results showed that about $26 \%$ of drivers reduced their speeds after passing the first speed limit sign but increased their speeds before reaching the work activity area, then again slowed down when arriving at the work activity area. Eleven percent of all drivers travelled faster than the posted speed limit when passing the first sign but slowed down when arriving at the work activity area. Only $12 \%$ reduced their speeds after passing the first signs and kept their speeds until they had passed the entire work area. These findings also indicate that even though most drivers decreased their speed, their speeds were still higher than the posted speed limit (about $70 \%$ of car and $55 \%$ of truck drivers). Paolo and Sar (2012) also found that speeds at the beginning of a work zone were higher than the posted speed limit and that nearly $80 \%$ of all drivers drove above this limit. Further analysis of the data from Benekohal et al. (1992) showed that the speed of a vehicle throughout the work zone was related to its initial speed; that is, drivers with higher initial speeds had higher speeds throughout the work zone compared to drivers with lower initial speeds (Benekohal and Wang, 1994). Those results support the assumption that drivers react differently to the roadwork environment and reduced speed limits, but do not provide suggestions as to why this variation occurs. One approach to addressing the variance between drivers' preferred speeds in work zones is to investigate their personal characteristics and how these might affect their speed choice.

Näätänen and Summala (1974) argued that drivers enter traffic with different types of motivations, which are influenced, among other things, by drivers' personalities and transient motivations (i.e., states of mind). Even though personality traits were found to be weak predictors of accidents (Wåhlberg et al., 2017), it is assumed that the willingness to commit driving violations might be explicable in terms of personality (Elander et al., 1993). Furthermore, Ulleberg and Rundmo (2003) noted that personality traits can help predict risky driver behaviour according a more global perspective and lead to inferences of the motivations underlying behaviours. Several studies have addressed the association between personality and driving behaviours. For instance, personality traits such as sensation-seeking and impulsivity were found to be correlated positively with overall traffic violations (Constantinou et al., 2011). Personality traits have moreover been shown to influence how drivers react to different traffic situations. The study conducted by Goldenbeld and van Schagen (2007) found that drivers scoring high on the trait sensation-seeking were less influenced by road characteristics and had higher preferred speeds for rural roads compared to other drivers. Using a video experiment, Steinbakk et al. (2019) found that drivers scoring high on normlessness tended to prefer higher speed in work zones, but that this effect was dependent upon the presence of roadwork activity. These results point to the fact that the relationship between personality traits and behaviour may be dependent of the situation strength, that is, whether the context provides enough of the clues and opportunities that would limit or enhance the possibility of a trait being expressed in behaviour (for a deeper discussion on the person-situation debate, see Judge and Zapata, 2015).

Another interesting factor to explain drivers' speeds is how they evaluate their driving skills. Drivers who have unrealistic beliefs about their driving skills may perceive the situation to be less dangerous and drive in a riskier manner (Martinussen et al., 2014). Goldenbeld and van Schagen (2007) found large differences between what drivers stated as preferred speeds and what they perceived as safe speeds for several road scenes. Preferred speeds were overall higher compared to the speed that was perceived as safe. One hypothesis is that drivers might assess their driving skills favourably, thinking that they can drive faster than the speed they otherwise consider safe. These results could explain the findings of Benekohal et al. (1993) who showed that most drivers who knew they were speeding over the limit at the work zone ( $94 \%$ of drivers who were interviewed) reported feeling that their speed was safe enough for the road conditions. Other studies have demonstrated that drivers who had more driving experience tended to evaluate their own driving abilities more positively (Tronsmoen, 2008), and drivers who rated their driving skills as high, or perceived themselves as more skilful than the average driver, had a greater tendency to engage in more risky behaviour (Horswill et al., 2004; Martinussen et al., 2014). Thus, self-assessment of driving skills may provide helpful information with which to understand speed preferences in work zones.

Considering the studies presented here, the present study aimed to explore the effects of road characteristics and drivers' individual differences, in terms of specific personality traits and self-assessment of driving skills, on speed preferences in a rural work zone. We hypothesised that drivers with high evaluations of their driving skills, drivers who have lower barriers against socially unapproved behaviour (trait normlessness), drivers who lack the ability to remain focused on a task (trait perseverance), and drivers who often tend to display impulsive behaviours influenced by negative emotions such as distress (trait negative urgency) would prefer higher speeds. As for the effects of road characteristics, we predicted that situations that presented clearer and adequate indications of what behaviour is expected or appropriate would influence the effects of personality traits on speed preferences (see also Judge and Zapata, 2015). Another interesting question was how much personality trait variables contribute to explaining preferred speeds when the road characteristics were controlled for.

\section{Method}

\subsection{Participants and procedure}

Participants were randomly drawn from an existing panel of the independent survey bureau Respons Analyse and invited by e-mail to participate. In total, 845 Norwegian drivers responded to an online questionnaire. First, the informed consent was presented. Participants were informed that participation was anonymous and that the data could not be retraceable to the individual. After agreeing to participate, participants completed the questionnaire. Of the respondents, $57 \%$ were male and $43 \%$ female. Their mean age was 51.47 (SD $=15.79$ ), ranging from 18 to 91 years old, with an average of 32 years $(S D=15.30)$ of holding a driver's licence. A plurality of participants had driven through a work zone one to three times in the past month (29\%), followed by one to two days weekly (23\%) and five to seven days weekly (20\%). 


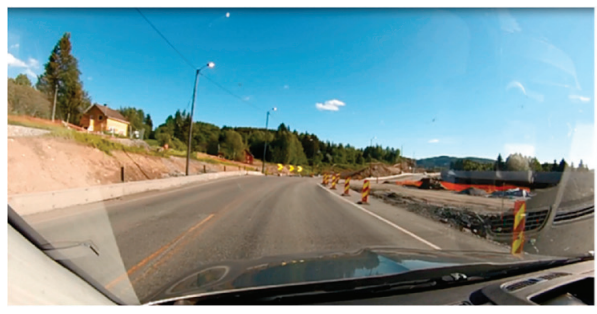

Picture 02

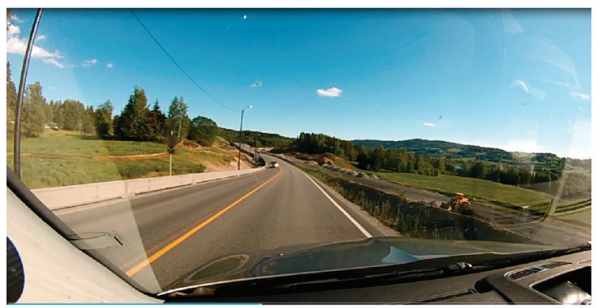

Picture 06

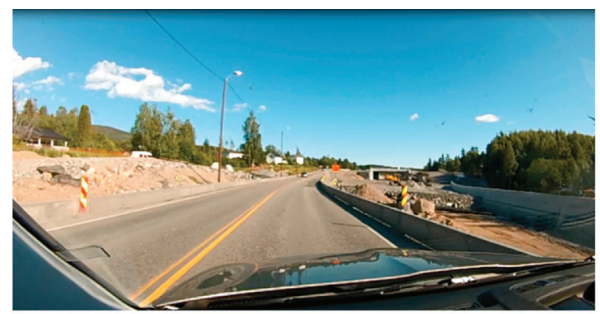

Picture 05

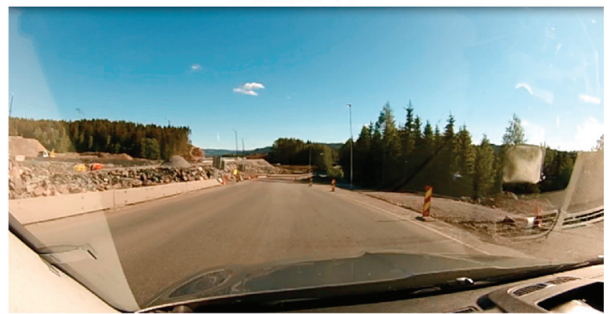

Picture 07

Fig. 1. Example of pictures used in the study. Speed limits were reduced to $50 \mathrm{~km} / \mathrm{h}$ for all depicted road sections.

\subsection{Materials and design}

Ten pictures of a real work zone were used. The road scenes were extracted from a video of one rural work zone in Norway. The video was taken from the perspective of the driver of a moving car. The screenshots were captured directly after passing a $50 \mathrm{~km} / \mathrm{h}$ reduced speed limit sign; however, the participants did not receive any information about the current speed limit. Fig. 1 displays examples of the road scenes used in the study.

A within-subjects design was used, in which all pictures were presented to all participants. The pictures were presented in a randomised order to rule out order effects. Participants received instructions to state at what speed they would prefer to drive through the depicted road section.

\subsection{Measures}

\subsubsection{Dependent variable}

Participants were instructed to state at what speed, in kilometres per hour, they would prefer to drive if they were driving on the road section displayed in each picture. The mean scores of preferred speeds were the dependent variable.

\subsubsection{Roadwork characteristics and drivers' individual differences}

The roadwork characteristics depicted on the pictures that were analysed were (1) curve: yes/no; (2) barriers (guardrail or jersey barriers) on same side: yes/no; (3) centre road marking: yes/no; and (4) road delineators (vertical panel or chevron signs): yes/no. The coding used for each picture is provided in the Table A1.

Three personality traits were selected which were found in a previous study to have a significant effect on preferred speeds in work zones (Steinbakk et al., 2019). The first trait was perseverance (see Whiteside and Lynam, 2001), which refers to the "individual's ability to remain focused on a task that may be boring or difficult" ( $p$. 685). The second trait was negative urgency, referring to the "tendency to commit rash or regrettable actions as a result of intense negative affect" (Whiteside and Lynam, 2001, p. 677). Those traits comprised four items each and were measured on a four-point scale ranging from "strongly disagree" to "strongly agree". The third trait was normlessness, from Kohn and Schooler (1983), which refers to the "individual's belief that it is acceptable to do whatever [one] can get away with" ( $p$. 87). This trait consisted of four items measured on a five-point scale ranging from "strongly disagree" to "strongly agree".

The self-assessment of driving ability was measured using the questionnaire developed by Tronsmoen (2008) for the Norwegian context. The instrument comprised 22 items. Participants needed to indicate to what degree they agree with the statements, on a five-point scale from "very untrue" to "very true". A high score on the scale indicated a more confident evaluation of the participant's own driving skills, while low scores indicated an average to lower confidence in driving skills.

\subsubsection{Demographic variables}

The demographic variables collected were gender, age, number of years holding a driver's licence, and frequency of driving through work zones (exposure).

\subsection{Statistical analysis}

To test whether variation in preferred speed could be explained by the proposed predictors, multilevel modelling (MLM) was employed. Multilevel modelling is advantageous with the kind of data used in the present study since each participant rated preferred speed based on 10 pictures. The repeated measurements are thus nested within participants, meaning that the assumption of independence of residuals can be violated. Multilevel modelling takes this kind of dependency into account by specifying that each of the repeated measurements (level 1) are nested within individuals (level 2) (see Hox, 2010). Ignoring such effects gives biased estimates of standard error, which could lead to incorrect inferences about the statistical significance of the effects of the predictors. Data were analysed using IBM SPSS, Version 25.0. Preferred speed was the outcome variable, and random intercepts for each participant were included in the multilevel model. Only fixed effects of the predictors were estimated. 
Table 1

The mean and standard deviations (SD) of preferred speeds for all pictures.

\begin{tabular}{lll}
\hline Picture & $\begin{array}{l}\text { Preferred speed }(\mathrm{km} / \mathrm{h}) \\
\text { Mean }\end{array}$ & S.D. \\
\hline 1 & 67.05 & 11.42 \\
2 & 53.93 & 12.82 \\
3 & 68.60 & 12.89 \\
4 & 61.81 & 11.98 \\
5 & 57.51 & 12.33 \\
6 & 76.60 & 10.55 \\
7 & 52.99 & 12.96 \\
8 & 70.85 & 12.94 \\
9 & 60.62 & 13.56 \\
10 & 70.12 & 12.57 \\
\hline
\end{tabular}

Note. All differences between preferred speed and posted speed limit were found to be statistically significant at the 0.001 level using one-ample $t$-test.

\section{Results}

\subsection{Credibility of speed limits: means of preferred speeds and standard} deviations for all scenes

The mean preferred speed for each picture is presented in Table 1. The mean preferred speed for all road scenes was $63.98 \mathrm{~km} / \mathrm{h}$ (SD $=9.35 \mathrm{~km} / \mathrm{h}$ ). One-sample $t$ tests were performed to analyse the level of credibility of a $50 \mathrm{~km} / \mathrm{h}$ speed limit for all road scenes. Credibility of speed limit was operationalised corresponding to the definition proposed by Goldenbeld and van Schagen (2007), that is, as the difference between the preferred speed limit and the actual speed limit, where the larger the difference, the lower the credibility. The results of the onesample $t$ tests showed that drivers' preferred speeds differed significantly from the actual speed limit $(50 \mathrm{~km} / \mathrm{h})$ for all road pictures. The level of credibility of the speed limit varied between the pictures, with the lowest credibility for picture 6 (difference of $27 \mathrm{~km} / \mathrm{h}$ ) and the highest credibility for picture 7 (difference of $3 \mathrm{~km} / \mathrm{h}$ ) (see Fig. 1).

A one-way repeated measure ANOVA was conducted on speed preferences for all pictures. There was a significant effect of picture on speed preferences $\left(F(9,819)=449.65, p<0.001, E t a^{2}=0.83\right)$, indicating that the differences between the speed at which drivers would prefer to drive in different work zone sections were quite large, even though all scenarios had $50 \mathrm{~km} / \mathrm{h}$ speed limits. The standard deviations were also large, with the highest standard deviation at $13.6 \mathrm{~km} / \mathrm{h}$ and the lowest at $10.6 \mathrm{~km} / \mathrm{h}$.

\subsection{The relationship between drivers' characteristics and preferred speeds}

Correlations between drivers' characteristics, personality traits, selfassessment of driving skills, and mean scores for preferred speeds are presented in Table 2 . The table also displays $\alpha$ values (internal consistency) for the measures of individual characteristics, varying from
Table 3

Multilevel analysis estimating the influence of roadwork characteristics and drivers' characteristics on preferred speed in roadwork areas. Unstandardised regression coefficients.

\begin{tabular}{llll}
\hline Predictor variable & Regression coefficient (SE) & $p$ value & $95 \% \mathrm{CI}$ \\
\hline Intercept & $48.64(3.56)$ & $<0.001$ & {$[41.64,55.63]$} \\
Model 1:Roadwork characteristics & $0.85(0.22)$ & $<0.001$ & {$[0.40,1.29]$} \\
Curve $^{\mathrm{a}}$ & $-5.14(0.26)$ & $<0.001$ & {$[-5.66,-4.62]$} \\
Barriers same lane $^{\mathrm{a}}$ & $10.89(0.26)$ & $<0.001$ & {$[10.37,11.41]$} \\
Centre road marking $^{\mathrm{a}}$ & $-8.63(0.22)$ & $<0.001$ & {$[-9.06,-8.19]$} \\
Road delineators $^{2}$ by model 1 & 0.19 & & \\
$R^{2}$ & & \\
Model 2: Drivers' characteristics & $-0.57(0.67)$ & 0.394 & {$[-1.90,0.74]$} \\
Gender & $0.10(0.02)$ & $<0.001$ & {$[0.06,0.14]$} \\
Age & $2.37(0.49)$ & $<0.001$ & {$[1.40,3.34]$} \\
Normlessness & $-0.74(0.61)$ & 0.225 & {$[-1.95,0.45]$} \\
Perseverance & $0.09(0.52)$ & 0.856 & {$[-0.92,1.11]$} \\
Negative Urgency & $1.57(0.60)$ & 0.009 & {$[0.39,2.75]$} \\
Mean assessment skills & 0.04 & & \\
$\Delta R^{2}$ by model 2 & 0.23 & & \\
$R^{2}$ by model 1 2 & & & \\
\hline
\end{tabular}

Note. Multilevel analysis with fixed effects of predictors from Model 2 presented, including a random intercept for participants. Covariance matrix of within-subject measurements was variance components. Ten repeated measurements (level 1) nested within each participant (level 2). N level $1=8450$ $\mathrm{N}$ level $2=845 . \mathrm{R}^{2}=0.23$.

a $0=$ not present, $1=$ present.

b $0=$ male, $1=$ female.

0.51 for normlessness to 0.92 for skill assessment. For preferred speeds, the results showed significant relationships with all variables except work zone exposure and the trait negative urgency. Age had the strongest relationship with mean preferred speeds, where the older the driver, the higher the mean preferred speeds. Results also indicated that drivers who scored higher on normlessness, as well as drivers who had higher self-assessment of their driving skills, preferred higher speeds. High assessment of driving skills was negatively related to gender, with male drivers having a more positive assessment of their driving skills.

\subsection{Effect of roadwork, drivers' characteristics and self-assessment of driving skills on preferred speeds}

First, road characteristics were entered in the multilevel analysis presented in Table 3. The four road characteristics explained 19\% of the variance in speed preferences. The presence of centre road marking gave the strongest influence upon preferred speed by on average increasing preferred speed by almost $11 \mathrm{~km} / \mathrm{h}$. Having road delineators present on the side of the road, however, led to a relatively large reduction of speed - on average $8.6 \mathrm{~km} / \mathrm{h}$. Likewise, the presence of barriers (guardrails or jersey barriers) on the side of the driving direction was estimated to lead to a reduction of speed of $5.1 \mathrm{~km} / \mathrm{h}$. The

Table 2

Pearson product-moment correlations between drivers' characteristics and preferred speeds $(\mathrm{N}=845)$.

\begin{tabular}{|c|c|c|c|c|c|c|c|c|}
\hline & 1 & 2 & 3 & 4 & 5 & 6 & 7 & $\alpha$ \\
\hline Gender $^{1}$ & - & & & & & & & - \\
\hline Age & $-0.15^{* *}$ & & & & & & & - \\
\hline Work zone exposure ${ }^{2}$ & $0.14 * *$ & 0 & & & & & & - \\
\hline Assessment of skills & $-0.30^{* *}$ & 0.02 & $-0.08^{*}$ & & & & & 0.92 \\
\hline Perseverance & $-0.07 *$ & $-0.10 * *$ & -0.03 & $-0.09^{*}$ & & & & 0.58 \\
\hline Normlessness & $-0.12^{* *}$ & $-0.14 * *$ & $-0.07^{*}$ & $0.22^{* *}$ & -0.04 & & & 0.51 \\
\hline Negative Urgency & $-0.07^{*}$ & $0.16^{* *}$ & 0 & $-0.15^{* *}$ & $0.12 * *$ & $0.12^{* *}$ & & 0.76 \\
\hline Mean preferred speeds & $-0.10^{* *}$ & $0.19^{* *}$ & -0.02 & $0.13^{* *}$ & $-0.007^{*}$ & $0.16^{* *}$ & 0.27 & - \\
\hline
\end{tabular}

Note. The values were 1 : gender, $1=$ male and $2=$ female; 2 : work zone exposure, $1=$ more than one time weekly and $2=$ less than three times monthly; * $\mathrm{p}<0.05 ; * * \mathrm{p}<0.001$. 
presence of an approaching curve led to an unexpected increase in preferred driving speeds, but only a small increase of $0.85 \mathrm{~km} / \mathrm{h}$.

Adding drivers' characteristics to the model increased the amount of explained variance by $4 \%$. Normlessness was significantly related to preferred speed: The higher the normlessness score, the higher the preferred speed. The estimated effect suggested that the difference between drivers at each end of the normlessness scale was almost $10 \mathrm{~km} / \mathrm{h}$ in preferred speed. Self-assessed driving skills was also related to preferred speed in the expected direction: The more confident the driver was in their own skills, the higher the level of preferred speed. The difference between driver scoring at each end of the skill assessment scale was about $6 \mathrm{~km} / \mathrm{h}$.

Preferred speed was found to increase significantly with driver age. This effect of age was rather small: The difference in preferred speed between, for example, a 30-year old driver and a 40-year old driver was estimated to be $1 \mathrm{~km} / \mathrm{h}$. Gender, negative urgency, and perseverance were not found to be significantly related to preferred speed.

\section{Discussion}

The present study aimed to explore the effects of road characteristics and drivers' individual differences, in terms of specific personality traits and self-assessment of driving skills, on speed preferences at a rural work zone. The high variation in preferred speeds among the pictures shows that different road sections are evaluated by various means, even though they all have the identical $50 \mathrm{~km} / \mathrm{h}$ posted speed limit. The drivers in this study were not aware of the posted speed limit and stated their mean preferred speeds for all road scenes as being $64 \mathrm{~km} / \mathrm{h}$. The discrepancies between the preferred speeds and actual posted speed limits indicate that the situations do not always provide the drivers with the necessary cues to understand what the appropriate behaviour is. Since participants did not know the speed limits, we could speculate that preferred speed would probably be closer to the limit if they had knowledge of this limit. However, since wide speed variance is a common risk factor in work zone (e.g., Advanced Research on Road Work Zone Safety Standards in Europe Consortium, 1998) this information is not guaranteed to diminish speed preference heterogeneity among drivers in this study. In real traffic, some drivers will choose to comply with the speed limit signs, while others will think that the value of the speed limit is too low and decide themselves the speed at which to drive. Variable speeds limits are supposed to have better effects on speed compliance, since they can be adjusted according to the road situation. In a simulator study, van Nes et al. (2010) found that the dynamic speed limits were perceived as more credible (compared to static speed limits) for some situations. Even though many positive aspects are associated with changing the value of the speed limits according to real-time changes in road conditions, it is also a point of concern whether drivers will be aware of the speed limit changes as they occur. Several studies have found that changes in traffic signs are often not perceived, especially if drivers are not looking for such a change, if they are familiar with the route, or if the changes are small (Harms and Brookhuis, 2016; Martens and Fox, 2007). Thus, the use of dynamic speed limits in work zones should be carefully investigated. As noted by Harms and Brookhuis (2016), even though the consequences of missing a change in increase of speed limit from 50 to $70 \mathrm{~km} / \mathrm{h}$ may be small, missing a change from 70 to $50 \mathrm{~km} / \mathrm{h}$ turns drivers into serious speed offenders by negligence alone. Another important question is whether a single speed limit value would be credible for all drivers. While studies indicate that it is impossible to have one speed limit that is equally credible for all drivers (Goldenbeld and van Schagen, 2007; Lee et al., 2017), it is reasonable to assume that a speed limit credible to most drivers could increase speed compliance and diminish mean speeds and speed variance in work zones. The results found by Debnath et al. (2014) could support this assumption. They found that speed behaviour in work zones was significantly influenced by the speeding characteristics of surrounding traffic where drivers were more likely to speed when other vehicles were also speeding. For this reason, making the speed limit more credible for most drivers has a potential to increase overall safety in work zones. An indication of what speed limit would be more credible can be achieved by checking speeds at the early stages of the work and adjusting the speed limit closer to the mean speeds. If the risk analysis suggests that a reduced speed limit is the best limit for safety reasons, countermeasures that enhance situational cues of a work zone should be used in addition to the speed limits.

Results from the multilevel analysis show that roadwork characteristics explained nearly $20 \%$ of the variance in speed preferences, where road delineators and barriers gave the strongest large reduction of speed preference. Vertical delineators or barriers are countermeasures that act as perceptual measures, while cones passing through the drivers' peripheral vision may lead to an illusion of increased speeds. A field study by Allpress and Leland Jr. (2010) tested for the effects of both uneven and even cone arrangements at a work zone. They found that the speeds decreased in both conditions, with a greater reduction when the cones were arranged in a random spacing. This effect was also maintained into the work activity area (without any cones), indicating that the cone arrangements had generalising effects on speeds. Since delineators are easily implemented and removed, they can be used at the beginning of work areas, with better effects when they are arranged in an uneven manner. Barriers separate physically the traffic lane from the work site, and at a road where they were present, a $5 \mathrm{~km} / \mathrm{h}$ decrease in preferred speeds was observed. Delineators and barriers provide situation cues that indicate to drivers that the road is not in a normal state and that speed adjustment is necessary. Our results also indicated that for roads in the worst conditions (in terms of worn out or non-existence centre road markings), drivers preferred lower speeds. The presence of centre road marking gave the strongest influence in preferred speeds, with an increase of almost $11 \mathrm{~km} / \mathrm{h}$. At places with apparently better road conditions, or at places in which the environmental cues are inconspicuous, other perceptual measures (such as delineators) should be used together with reduced speed limits to achieve better compliance. We should add that, even though the presence of centre road marking led to an increase in preferable speeds, we do not have enough data to recommend its removal from work zones. Road marking in a work zone may provide guidance to drivers on lane position; however, apparent new road marking in work zones may indicate to drivers that the road is in good condition; thus, other countermeasures that increase the situational cues for the "work zone situation" should be considered. Our results surprisingly showed that the presence of a curve led to an increase in preferred speeds, which is contrary to previous studies (e.g., Goldenbeld and Van Schagen, 2007). However, this increase was rather small $(1 \mathrm{~km} / \mathrm{h})$, and an explanation may be that the curves depicted in the scenes used in this study did not seem very sharp. Summarising the effects of roadwork characteristics, we can conclude that strong environmental cues that clearly indicate that the area was a work zone (e.g., presence of delineator, barriers, and weak road markings), influenced the preferred speeds to be lower.

Our results showed that the variables encompassing drivers' characteristics only added $4 \%$ to the amount of explained variance in the model. We can argue that the traffic environment is a place that constrains to some extent the expression of individual differences, since there are rules and regulations that all drivers must follow. Thus, driving could be regarded a "strong situation" (see Judge and Zapata, 2015), which could explain why we found that driver's characteristics only explained a small amount of explained variance. Moreover, driving abilities are to some degree equivalent, since all drivers are required to pass a driving test to be allowed to drive. In this sense, drivers should present low variance in behaviour (in the present case, low variance in speed preferences) across various personality traits, which was not the case in the present study. Older and male drivers tended to prefer higher speeds; however, only age was a significant predictor for speed preference. These results are supported by studies that demonstrated that middle-aged drivers and males are more often involved in fatal 
crashes in work zones (Norwegian Public Roads Administration, 2011). The trait normlessness was the only personality trait that was significantly related to preferred speed, where drivers scoring higher in the trait preferred higher speeds. Higher normlessness scores were found previously to be associated with more positive attitudes towards speeding, which in turn was related to higher preferred speeds in work zones (Steinbakk et al., 2019). Normlessness was also found to be positively correlated with speeding, risk taking in traffic, accidents, and near-accidents (e.g., Iversen and Rundmo, 2002; Machin and Sankey, 2008; Steinbakk et al., 2019; Ulleberg and Rundmo, 2003; Yang et al., 2015). Individuals scoring high on this trait are supposed not to care much about violating the rules if it functions as a way to satisfy their motives or achieve their goals. Providing visible and unambiguous situational cues in the work zone has the potential to prevent an eventual manifestation of this personality trait. As demonstrated by Steinbakk et al. (2019), when there was visible roadwork activity, individuals scoring high in this trait preferred lower speeds. Another interesting result was that drivers scoring high in the normlessness trait also tended to assess their skills more favourably. Summala (1988) argued that, even though the driver is motivated to escape or avoid the experience of risk, they often use the road to satisfy their motives of mobility. According to him, the adaptation to risk is largely a function of increasing self-confidence, because drivers' feelings of uncertainty (that would have inhibitory effects) diminish as the confidence in their control skills increases, which tends to eliminate conscious attention to safe driving practices. Indeed, Horswill et al. (2004) found that drivers who considered themselves more skilful reported faster driving speeds and tended to also consider themselves more skilful at hazard perception. Drivers scoring high in normlessness and assessing their driving skills as high may think that they are entitled to choose whatever speed they find acceptable. Providing reasons for the speed limit (e.g., using other perceptual or barriers countermeasures) may influence their perception and thus their speeds. The situational cues should provide guidance as to what kind appropriate behavioural responses are correct for a specific situation (see Judge and Zapata, 2015). Traffic safety campaigns can also focus on human limitations of perception and give drivers some tools for a "reality check".

The present study has some limitations that should be noted. An important issue is related to external validity. Pictures provide limited information compared to actual driving and may not yield comprehensive results of drivers' speed choices in real life. Debnath et al. (2015) found that asking drivers about their self-nominated speeds did not necessarily produce answers that were the same as the speeds they would drive in a work zone. However, as they pointed out, asking drivers about their speeds can still be helpful for understanding how their individual differences may affect their actual speeds in real traffic. The advantage in using an online questionnaire and pictures to investigate speed preferences is that these permit the researchers to collect data that otherwise would be impossible or difficult to collect in the field. Since the results of the present study corroborate results from field studies in work zones, we can assume that they are rather valid. A deeper discussion on external validity of studies using photographs is provided by Goldenbeld and van Schagen (2007) and by Steinbakk et al. (2017), (2019). Further studies could combine different methods, such as observation or use of simulators, to validate the use of pictures to assess drivers' speed choices in different traffic situations.

Methods using self-reports on preferred speeds should always be critically analysed. For instance, participants may be prone to list a lower preferable speed than the speed they would choose in real life. Still, we could show that preferable speeds were highly different among drivers and among road scenes, which is also corroborated by numerous field studies. Another issue concerns the self-assessment of driving skills. There is evidence that the association between assessment of driving skills and actual driving skills is not always accurate. For instance, Martinussen et al. (2017) found that more experienced drivers were most inaccurate in their self-assessments of hazard prediction, hazard detection, and overtaking skills when driving in a simulator. Nonetheless, it is interesting to investigate drivers' own self-assessment of driving skills, whether accurate or not, since it can help to understand speed preferences in work zones.

Another limitation that should be acknowledged is that this study only examined one work zone with a limited number of road characteristics. This also may limit the generalisability of the results to situations in other work zones. For this reason, other types of work zones and different traffic and weather conditions (such as night-time, rainy weather, etc.) should be further explored. It would be also valuable to investigate additional roadwork countermeasures and how they could influence each other.

The low percentages with which the variables analysed in this study explain variance in speed preferences suggest that other variables should be further investigated to increase the understandings of drivers' behaviour in work zones. A suggestion for future research is to investigate other variables such as social pressure and subjective risk of police control. It is nevertheless worth mentioning that it is not unusual within traffic safety research to find low amounts of explained variance, especially when general measures (such as personality traits) are used to predict highly specific measures (such as speed in a work zone).

\section{Practical implications and conclusions}

Based on the results presented here, we can assume that posted reduced speed limits in work zones may not alone be the best way to increase safety in work zones, especially if the road appears to be in a good condition and no further countermeasures are used. However, reduced speed limits could contribute to increased speed violations, especially at roads perceived to be in better condition (e.g., with centre road markings). At those places, other traffic countermeasures are necessary to justify the speed limit reduction and increase the situational cues that indicate the appropriate behaviour (i.e., slow down). In this study, the presence of road delineators contributed to a reduction of nearly $9 \mathrm{~km} / \mathrm{h}$ in speed preferences. We can also argue that perceptual countermeasures, beyond increasing speed perception, are objects that can be run over and potentially damage ones' vehicle. This would provide a motivation to drivers to slow down and be more careful when driving in those areas.

Work zones are often a complex traffic environment, in which the safety of both roadworkers and road users should be part of a risk assessment. Road authorities should bear in mind that posted reduced speed limits should be used with caution. If the environment does not provide enough cues to support this limit, they may not appear credible to all drivers and could intensify speed variation and increase crash risks. Other measures should be used in strategic locations at the work zone, especially in locations in which the road appears to be in good condition, to provide enough situational cues to encourage most drivers to slow down.

The results of our study point to the fact that cues in the environment are a substantial factor in providing drivers a reason for the reduced posted speed limit and important to understand their speed preferences and speed limit credibility in work zones.

\section{Declaration of Competing Interest}

The authors declare that they have no known competing financial interests or personal relationships that could have appeared to influence the work reported in this paper.

\section{Acknowledgments}

The authors are grateful to Norwegian Public Roads Administration, Norway for funding the study. We are also grateful to Morten Hafting for the work zone video. 
Appendix A

Table A1

Pictures and coding of road characteristics.

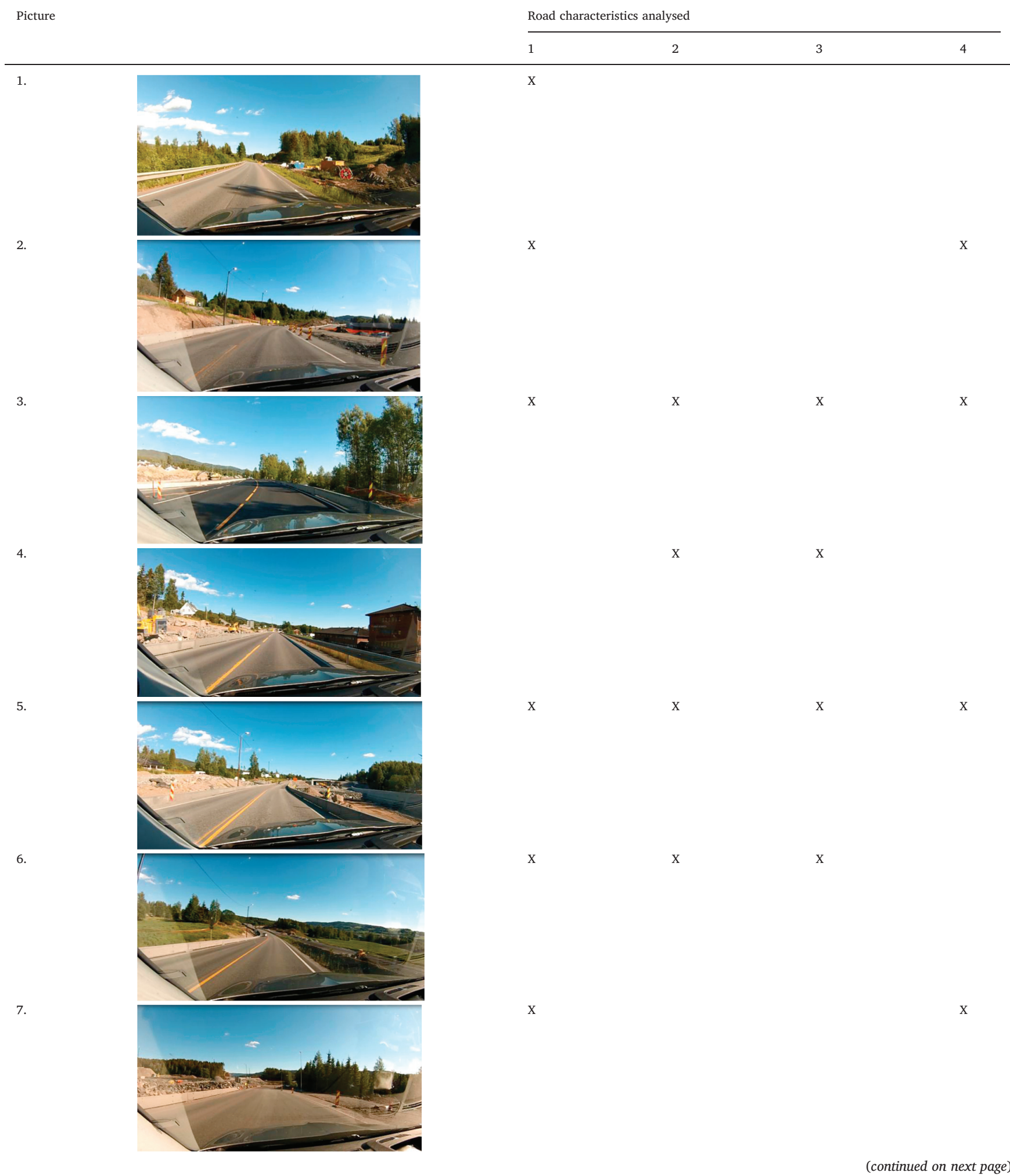


Table A1 (continued)

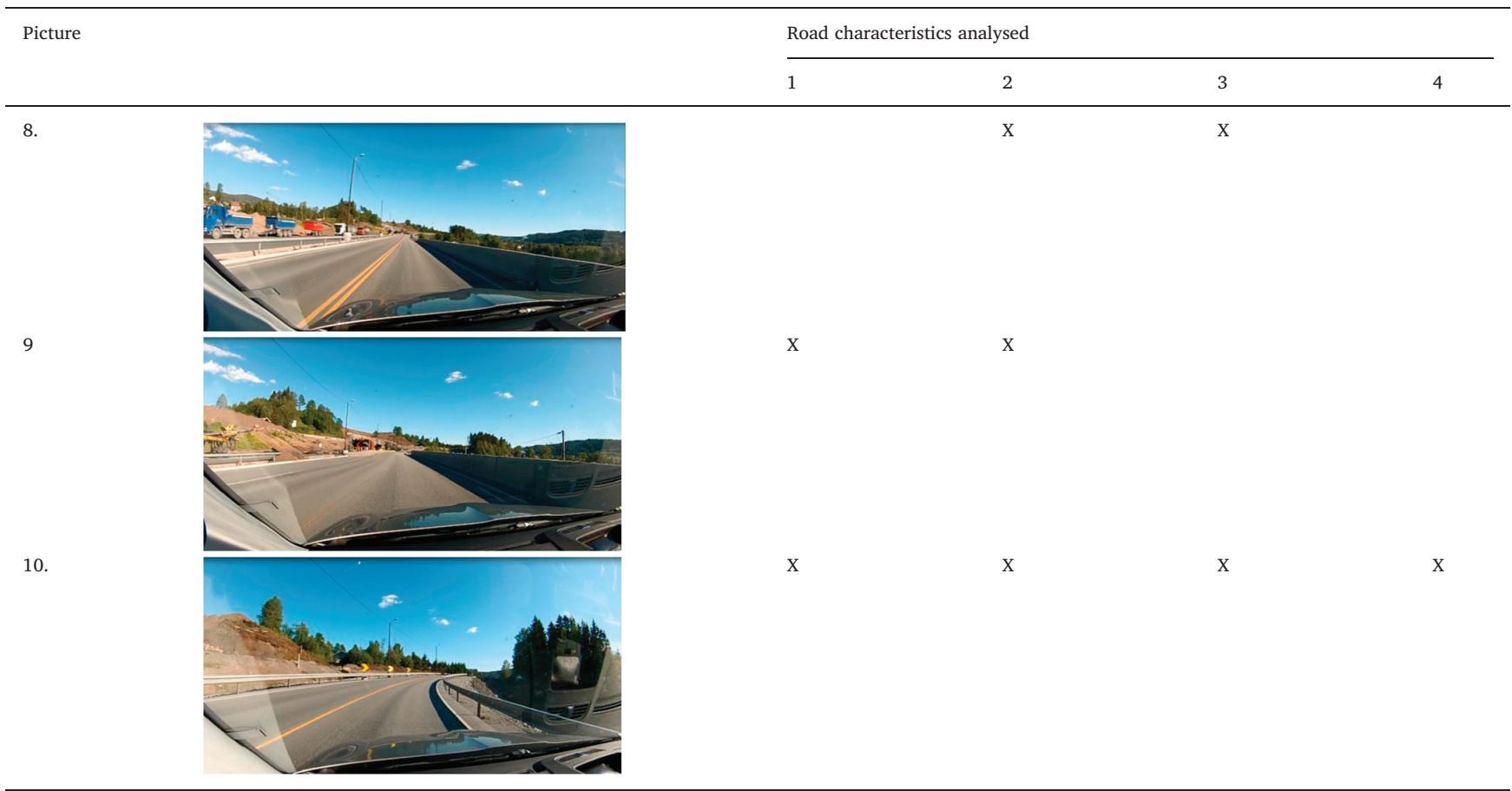

Note. 1 = curve; 2 = roadside barrier, $3=$ centre road marking, $4=$ delineators

\section{References}

Aarts, L., Van Schagen, I., 2006. Driving speed and the risk of road crashes: a review. Accid. Anal. Prev. 38 (2), 215-224.

Advanced Research on Road Work Zone Safety Standards in Europe Consortium, 1998. Road Work Zone Safety Practical Handbook. Final Report for Publication, 1-87. National Technical University Athens.

Akepati, S., Dissanayake, S., 2011. Characteristics and contributory factors of work zone crashes. 90th Transportation Research Board Annual Meeting, 11-3769. Transportation Research Board., Washington DC.

Allpress, J.A., Leland Jr, L.S., 2010. Reducing traffic speed within roadwork sites using obtrusive perceptual countermeasures. Accid. Anal. Prev. 42 (2), 377-383.

Bai, Y., Finger, K., Li, Y., 2010. Analyzing motorists' responses to temporary signage in highway work zones. Saf. Sci. 48 (2), 215-221.

Benekohal, R.R.F., Wang, L., 1994. Relationship between initial speed and speed inside a highway work zone. Transp. Res. Rec.(1442).

Benekohal, R.F., Orloski, R.L., Hashmi, A.M., 1993. Drivers' opinions on work zone traffic control. Transportation quarterly 47 (1), 19-38.

Benekohal, R.F., Wang, L., Orloski, R., Kastel, L.M., 1992. Speed-reduction patterns of vehicles in a highway construction zone. Transp. Res. Rec.(1352).

Constantinou, E., Panayiotou, G., Konstantinou, N., Loutsiou-Ladd, A., Kapardis, A., 2011. Risky and aggressive driving in young adults: personality matters. Accid. Anal. Prev. 43 (4), 1323-1331.

Debnath, A.K., Backman, R., Haworth, N., 2014. A Tobit model for analysing speed limit compliance in work zones. Saf. Sci. 70, 367-377.

Debnath, A.K., Backman, R., Haworth, N., 2015. A comparison of self-nominated and actual speeds in work zones. Transp. Res. Part F Traffic Psychol. Behav. 35, 213-222.

Domenichini, L., La Torre, F., Branzi, V., Nocentini, A., 2017. Speed behaviour in work zone crossovers. A driving simulator study. Accid. Anal. Prev. 98, 10-24.

Elander, J., West, R., French, D., 1993. Behavioral correlates of individual differences in road-traffic crash risk: an examination of methods and findings. Psychol. Bull. 113 (2), 279.

Elvik, R., 2010. A restatement of the case for speed limits. Transp. Policy (Oxf) 17, 196-204.

Elvik, R., 2013. A re-parameterisation of the Power Model of the relationship between the speed of traffic and the number of accident victims. Accid. Anal. Prev. 50, 854-860.

Finley, M.D., Jenkins, J., McAvoy, D.S., 2015. Motorists' speed response to Non-variable and variable work zone speed limits and other work zone conditions. Transportation Research Board 94th Annual Meeting. (No. 15-3214).

Goldenbeld, C., van Schagen, I., 2007. The credibility of speed limits on $80 \mathrm{~km} / \mathrm{h}$ rural roads: the effects of road and person(ality) characteristics. Accid. Anal. Prev. 39, $1121-1130$.

Harms, I.M., Brookhuis, K.A., 2016. Dynamic traffic management on a familiar road: Failing to detect changes in variable speed limits. Transp. Res. Part F Traffic Psychol. Behav. 38, 37-46.
Horswill, M.A., Waylen, A.E., Tofield, M.I., 2004. Drivers ratings of different components of their own driving skill: a greater illusion of superiority for skills that relate to accident involvement. J. Appl. Soc. Psychol. 34, 177-195.

Hou, Y., Edara, P., Sun, C., 2013. Speed limit effectiveness in short-term rural interstate work zones. Transp. Lett. Int. J. Transp. Res. 5.

Hox, J.J., 2010. Multilevel Analysis. Techniques and Applications, 2nd ed. Routledge, New York.

Høye, A., Phillips, R., Hesjevoll, I.S., 2015. Evaluering av E18 Gulli-Langåker: Trafikantenes sikkerhet i anleggsperioden [Evaluation of E18 Gulli-langåker: Road Safety during the Construction Period]. TøI Report 1445. Institute of Transport Economics, Oslo, Norway.

Iversen, H., Rundmo, T., 2002. Personality, risky driving and accident involvement among Norwegian drivers. Personality and individual Differences 33 (8), 1251-1263.

Judge, T.A., Zapata, C.P., 2015. The person-situation debate revisited: Effect of situation strength and trait activation on the validity of the Big Five personality traits in predicting job performance. Academy of Management Journal 58 (4), 1149-1179.

Kohn, M.L., Schooler, C., 1983. Work and Personality: an Inquiry into the Impact of Social Stratification. Ablex Publishing Corporation, New Jersey.

Lee, Y.M., Chong, S.Y., Goonting, K., Sheppard, E., 2017. The effect of speed limit credibility on drivers' speed choice. Transp. Res. Part F Traffic Psychol. Behav. 45, $43-53$.

Li, Y., Bai, Y., 2009. Highway work zone risk factors and their impact on crash severity. J. Transp. Eng. 135 (10), 694-701.

Machin, M.A., Sankey, K.S., 2008. Relationships between young drivers' personality characteristics, risk perceptions, and driving behaviour. Accid. Anal. Prev. 40 (2), $541-547$.

Martens, M.H., Fox, M.R., 2007. Do familiarity and expectations change perception? Drivers' glances and response to changes. Transp. Res. Part F Traffic Psychol. Behav. 10 (6), 476-492.

Martinussen, L.M., Møller, M., Prato, C.G., 2014. Assessing the relationship between the driver behavior questionnaire and the driver skill inventory: revealing sub-groups of drivers. Transp. Res. Part F Traffic Psychol. Behav. 26, 82-91.

Martinussen, L.M., Møller, M., Prato, C.G., 2017. Accuracy of young male drivers' selfassessments of driving skill. Transp. Res. Part F Traffic Psychol. Behav. 46, 228-235.

Näätänen, R., Summala, H., 1974. A model for the role of motivational factors in drivers' decision-making. Accid. Anal. Prev. 6 (3), 243-261.

Norwegian Public Roads Administration, 2011. Temaanalyse av trafikkulykker i tilknytning til vegarbeid. Basert på data fra dybdeanalyser av dødsulykker i vegtrafikken 2005- 2009 [Theme analysis of traffic accidents in connection with work zones. Based on data from in-depth analysis of fatalities in road traffic 2005-2009]. Norwegian Public Roads Administration.

Paolo, P., Sar, D., 2012. Driving speed behaviour approaching road work zones on twolane rural roads. Procedia-Social and Behavioral Sciences 53, 672-681.

Qi, Y., Srinivasan, R., Teng, H., Baker, R., 2013. Analysis of the frequency and severity of rear-end crashes in work zones. Traffic Inj. Prev. 14 (1), 61-72.

Rahman, M., Strawderman, L., Garrison, T., Eakin, D., Williams, C.C., 2017. Work zone 
sign design for increased driver compliance and worker safety. Accid. Anal. Prev. 106, 67-75.

Silverstein, C., Schorr, J., Hamdar, S.H., 2014, work zones vs. Non-work zones: risk factors leading to rear-End and sideswipe collisions. Transportation Research Board 93rd Annual Meeting.

Steinbakk, R.T., Ulleberg, P., Sagberg, F., Fostervold, K.I., 2017. Analysing the influence of visible roadwork activity on drivers' speed choice at work zones using a videobased experiment. Transp. Res. Part F Traffic Psychol. Behav. 44, 53-62.

Steinbakk, R.T., Ulleberg, P., Sagberg, F., Fostervold, K.I., 2019. Speed preferences in work zones: Does the presence of roadwork activity moderate the influence of personality traits? Transp. Res. Part F Traffic Psychol. Behav. 62, 390-405.

Summala, H., 1988. Risk control is not risk adjustment: the zero-risk theory of driver behaviour and its implications. Ergonomics 31 (4), 491-506.

Summala, H., Hietamäki, J., 1984. Drivers' immediate responses to traffic signs. Ergonomics 27 (2), 205-216.

Tronsmoen, T., 2008. Associations between self-assessment of driving ability, driver training and crash involvement among young drivers. Transp. Res. Part F Traffic Psychol. Behav. 11, 334-346.
Ulleberg, P., Rundmo, T., 2003. Personality, attitudes and risk perception as predictors of risky driving behaviour among young drivers. Saf. Sci. 41 (5), 427-443.

Ullman, G.L., Brewer, M.A., 2014. Driver perceptions of traffic calming versus active enforcement efforts in work zones. Transportation Research Record: Journal of the Transportation Research Board 2425, 25-31.

van Nes, N., Brandenburg, S., Twisk, D., 2010. Improving homogeneity by dynamic speed limit systems. Accid. Anal. Prev. 42 (3), 944-952.

Wåhlberg, A., Barraclough, P., Freeman, J., 2017. Personality versus traffic accidents; meta-analysis of real and method effects. Transp. Res. Part F Traffic Psychol. Behav. 44, 90-104.

Wang, J., Hughes, W., Council, F., Paniati, J., 1996. Investigation of highway work zone crashes: what we know and what we don't know. Transportation research record: Journal of the transportation research board (1529), 54-62.

Whiteside, S.P., Lynam, D.R., 2001. The five factor model and impulsivity: using a structural model of personality to understand impulsivity. Pers. Individ. Dif. 30 (4), 669-689.

Yang, H., Ozbay, K., Ozturk, O., Xie, K., 2015. Work zone safety analysis and modeling: a state-of-the-art review. Traffic Inj. Prev. 16 (4), 387-396. 